\section{ADVANCED STEEL CONSTRUCTION}

\section{An International Journal}

Volume 6 Number 3

September 2010

CONTENTS

\section{Technical Papers}

Experimental Investigation of the Shear Resistance of Steel Frames with Precast Concrete Infill Panels J.C.D. Hoenderkamp, H. Hofmeyer and H.H. Snijder

Method of Characteristics for Dynamic Geometrically Non-Linear Analysis of Beams A.S. Shatnawi, S.Z. Al-Sadder, M.S. Abdel-Jaber, R.A.Othman and N.S. Ahmed

Formation and Calculation Analyses of the Cylindrical Latticed-Built-Up-Member-System Reticulated Mega-Structure

Yongjun He and Xuhong Zhou

Cable Supported Barrel Vault Structure System and Research on Mechanics Feature Zhihua Chen, Wentao Qiao and Xiangyu Yan

Further Research on Chord Length and Boundary Conditions of CHS T- and X-Joints G.J. van der Vegte and Y. Makino

Experimental Test Simulating a Column Loss in a Composite Frame

Jean-François Demonceau and Jean-Pierre Jaspart

Experiment and FE Analysis on Shear Resistance of Cold-Formed Steel Stud Assembled Wall in Residential Structure

Xuhong Zhou, Yongjun He, Yu Shi, Tianhua Zhou and Yongjian Liu

Conference Announcemen

Copyright $\odot 2010$ by :

The Hong Kong Institute of Steel Construction

Website: $h t t p: / / w w w . h k i s c . o r g$

ISSN 1816-112X

Science Citation Index Expanded, Materials Science Citation Index and ISI Alerting

Cover: Curved Roof of the New Wuhan Bullet Train Station in China

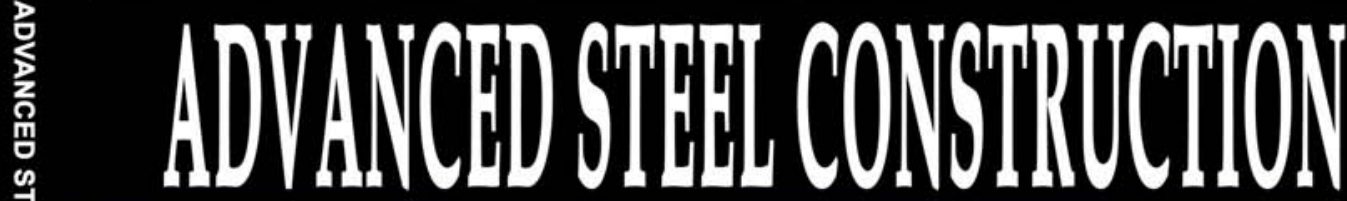

an International Journal ISSN 1816-112X

Volume 6 Number 3

September 2010

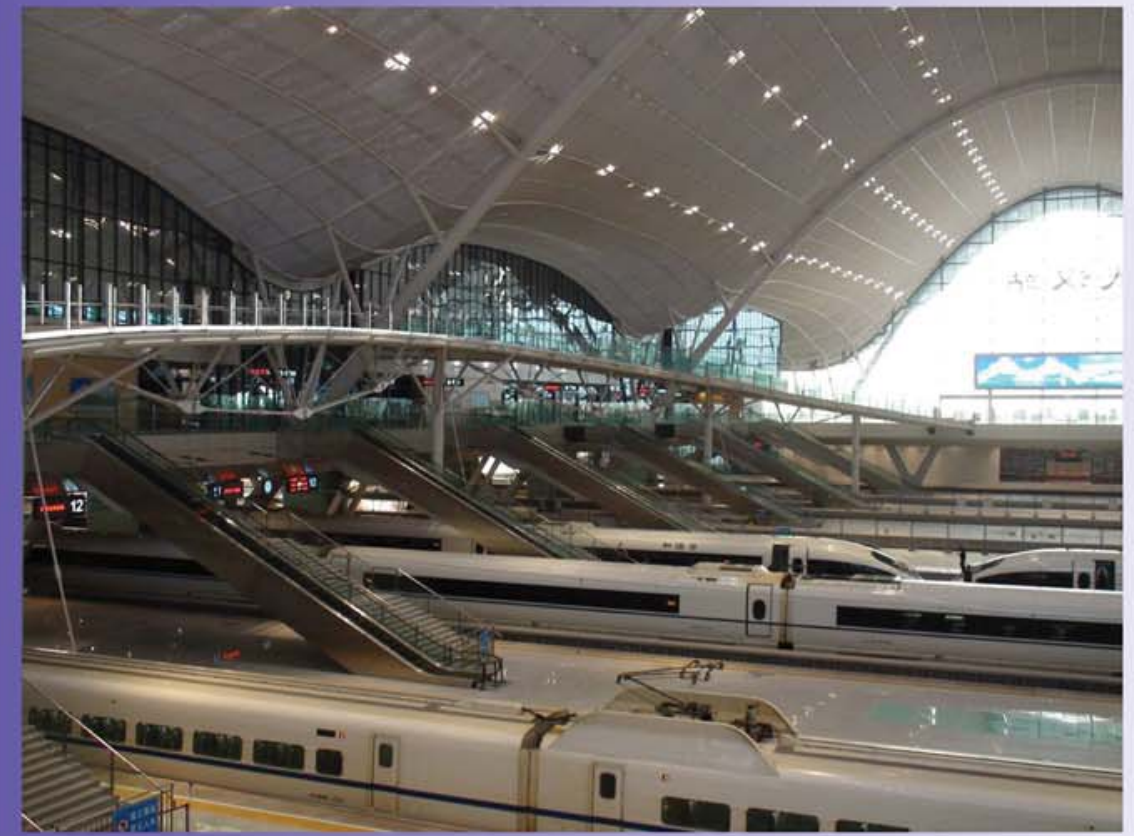

Editors-in-Chief

S.L. Chan, The Hong Kong Polytechnic University, Hong Kong

W.F. Chen, University of Hawaii at Manoa, USA

R. Zandonini, Trento University, Italy 


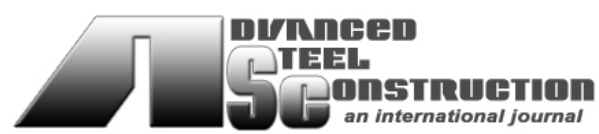

ISSN 1816-112X

Science Citation Index Expanded, Materials Science Citation Index and ISI Alerting

\section{EDITORS-IN-CHIEF}

Asian Pacific, African and organizing Editor

S.L. Chan

The Hong Kong Polyt. Univ., Hong Kong

\section{American Editor \\ W.F. Chen \\ Univ. of Hawaii at Manoa, USA}

\section{European Editor}

R. Zandonini

Trento Univ., Italy

\section{INTERNATIONAL EDITORIAL BOARD \\ F.G. Albermani}

The Univ. of Queensland, Australia

I. Burgess

Univ. of Sheffield, UK

F.S.K. Bijlaard

Delft Univ. of Technology, The Netherlands

R. Bjorhovde

The Bjorhovde Group, USA

M.A. Bradford

The Univ. of New South Wales, Australia

D. Camotim

Technical Univ. of Lisbon, Portugal

C.M. Chan

Hong Kong Uni v. of Science \& Technolog

Hong Kong

T.H.T. Chan

Queensland Univ. of Technology, Australia

S.P. Chiew

Nanyang Technological Univ., Singapore

W.K. Chow

The Hong Kong Polyt. Univ., Hong Kong

K.F. Chung

The Hong Kong Polyt. Univ., Hong Kong

G.G. Deierlein

Stanford Univ., California, USA

\section{Advanced Steel \\ Construction an international journal}

Dezi

Univ. of Ancona, Italy

D. Dubina

The Politehnica Univ. of Tim

Romania

R. Greiner

Technical Univ. of Graz, Austria

G.W.M. Ho

Ove Arup \& Pa rtners Hong Kon g Ltd. Hong Kong

B.A. Izzuddin

Imperial College of Science, Technology and Medicine, UK

J.P. Jaspart

Univ. of Liege, Belgium

S. A. Jayachandran

SERC, CSIR, Chennai, India

S. Kitipornchai

City Univ. of Hong Kong, Hong Kong

D. Lam

Univ. of Leeds, UK

G.Q. Li

Tongji Univ., China

J.Y.R. Liew

National Univ. of Singapore, Singapore

X. Liu

Tsinghua Univ., China

E.M. Lui

Syracuse Univ., USA

Y.L. Mo

Univ. of Houston, USA

$\mathrm{y}$,

CUST, Clermont Ferrand, France

D.A. Nethercot

Imperial College of Science, Technology and Medicine, UK

Y.Q. Ni

The Hong Kong Polyt. Univ., Hong Kong

D.J. Oehlers

The Univ. of Adelaide, Australia

K. Rasmussen

The Univ. of Sydney, Australia

T.M. Roberts

Cardiff Univ., UK
J.M. Rotter

The Univ. of Edinburgh, UK

C. Scawthorn

osoara, Scawthorn Porter Associates, USA

P. Schaumann

Univ. of Hannover, Germany

G.P. Shu

Southeast Univ. China

J.G. Teng

The Hong Kong Polyt. Univ., Hong Kong

G.S. Tong

Zhejiang Univ., China

K.C. Tsai

National Taiwan Univ., Taiwan

C.M. Uang

Univ. of California, USA

B. Uy

University of Western Sydney

M. Veljkovic

Univ. of Lulea, Sweden

F. Wald

Czech Technical Univ. in Prague, Czech

Y.C. Wang

The Univ. of Manchester, UK

Y.L. Xu

The Hong Kong Polyt. Univ., Hong Kong

D. White

Georgia Institute of Technology, USA

E. Yamaguchi

Kyushu Institute of Technology, Japan

Y.B. Yang

National Taiwan Univ., Taiwan

B. Young

The Univ. of Hong Kong, Hong Kong

X.L. Zhao

Monash Univ., Australia

Z.H. Zhou

Alpha Consultant Ltd., Hong Kong 


\begin{tabular}{ll}
\hline \hline & General Information \\
& Advanced Steel Construction, an international journal \\
\hline \hline Aims and scope
\end{tabular}

\section{Aims and scope}

The International Journal of Advanced Steel Construction provides a platform for the publication and rapid dissemination of ori ginal and up-to-date research and tec hnological developments in steel c onstruction, design and anal ysis. Scope of research $p$ apers published in this journal includes but is not limite $d$ to theor etical and expe rimental research on elements, assemblages, sy stems, material, design philosophy and codification, standards, fabrication, projects of innov ative nature an d computer tech niques. The journal is specifically $t$ ailored to channel the e xchange of tec hnological know-ho $w$ bet ween $r$ esearchers an d practitioners. Contributions from all aspects related to the recent developments of advanced steel construction are welcome.

\section{Instructions to authors}

Submission of the manuscript. Authors may submit double-spaced manuscripts preferably in MS Word by emailing to one of the chief editors as follows for arrangement of review. Alternatively papers can be submitted on a diskette to one of the chief editors.

Asian Pacific, African and organizing editor: Professor S.L. Chan, Email: ceslchan@polyu.edu.hk

American editor :

European editor:

Professor S.L. Chan, Email: ceslchan@polyu.edu

Professor R. Zandonini, Email: riccardo_zandonini@ing.unitn.it

All manuscripts submitted to the journal are recommended to accompany with a li st of four potential reviewers suggested by the author(s). This list should include the complete name, add ress, telephone and fax num bers, em ail address, and at least five keywords that identify the expertise of each reviewer. This scheme will improve the process of review.

Style of manuscript

General. Author(s) should provide full postal and email addresses and fax number for correspondence. The manuscript including abstract, keywords, references, figures and tables should be in English with pages numbered and typed with double line spacing on single side of A4 or letter-sized paper. The front page of the article should contain:

a) a short title (reflecting the content of the paper);

b) all the name(s) and postal and email addresses of author(s) specifying the author to whom correspondence and proofs should be sent;

c) an abstract of $100-200$ words; and

d) 5 to 8 keywords.

The paper must contain an introduction and a conclusion. The length of paper should not exceed 25 journal pages (approximately 15,000 words equivalents).

Tables and figures. Tables and figures including photographs should be typed, numbered consecutively in Arabic numerals and with short titles. They should be referred in the text as Figure 1, Table 2, etc. Originally drawn figures and photographs should be provided in a form suitable for photographic reproduction and reduction in the journal.

Mathematical expressions and units. The Systeme Internationale (SI) should be followed whenever possible. The numbers identifying the displayed mathematical expression should be referred to in the text as Eq. (1), Eq. (2).

References. References to published literature should be referred in the text, in the order of citation with Arabic numerals, by the last name(s) of the author(s) (e.g. Zandonini and Zanon [3]) or if more than three authors (e.g. Zandonini et al. [4]). References should be in English $w$ ith occasional allow ance of 1-2 e xceptional referenc es in local lang uages and $r$ eflect the curren $t$ state-of-technology. Journal titles should be abbreviated in the style of the Word List of Scientific Periodicals. References should be cited in the following style $[1,2,3]$.

Journal: [1] Chen, W.F. and Kishi, N., "Semi- rigid Steel Beam-to-column Connections, Data Base and Modellin g", Journal of Structural Engineering, ASCE, 1989, Vol. 115, No. 1, pp. 105-119.

Book: [2] Chan, S.L. and Chui, P.P.T., "Non-linear Static and Cyclic Analysis of Semi-rigid Steel Frames", Elsevier Science, 2000 .

Proceedings: [3] Zandonini, R. a nd Zanon, P., "Experimental Analy sis of S teel Beams with Semi -rigid Joint s", Proceedings of International Conference on Advances in Steel Structures, Hong Kong, 1996, Vol. 1, pp. 356-364.

Proofs. Proof will be sent to the c orresponding author to correct an y typesetting errors. Alternations to the original manuscript at this stage will not be accepted. Proofs should be returned within 48 hours of receipt by Express Mail, Fax or Email.

Copyright. Submission of an article to "Advanced Steel Construction" implies that it presents the original and unpublished work, and not under consideration for publication nor published elsewhere. On acceptance of a manuscript submitted, the copyright thereof is transferred to the publisher $b y$ the Transfer of $C$ opyright Agreement and upon $t$ he acceptance of publication for the $p$ apers, the corresponding author must sign the form for Transfer of Copyright.

Permission. Quoting from this journal is granted provided that the customary acknowledgement is given to the source.

Page charge and Reprints. There will be no page charges if the length of paper is within the limit of 25 journal pages. A total of 30 free offprints will be supplied free of charge to the corresponding author. Purchasing orders for additional offprints can be made on order forms which will be sent to the authors. These instructions can be obtained at the Hong Kong Institute of Steel Construction, Journal website: http://www.hkisc.org

The International Journal of Advanced Steel Construction is published quarterly by non-profit making learnt society, The Hong Kong Institute of Steel Construction, c/o Department of Civil \& Structural Engineering, The Hong Kong Polytechnic University, Hung Hom, Kowloon, Hong Kong.

Disclaimer. No responsibility is assumed for a ny injury and / or damage to per sons or property as a matter of products liability, negligence or otherwise, or from any use or operation of any methods, products, instructions or ideas contained in the material herein.

Subscription inquiries and change of address. Address all subscription inquiries and correspondence to Member Records, IJASC. Notify an address change as soon as possible. All communications should include both old and new addresses with zip codes and be accompanied by a mailing label from a recent issue. Allow six weeks for all changes to become effective.

The Hong Kong Institute of Steel Construction

HKISC

c/o Department of Civil and Structural Engineering,

The Hong Kong Polytechnic University,

Hunghom, Kowloon, Hong Kong, China.

Tel: 852- 27666047 Fax: 852- 23346389

Email: ces/chan@polyu.edu.hk Website: http://www.hkisc.org/

ISSN 1816-112X

Science Citation Index Expanded, Materials Science Citation Index and ISI Alerting

Copyright $\odot 2010$ by:

The Hong Kong Institute of Steel Construction. 


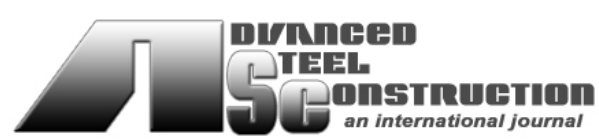

ISSN 1816-112X

Science Citation Index Expanded, Materials Science Citation Index and ISI Alerting

\section{EDITORS-IN-CHIEF}

Asian Pacific, African and organizing Editor

S.L. Chan

The Hong Kong Polyt. Univ., Hong Kong

Email: ceslchan@polyu.edu.hk

\section{American Editor}

W.F. Chen

Univ. of Hawaii at Manoa, USA

Email:waifah@hawaii.edu

\section{European Editor}

R. Zandonini

Trento Univ., Italy

Email: riccardo.zandonini@ing.unitn.it

\section{Advanced Steel \\ Construction an international journal}

\begin{tabular}{lll}
\hline VOLUME 6 & NUMBER 3 & SEPTEMBER 2010 \\
\hline
\end{tabular}

Technical Papers

Experimental Investigation of the Shear Resistance of Steel

Frames with Precast Concrete Infill Panels

J.C.D. Hoenderkamp, H. Hofmeyer and H.H. Snijder

Method of Characteristics for Dynamic Geometrically Non-Linear Analysis of Beams

A.S. Shatnawi, S.Z. Al-Sadder, M.S. Abdel-Jaber, R.A. Othman and N.S. Ahmed

Formation and Calculation Analyses of the Cylindrical

Latticed-Built-Up-Member-System Reticulated Mega-Structure

Yongjun He and Xuhong Zhou

Cable Supported Barrel Vault Structure System and Research

on Mechanics Feature

Zhihua Chen, Wentao Qiao and Xiangyu Yan

Further Research on Chord Length and Boundary Conditions of CHS T- and X-Joints

G.J. van der Vegte and Y. Makino

Experimental Test Simulating a Column Loss in a Composite Frame

Jean-François Demonceau and Jean-Pierre Jaspart

Experiment and FE Analysis on Shear Resistance of Cold-Formed Steel Stud Assembled Wall in Residential Structure Xuhong Zhou, Yongjun He, Yu Shi, Tianhua Zhou and Yongjian Liu

Conference Announcement 


\title{
EXPERIMENTAL INVESTIGATION OF THE SHEAR RESISTANCE OF STEEL FRAMES WITH PRECAST CONCRETE INFILL PANELS
}

\author{
J.C.D. Hoenderkamp, H. Hofmeyer and H.H. Snijder \\ Department of Architecture, Building and Planning, Structural Design Group \\ Technische Universiteit Eindhoven, The Netherlands \\ *(Corresponding author: E-mail: j.c.d.hoenderkamp@tue.nl)
}

Received: 31 May 2008; Revised: 7 December 2008; Accepted: 8 January 2009

\begin{abstract}
At the Technische Universiteit Eindhoven a research program on composite construction is underway aiming at the development of design rules for steel frames with discretely connected precast concrete infill panels subject to in-plane horizontal loading. This paper presents experimental and finite element results of an investigation into their lateral stiffness and strength. A discrete connection between steel frame and concrete panel consist of one or two achor bars welded to a partially cast-in steel plate which is fastened with two bolts to a gusset plate welded to a frame member. The bolts in the connection are loaded in shear only. Two variations on this type of connection were tested experimentally. To avoid brittle failure, the connections are designed for a failure mechanism consisting of ovalisation in the bolt holes due to bearing of the bolts. Experimental pull-out and shear tests on individual frame-panel connections were performed to establish their stiffness and failure load. Two full scale experiments were done on one-storey one-bay 3 by $3 \mathrm{~m}$ infilled frame structures which were horizontally loaded at the top. With the known characteristics of the frame-panel connections from the experiments on individual connections, finite element analyses were performed on the infilled frame structures taking non-linear behaviour of the structural components into account. The finite element model yields good results for the lateral stiffness and lower and upper bounds for strength.
\end{abstract}

Keywords: Composite construction, full scale experimental testing, semi-integral infilled frames, precast concrete infill panels, steel frame to concrete panel connections, high-rise structures

\section{INTRODUCTION}

\subsection{Classification of Structure}

When subjected to an in-plane horizontal or racking load, the infill in steel framed structures will cause different types of composite behaviour depending on the material used and the way it is attached to the skeletal structure. Since the early fifties research has been carried out on the structural behaviour of steel frames with masonry infill (Thomas [1], Polyakov [2], Benjamin and Williams [3], Holmes [4]) and concrete infill or an isotropic infill material with a brittle type of tensile failure and a plastic type of compressive failure similar to medium strength concrete (Holmes [4], Stafford Smith [5,6]). The infill used to be considered as a non-structural element in design practice thereby conservatively neglecting its significant structural benefits. It was shown (Stafford Smith [5]) that ignoring the infilling may not be conservative but can cause certain elements in the lower parts of the structure to be overloaded.

Infilled frames have generally been classified as non-integral or fully-integral (Figures 1a and 1b). When connections such as strong bonding or shear connectors at the structural interface between the frame and infill are absent as for example with brick infill, the structure is called a non-integral infilled frame. In general, the stiffness and strength of non-integral infilled frames are dependent on the characteristics of separation and slip of the infill panel at the interface. Providing strong bonding or shear connectors at the interface significantly improves the performance of infilled 
frames. Such frames are called fully-integral infilled frames and generally have larger lateral stiffness and strength than non-integral infilled frames. When precast concrete infill panels are connected to steel frames at discrete locations, interaction at the structural interface is neither complete nor absent. A structure comprising a steel frame with an intermittently connected precast concrete panel can be considered as semi-integral (Figure 1c). The contribution of precast concrete

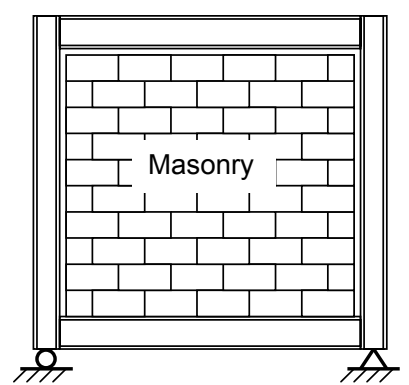

(a) Non-Integral

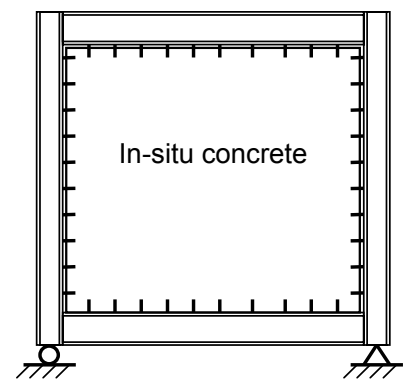

(b) Fully-Integral

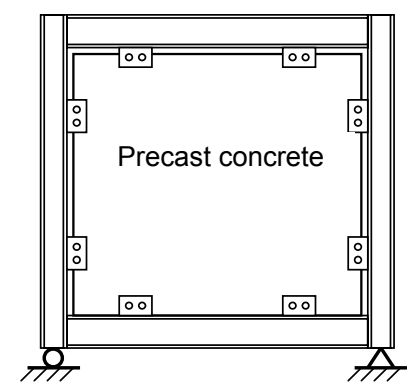

(c) Semi-Integral

Figure 1. Classification of Infilled Steel Frames

infill panels to the lateral stiffness and strength of steel and concrete frames could be significant if the optimum quality, quantity and location of the discrete interface connections can be determined. Precast concrete panels with openings for windows would allow them to be placed in the building perimeter where they can contribute significantly to the lateral stiffness of the structure.

A research program at the Technische Universiteit Eindhoven is aimed at investigating the composite behaviour of semi-integral infilled frames subject to in-plane lateral loading. Recently the investigation has been focussed on the structural behaviour of discrete connections between the steel frame and precast concrete infill panel in addition to their influence on the lateral structural behaviour of an infilled steel frame. This publication describes the experimental testing of a frame panel connection with two different anchor configurations. It also presents results of two full scale experimental tests on 3 by $3 \mathrm{~m}$ one story high and one bay wide infilled frame structures subject to horizontal loading. A simple finite element model was developed to obtain the lateral stiffness and strength of these frames.

The investigation into the composite behaviour of precast reinforced concrete façades as infill panels in steel frames with discrete interface connections represents a new area of research in infilled frames. It aims at giving a better understanding of the complex behaviour of this structural system and ultimately at providing design rules for the structural performance in resisting racking loads.

\section{STRUCTURAL BEHAVIOUR}

\section{$2.1 \quad$ Non-Integral Infilled Frames}

Experimental investigations on non-integral infilled frames under racking load have shown (Stafford Smith [5-7], Barua and Mallick [8], Liauw and Kwan [9], Liauw and Lo [10], Ng'andu et al. [11]) that poor interaction between the frame and infill due to the absence of connectors or bonding causes friction only at the structural interface. As the infill panel takes a large portion of the lateral load at its loaded corners, the effects of the infill panel are similar to the action of a single diagonal strut bracing the frame. This analogy is justified by the phenomenon of slip and separation at the interface between the frame and the infill due to the difference in the deformed shapes of the surrounding steel frame and the concrete infill panel. Consequently, friction-slip at the 
interface becomes a governing factor in a non-integral infilled frame. The separation at the structural interface in addition to irregularities and unevenness produce considerable variations in strength and stiffness (Dawe and Seah [12]).

\section{$2.2 \quad$ Fully-Integral Infilled Frames}

When a continuous connection is provided by means of strong bonding or shear connectors at the structural interface between frame and infill panel, the separation at the interface will be restricted. Friction-slip, which is dependent on normal stress, will not play an important role in fully-integral infilled frames. In addition, the provision of shear connectors overcomes the problem of initial gap (lack of fit) at the interface. Consequently, fully-integral infilled frames in general have larger lateral stiffness and strength than non-integral infilled frames (Mallick and Garg [13]). They maintain their strength up to large deflections before final collapse of the structure.

\subsection{Semi-Integral Infilled Frames}

The idea of semi-integral infilled steel frames was earlier considered (Liauw and Kwan [14]) in a plastic theory of integral infilled frames with continuous connections along the beams and columns, where a finite shear strength at the infill-frame interface was taken into account over specified distances. The limited shear resistance of the partial connections were employed to obtain the collapse load of the infilled frame by considering two failure modes: corner crushing and diagonal crushing. The use of discrete beam-infill connections away from the beam-column joints avoids corner crushing and increased shear forces in the columns. Steel-concrete contact only occurs at the frame-panel connections where the forces from the steel frame are introduced into the concrete via anchor bolts. This way the infill panel functions as a bracing system with compression and tension forces.

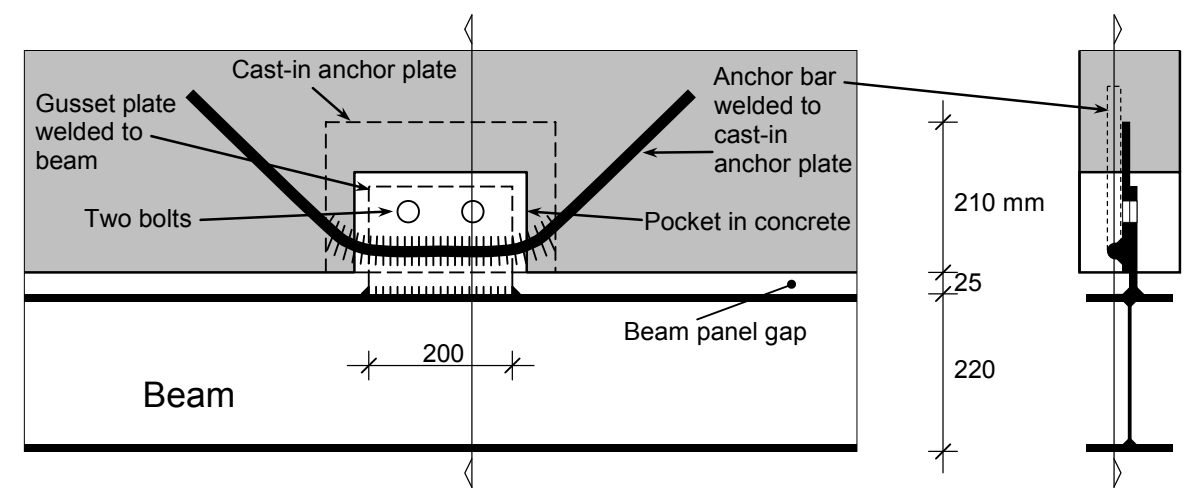

Figure 2. Typical Steel Beam to Concrete Panel Connection

The design of a discrete steel frame to concrete panel connection can take various forms (Teeuwen et al. $[15,16])$. The type of discrete interface connection for semi-integral frames used in this investigation is as shown in Figure 2. It consists of an anchor bolt, welded to a steel plate and precast in a pocket at the edge of the concrete panel. The cast-in anchor plate is bolted to a gusset plate that is welded to a frame member. The connection is located on the center line of the structural elements thereby keeping eccentricities to a minimum. It is assumed that this connection acts as a hinge and is able to transfer normal and shear forces at the structural interface. Due to the gap between the concrete panel and the steel beams and columns, friction will not take place. The specific intermittent connection systems in infilled frames will cause stress concentrations in the concrete panels which will influence the strength of the structure. The formation of stress paths constitutes an equivalent bracing pattern within the panel that will contribute to the stiffness of the structure. 


\subsection{Preliminary Finite Element Analysis}

An earlier finite element study (Tang et al. [17]) of the influence of discrete interface connections on the structural behaviour of a square steel frame with a precast reinforced concrete infill panel subject to racking load was limited to linear elastic analysis of 3.6 by $3.6 \mathrm{~m}$ one bay one story high frames. The infill panel had a thickness of $200 \mathrm{~mm}$. HE220A sections were used for the columns and IPE200 for the beams. Plane stress elements representing the concrete panel were pin-connected to the frame members at discrete locations. Beam elements used for beams and columns were hinge connected at the corners. Numerical linear elastic analyses were performed to study the behaviour of the infilled frame subject to a horizontal point load at the top. Ten different

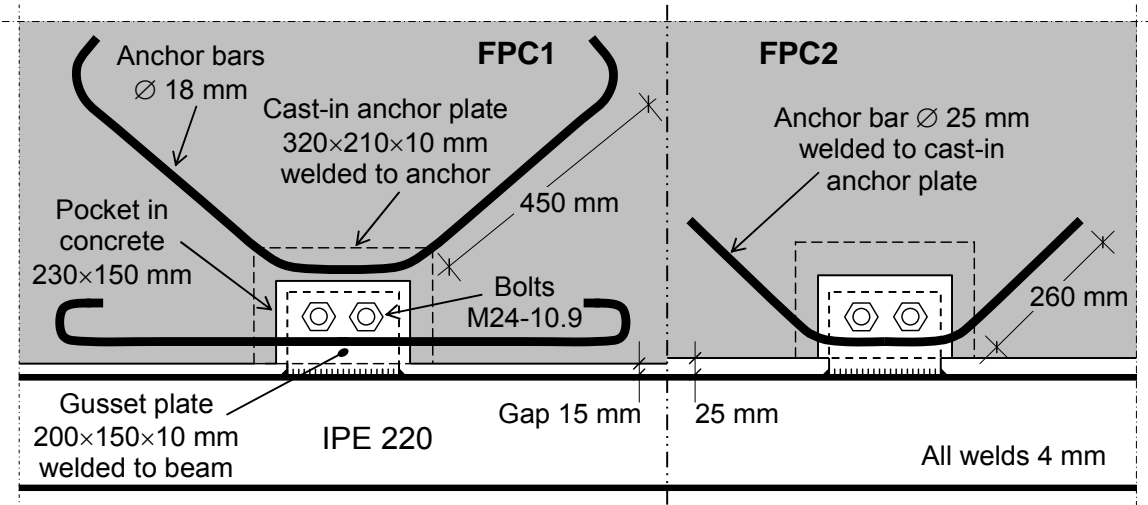

Figure 3. Steel Beam to Precast Concrete Panel Connections

patterns of discrete interface connections were investigated whereby the number and the locations of the connections were varied. It was observed that stress patterns in the panels of semi- and fully-integral infilled frames show extensive similarities. It was concluded that semi-integral frames are able to achieve similar structural performance as fully-integral frames; interface connections on beams are more efficient than on columns and the lateral stiffness of the structure improves when the connections are located closer to the beam-to-column joints.

\section{EXPERIMENTAL TESTING}

\subsection{Frame-Panel Connection}

Frame-panel connections, FPC1 and FPC2 as shown in Figure 3, consist of one or two anchor bars welded to an anchor plate which is precast in a pocket at the edge of the concrete panel. A concrete panel measures $1400 \mathrm{~mm}$ by $600 \mathrm{~mm}$ with a thickness of $150 \mathrm{~mm}$. The reinforcing bars are placed in two directions at both sides, see Table 1. The cast-in anchor plate is bolted to a gusset plate which is welded to the beam. It is assumed that this connection transfers normal and shear forces only. The connections were designed to fail in bearing, i.e. ovalisation of the bolt holes. Specific data for the materials are given in Table 1 . The compressive strength of the concrete was obtained from standard cube tests of $150 \times 150 \times 150 \mathrm{~mm}$. The equivalent characteristic cylinder strengths are given in brackets. The tests on the individual frame-panel connections were performed to establish structural characteristics such as strength and stiffness. Separate tests were done in two orthogonal directions: pull-out tests perpendicular to the edge of the panel and shear tests parallel to the edge of the panel. 


\subsubsection{Connection in shear}

The shear connection tests were done in pairs as shown in Figure 4a. An axial force is applied to the vertical steel member connected to two concrete panels which are fully supported on their short side.

Table 1. Measured Material Properties of Frame Panel Connections

\begin{tabular}{|c|c|c|c|c|c|c|c|c|c|}
\hline & Bolts & \multicolumn{2}{|c|}{$\begin{array}{c}\text { Anchor bars } \\
\text { FeB500 }\end{array}$} & \multicolumn{2}{c|}{$\begin{array}{c}\text { Anchor plates } \\
\text { 320 } 210 \times 10 \mathrm{~mm}\end{array}$} & \multicolumn{2}{c|}{$\begin{array}{c}\text { Gusset plates } \\
200 \times 150 \times 10 \mathrm{~mm}\end{array}$} & \multicolumn{2}{c|}{$\begin{array}{c}\text { Concrete panels } \\
1400 \times 600 \times 150 \mathrm{~mm}\end{array}$} \\
\cline { 2 - 10 } & $\mathrm{M} 24$ & $\begin{array}{c}\varnothing \\
\mathrm{mm}\end{array}$ & $\begin{array}{c}\mathrm{f}_{\mathrm{u}} \\
\mathrm{N} / \mathrm{mm}^{2}\end{array}$ & $\begin{array}{c}\mathrm{f}_{\mathrm{y}} \\
\mathrm{N} / \mathrm{mm}^{2}\end{array}$ & $\begin{array}{c}\mathrm{f}_{\mathrm{u}} \\
\mathrm{N} / \mathrm{mm}^{2}\end{array}$ & $\begin{array}{c}\mathrm{f}_{\mathrm{y}} \\
\mathrm{N} / \mathrm{mm}^{2}\end{array}$ & $\begin{array}{c}\mathrm{f}_{\mathrm{u}} \\
\mathrm{N} / \mathrm{mm}^{2}\end{array}$ & $\begin{array}{c}\text { Reinforcing } \\
\text { bars }\end{array}$ & $\begin{array}{c}\mathrm{f}_{\mathrm{ck}} \\
\mathrm{N} / \mathrm{mm}^{2}\end{array}$ \\
\hline FPC1 & 10.9 & 25 & $500^{*}$ & 529 & 579 & 529 & 579 & $\varnothing 10 @ 200$ & $\begin{array}{c}47 \\
(37)^{* *}\end{array}$ \\
\hline FPC2 & 10.9 & 18 & $500^{*}$ & 247 & 408 & 294 & 432 & $\varnothing 8 @ 150$ & $\begin{array}{c}44 \\
(34)^{* *}\end{array}$ \\
\hline
\end{tabular}

* assumed, ** approximate cylinder strength in brackets

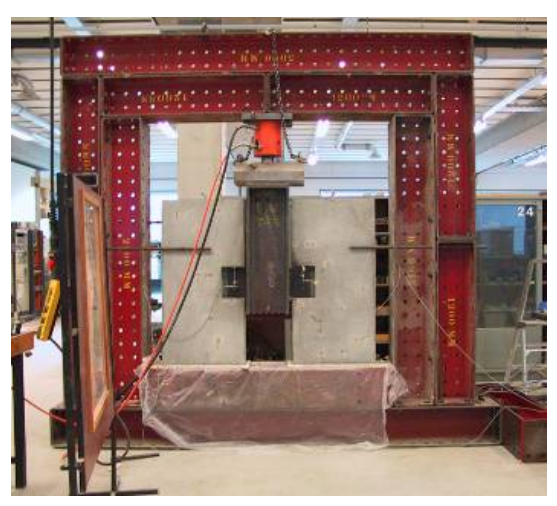

(a) Shear Test

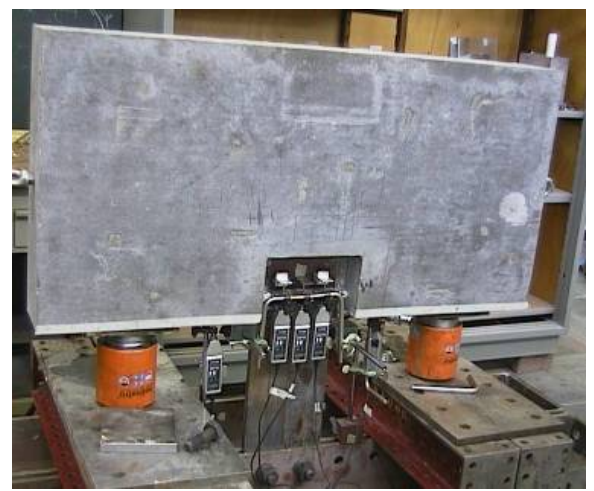

(b) Tension Test

Figure 4. Test Set-Ups

Six frame-panel connections of type FPC1 and two connections of type FPC2 were tested in shear. Vertical displacements were measured on the steel section, the bolts, the connection plates and the concrete panels. The curves in Figure 5 indicate load-displacement measurements for FPC1. The force in $\mathrm{kN}$ indicates the load taken by a single connection. The displacements are obtained from the above measurements and represent the sum of anchor plate movement and ovalisation in the connection plates. The unintended use of higher strength materials for the gusset and anchor plates of connection FPC1 resulted in shear failure in the bolts during the first two tests. The last shear test on FPC1 was stopped at 337kN. The load-deflection curve of the shear test for FPC2 in Figure 6 displays bi-linear behaviour up to a maximum resistance of $350 \mathrm{kN}$. At this load the anchor plate split the concrete. The shear strengths and average shear stiffnesses of the connections are given in Table 2. 


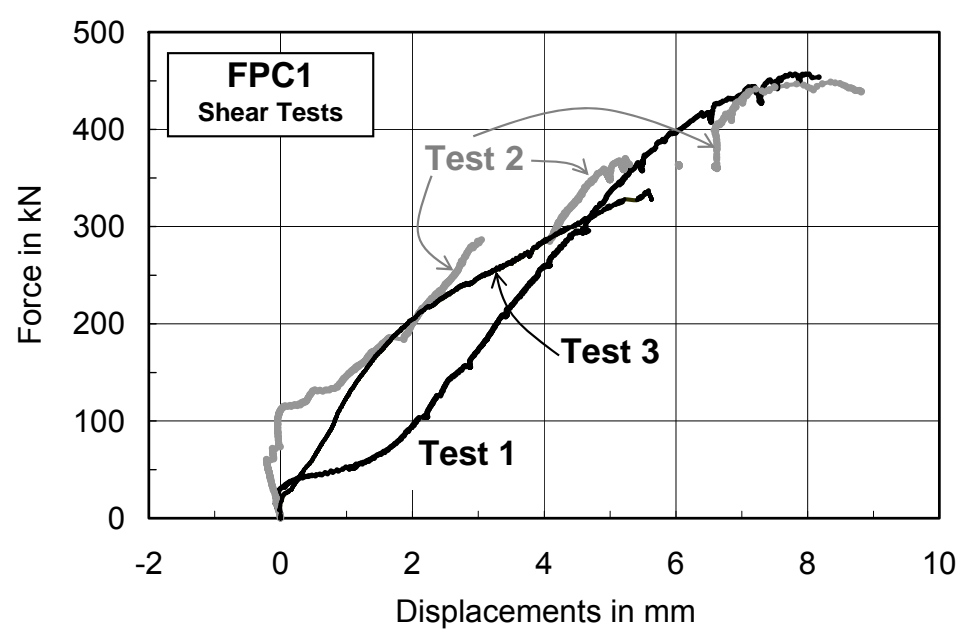

Figure 5. Shear Tests of Frame-Panel Connection 1

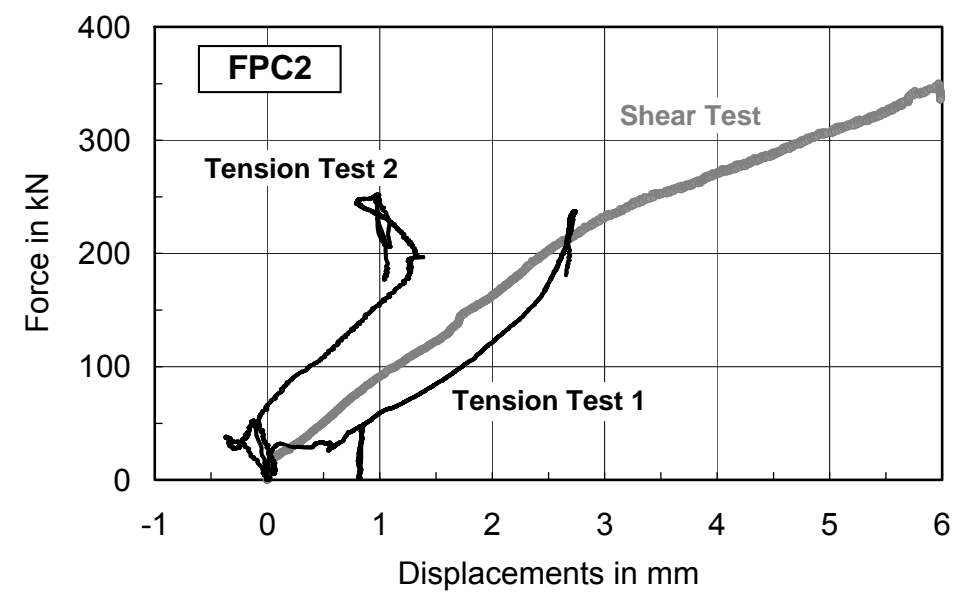

Figure 6. Shear and Tension Tests of Frame-Panel Connection 2

\subsubsection{Connection in tension}

The test set-up shown in Figure $4 \mathrm{~b}$ comprises a single concrete panel that is placed on two jacks. The cast-in anchor plate is bolted to two $450 \mathrm{~mm}$ long steel holding strips of 100 by $20 \mathrm{~mm}$ which are connected to the test rig. Vertical displacements were measured on the the anchor plates, the bolts and the concrete panels. Four connections of type FPC1 were tested and their force-displacement curves are shown in Figure 7. The displacements are obtained from the above measurements and represent the sum of anchor plate movement and ovalisation in the anchor plates. Connection FPC2 was tested twice. Its tension behaviour is shown in Figure 6. The modes of failure for all tension tests were identical: anchor pull-out. The diagrams allow the strength and stiffness characteristics of the pull-out connections to be determined. They are given in Table 2 . 


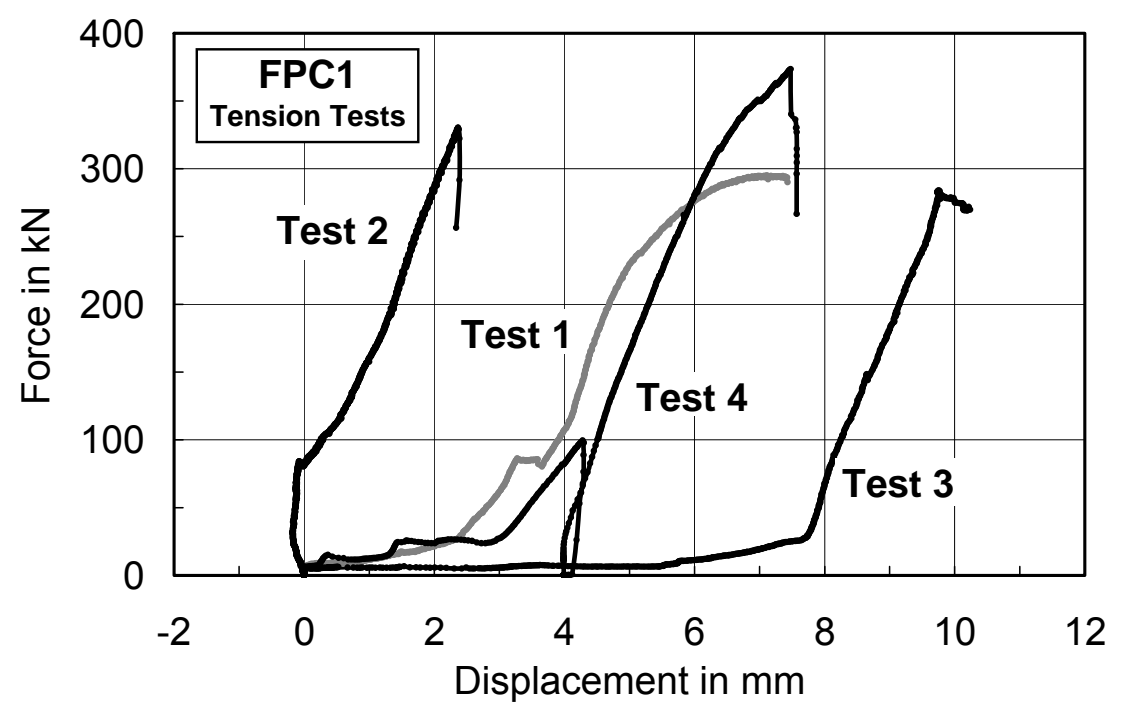

Figure 7. Tension Tests of Frame-Panel Connection 1

Table 2. Connection Properties obtained from FPC Tests

\begin{tabular}{|c|c|c|c|c|c|}
\hline \multicolumn{2}{|c|}{ Test } & \multicolumn{2}{c|}{ Shear } & \multicolumn{2}{c|}{ Tension } \\
\cline { 3 - 6 } \multicolumn{2}{|c|}{} & $\begin{array}{c}\text { Stiffness } \\
\mathrm{K}_{\mathrm{s}} \text { in } \mathrm{kN} / \mathrm{mm}\end{array}$ & $\begin{array}{c}\text { Strength } \\
\mathrm{F}_{\mathrm{s} ; \mathrm{u}} \text { in } \mathrm{kN}\end{array}$ & $\begin{array}{c}\text { Stiffness } \\
\mathrm{K}_{\mathrm{p}} \text { in } \mathrm{kN} / \mathrm{mm}\end{array}$ & $\begin{array}{c}\text { Strength } \\
\mathrm{F}_{\mathrm{p} ; \mathrm{u}} \text { in } \mathrm{kN}\end{array}$ \\
\hline \multirow{4}{*}{ FPC1 } & 1 & $\mathbf{8 6 . 2}$ & $\mathbf{4 5 7}$ & $\mathbf{1 1 2 . 9}$ & $\mathbf{2 9 5}$ \\
\cline { 2 - 6 } & 2 & 88.2 & 448 & 103.6 & 330 \\
\cline { 2 - 6 } & 3 & 54.9 & $337 *$ & 121.7 & 284 \\
\cline { 2 - 6 } & 4 & - & - & 118.4 & 374 \\
\cline { 2 - 6 } & Avg & $\mathbf{( 7 6 . 4 )}$ & $\mathbf{( 4 5 3 )}$ & $\mathbf{( 1 1 4 . 2 )}$ & $(321)$ \\
\hline \multirow{4}{*}{ FPC2 } & 1 & $\mathbf{5 6 . 8}$ & $\mathbf{3 5 0}$ & $\mathbf{8 6 . 1}$ & $\mathbf{2 3 7}$ \\
\cline { 2 - 6 } & 2 & - & - & 91.4 & 252 \\
\cline { 2 - 6 } & Avg & $\mathbf{( 5 6 . 8 )}$ & $(350)$ & $(88.8)$ & $(245)$ \\
\hline
\end{tabular}

* test halted before ultimate load

\subsection{Full Scale Frame-Panel Tests}

The full scale test rig shown in Figure 8 consists of a vertical and a diagonal loop comprising HE300B sections causing the test rig members to be subject to tensile or compressive forces only. The 3.0 by $3.0 \mathrm{~m}$ infilled frames as shown in Figure 9 are built up with IPE220 sections for the beams and HE300B sections for the columns. The beam-to-column connections consist of $10 \mathrm{~mm}$ thick header plates welded all around to the beam. The header plates are connected to the column flange with one bolt M24 10.9 at mid height on each side of the beam web. The infill panel is connected to the steel beams at four locations, $875 \mathrm{~mm}$ from the column center lines with a $15 \mathrm{~mm}$ gap between steel and concrete all the way around for Test A with FPC1 type connections. A 25 mm gap was used for Test B with FPC2 type connections, see Figure 3. The reinforcement of the full scale concrete panels is the same as was used for the testing of the two frame-to-panel connections. 


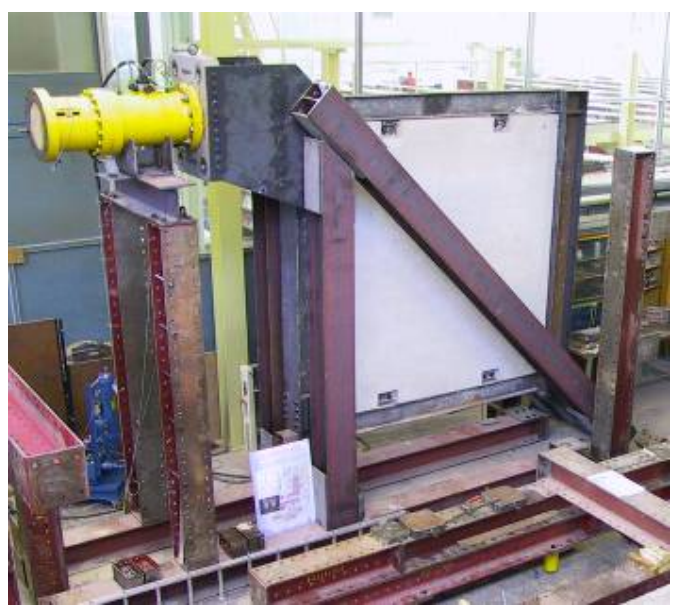

Figure 8. Full-Scale Test Set-Up

The specimens were horizontally loaded at the top by a $2 \mathrm{MN}$ capacity jack. The load application at the upper beam was displacement controlled at $0.5 \mathrm{~mm}$ per minute. Before testing the infilled frame structure, the bare steel frame without the infill panel was tested up to a lateral load of $21.8 \mathrm{kN}$. This yields a lateral frame stiffness of $1.28 \mathrm{kN} / \mathrm{mm}^{2}$ and a rotational stiffness of the beam-to-column connections of $2.53 \times 10^{3} \mathrm{kNm} / \mathrm{rad}$.

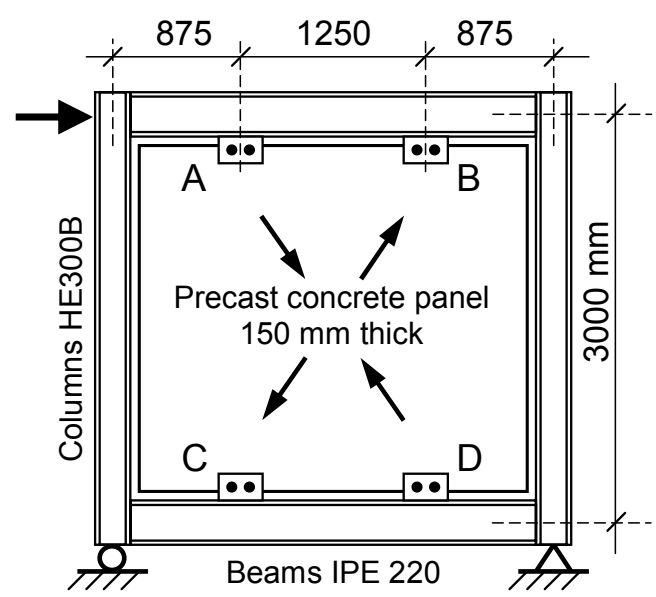

Figure 9. Steel Frame with Precast Concrete Infill Panel

The load-displacement curves in Figure 10 show that in the initial stages up until $90 \mathrm{kN}$ for Test A and $75 \mathrm{kN}$ for Test $\mathrm{B}$, the structure displayed a rather flexible behaviour. It is taken that in this settling-in stage not all four connections were participating in resisting the applied horizontal loading on the structure. On Test A the horizontal load was increased to $345 \mathrm{kN}$ where the linear elastic behaviour with a lateral stiffness of $15.9 \mathrm{kN} / \mathrm{mm}$ changed significantly. At an applied load of about $360 \mathrm{kN}$ it was observed that the steel beams were in contact with the concrete panel. Outside the reach of the LVDT measuring the horizontal deflection of the steel frame, the load was further increased to $421 \mathrm{kN}$. As this was the first full scale experiment with a newly designed test rig it was decided to halt the test. After dismantling, it was observed that ovalisation of the bolt holes had taken place at several locations. Beyond $75 \mathrm{kN}$ the lateral stiffness of infilled frame B is 12.5 $\mathrm{kN} / \mathrm{mm}$ until $241 \mathrm{kN}$ when pull-out failure occurred at the lower left frame-panel connection, point $\mathrm{C}$ in Figure 9. The load was further increased to $276 \mathrm{kN}$ when pull-out failure occurred at the upper connection on the right at point $\mathrm{B}$. With only a compression diagonal present the infilled frame reached a lateral load capacity of $257 \mathrm{kN}$ when the concrete panel made contact with the steel frame. It was then decided to take the load off the structure. 


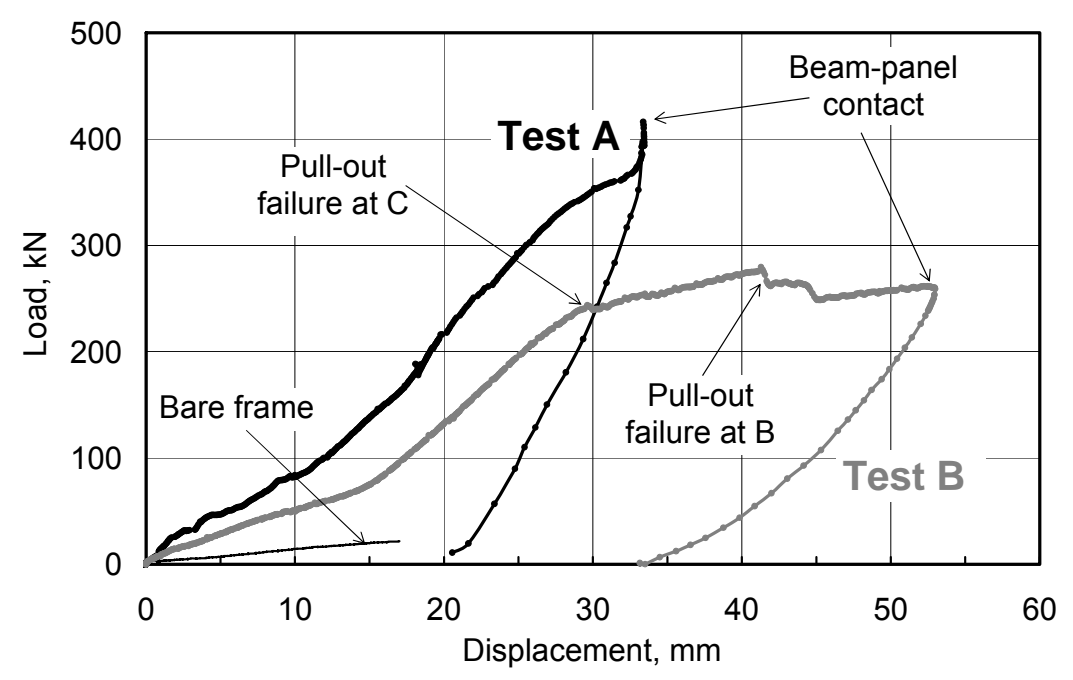

Figure 10. Experimental Results of Full-Scale Tests

\section{FINITE ELEMENT ANALYSES}

\subsection{Finite Element Model}

A finite element model has been developed for simulating the two full-scale tests. The model consists of a steel frame, a concrete infill panel and connections represented by springs connecting the gusset plates of the beams to the panel. The finite element model is shown in Figures 11 and 12.

\subsubsection{Steel frame}

Beam elements (BEAM3, [18]) are used for the frame members. The sectional properties of the beams and columns fit the sections used in the tests and are based on nominal dimensions. The

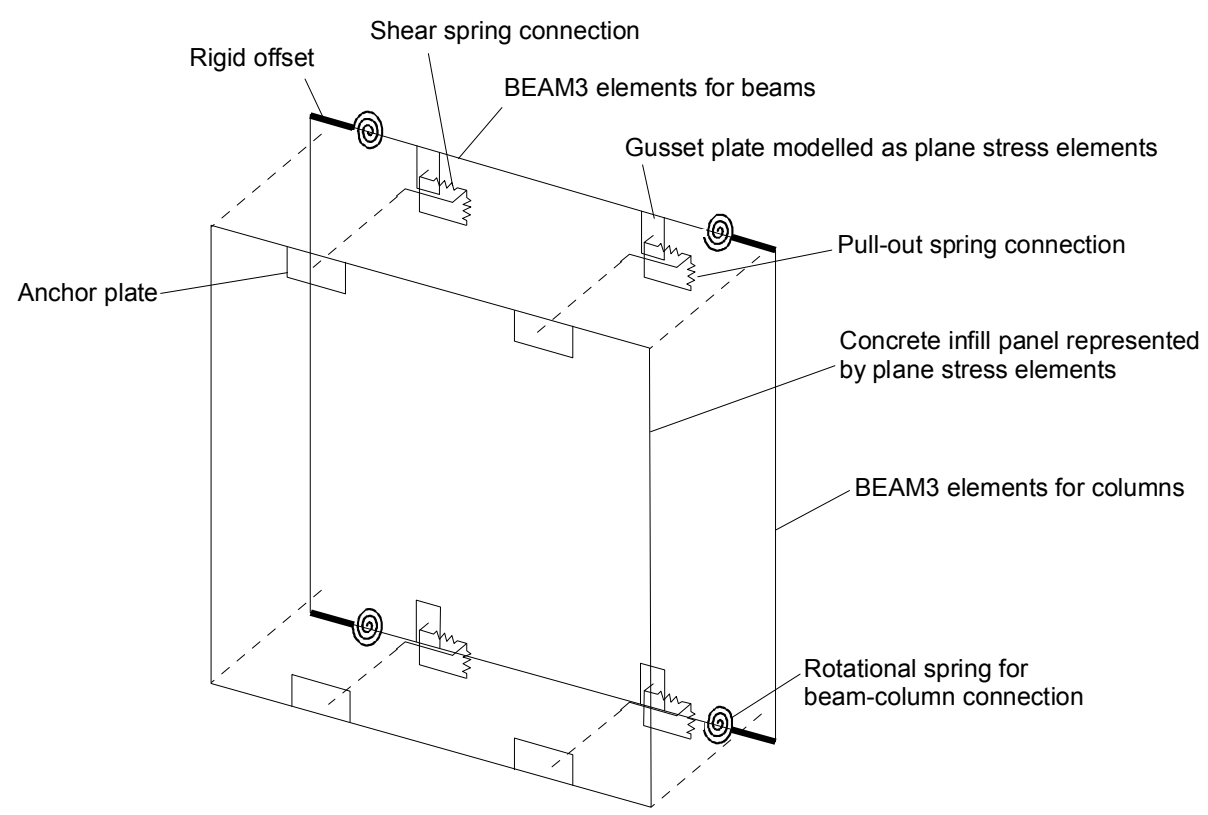

Figure 11. Finite Element Model Set-Up (Offset Infill Panel for Clarity)

connection between column and beam is modelled by a rigid offset (BEAM3 with a very high stifness) to take the column depth into account and a rotational spring (COMBIN14, [18]) which models its stiffness. 


\subsubsection{Precast concrete infill panel with anchor plate}

The precast concrete infill panel as shown in Figure 12a was modelled by plane stress elements (PLANE82, [18]), with a thickness of $150 \mathrm{~mm}$. For Test A, Young's modulus is $E_{\mathrm{A}}=29.2 \mathrm{kN} / \mathrm{mm}^{2}$ and for Test $B E_{B}=31.0 \mathrm{kN} / \mathrm{mm}^{2}$. The plane stress elements of the concrete panel are connected to the plane stress elements of the steel anchor plates which share the same orthogonal grid. There is no overlapping of elements. The finite elements of the anchor plates (PLANE82, [18]) are modeled as steel plates with a thickness of $10 \mathrm{~mm}$ and $E_{\mathrm{s}}=210 \mathrm{kN} / \mathrm{mm}^{2}$. This way of modelling minimizes stress concentrations in the materials.

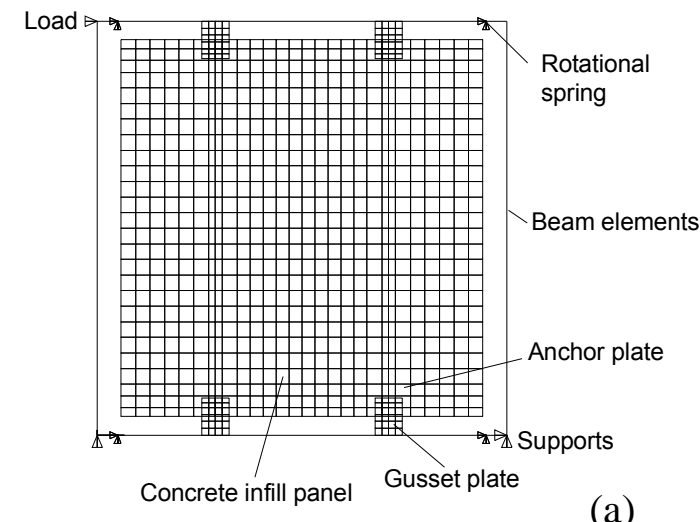

(a) (b)

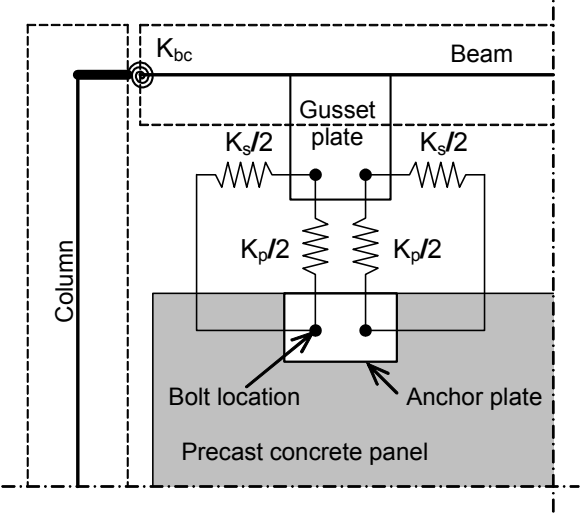

Figure 12. Finite Element Model of Frame-Panel-Connection

\subsubsection{Frame-to-panel connections}

The gusset plates, welded to the beams, are also modeled as steel plates (PLANE82, [18]) with a thickness of $10 \mathrm{~mm}$ and $E_{\mathrm{s}}=210 \mathrm{kN} / \mathrm{mm}^{2}$. The connection between an achor plate and a gusset plate is modelled by four springs using element COMBIN39 [18], see Figure 12b. They represent the anchor behaviour in the concrete and ovalisation in the steel connection plates: two in the shear direction and two in the tension direction. The results of Test 1 on shear and tension for FPC1 and FPC2 were used in the full scale frame-panel simulations; see bold type values in Table 2. The tensile strengths were reduced due to interaction with the shear load on the connections (Saari et al. [19], McMakin et al. [20]). Two tension-shear interaction curves were employed in an attempt to establish upper and lower bounds for the lateral load capacities of the infilled frames. Linear and

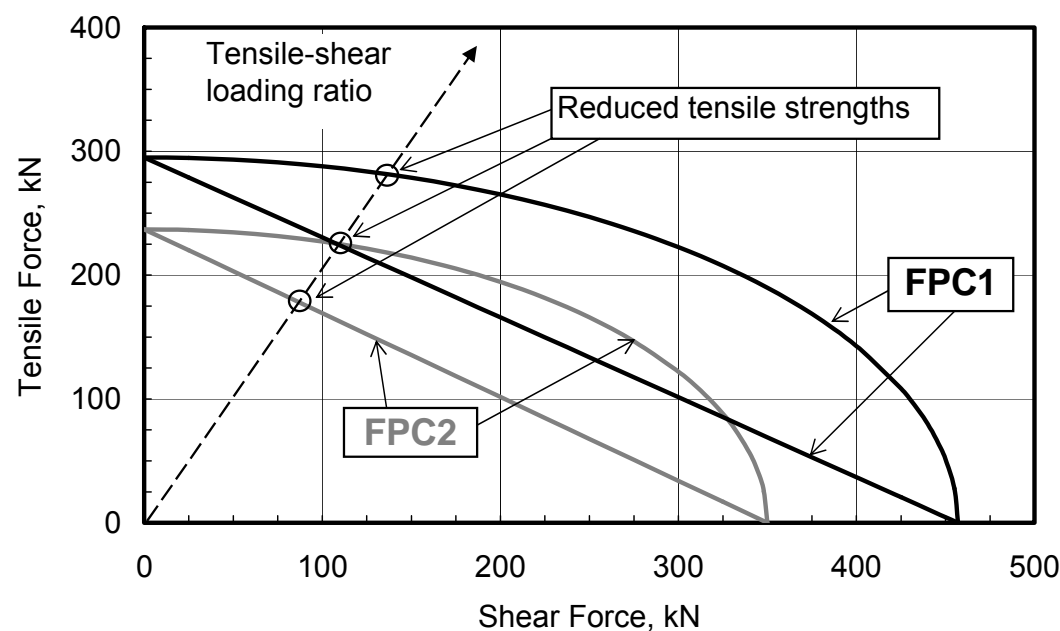

Figure 13. Tensile Strength Reduction of Connections due to Load Interaction 


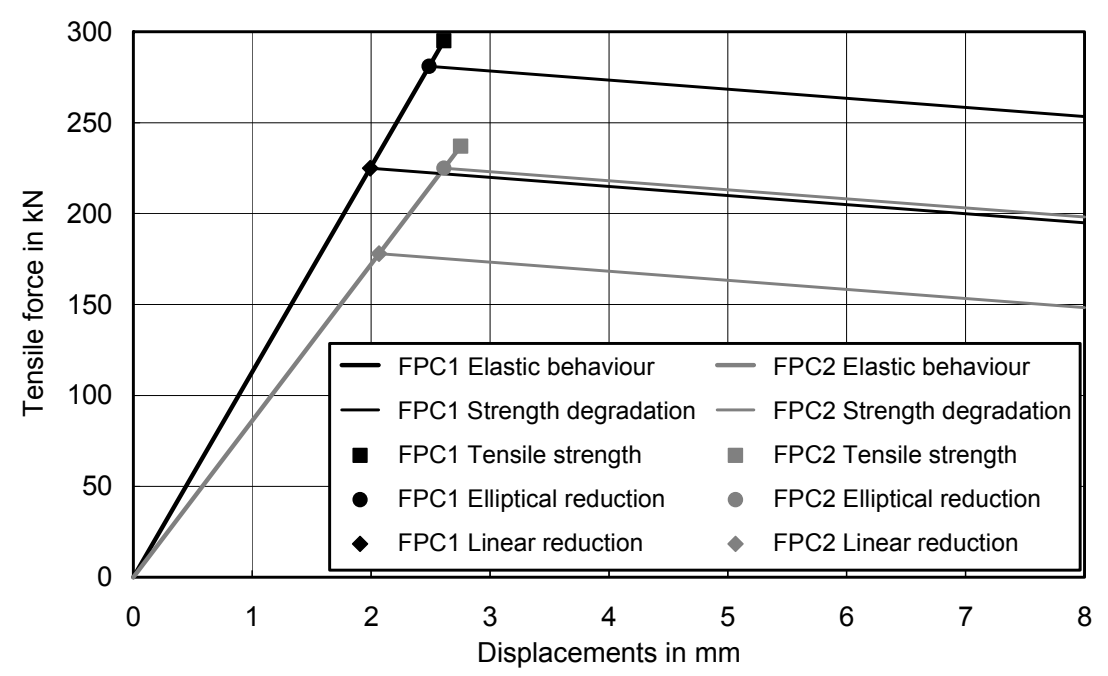

Figure 14. Tensile Characteristics of FPC1 and FPC2 Applied in Simulations

elliptical interaction curves are displayed in Figure 13. The applied tensile-shear load ratio as a result of the locations of the discrete connections clearly indicates that the connections will fail mainly in tension.

The full FPC1 tensile strength from Test 1 of $295 \mathrm{kN}$ was linearly and elliptically reduced to $F_{\mathrm{p} ; \mathrm{u} ; \text {; lin }}=225 \mathrm{kN}$ and $F_{\mathrm{p} ; \mathrm{u} ; 1 ; \text { ellip }}=281 \mathrm{kN}$ resp. Analoguously for Test 1 of FPC2, the reduced values for its $237 \mathrm{kN}$ full tensile strength then become $F_{\mathrm{p} ; \mathrm{u} ; \text {; ;in }}=178 \mathrm{kN}$ and $F_{\mathrm{p} ; \mathrm{u} ; \text {; } \text {;llip }}=225 \mathrm{kN}$. Bi-linear curves for tension, compression and shear behaviour were assumed to be sufficiently accurate. The elastic behaviour in tension is followed by a gradual linear reduction in load due to anchor pull-out: $K_{\mathrm{p} ; \mathrm{pl}}=-5 \mathrm{kN} / \mathrm{mm}$. The tension behaviour of the connections used in the simulations is shown in Figure 14. For each connection the tensile stiffness in the elastic region is taken to be identical to the stiffness in compression. The compression behaviour is assumed to be elastic perfectly plastic. The shear failure load of the bolts in connection FPC1 was taken as the compressive strength of that connection, i.e. $457 \mathrm{kN}$. The calculated onset of plate bearing by the bolts in connection FPC2 was used for limiting its compressive strength to $282 \mathrm{kN}$. The behaviour of the connections in shear is also assumed to be elastic perfectly plastic. The shear strength for FPC1 is $457 \mathrm{kN}$ and $350 \mathrm{kN}$ for FPC2.

\subsection{Simulations of Full-Scale Tests}

Two finite element simulations were carried out for Test A and for Test B. One analysis was performed with an elliptically reduced tensile strength for the connection and one with a linearly reduced tensile strength. The load-displacement curve of the simulations are shown in Figure 15 for Test A and Test B in separate diagrams where they are compared to the experimentally obtained curves, omitting the settling-in phase. The diagrams clearly show that in the plastic regions, the experimentally obtained load-deflection curves fall between the results from the two finite element simulations. The use of an elliptically reduced tensile capacity of the connection yields numerically obtained strengths at first yield and ultimate strengths that are larger than the experimental loads. The employment of a linear tensile strength reduction of the connection leads to lower strengths than experimentally obtained for most of the plastic region. The diagrams also show that the finite element model is able to give reasonably accurate values for the elastic stiffness of a steel frame which is discretely connected to a precast concrete infill panel. The differences between numerically and experimentally obtained lateral stiffness are 6\%. Table 3 shows numerically and experimentally obtained structural properties of the infilled frames in addition to their comparison. 
At first yield one of the two pull-out springs in each connection to the tension diagonal fails. Differential rotation between gusset and anchor plates causes one spring to fail just before the other.
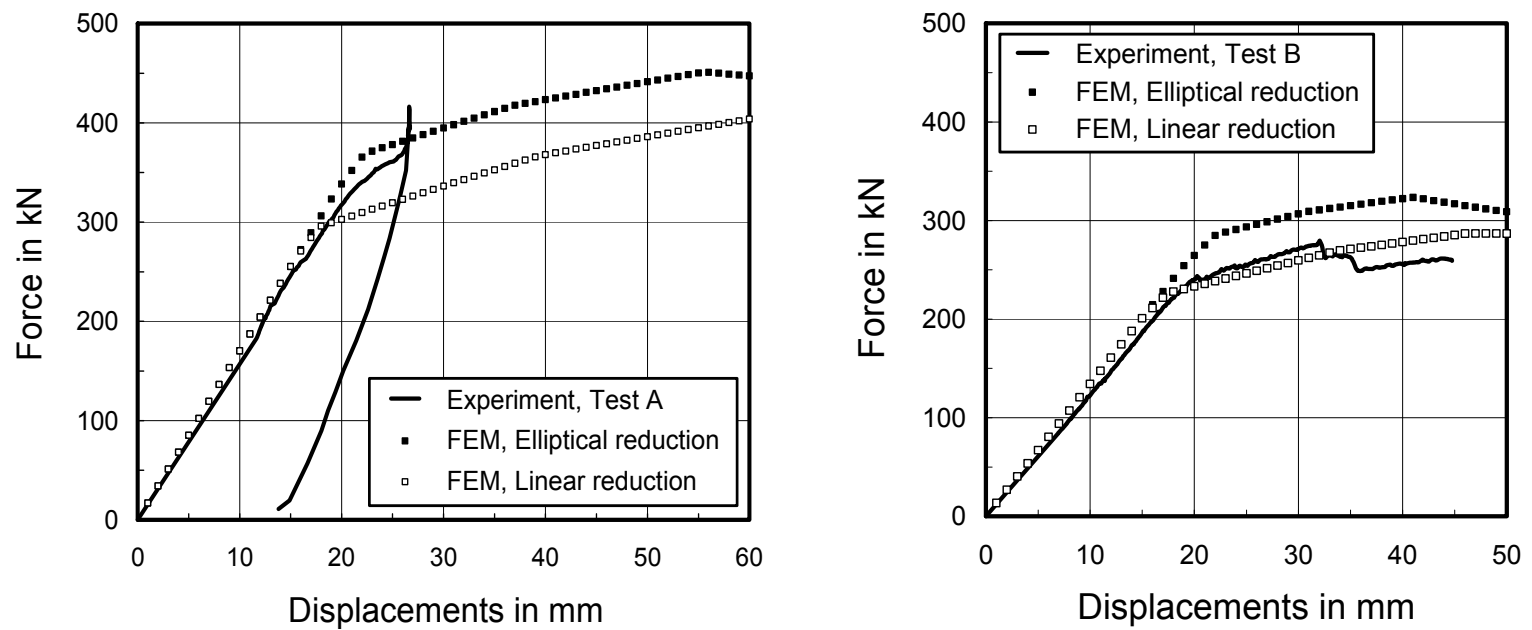

Figure 15. Experimental and Numerical Results of Full-Scale Tests

The strengths at yield as given in Table 3 are the loads for the condition where all four pull-out springs of the tension diagonal connections (locations B and C in Figure 9) have failed in tension. The ultimate strength is reached when all four "tension springs" at the connections of the compression diagonal (locations A and D in Figure 9) have failed in compression. The behaviour of all eight shear springs at the connections remains elastically linear. The simulations of the plastic behaviour, with maximum errors of $17 \%$ for strength, were less accurate than for the elastic region.

Table 3. Properties of Steel Frames with Precast Concrete Infill Panels

\begin{tabular}{|c|c|c|c|c|c|c|c|c|c|}
\hline & \multicolumn{3}{|c|}{$\begin{array}{l}\text { Yielding level } \\
\mathrm{kN}\end{array}$} & \multicolumn{3}{|c|}{$\begin{array}{l}\text { Ultimate strength } \\
\qquad \mathrm{kN}\end{array}$} & \multicolumn{3}{|c|}{$\begin{array}{c}\text { Lateral stiffness } \\
\mathrm{kN} / \mathrm{mm}\end{array}$} \\
\hline & 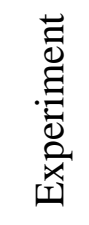 & 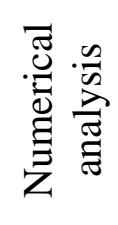 & ○。 & 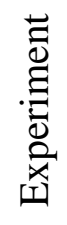 & 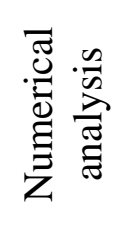 & ᄋᄋ & 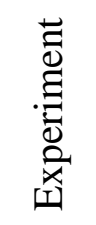 & 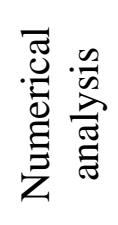 & ᄋᄋ \\
\hline Test A & 345 & $\begin{array}{c}366^{*} \\
293^{* *} \\
(311)\end{array}$ & $\begin{array}{c}+6 \\
-15 \\
(-10)\end{array}$ & - & $\begin{array}{c}451^{*} \\
407 * * \\
(416)\end{array}$ & - & 15.9 & $\begin{array}{c}16.9 \\
(16.9)\end{array}$ & $\begin{array}{c}+6 \\
(+6)\end{array}$ \\
\hline Test B & 241 & $\begin{array}{c}283^{*} \\
226^{* *} \\
(240)\end{array}$ & $\begin{array}{c}+17 \\
-6 \\
(-1)\end{array}$ & $\begin{array}{c}27 \\
6\end{array}$ & $\begin{array}{c}323 * \\
287 * * \\
(287)\end{array}$ & $\begin{array}{c}+17 \\
+4 \\
(+4)\end{array}$ & 12.5 & $\begin{array}{c}13.3 \\
(14.5)\end{array}$ & $\begin{array}{c}+6 \\
(+16)\end{array}$ \\
\hline
\end{tabular}

* Elliptical reduction tensile strength of connection, ** Linear reduction tensile strength of connection (-) Using averaged connection properties with linear reduction of tensile strength

For an additional simulation it is suggested that the input properties for the connections be adjusted to take the spread of the experimental results for all connection tests into account. This would lead to a $9 \%$ increase in tensile strength for FPC1 to $321 \mathrm{kN}$ and a 3\% increase for FPC2 to $245 \mathrm{kN}$. The average values of the other properties are shown in Table 2. Employing linear reductions for the tensile strengths yields $F_{\mathrm{p} ; \mathrm{u} ; 1 ; \text { lin;avg }}=239 \mathrm{kN}$ and $F_{\mathrm{p} ; \mathrm{u} ; \text {; ;in;avg }}=183 \mathrm{kN}$. The load deflection diagram of the simulations is shown in Figure 16 where they are compared to the experimental curves. The results for the simulation are further shown in brackets in Table 3. They show improved results for 
strength at yield level as the errors with a linear tensile strength reduction are now $-10 \%$ and $-1 \%$ resp. The results for the elastic lateral stiffness do not improve.

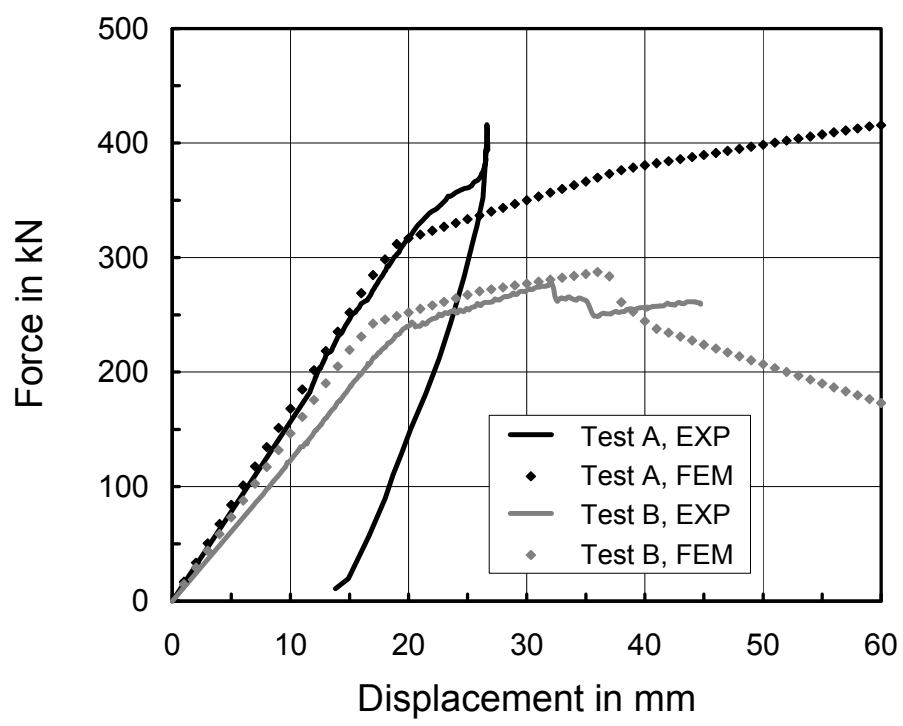

Figure 16. Experimental Tests Compared to Numerical Simulations

Using Averaged Experimental Properties for Connections

\section{CONCLUSIONS}

This article presents experimental and numerical studies on the behaviour of two full scale one-bay-one-story steel frames with pre-cast concrete infill panels subjected to in-plane horizontal loading. The concrete panels are discretely connected to the top and bottom beams of the steel frames at four locations. Two different types of frame-panel connections were tested experimentally. This allowed characteristic properties for stiffness and strength of the connections to be represented by bi-linear springs in finite element analyses of the infilled frames. The interaction between shear and tensile capacities of the two connections was taken into account.

Finite element simulations with linearly and elliptically reduced tensile strength of the connections were performed for each full-scale infilled frame structure taking into account non-linear material properties. The numerical models yield good results for the elastic behaviour and reasonable results for the plastic region.

It has been shown that simple finite element models make it possible to systematically investigate the influence of connections on the overall behaviour of steel frames with discretely connected precast concrete infill panels subject to in-plane lateral loading.

The following can be concluded from this investigation:

(i) The full-scale experimental tests show that a precast concrete panel in a semi-integral infilled steel framed structure with discrete frame-panel connections at the top and bottom beams can significantly improve the lateral stiffness of bare steel frames.

(ii) The observed lateral stiffness of the two infilled frame structures after the settling-in phase, are roughly 12 and 10 times the bare frame stiffness.

(iii) The lateral stiffness and ultimate strength of the two infilled structures were governed by the discrete frame-panel connections. 


\section{REFERENCES}

[1] Thomas, F.G., "The Strength of Brickwork”, The Structural Engineer, 1953, Vol. 31, pp. 35-46.

[2] Polyakov, S.V., "On the Interaction between Masonry Filler Walls and Enclosing Frame when Loaded in the Plane of the Wall”, English Translation in Earthquake Engineering, Earthquake Engineering Research Institute, San francisco, 1960, pp. 36-42.

[3] Benjamin, J.R. and Williams, H.A., "The Behaviour of One-story Reinforced Concrete Shear Walls”, Journal of Structural Engineering, ASCE, 1958, Vol. 84, No. 4, pp. 1-29.

[4] Holmes, M., "Steel Frames with Brickwork and Concrete Infilling”, Proc. Insti. Civ. Engrs., 1961, Vol. 19, pp. 473-478.

[5] Stafford Smith, B., "Lateral Stiffness of Infilled Frames”, Journal of the Structural Division ASCE, 1962, Vol. 88, No. 6, pp. 183-199.

[6] Stafford Smith, B., "Behaviour of Square Infilled Frames”, Journal of the Structural Division, ASCE, 1966, Vol. 92, No. 1, pp. 381-403.

[7] Stafford Smith, B., "Methods for Predicting the Lateral Stiffness and Strength of Multi-storey Infilled Frames”, Building Science, 1967, Vol. 2, pp. 247-257.

[8] Barua, H.K. and Mallick, S.K. "Behaviour of Mortar Infilled Steel Frames under Lateral Load”, Building Environment, 1977, Vol. 12, pp. 263-272.

[9] Liauw, T.C., and Kwan, K.H., "Nonlinear Behaviour of Non-integral Infilled Frames", Computers \& Structures, 1984, Vol. 18, No. 3, pp. 551-560.

[10] Liauw, T.C. and Lo, C.Q., "Multibay Infilled Frames without Shear Connectors", Journal American Concrete Institute, 1988, Vol. 85, pp. 423-428.

[11] Ng'andu, B.M., Martens, D.R.W. and Vermeltfoort, A.T., “The Contribution of CASIEL Infill Walls to the Shear Resistance of Steel Frames”, Heron, Vol. 51, No. 4, 2006, pp. 201-223.

[12] Dawe, J.L. and Seah, C.K., "Behaviour of Masonry Infilled Steel Frames", Journal of the Canadian Society of Civil Engineering, 1989, Vol. 16, pp. 865-876.

[13] Mallick, D.V. and Garg, R.P., "Effect of Openings on the Lateral Stiffness of Infilled Frames", Proc. Insti. Civil Engrs., 1971, Vol. 49, pp. 193-210.

[14] Liauw, T.C. and Kwan, K.H., "Plastic Theory of Infilled Frames with Finite Interface Shear Strength”, Proc. Insti. Civ. Engrs., Part 2, 1983, Vol. 75, pp. 707-723.

[15] Teeuwen, P.A., Kleinman, C.S., Snijder, H.H. and Hofmeyer, H., "Full-scale Testing of Infilled Steel Frames with Precast Concrete Panels Provided with a Window Opening”, Heron, Vol. 53, No. 4, 2008, pp. 195-224.

[16] Teeuwen, P.A., Kleinman, C.S., Snijder, H.H. and Hofmeyer, H., "Experimental and Numerical Investigations into the Composite behaviour of Steel Frames and Precast Concrete Infill Panels with Window Openings”, Steel and Composite Structures, Vol. 10, No. 1, pp. $1-21$.

[17] Tang, R.B., Hoenderkamp, J.C.D. and Snijder, H.H., "Preliminary Numerical Research on Steel Frames with Precast Reinforced Concrete Infill Panels", Proceedings of the First International Conference on Structural Stability and Dynamics, Editors: Yang, Y.B., Leu, L.J. and Hsieh, S.H., Taipei, Taiwan, 2000, pp. 575-580.

[18] Ansys Academic Research 12.0.1, ANSYS, Inc. Southpointe, 275 Technology Drive, Canonsburg, PA 15317, United States.

[19] Saari, W.K., Hajjar, J.F., Schultz, A.E. and Shield, C.K., "Behaviour of Shear Studs in Steel Frames with Reinforced Concrete Infill Walls”, Journal of Constructional Steel Research, 2004, Vol. 60, pp. 1453-1480.

[20] McMakin, PJ, Slutter, R.R. and Fisher, J.W., "Headed Steel Anchors under Combined Loading”, Engineering Journal, AISC, 1973, Vol. 10, pp. 43-52. 


\title{
METHOD OF CHARACTERISTICS FOR DYNAMIC GEOMETRICALLY NON-LINEAR ANALYSIS OF BEAMS
}

\author{
A.S. Shatnawi ${ }^{1 *}$, S.Z. Al-Sadder ${ }^{2}$, M.S. Abdel-Jaber ${ }^{1}$, R. A. Othman ${ }^{3}$ and N. S. Ahmed ${ }^{3}$ \\ ${ }^{1}$ Associate Professor, Department of Civil Engineering, The University of Jordan, Amman 11942, Jordan \\ ${ }^{2}$ Assistant Professor, Department of Civil Engineering, Hashemite University, Zarqa 13115, Jordan \\ ${ }^{3}$ Assistant Professor, Department of Civil Engineering, Baghdad University, Baghdad, Iraq \\ *(Corresponding author: E-mail: ashatnawi@ju.edu.jo)
}

Received: 14 January 2009; Revised: 30 October 2009; Accepted: 22 April 2010

\begin{abstract}
The large deflection of slender beams subjected to dynamic excitation is investigated in this paper. One-dimensional flexural vibration consisting of bending and shear waves is considered. A new formulation for the flexural wave behavior in geometrically non-linear beams is introduced. The formulation of the non-linear governing equations is established by considering elements under the effect of large-deflection and large-rotation while subjected to dynamic excitation. The governing equations are re-written in a numerical form using the method of characteristics. As representative examples, different types of support and load conditions are studied, e.g., cantilever and propped cantilever beams. The results showed that the method of characteristics with the proposed formulation is a suitable method to represent wave propagation phenomena in large deflection.
\end{abstract}

Keywords: Slender beam, large deflection; non-linear dynamics, method of characteristics

\section{INTRODUCTION}

Behavior of structural members could be assumed as linear behavior when material and geometrical changes due to applied external loads are small. Usually the change in material property is due to the change in the modulus of elasticity, while the change in geometry might be due to a change in cross-sectional area or length. When these changes are small, the linear system gives accurate results. However, there are many situations such as severe earthquake motion with vertical or horizontal components (or both), suspension beams or bridges of large spans subjected to pulse, wind or any dynamic loading, in which linear models will not yield acceptable results.

The most common methods of analysis of structural dynamics are based on finite element techniques [1,2] or on analytical solutions of the equations of motion [3-5]. Analytical methods are difficult to be obtained for structures with many degrees of freedom or when coupled action exists between axial and flexural waves. In addition, they are not usually formulated in a manner that makes it easy to simulate high frequency wave action within the individual structural members. A number of existing studies oriented towards the large deflection and/or wave propagation are observed $[6,7]$.

There is an obvious advantage in having a single method of analysis capable of simulating all types of dynamic behavior, whether gradual (slow) to more rapid or transient. Such a method is the Method of Characteristics (MOC) [8-12] that is considered herein and is shown to be capable of simulating static as well as dynamic problems. The popularity of the method comes from three of its attributes:

1.The possibility to reduce the partial differential equations to straightforward ordinary differential equations.

2.The mathematics of MOC underlines the essential physical wave behavior, as the associated characteristics directions are the time-space paths of information flow in the physical system. 
3.The computer resources required are relatively small, thus enabling highly complex structures to be simulated.

In the theoretical analysis of dynamic elasticity, MOC has received limited attention. Recently only serious attempts have been made to study the problem of elastic waves propagation by MOC. It was first applied by Pfgiffe [8] who obtained a general solution of the Timoshenko beam equations. Plass [9] extended the numerical method to involve beams with two different wave speeds. Subsequently, Chou and Mortimer [10] solved the same problem using MOC. They also carried out numerical integration for the special case where the shear and bending wave speeds are equal.

MOC was also applied by Chou and Koening [11] to several spherical and cylindrical problems. Vardy and Chan [12] used the method to model waves in skeletal structures comprising prismatic members. They used this method with the presence of coupling between axial and flexural waves. Vardy and Al-Sarraj [13], presented detailed formulations and numerical applications for the use of MOC in predicting the dynamic behavior of linear one-dimensional members (beams). Al-Sarraj et al [14] and Al-Sadder et al. [15] applied MOC to problems of non-linear vibration of axially loaded bars and beams, respectively. Consequently, the large deflection problems of beams was studied in static case by using different methods of analysis. Haisler et al. [16] and Haisler and Stricklin [17] presented solution techniques which are applicable to the solution of the non-linear algebraic or differential equations characterizing geometrically non-linear behavior.

In the following mathematical formulation, equations of motion in Cartesian coordinates are obtained for each type of wave Consequently, material property relationships are differentiated with respect to time. This leads to pairs of partial differential equations relating a force and a velocity or a couple and an angular velocity. Each pair of equations is expressed in ordinary differential form using MOC and the explicit finite difference technique is used to obtain the solution by a process of time marching. The accuracy and stability of the numerical solution are evaluated and discussed.

In the present work, the large deflection problem of slender beams is studied in dynamic state. One-dimensional flexural vibration is considered and a new formulation for the flexural wave behavior in geometrically non-linear beams is introduced by using MOC, and the numerical solution of the new equations is done by using the finite difference techniques.

\section{FORMULATION OF THE PROBLEM}

A small element of a beam of constant flexural rigidity $E I$ and actual length $d s$ with cross-section area, $A$, is considered as shown in Figure 1.

For simplifying, the following notations are defined as:

$M$ : bending moment

$V$ : lateral force

$\lambda$ : lateral velocity

$\psi:$ angular velocity

$\rho:$ density of the material

$A$ : area of cross section

$F$ : axial force

$Q$ : shear force

I: second moment of area

$E$ : modulus of elasticity 


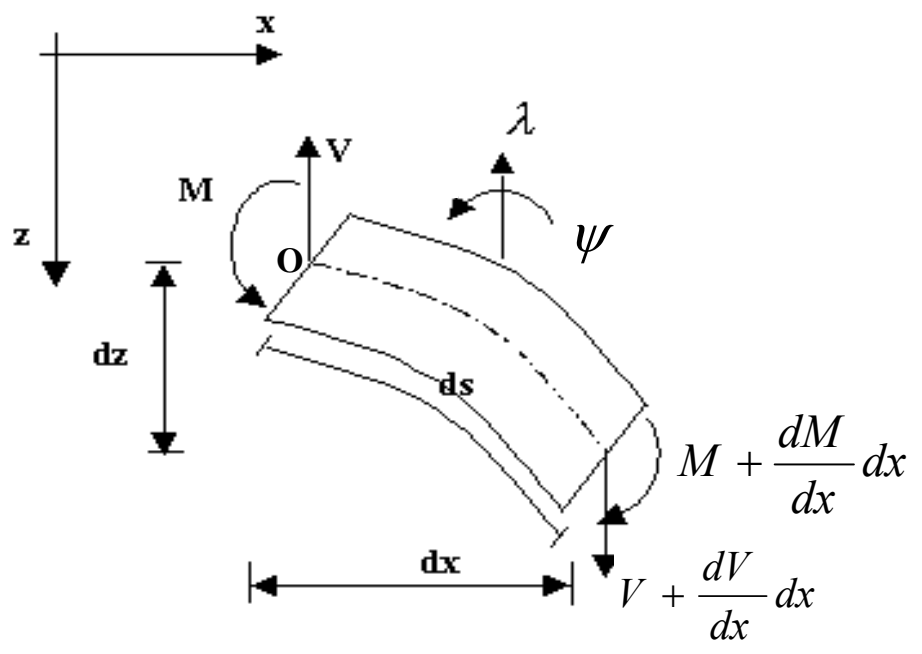

Figure 1. Small Beam Increment under Large Deflection.

Now, according to Newton's second law and applying dynamic equilibrium of forces in vertical direction, gives:

$-V+V+\frac{d V}{d x} d x=\rho A d s \frac{\partial \lambda}{\partial t}$

Where the right side of Eq. 1 represents the mass multiplied by acceleration.

Simplifying Eq. 1 yields

$$
\frac{d V}{d x}=\rho A \frac{\partial \lambda}{\partial t} \frac{d s}{d x}
$$

Then, from Figure 2, the relations between the two components and the original lateral force can be obtained as:

$$
V=Q \cos \theta+F \sin \theta
$$

$Q \sin \theta=F \cos \theta$

By substituting Eq. 4 into Eq. 3, one may obtain the following:

$$
V=\frac{Q}{\cos \theta}
$$

By differentiating Eq. 5 with respect to " $x$ " along with substituting $\cos \theta=\frac{d x}{d s}$ (as shown in Figure 2), one may obtain the following:

$$
\frac{d V}{d x}=Q \frac{d^{2} s}{d x^{2}}+\frac{d Q}{d x} \frac{d s}{d x}
$$




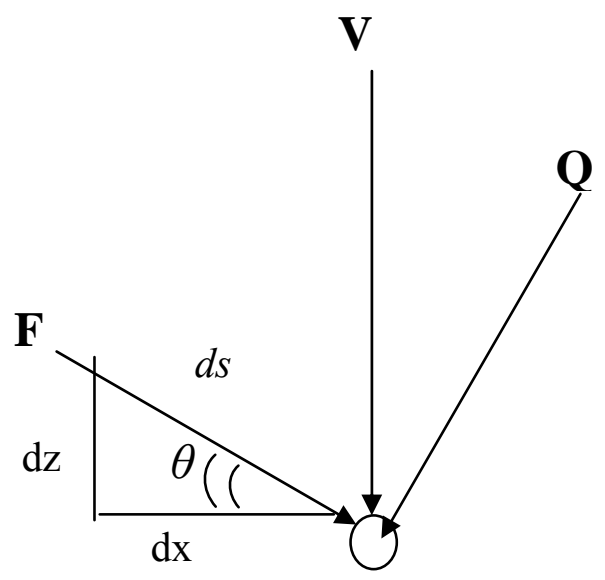

Figure 2. Relations Between Forces' Components.

Substituting Eq. 6 in Eq. 2 to get

$Q \frac{d^{2} s}{d x^{2}}+\frac{d Q}{d x} \frac{d s}{d x}=\rho A \frac{d \lambda}{d t} \frac{d s}{d x}$

$\frac{d Q}{d x}+Q \frac{d^{2} s}{d x^{2}} \frac{d x}{d s}=\rho A \frac{d \lambda}{d t}$

Similarly, applying dynamic equilibrium of moment about point $\mathrm{O}$ shown in Figure 1 gives:

$-M+M+\frac{d M}{d x} d x+\left(V+\frac{d V}{d x} d x\right) d x=\rho I d s \frac{d \psi}{d t}$

Where the right side of Eq. 9 represents the mass moment of inertia multiplied by the angular (rotational) acceleration which is expressed as the derivative of the angular velocity $(d \psi / d t)$.

Simplifying Eq. 9 yields

$\frac{d M}{d x}+V=\rho I \frac{d \psi}{d t} \frac{d s}{d x}$

Substituting Eq. 5 into Eq. 10 yields

$\frac{d M}{d x}+Q \frac{d s}{d x}=\rho I \frac{d \psi}{d t} \frac{d s}{d x}$

where

$$
\frac{d s}{d x}=\left[1+\left(\frac{d z}{d x}\right)^{2}\right]^{\frac{1}{2}}
$$

The material property relationships obtained from Hook's Law are differentiated with respect to time, $t$, to give the other two equations as follows [13]: 
- Shear:

$\frac{\partial Q}{\partial t}=K_{1} G A\left(\frac{\partial \lambda}{\partial x}-\psi\right)$

Moment:

$\frac{\partial M}{\partial t}=E I \frac{\partial \psi}{\partial x}$

Where, $K_{1}=$ Shear correction factor; $G=$ Shear modulus; and $\psi=$ Angular velocity

Eqs. 8, 13 and 11, 14 are pairs of hyperbolic partial differential equations where each of them may be expressed as an ordinary differential equation provided that their range of applicability is restricted to certain characteristic directions in the $x$ - $t$ plane [13]. In their characteristic form, the equations become as:

Shear along $\frac{d x}{d t}= \pm C_{S}$

$\frac{d Q}{d t} \pm C_{S} \rho A \frac{\partial \lambda}{\partial t}= \pm C_{S} Q \frac{d^{2} s}{d x^{2}} \frac{d x}{d s}-K_{1} G A \psi$

Moment along $\frac{d x}{d t}= \pm C$

$\frac{d M}{d t} \pm \rho I C \frac{d \psi}{d t} \frac{d s}{d x}= \pm C \frac{d s}{d x}$

where $C=\sqrt{\frac{E}{\rho}}$ and $C_{S}=\sqrt{\frac{K_{1} E}{\rho}}$ are speeds of transmission of moment and shear waves along member.

These equations can be integrated along the lines $L^{\prime} \mathrm{P} \& \mathrm{R}^{\prime} \mathrm{P}$ in the case of shear wave and LP \& RP in the case of bending wave as shown in Figure 3. Using central difference expressions yields:

- Shear:

$\left(Q_{P}-Q_{L}^{\prime}\right)-\rho A C_{S}\left(\lambda_{P}-\lambda_{L}^{\prime}\right)=-\rho A C_{S}\left(\frac{\psi_{p}+\psi_{L}^{\prime}}{2}\right) \Delta x-\frac{d^{2} s}{d x^{2}} \frac{d x}{d s}\left(\frac{Q_{P}+Q_{L}^{\prime}}{2}\right) \Delta x$

$\left(Q_{P}-Q_{R}^{\prime}\right)+\rho A C_{S}\left(\lambda_{P}-\lambda_{R}^{\prime}\right)=-\rho A C_{S}\left(\frac{\psi_{p}+\psi_{R}^{\prime}}{2}\right) \Delta x+\frac{d^{2} s}{d x^{2}} \frac{d x}{d s}\left(\frac{Q_{P}+Q_{R}^{\prime}}{2}\right) \Delta x$

- Moment:

$$
\begin{aligned}
& \left(M_{P}-M_{L}\right)-\rho I C\left(\psi_{p}-\psi_{L}\right) \frac{d s}{d x}=-\left(\frac{Q_{P}+Q_{L}}{2}\right) \frac{d s}{d x} \Delta x \\
& \left(M_{P}-M_{R}\right)+\rho I C\left(\psi_{p}-\psi_{R}\right) \frac{d s}{d x}=+\left(\frac{Q_{P}+Q_{L}}{2}\right) \frac{d s}{d x} \Delta x
\end{aligned}
$$




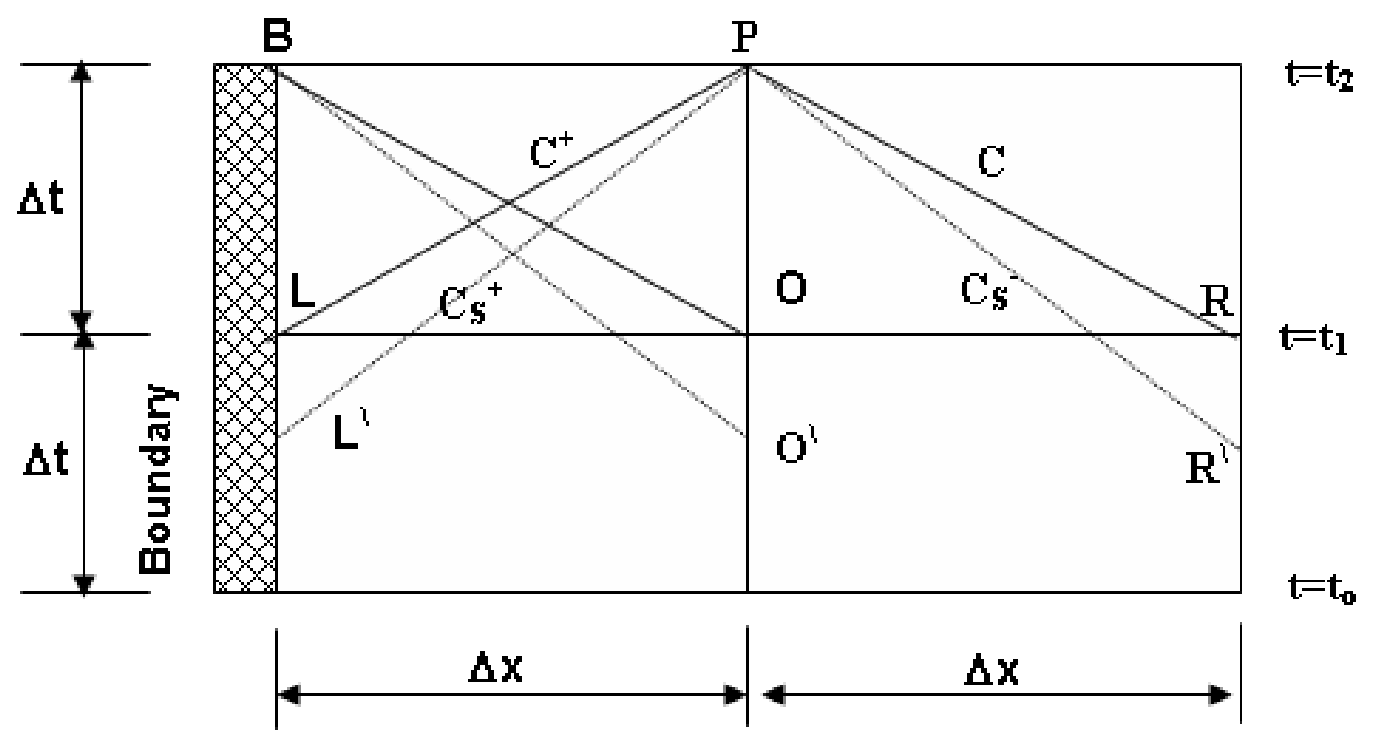

Figure 3. Numerical Characteristics Scheme.

\section{NUMERICAL EXAMPLES}

The non-linear dynamic governing equations that are represented by Eqs. 17 to 20 are solved simultaneously by a computer program using FORTRAN77 language. Several examples were carried out to evaluate the dynamic behavior of prismatic slender beams under large deflection. For all examples, the following numerical data of steel type prismatic and slender beam are used:

$\mathrm{L}=1 m, A=0.01 m^{2}, \mathrm{I}=8.333 \times 10^{-6} m^{4}, \mathrm{E}=200 \mathrm{GPa}, \rho=8000 \mathrm{~kg} / \mathrm{m}^{3}$

\subsection{Stability and Convergence of MOC}

The convergence of the MOC is usually tested using grid size dependence. Figures $4 \mathrm{a}$ and $4 \mathrm{~b}$ represent the nonlinear dynamic behavior for different number of grid lengths in a cantilever beam subjected to a constant applied tip moment. In linear analysis, 16-grid lengths are usually sufficient. Also, 16-grid lengths are sufficient for nonlinear axial and torsional waves [13 and 14]. The behavior of flexural waves is more complicated and hence a finer mesh is needed. However, Figures $4 \mathrm{a}$ and $4 \mathrm{~b}$ show that using 32-grid lengths are giving converging results and are giving sufficient accuracy when compared to the case of using 16-grid lengths. Using higher grid lengths will yield approximately same response obtained by using 32-grid lengths. For example, using 64-grid lengths produced results with slight difference in accuracy that is negligible, taking into consideration that the time required for performing analysis with 64-grid lengths was four times more than that needed using 32-grid lengths. Thus, the 32-grid lengths have been used in all numerical examples. However, the accuracy of solution obtained using MOC can be checked by comparison with results from other methods of solution.

Nonlinear dynamic response of a cantilever beam subjected to tip moment has been carried out using MOC and compared to results obtained by using MSC/NASTRAN [18], where finite element analysis is used. Figure 5 shows that the displacements at free end of a cantilever beam subjected to tip moment obtained by using $\mathrm{MOC}$ are slightly different than those obtained by using MSC/NASTRAN. A convergence criterion within MSC/NASTRAN proved that 10 elements for the beam under consideration gave sufficient accuracy where the nonlinear static finite element analysis was adopted. Large deflection option is chosen with Modified Newton-Raphson iterative solution of the non-linear equation. The slight difference between MOC and MSC/NASTRAN 
results is expected due to the different numerical approach adopted in the analysis. However, both methods yielded reasonable agreement. Precisely, In MOC, the displacement is calculated from the resulting velocity through approximate iterative numerical integration with different precisions and approach than those used in the case of using MSC/NASTRAN.

\subsection{Effect of Different Dynamic Loads}

Figures $6 \mathrm{a}$ and $6 \mathrm{~b}$ show a comparison between the behavior of a cantilever beam subjected to a suddenly applied constant bending moment at its free end for both large deflection dynamic behavior (i.e., non-linear) and small deflection dynamic behavior (i.e., linear). Figure 7a shows the bending moment at the fixed end for a propped cantilever beam under tip bending moment for both dynamic behaviors under large and small deflection. Figures $7 \mathrm{~b}$ to $7 \mathrm{~d}$ show the shear force at different locations for a propped cantilever beam subjected to a tip bending moment for both dynamic behaviors of large and small deflection.

Figures $8 \mathrm{a}$ and $8 \mathrm{~b}$ show the bending moment and shear force at the fixed end for a cantilever beam subjected to a tip vertical force. Results show that the shear force and bending moment-time history have similar shapes with magnified values in the case of large deflection.

In dynamic analysis, MOC is well suited to determine the fundamental natural frequencies of the structure by observing the repetitive pattern of the force or velocity response caused by the dynamic load as the frequency does not appear explicitly in MOC equations. Also by using Fast Fourier transform algorithm, high frequencies may be determined [13]. Natural frequencies could be obtained by any suitable method including analytical methods. However, in the present study, the natural frequencies of the structure were obtained by using the software MSC/NASTRAN [17] since it is used for comparison purposes. Then, these frequencies are used by suitable FORTRAN77 computer program to simulate the resonance condition.

Figure 9 shows the dynamic response of a propped cantilever beam subjected to a periodic load at its free end where the resonance occurred when the load frequency $\left(\omega_{\mathrm{p}}\right)$ matches the natural frequency of the beam $\left(\omega_{n}\right)$.

Non-linear systems exhibit phenomena that cannot occur in linear systems. In this phenomenon, it can be seen that the amplitude of the vibration of the system has been found to increase or decrease as in the large deformation stage, the fundamental frequency is changed. This may have an important influence in resonance, as there will be a difference between the load and structure frequencies, i.e., canceling the resonance condition. When harmonic loading is applied with a frequency equal to the natural frequency of the beam, resonance will occur. The deflection in this case will increase with time leading to an increase in the member length and that will decrease the natural frequency of the beam. At a certain time the frequency of the loading is not matching with the natural frequency of the beam. The difference between them will be large enough to cause a jump in the vibration of the beam, as shown in Figure 10a. In addition, Figure 10b shows the change in the length of the beam that corresponds to the change in the response during the resonance case. One may keep in mind that jump phenomenon can not be observed in a linear analysis. 

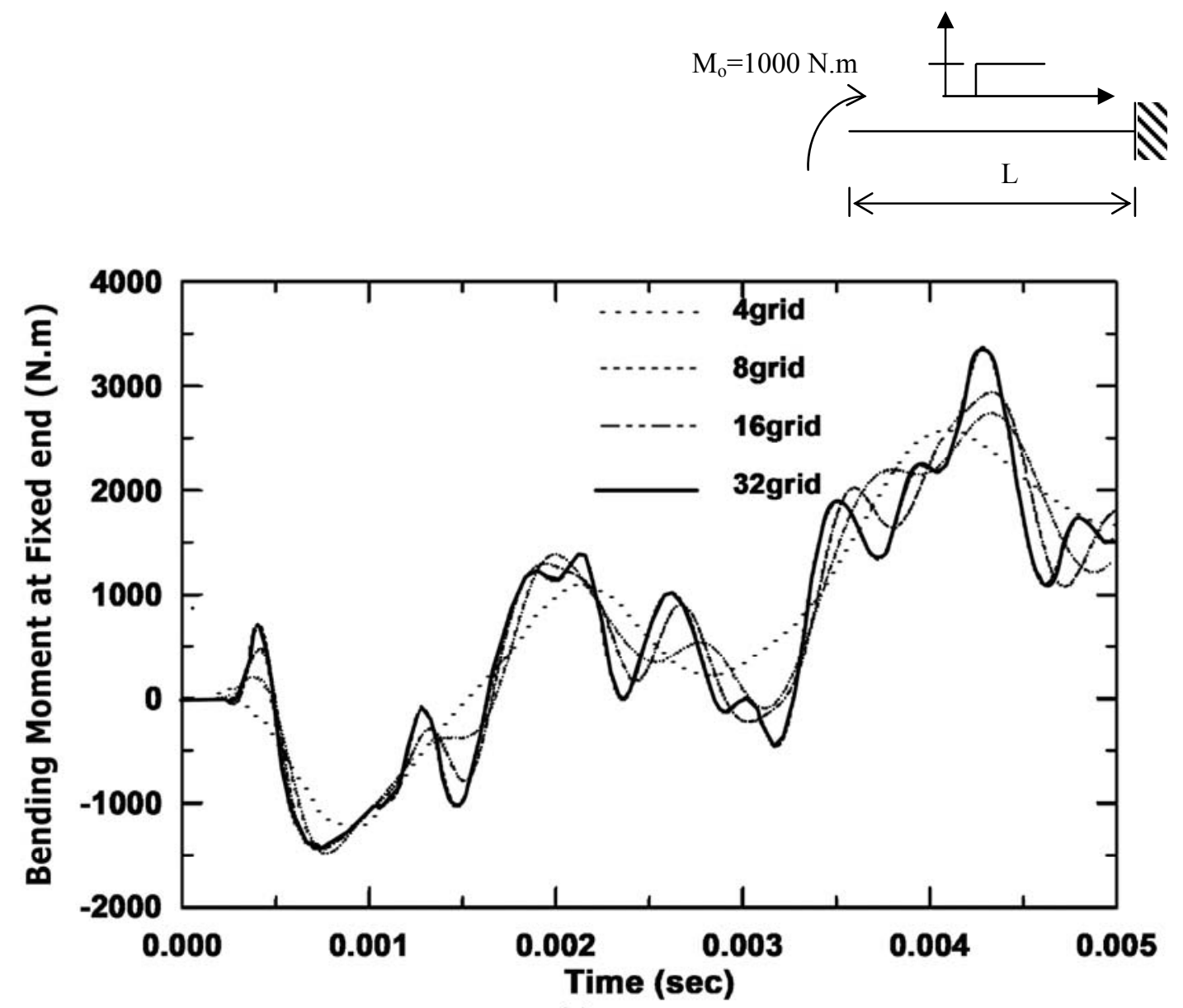

(a)

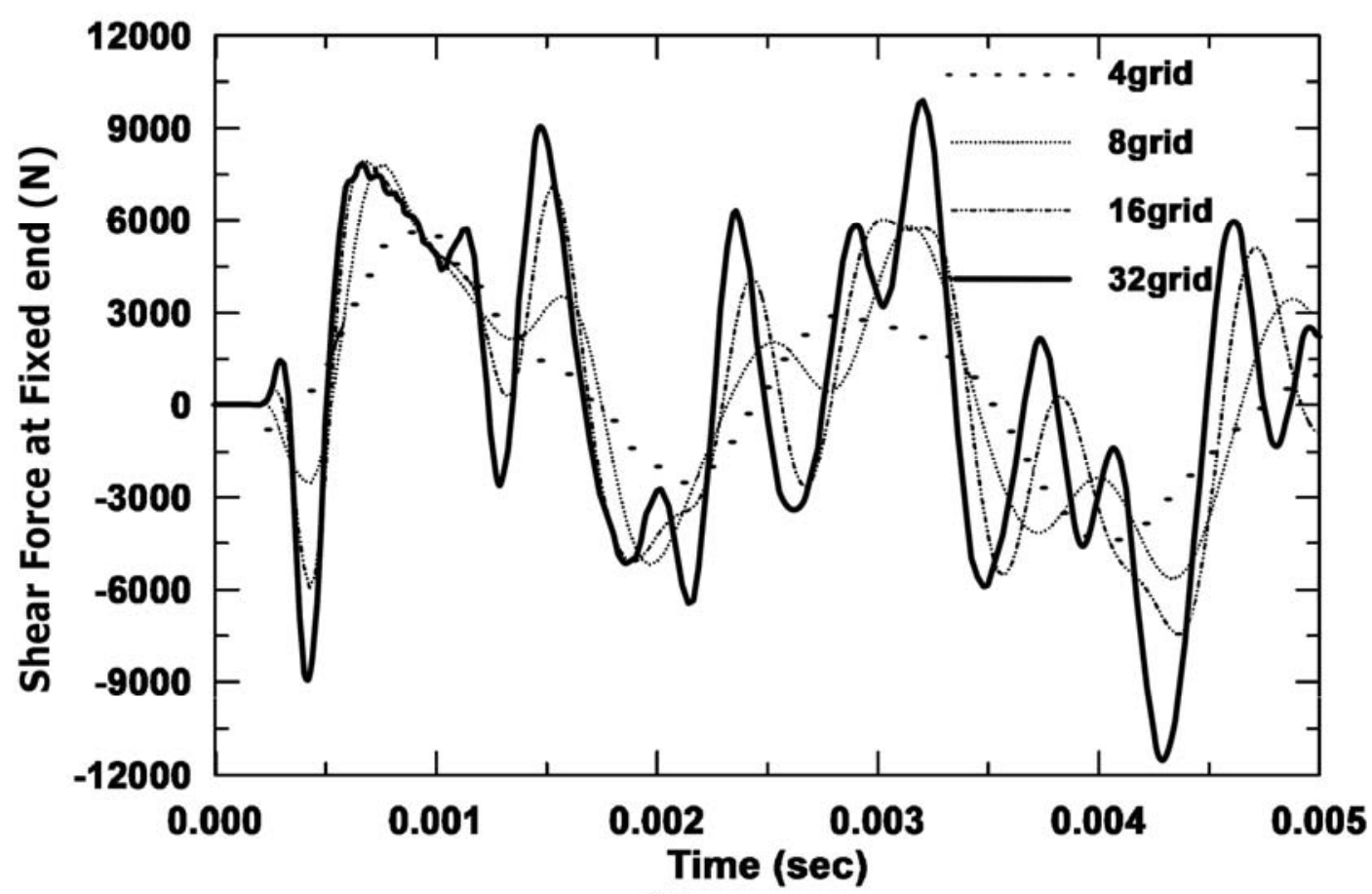

(b)

Figure 4. Grid Size Dependence for Large Deflection Dynamic Behavior. 

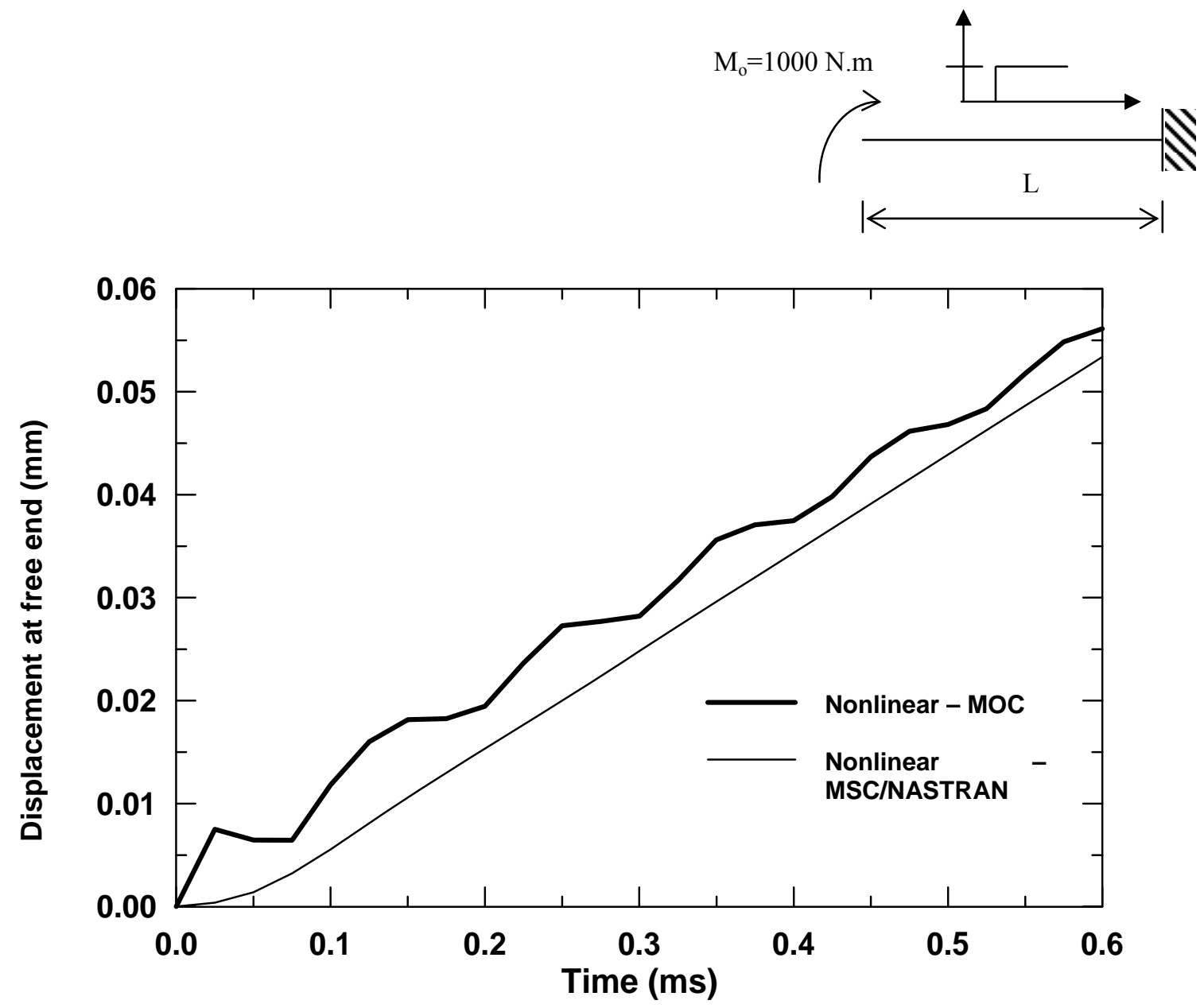

Figure 5. Comparison between MOC and MSC/NASTRAN for Nonlinear Dynamic Behavior of a Cantilever Beam subjected to Tip Moment. 

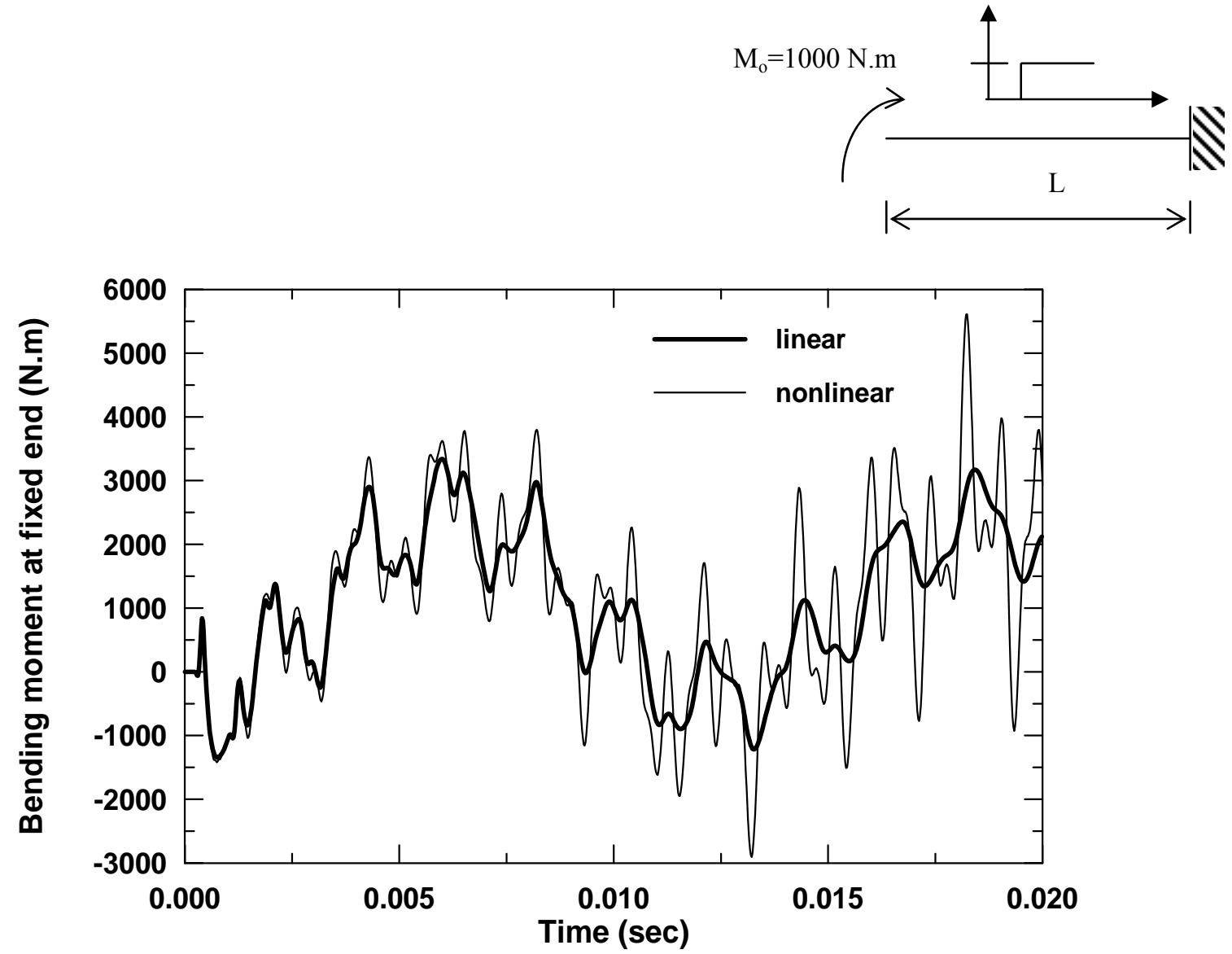

(a)

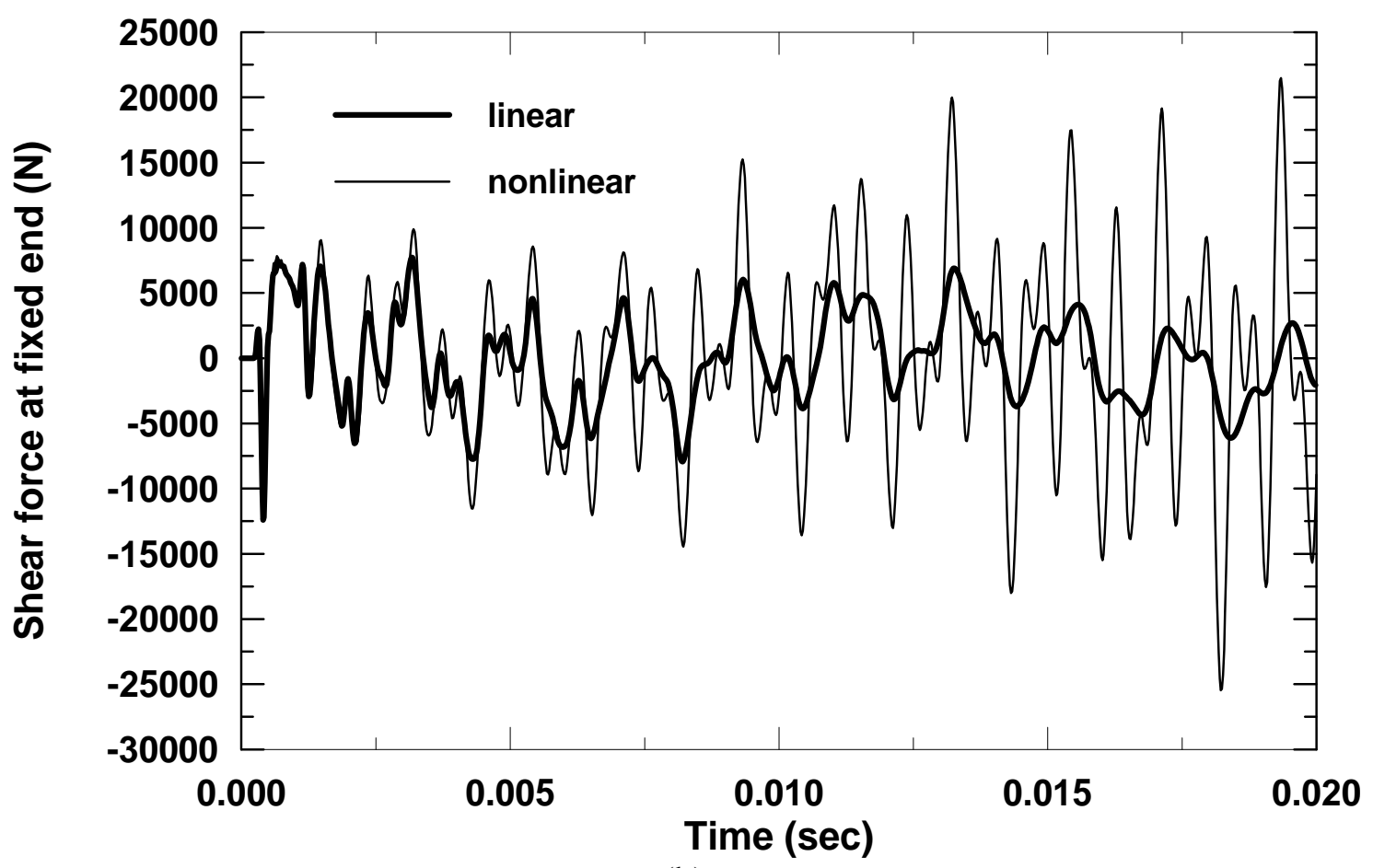

(b)

Figure 6. Comparison between Dynamic Responses under Large and Small Deflection for a Cantilever Beam under Tip Bending Moment. 


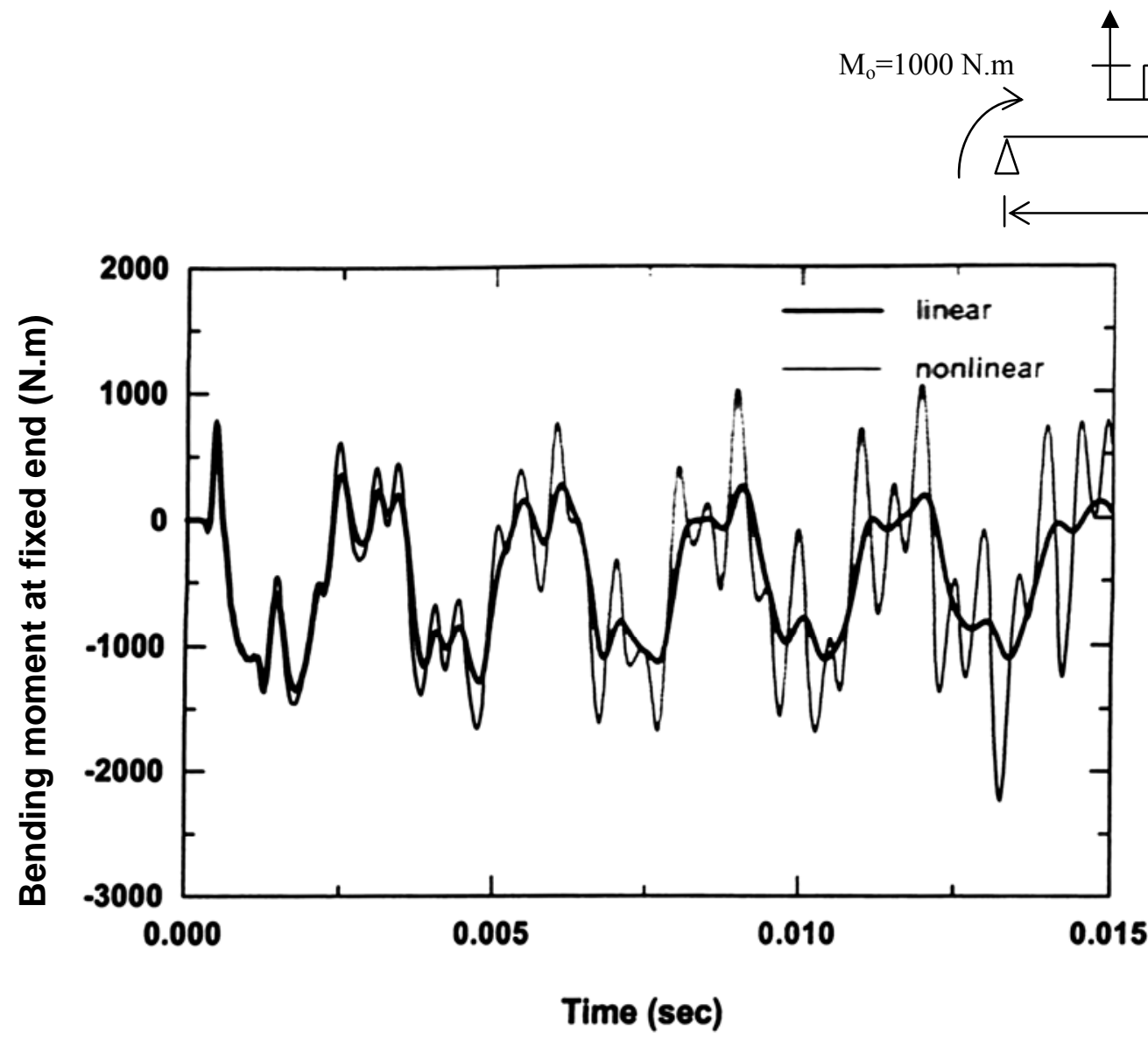

(7a)

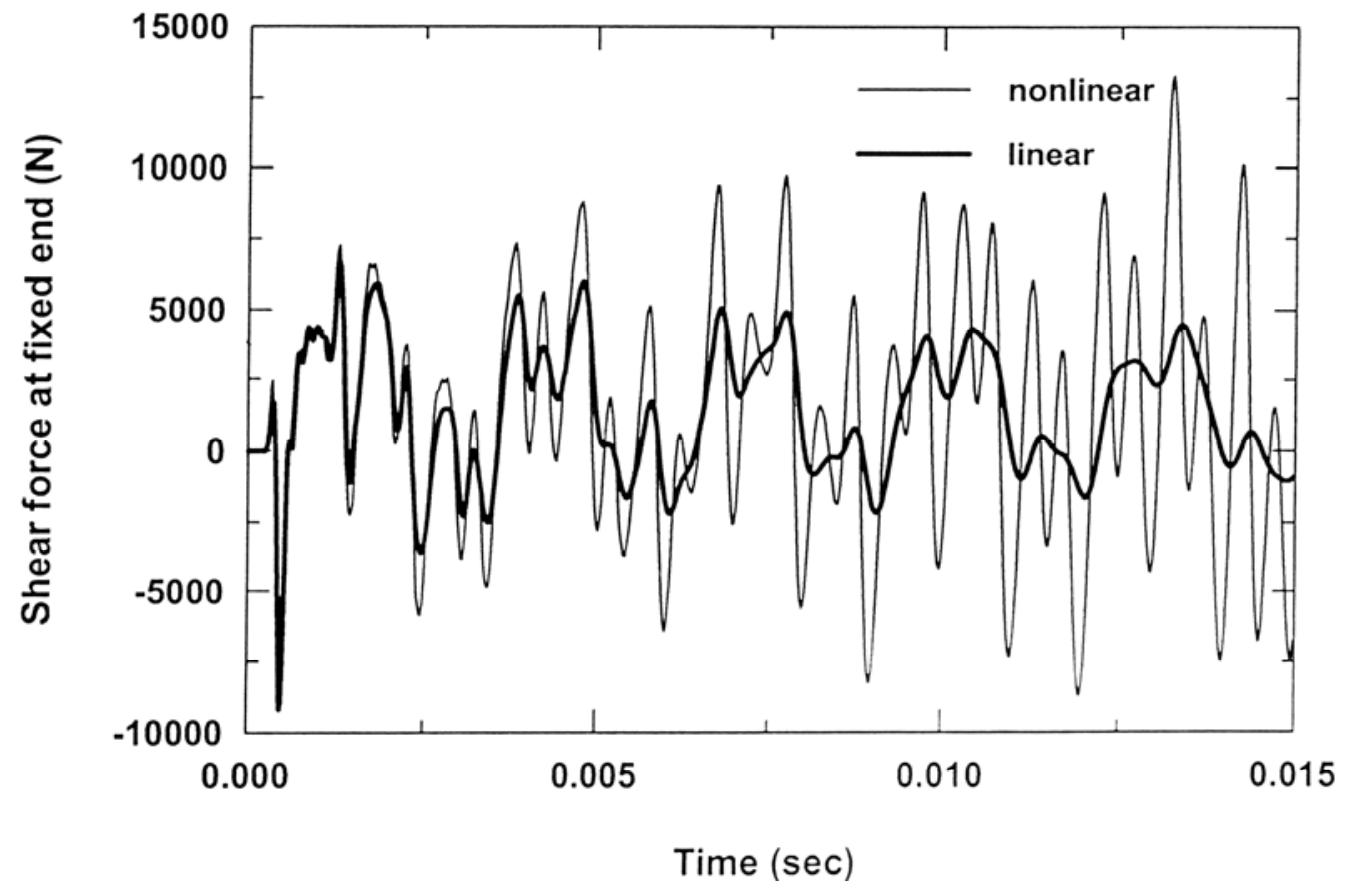

(7b)

Figure 7. Comparison between Dynamic Behaviors under Large and Small Deflection for a Propped Cantilever Beam under Tip Bending Moment. 


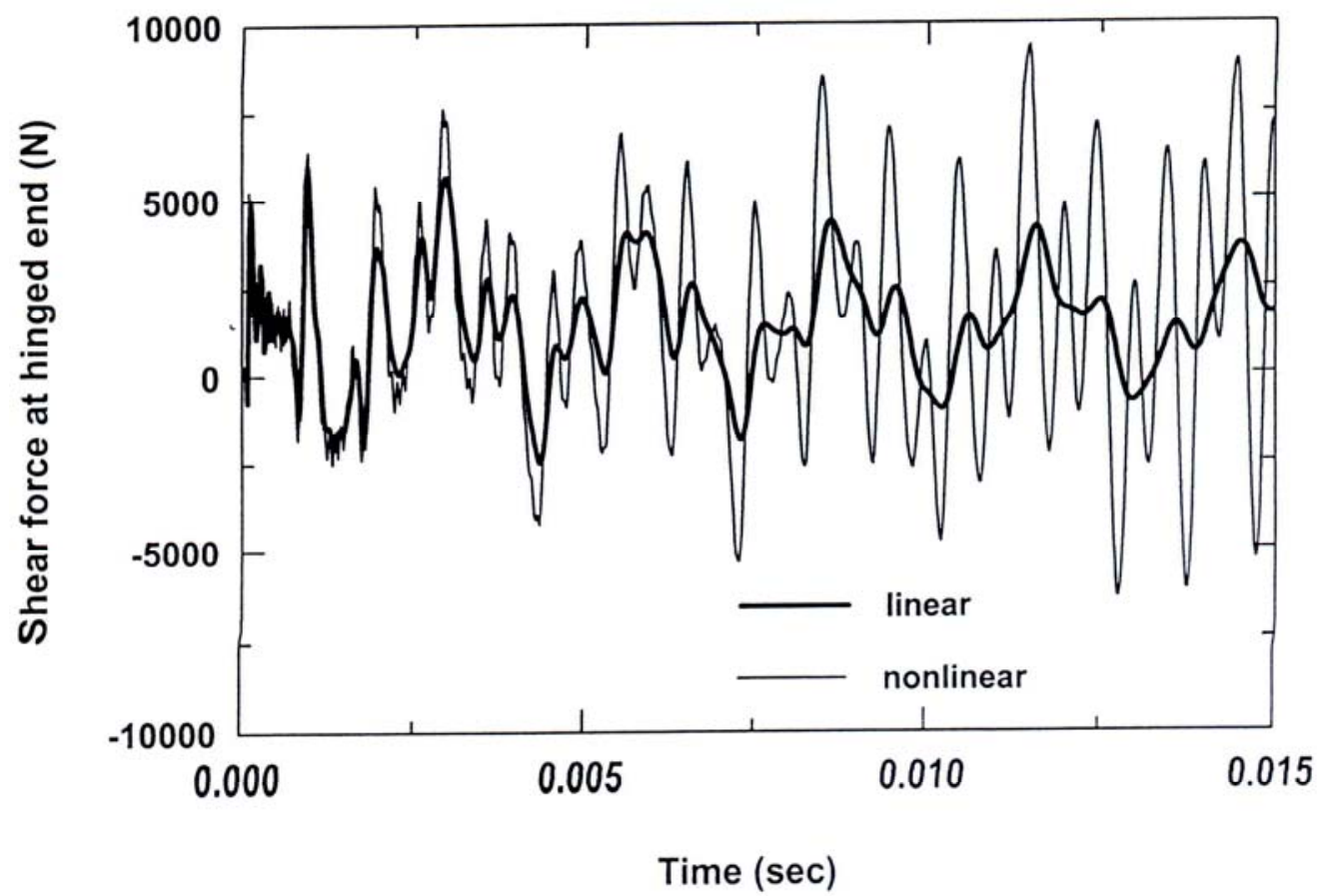

(7c)

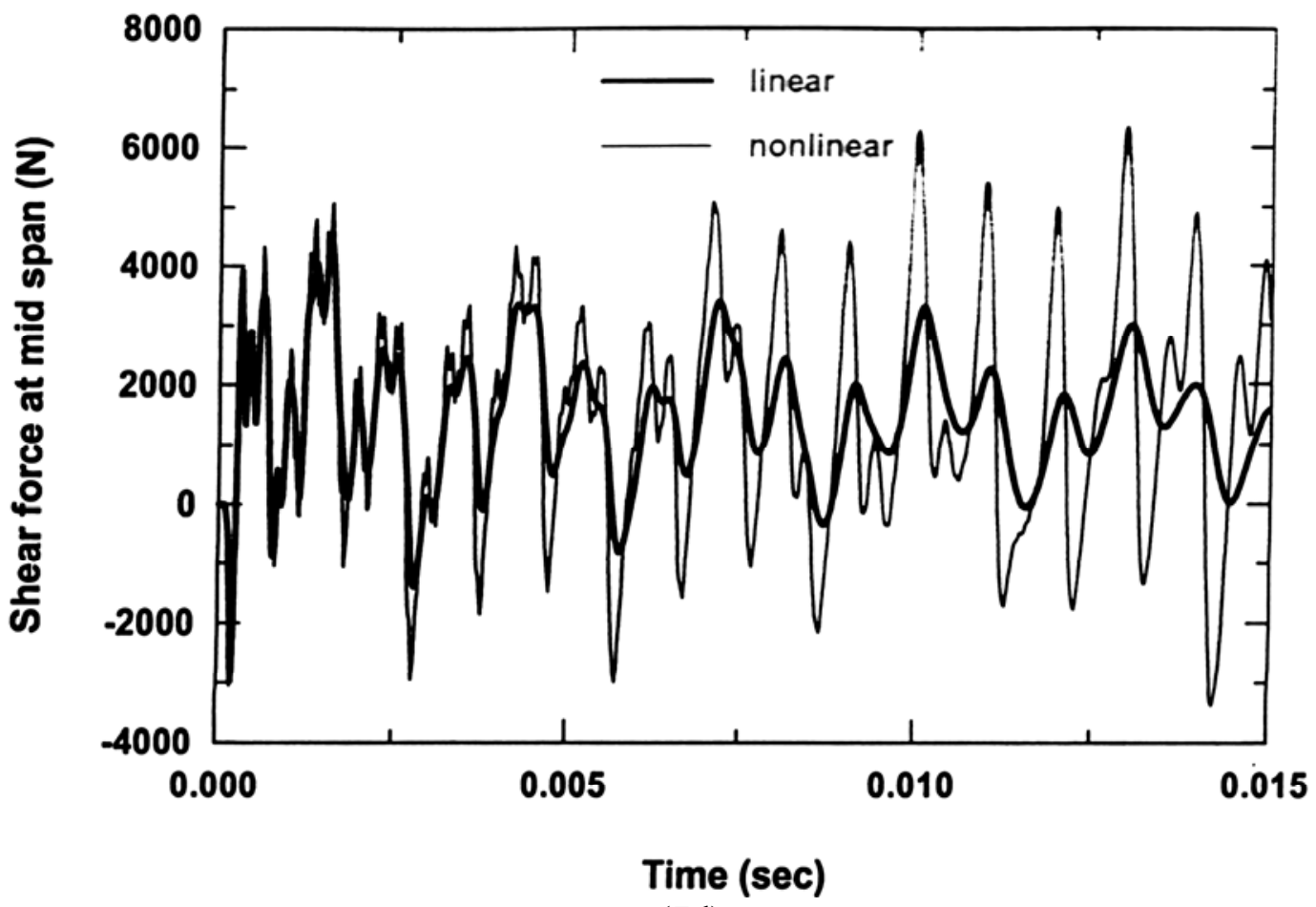

(7d)

Figure 7 Cont'd. 


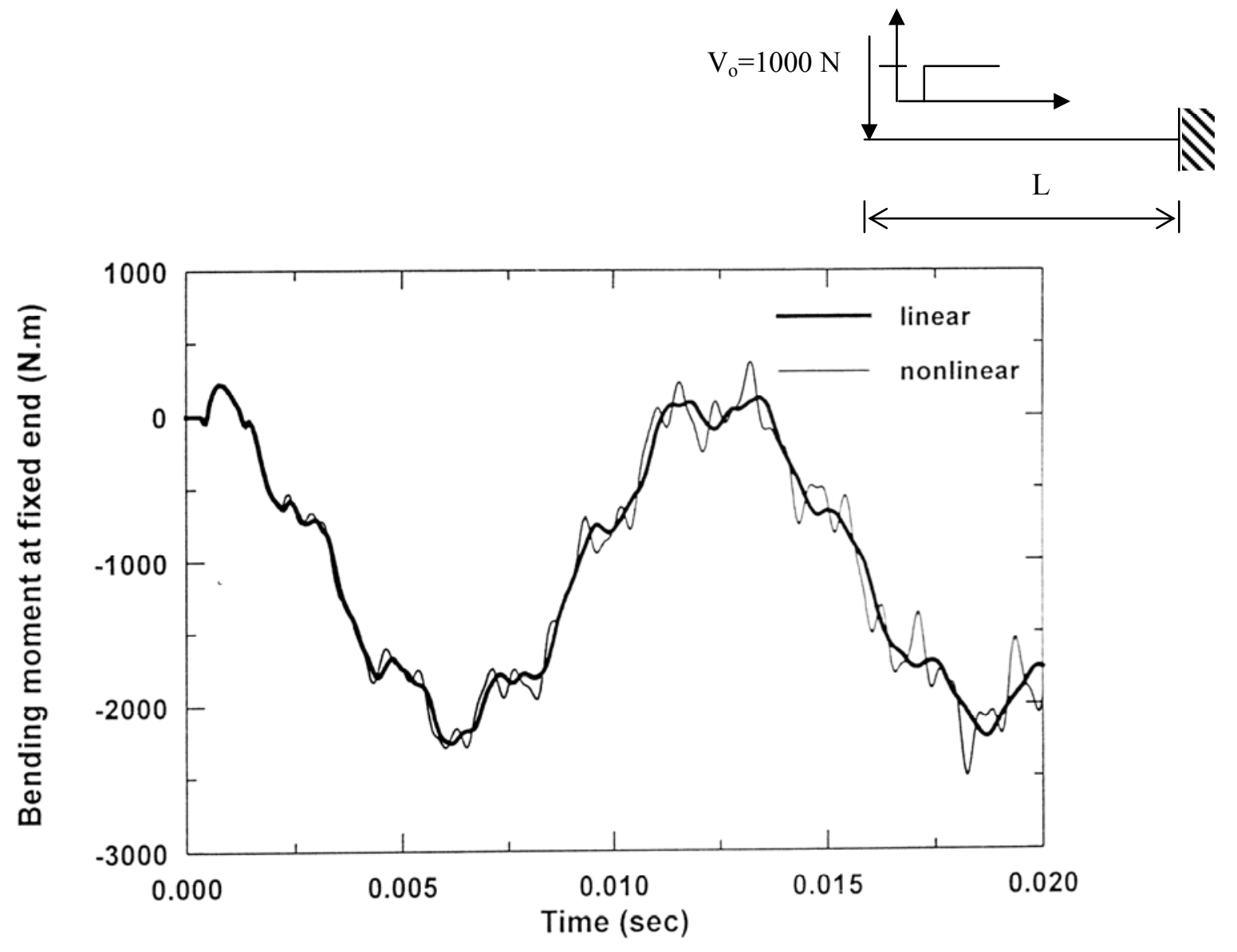

(a)

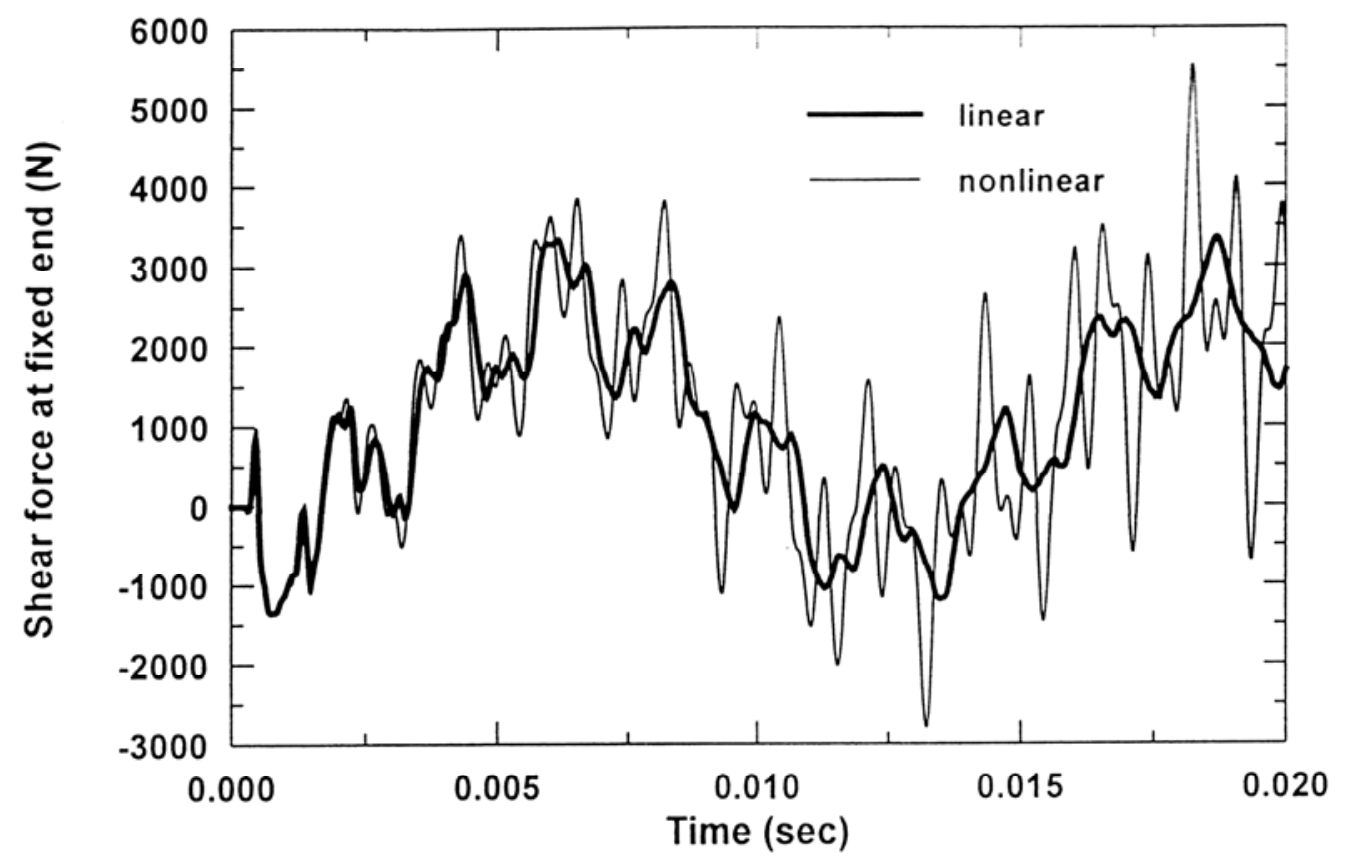

(b)

Figure 8. Comparison between Dynamic Behaviors under Large and Small Deflection for a Cantilever Beam under Tip Vertical Force. 


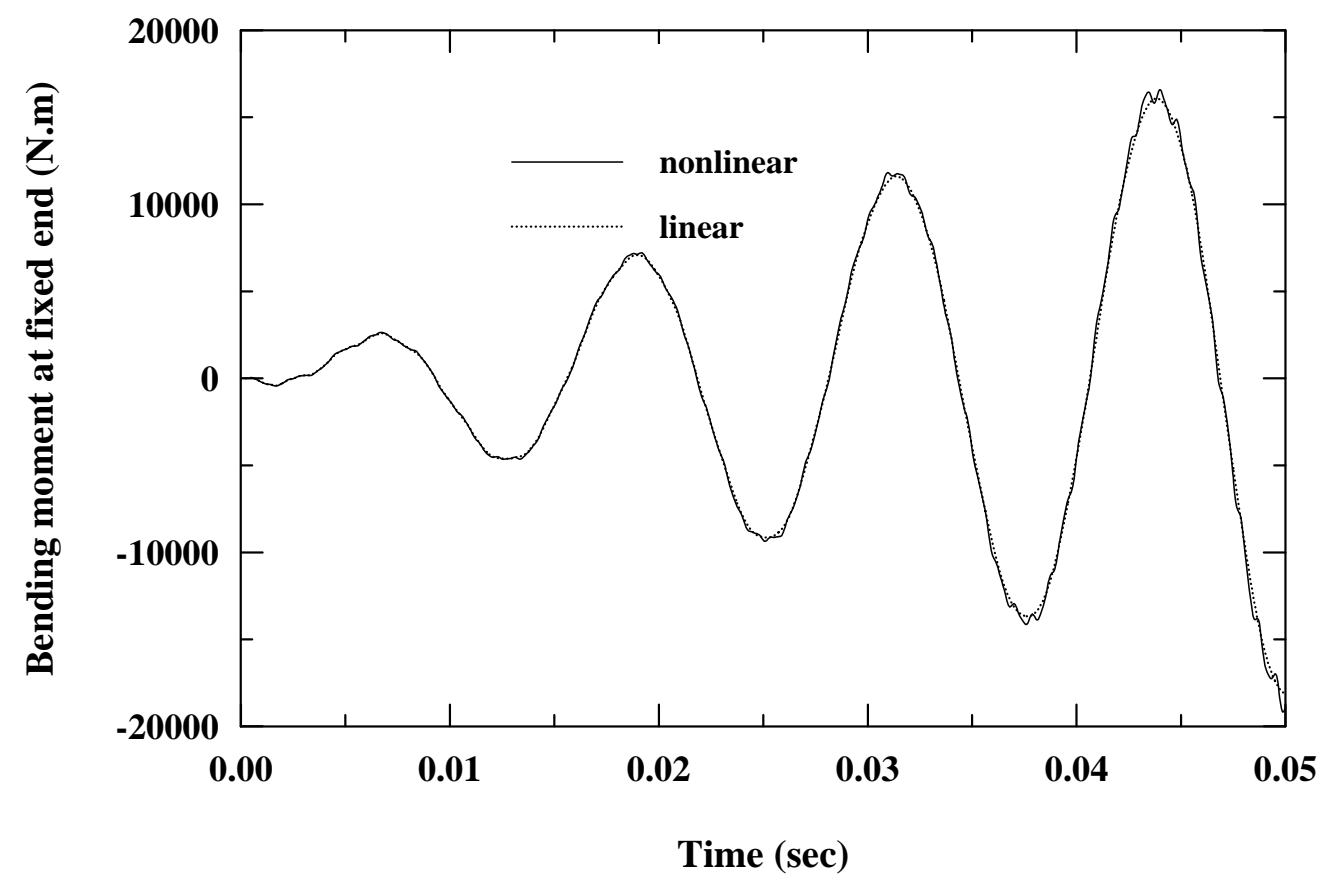

(a)

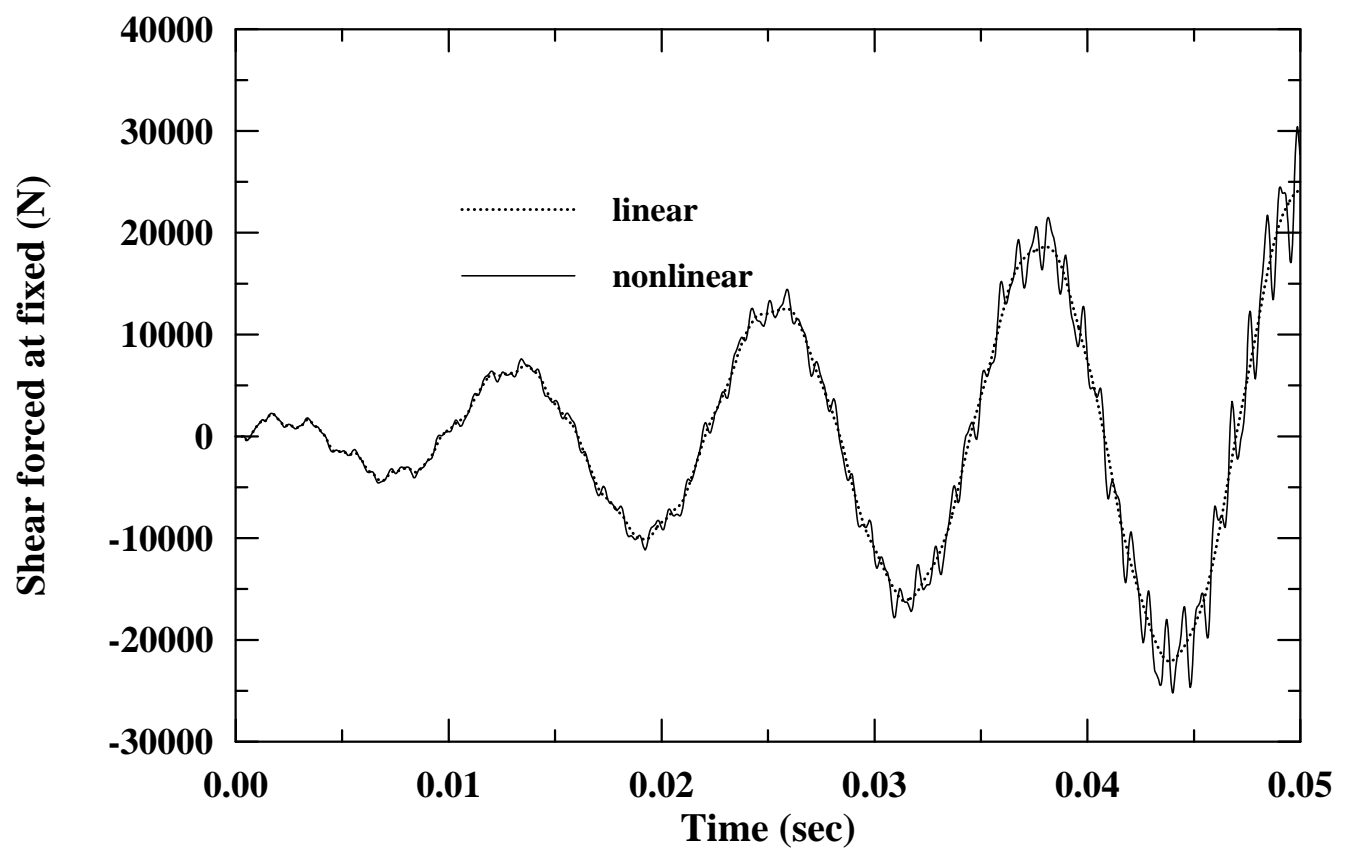

(b)

Figure 9. Resonance (i.e., $\omega_{\mathrm{p}}=\omega_{\mathrm{n}}$ ) for Linear and Nonlinear Cases. 

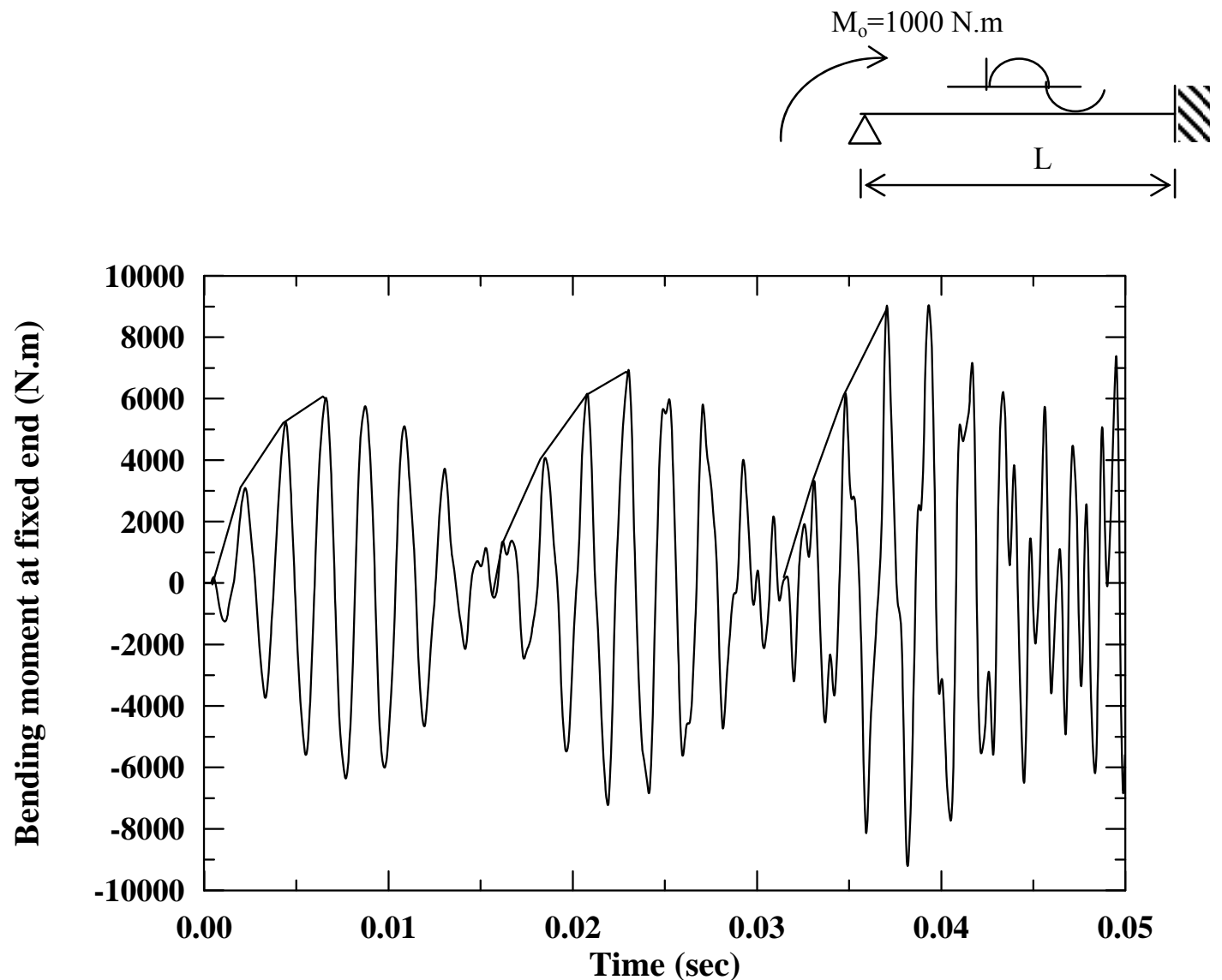

(a)

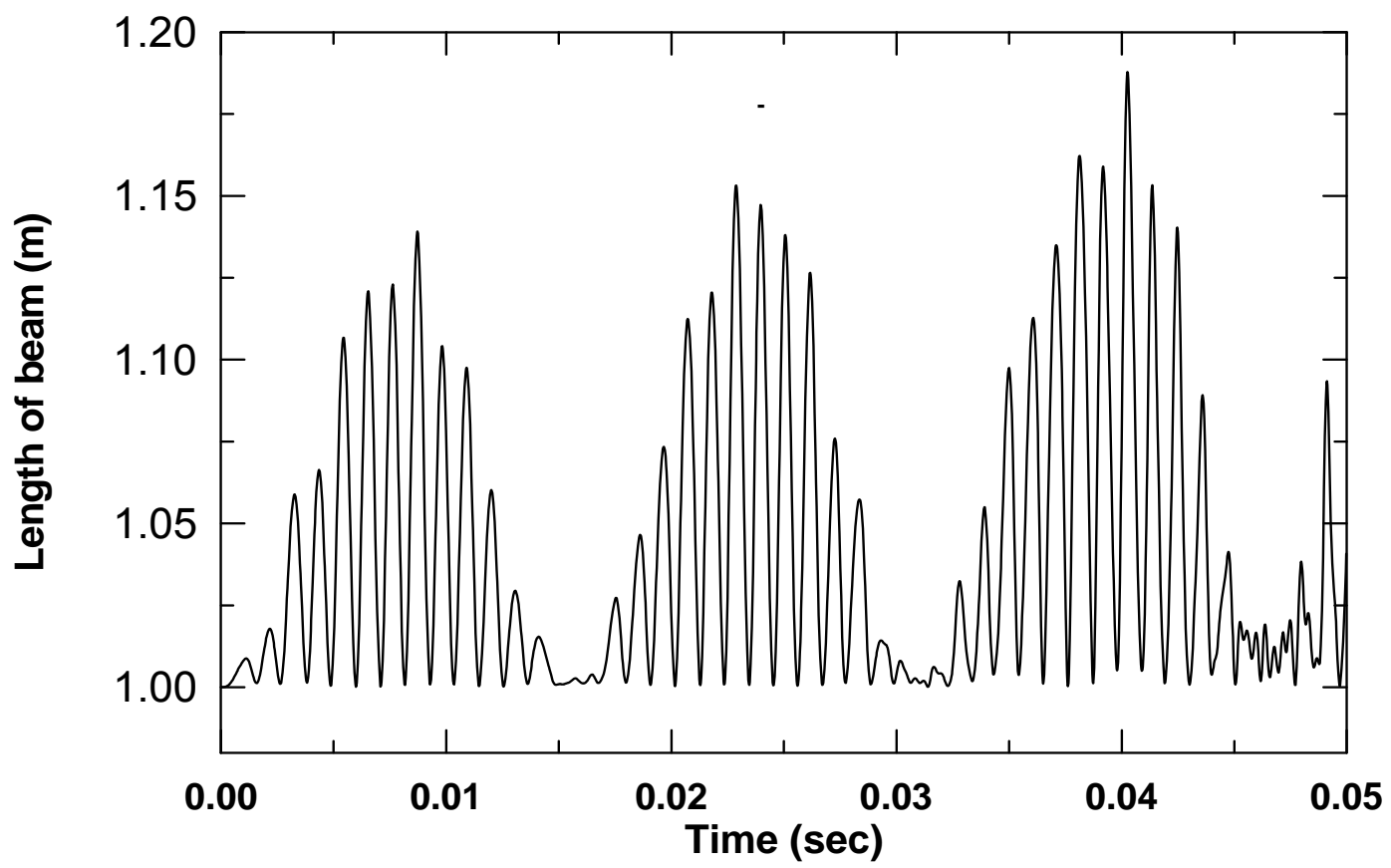

(b)

Figure 10. Jump Phenomena in Large Deflection at Resonance (i.e., $\omega_{\mathrm{p}}=\omega_{\mathrm{n}}$ ). 


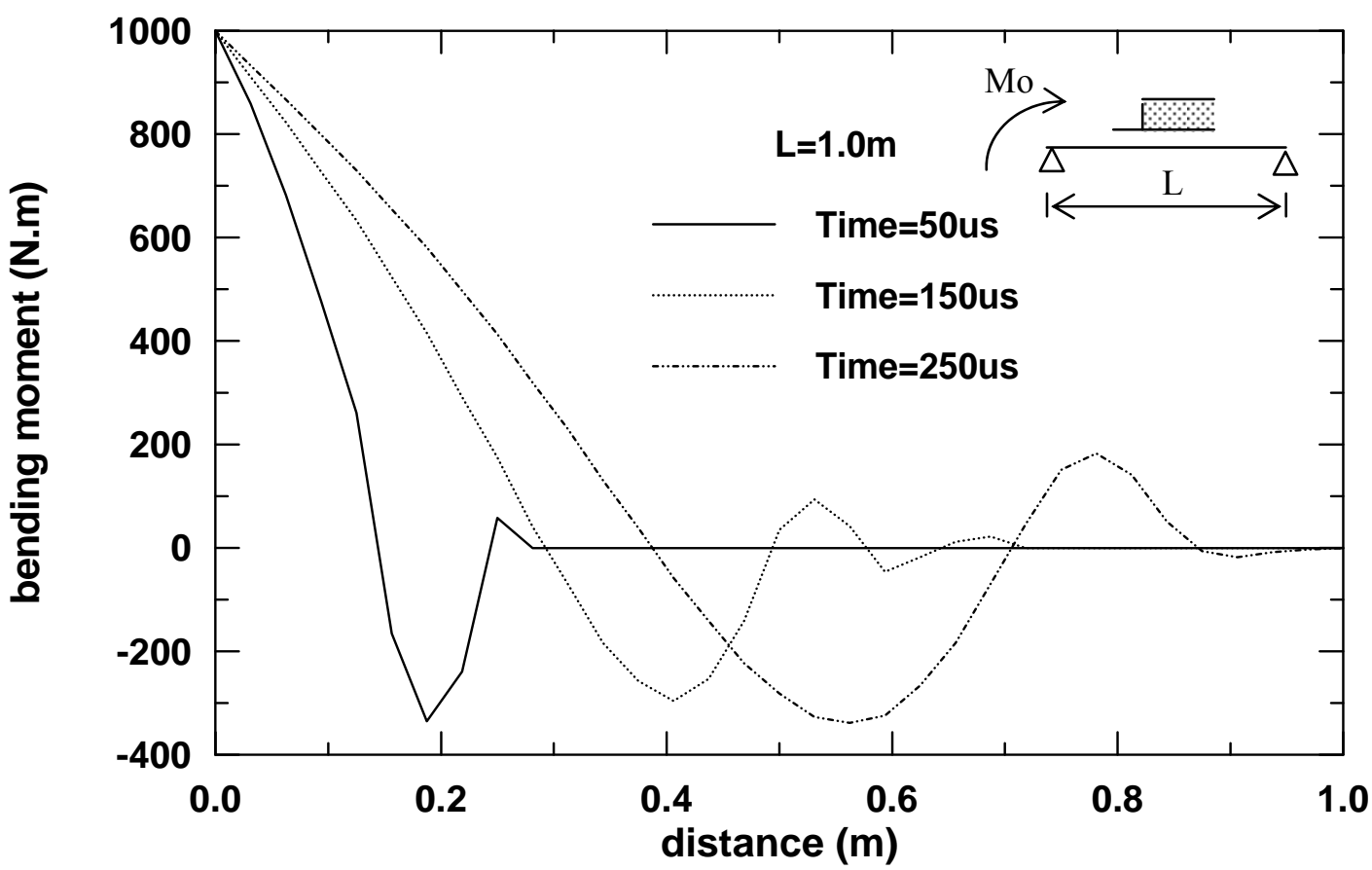

(11a)

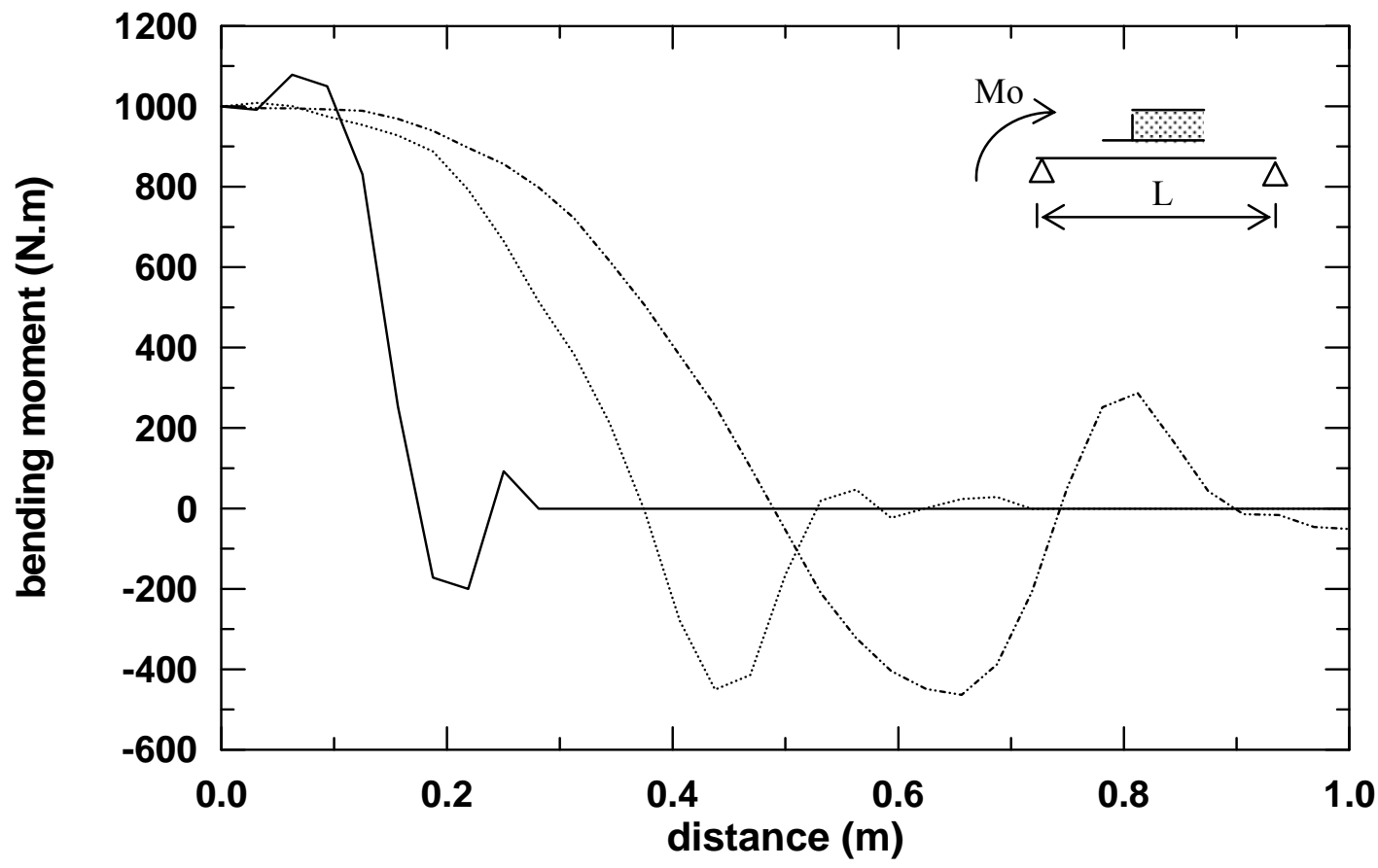

(11b)

Figure 11. Effect of Boundary Conditions on Wave Propagation. 

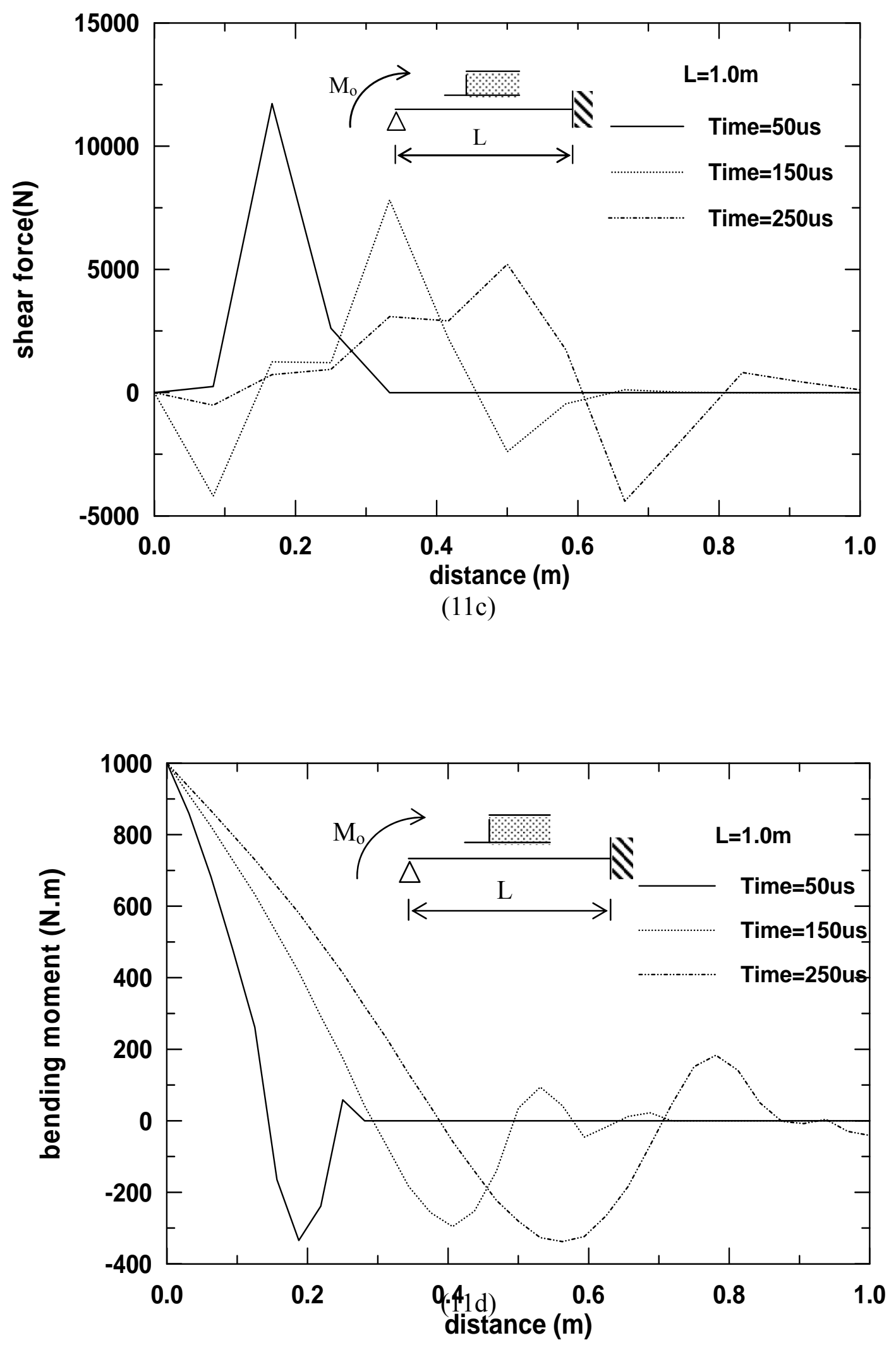

Figure 11. cont'd 

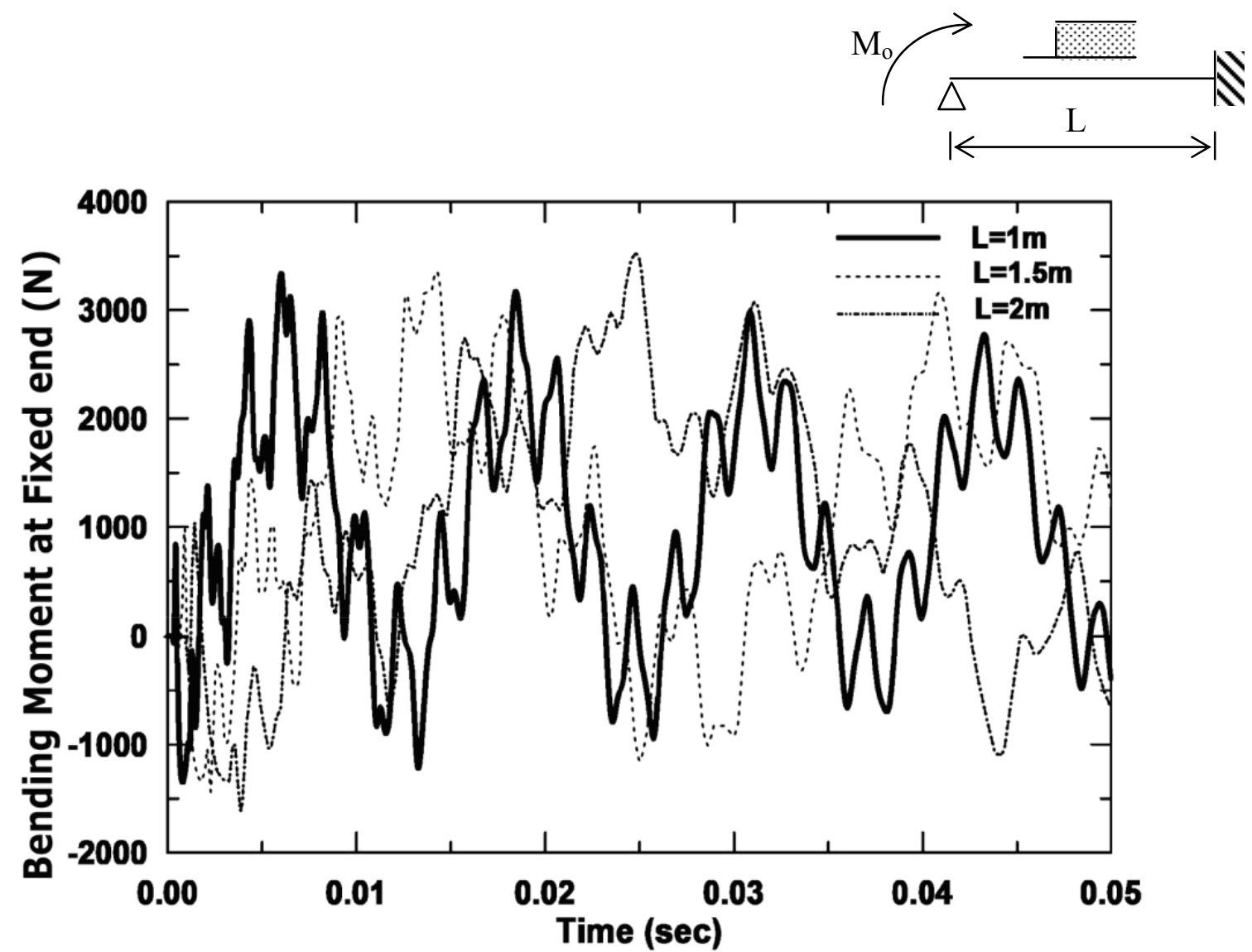

(12a)

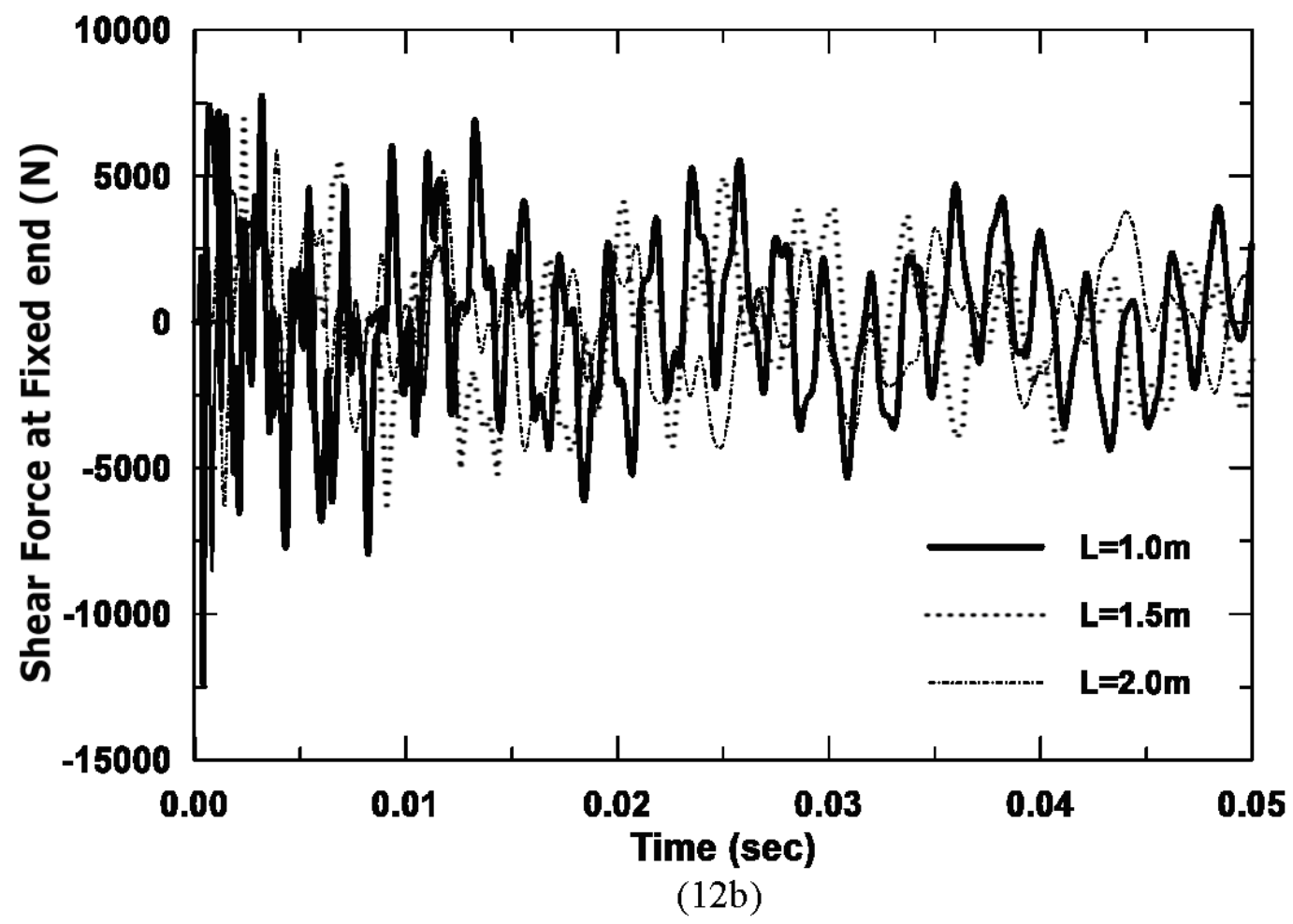

Figure 12. Effect of Beam Length on Wave Propagation 

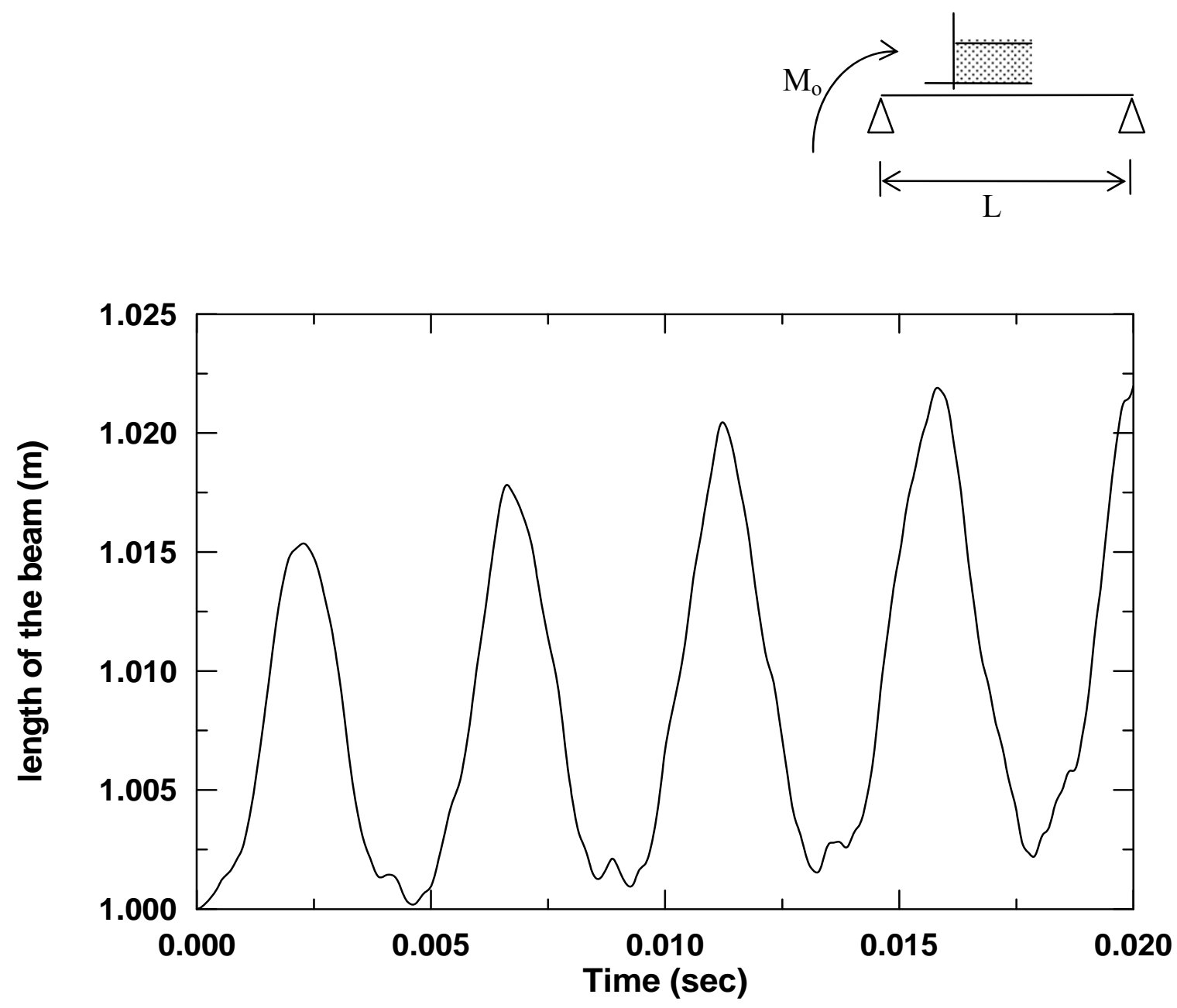

Figure 13. Actual Length of Beam during Vibration

\subsection{Effect of Boundary Conditions on Wave Propagation}

The propagation of bending waves in beams with different boundary conditions is illustrated in Figure 11. Figure 11a shows the bending moment variation of a simply supported beam subjected to a constant moment at one end. Consequently, Figures $11 \mathrm{~b}$ and $11 \mathrm{c}$ show bending and shear wave propagations in a cantilever subjected to a constant bending moment at its free end. Figure 11d explains how the waves are transmitted along a propped cantilever beam from the point of applied load to the rest of beam. The interaction of the applied waves that propagate through the beam length with those reflected at the fixed end, and the differences between the propagation speeds of the bending and shear waves cause significant changes in the shape of bending and shear waves as they travel throughout the beam. In addition, Figure 11 shows the dissipative nature of the flexural waves because of the difference between the bending and shear wave speeds.

\subsection{Effect of Beam Length on Wave Propagation}

Figure 12 shows the dynamic response of a cantilever beam subjected to constant applied moment at its free end with different lengths. It is observed that the waves travel in constant speed and when the length of beam is increased, the waves need more time to reach the boundary or any other point. Figure 12 explains the fact that when the length increases, the natural frequency will decrease. In 
linear analysis, the length of the member remains constant during the analysis and the change in length is assumed to be negligible. In the present procedure, a new length of the member is calculated every time step as shown in Figure 13. This leads to a change in natural period and in amplitude of vibration, thus producing nonlinear behavior of the member.

\section{CONCLUSIONS}

A new formulation for the flexural wave behavior in geometrically non-linear beams is introduced. The formulation of the non-linear governing equations is established by considering elements under the effect of large-deflection and large-rotation while subjected to dynamic excitation. The governing equations are re-written in a numerical form using MOC. Several conclusions can be summarized as:

\section{$\underline{\text { General Conclusions }}$}

- MOC can be used to simulate the linear and non-linear dynamic behavior of prismatic members subjected to any type of loading.

- The main advantage of MOC is that the non-linear equations are solved directly without the need for any iterative or incremental procedures.

- The interaction between shear and bending waves leads the flexural waves to propagate in prismatic members in a depressive (changed) form.

- MOC can efficiently predict forces, velocities and displacements throughout the member at any time increment.

- Equations describing the longitudinal transmission of stress waves along one-dimensional prismatic members can be expressed in a characteristic form and integrated by approximate finite difference methods.

- Unlike finite element methods, MOC takes proper account of wave motions along the members and so gives more realistic predictions of behavior at high frequencies.

\section{$\underline{\text { Specific Observations }}$}

- From analysis, convergence of behavior is achieved with 32 grid lengths along the member.

- The propagation of the flexural waves is not only dependent on the material properties but also on the sectional properties.

- The dynamic load factor is greater than (2) in flexural wave vibration.

- The fundamental frequency can be obtained by observing the repetitive pattern of the response. Also by using Fast Fourier transform algorithm, high frequencies can be determined.

- The non-linear large deflection time period and frequency of vibration are approximately equal to linear small deflection values.

- In the numerical integration it is important to carry out interpolations along the t-axis not along $\mathrm{x}$-axis.

- In linear (small-angle bending) dynamic vibration phenomenon can not be predicted but it can be predicted in non-linear (large-angle bending) dynamic vibration. 


\section{REFERENCES}

[1] Zienkiewicz, O.Z., "The Finite Element Method”, 3rd Edition. McGraw-Hill, 1977.

[2] Ross, C.T.F., "Finite Element Method in Structural Mechanic, 1st edition, Chichester Ellis Harwood, 1985.

[3] Clough, R.W. and Penzien, J., "Dynamics of Structures", NY : McGraw-Hill, 1975.

[4] Coates, R.C., Couiie, M.G. and Kong, F.K., "Structural Analysis", 2nd Edition, New York: Van Nostrand Reinhold, 1986.

[5] Johnson, D. “Advanced Structural Mechanics", London: Collins, 1986.

[6] Pany, C. and Rao, G.V., "Large Amplitude Free Vibrations of a Uniform Spring-Hinged Beam", Journal of Sound and Vibration, 2004, Vol. 271, pp. 1163-1169.

[7] Lande, R.H. and Langley, R.S., "The Energetics of Cylindrical Bending Waves in a Thin Plate", Journal of Sound and Vibration, 2005, Vol. 279, pp. 513-518.

[8] Pfgiffer, R., “über Die Differertialbeichung der Trasversalen Stabschwingunguen," Z Angew. Math. Mech., 1947, No. 3, pp. 25-27.

[9] Plass, H.I., "Some Solution of Timoshenko Beam Equation for Short Pulse-Type Loading," Journal of Applied Mechanics, 1958, Vol. 25, pp.379-385.

[10] Chou, P.C. and Mortimer, "Solution of One-dimensional Elastic Wave Problems by the (MOC)," J. of Applied Mechanics, ASME, 1967, Vol. 34, pp.745-750.

[11] Chou, P.C. and Koening, H.A., "A Unified Approach to Spherical Elastic Waves by the (MOC)," Journal of Applied Mechanics, Trans., ASME, 1966, Series 1, No. 88, pp.159-168.

[12] Vardy, A.E. and Chan, L.I., "Truss Analysis by Boundary Characteristics," ASCE, Journal of Engineering Mechanics, 1988, Vol. 114, No. 3, pp. 520-535.

[13] Vardy, A.E. and Al-Sarraj, A.T. "Method of Characteristics Analysis of One-Dimensional Members", Journal of Sound and Vibration, 1989, Vol. 129, No. 3, pp. 479-487.

[14] Alsarraj, A.T., Othman, R.A. and Jwad, Z.M., "Non-linear Vibration of Axially Loaded Bars," Journal of Engineering and Technology, 1994, Vol. 12, No. 9, pp. 37-45.

[15] Al-Sadder, Samir, Othman, R., Shatnawi, Anis and Abdel-Jaber, M., "Dynamic Behavior of Slender Steel Beams under Large Deflection by the Method of Characteristics", $6^{\text {th }}$ Int. Conference on Steel and Aluminum Structural Engineering, ICSAS'07, 2007.

[16] Haisler, W.E., Stricklin, J.A. and Stebbins, F.J., "Development and Evaluation of Solution Procedures for Geometrically Nonlinear Structural Analysis,” AIAA Journal, 1972, Vol.10, No. 3, pp. 264-272.

[17] Haisler, W.E. and Stricklin, J.A. "Displacement Incrementation in Nonlinear Structure Analysis by the Self-correcting Method," International Journal for Numerical Methods in Engineering, 1977, Vol. 11, pp. 3-10.

[18] MSC/NASTRAN for Windows 95: McNeal-Schwendler Corporation, CA, USA, 1995. 


\title{
FORMATION AND CALCULATION ANALYSES OF THE CYLINDRICAL LATTICED-BUILT-UP-MEMBER-SYSTEM RETICULATED MEGA-STRUCTURE
}

\author{
Yongjun $\mathrm{He}^{1, *}$ and Xuhong Zhou ${ }^{1,2}$ \\ ${ }^{1}$ Professor, College of Civil Engineering, Hunan University, Changsha, 410082, China \\ ${ }^{2}$ Professor, Lanzhou University, Lanzhou, 730000, China \\ *(Corresponding author: E-mail: hyj0087@163.com)
}

Received: 12 April 2009; Revised: 11 November 2009; Accepted: 30 November 2009

\begin{abstract}
An innovative super-long-span spatial structure, cylindrical latticed-built-up-member-system reticulated mega-structure with double-layer grid substructures, is present and studied in this paper. The structural configuration including formation of members of the main structure and layout of the substructures is first analyzed. And the calculation methods are studied, including the equivalent cross-sectional areas of the latticed built-up members, internal forces of the sub-members, and the optimization of the whole structure. Then the optimization analyses of the cross sections of members are carried out aiming for the minimum steel consumption of the structure. In addition, comparison on steel consumption of the reticulated mega-structure with that of the conventional reticulated structure is carried out in detail, and the reasonable span range of the cylindrical latticed-built-up-member-system reticulated mega-structure is last obtained.
\end{abstract}

Keywords: Reticulated mega-structure; formation method; latticed built-up member; substructure; calculation method; optimization analysis

\section{INTRODUCTION}

Today, reticulated shells are widely adopted and their spans tend to become larger and larger. As the simplest type of reticulated shells, the reticulated cylindrical shells, especially the double-layer ones, are employed more extensively than other types of shells. With the development of human society, people have put forward higher requirement for the span of spatial structure (Dong and Yao [1], Makowski [2]). However, for the double-layer reticulated cylindrical shell structure, some problems will occur inevitably with further increase of the span, such as the instability of the whole structure because of the too small structural thickness-to-span ratio, buckling of struts for their oversize lengths and large internal forces, as well as the increasing steel consumption and corresponding economic problems. Multi-layer forms have been applied successfully to shorten members and thus to reduce the probability of strut buckling for the flat grid structure. Besides, the maximum member internal force as well as steel consumption of the structure can be lowered, and the structural stiffness can also be improved. But the effectiveness of multi-layer forms in the reticulated cylindrical shell structure is not so outstanding. Some comparison analyses between the double-layer and triple-layer super-long-span reticulated cylindrical shell structures (Wang and Li [3]) indicated that, it might be impossible to break the restriction of large internal forces and thus to increase structural span by adopting multi-layer forms for reticulated shells. Moreover, the method densifies grids, producing large amount of members. So the double-layer form is more reasonable. But for the super-long-span reticulated shell, double-layer form means long bars with large internal forces in the structure.

How can we break the restrictions of large internal forces and structural overall buckling to construct super-long-span structure? The concept of reticulated mega-structure (He et al. [4]) gives us a satisfactory answer. The whole structure is made up of two levels. The first level is the large grid structure called main structure, which bears all loads and transfers them to the supporting structure. The second level is the substructures embedded in the large grids of the main structure, which only bear the loads within the corresponding large grids and transfer them to the main 
structure. Some researches on the formation method, static properties, seismic performances, and the stabilities of the cylindrical intersecting-latticed-three-dimensional-beam-system (ILTDBS) reticulated mega-structure have been carried out comprehensively and systematically (He et al. [5-7]). Another kind of reticulated mega-structure, cylindrical latticed-built-up-member-system reticulated mega-structure is presented and studied in this paper, including the layout method of substructures, calculation method of the latticed built-up member, and the optimization analyses of the whole structure. Comparison analysis on steel consumption between the latticed built-up member system reticulated mage-structure and the conventional reticulated shell is then carried out, and the rational span for cylindrical reticulated mega-structure is finally recommended.

\section{STRUCTURAL CONFIGURATION AND LAYOUT}

\subsection{The Main Structure and Its Members}

The cylindrical latticed-built-up-member-system reticulated mega-structure braced with conventional grid substructures is an innovative super-long-span spatial structure. As shown in Figure 1, the main structure is a super double-layer cylindrical reticulated structure consisting of latticed built-up members, the large grid size ranges from 10 to $30 \mathrm{~m}$, and the substructures are placed within the upper large grids of the main structure (Not all the substructures are displayed for clarity of the figure). To avoid the serious buckling of the compression members for their oversize lengths, the latticed built-up members are adopted in this paper. As shown in Figure 2, triangle and quadrangle are two basic cross-sectional shapes of the latticed built-up members, and their three or four parallel chords are generally identical and continuous. The transverse and diagonal web sub-members are connected with the chords by directly welded tubular joints(Chiew and Soh [8], Dexter and Lee [9,10]). Web system can take single-diagonal or double-diagonal types. For convenient connection of the latticed built-up members with each other, two cone-shaped ends of each built-up member are adopted as shown in Figure 2, and the built-up members are connected by large welded hollow spherical joints, which are called main nodes of the main structure in this paper and can be treated as pin connection in analysis. Therefore the whole of a latticed built-up member acts as a two-force member within the structure. Since the latticed built-up members are connected with each other by pin connections, the structure must become a geometrically unstable system (Adrin and Virgil [11]) if each sub-member in the built-up members is considered as an element in calculation of the whole structure, and thus the unique solution cannot be obtained. So each latticed built-up member should be equivalently regarded as a single and continuous member in analysis.

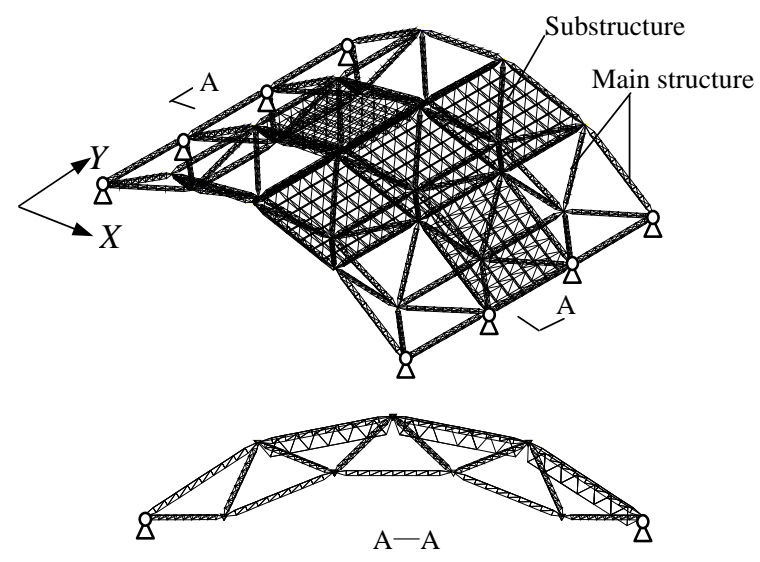

Figure 1. Cylindrical Latticed-Built-Up-Member-System Reticulated Mega-Structure with Double-Layer Grid Substructures
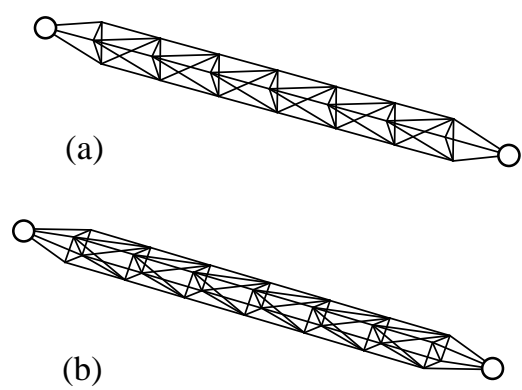

Figure 2. Latticed Built-Up Members: (a) with Equilateral Triangular Cross Section; (b) with Quadrangular Cross Section 


\section{$2.2 \quad$ Layout Styles of the Substructures}

Because the upper chord latticed built-up members of the main structure are axially loaded members connected with each other by pin connections, the substructures are generally double-layer plane-plate grids, every one of which is supported by four large nodes of the main structure. According to the relationship between two adjacent substructures, there are two layout styles of substructure as shown in Figure 3. The first one is the independent layout as shown in Figure 3(a), in which each substructure is supported independently on the main structure and not

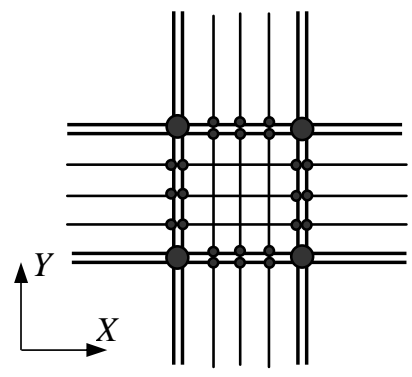

(a) Independent Layout

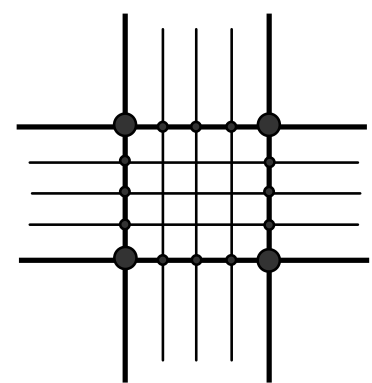

(b) Hinge-Connection Layout

Figure 3. Layout Styles of Substructures

connected with others. And the second one is the hinge-connection layout as shown in Figure 3(b), in which the adjacent substructures are connected together by the common upper chord members and nodes located at their edges, but their lower chord and web members are independent, therefore the common edge of every two substructures is similar to a hinge axis between them. (In Figure 3, the large black dots denote the upper chord main nodes of the main structure, while the small ones present the upper chord nodes along the edges of the substructures.)

\section{CALCULATION METHOD}

\subsection{Calculation of the Latticed Built-up Member}

Based on the accurate calculation of the latticed built-up members subjected to axial load by finite element method (Zienkiewicz et al. [12]), it has been found out that, the axial load of the single-diagonal-type latticed built-up member is basically resisted by the parallel chords, and the internal forces of both the diagonal and transverse rods are almost zero. But for the double-diagonal-type members, besides the parallel chords, the diagonal rods and transverse rods also participate in bearing load.

\subsubsection{Effective cross-sectional area and internal forces of the latticed built-up members}

Here the latticed built-up member with equilateral triangular cross section is first taken as example to study, and some hypotheses, which have been validated by accurate results, are made as follows for convenience of investigation.

(1) The cross-sectional plane of the latticed built-up member still keeps planar after deformation, and 
(2) The equilateral triangular cross section still keeps as equilateral triangular after deformation. So the effective cross-sectional area $A$ of the single-diagonal-type latticed built-up member equals to summation of its three parallel chords, that is,

$$
A=A_{z 1}+A_{z 2}+A_{z 3}=3 A_{z}
$$

where $A_{z 1}, A_{z 2}$, and $A_{z 3}$ are the cross-sectional areas of the three parallel chords, and they are generally assumed to be identical as $A_{z}$. Therefore the internal force of each chord is

$$
F_{z i}=\frac{A_{z i}}{A_{z 1}+A_{z 2}+A_{z 3}} P=\frac{P}{3} \quad(i=1,2,3)
$$

For the axially loaded double-diagonal-type latticed built-up member, the axial force $P$ at its any cross section is resisted by the parallel chords and diagonal rods as shown in Figure 4. According to the equilibrium condition along the axial direction, the following equation can be obtained.

$6 F_{c} \sin \theta+3 F_{z}=P$

And according to Hooke's law we have

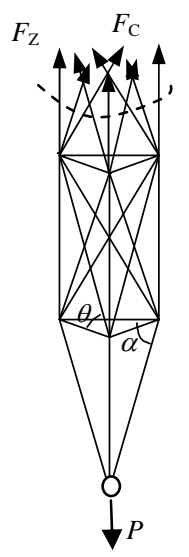

Figure 4. Force Schematic Diagram of the Latticed Built-Up Member

$$
\begin{aligned}
& F_{z}=E \varepsilon_{z} A_{z} \\
& F_{c}=E \varepsilon_{c} A_{c}
\end{aligned}
$$

in which, $\theta$ is the angle between diagonal and transverse rods as shown in Figure 4; $A_{z}, \varepsilon_{z}$, and $F_{z}$ are the cross-sectional area, axial strain, and internal force of a chord, respectively; similarly, $A_{c}, \varepsilon_{c}$, as well as $F_{c}$ are those of a diagonal rod, respectively; and $E$ is the Young's modulus.

Based on hypothesis (1), the following relationship can be obtained.

$\varepsilon_{c}=\frac{\Delta l_{c}}{l_{c}}=\frac{\Delta l \sin \theta}{l / \sin \theta}=\varepsilon_{z} \sin ^{2} \theta$

where $l$ and $\Delta l$ are the length and elongation of a chord in a mid segment, respectively; $l_{c}$ and $\Delta l_{c}$ are those of a diagonal rod, respectively.

According to Eqs. 3, 4 and 5, we have

$$
F_{z}=\frac{P A_{z}}{6 A_{c} \sin ^{3} \theta+3 A_{z}}
$$




$$
F_{c}=\frac{P A_{c} \sin ^{2} \theta}{6 A_{c} \sin ^{3} \theta+3 A_{z}}
$$

Here the effective cross-sectional area $A$ of mid segment of the latticed built-up member is introduced, then

$$
A=\frac{P}{E \varepsilon_{z}}
$$

Based on Eqs. 4a, 6a and 7, one has

$$
A=3\left(A_{z}+2 A_{c} \sin ^{3} \theta\right)
$$

And according to the equilibrium of nodal forces, the internal force of transverse rod $F_{h}$ can be obtained as

$F_{h}=-2 F_{c} \cos \theta$

\subsubsection{Determination of the equivalent cross-sectional area}

As to the axially loaded double-diagonal-type latticed built-up member, the parallel chords, transverse rods, and the diagonal rods all participate in bearing load, so all of these rods should be considered in calculation of its axial elongation. From the force-deformation pattern of the transverse and diagonal rods in a side face of one segment under unit force as shown in Figure 5 and according to the force method, the axial elongation $\delta_{11}$ can be obtained as

$\delta_{11}=\sum \frac{\bar{N}_{i}^{2} l_{i}}{E A_{i}}=\frac{2 \bar{F}_{c}^{2} l_{c}}{E A_{c}}+\frac{\bar{F}_{h}^{2} l_{h}}{E A_{h}}$

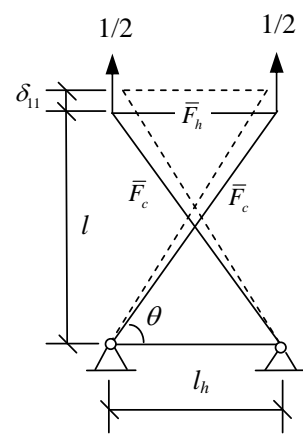

Figure 5. The Force-Deformation Pattern of the Diagonal and Transverse Rods in One Side Face

in which $\bar{F}_{h}$ and $\bar{F}_{c}$ are the internal forces of the transverse and diagonal rods under the action of unit force, respectively.

From Figure 5 we have $\bar{F}_{h}=1 /(2 \tan \theta), \bar{F}_{c}=1 /(2 \sin \theta), l_{h}=l /(\tan \theta)$, as well as $l_{c}=l /(\sin \theta)$. Substituting them into Eq. (10) yields the combined stiffness $k_{11}$ of the transverse and diagonal rods in one side face as follows,

$k_{11}=\frac{1}{\delta_{11}}=\frac{E}{l}\left(\frac{4 \sin ^{3} \theta A_{h} A_{c}}{A_{c} \cos ^{3} \theta+2 A_{h}}\right)$ 
According to the assumption of planar cross sections, as well as the assembling theory of parallel stiffness, the axial elongation $\Delta_{l}$ of one segment under axial force $P$ is

$$
\Delta_{l}=\frac{P}{3\left(k_{11}+E A_{z} / l\right)}=\frac{P l}{E\left(3\left(\left(4 \sin ^{3} \theta A_{h} A_{c}\right) /\left(A_{c} \cos ^{3} \theta+2 A_{h}\right)+A_{z}\right)\right)}
$$

Therefore the equivalent cross-sectional area of mid segment $A_{e}$ is given by

$$
A_{e}=3\left(4 \sin ^{3} \theta A_{h} A_{c}\right) /\left(A_{c} \cos ^{3} \theta+2 A_{h}\right)+3 A_{z}
$$

Similarly, the equivalent cross-sectional area $A_{e}^{0}$ of the whole built-up member accounting for the effect of the two cone-shaped ends can be obtained as

$$
A_{e}^{0}=\frac{9 n A_{e} A_{d} A_{h} \sin ^{3} \alpha}{9(n-2) A_{d} A_{h} \sin ^{3} \alpha+6 A_{e} A_{h}+4 \sqrt{3} A_{e} A_{d} \cos ^{3} \alpha}
$$

where, $n$ is number of segments including the two end cones of the latticed built-up member; $A_{d}$ is the cross-sectional area of the inclined rods at the end cones of the member; $\alpha$ the inclination angle of the inclined rod to the cross-sectional plane of the built-up member, from Figures 4 and 5 we have $\tan \alpha=\sqrt{3} l / l_{h}$; in addition, $A_{e}$ is determined by Eq. 13, but $A_{e}=3 A_{z}$ for the single-diagonal-type latticed built-up member.

Then the elongation $\Delta L$ of the latticed built-up member with length of $L$ under the action of axial force $P$ is given by

$$
\Delta L=P L /\left(E A_{e}^{0}\right)
$$

Obviously, the equivalent cross-sectional area $A_{e}^{0}$ reflects the stiffness character of the latticed built-up member more exactly. And its precision reflects the calculation precision of the whole structure since it will be adopted in overall analysis of the structure.

\subsubsection{Numerical example}

Given that, a latticed built-up member with spacing between parallel chords of $0.625 \mathrm{~m}$ is subjected to a pair of axial force $F=10 \mathrm{kN}$ on the two ends; the total length of the member is $10 \mathrm{~m}$ and it is divided into eight equal segments; in addition, the cross section of all sub-members is $\phi 76 \times 4$. Eqs. 2, 6 and 9 are adopted to calculate the internal forces of various sub-members, while Eqs. 13, 14 and 15 are used to calculate the total elongation of the latticed built-up member. The accurate results are also obtained by finite element method. And the result comparison between the accurate and simplified methods is shown in Table 1, in which both the single-diagonal and double-diagonal types of web system are considered, respectively.

From the table it can be seen that, the axial deformation of the latticed built-up member and the internal forces of various sub-members obtained by the formulas in this paper very consist with the accurate results. Results of the single-diagonal-type member by the simplified method almost have no error in comparison with the accurate ones, and the percentage errors for the double-diagonal-type one also maintain within 3\%. 
Table 1. Result Comparison of Latticed Built-up Members between the Accurate and Simplified Methods

\begin{tabular}{|c|c|c|c|c|c|}
\hline $\begin{array}{c}\text { Type of the } \\
\text { latticed built-up } \\
\text { member }\end{array}$ & Calculation method & $\begin{array}{c}\text { Internal force of } \\
\text { chord members } \\
/ \mathrm{kN}\end{array}$ & $\begin{array}{c}\text { Internal force of } \\
\text { web members } \\
/ \mathrm{kN}\end{array}$ & $\begin{array}{c}\text { Internal force of } \\
\text { transverse rods } \\
/ \mathrm{kN} \\
\end{array}$ & $\begin{array}{c}\text { Total elongation } \\
\qquad / 10^{-4} \mathrm{~m}\end{array}$ \\
\hline \multirow{3}{*}{$\begin{array}{l}\text { Double-diagonal } \\
\text { type }\end{array}$} & Accurate method $a$ & 1.506 & 1.022 & -0.912 & 1.101 \\
\hline & Simplified method $b$ & 1.371 & 1.097 & -0.981 & 1.080 \\
\hline & $(|b|-|a|) /|a|$ & $-8.2 \%$ & $7.3 \%$ & $7.6 \%$ & $-1.8 \%$ \\
\hline \multirow{3}{*}{$\begin{array}{l}\text { Single-diagonal } \\
\text { type }\end{array}$} & Accurate method $a$ & 3.336 & - & - & 1.816 \\
\hline & Simplified method $b$ & 3.333 & - & - & 1.810 \\
\hline & $(|b|-|a|) /|a|$ & $-0.09 \%$ & - & - & $-0.3 \%$ \\
\hline
\end{tabular}

Similarly, with hypothesis that the cross sections of various parallel chords are identical, the formula of equivalent cross-sectional area of the latticed built-up member with quadrangular cross section and those of the internal forces of various sub-members in it can be obtained. For the single-diagonal-type member, the internal forces of both the diagonal and transverse rods are all equal to zero, and the internal force of the chord members $F_{z}$ as well as the equivalent cross-sectional area $A_{e}^{0}$ are, respectively, as follows.

$F_{z}=P / 4$

$A_{e}^{0}=\frac{4 n A_{Z} A_{d} A_{h} \sin ^{3} \alpha}{(n-2) A_{d} A_{h} \sin ^{3} \alpha+2 A_{Z} A_{h}+2 \sqrt{2} A_{Z} A_{d} \cos ^{3} \alpha}$

But for the double-diagonal-type one, the internal forces of various sub-members are given by

$$
\begin{aligned}
& F_{z}=\frac{P A_{z}}{8 A_{c} \sin ^{3} \theta+4 A_{z}} \\
& F_{c}=\frac{P A_{c} \sin ^{2} \theta}{8 A_{c} \sin ^{3} \theta+4 A_{z}} \\
& F_{h}=-2 F_{c} \cos \theta
\end{aligned}
$$

And its equivalent cross-sectional area is

$$
A_{e}^{0}=\frac{2 n A_{e} A_{d} A_{h} \sin ^{3} \alpha}{2(n-2) A_{h} A_{d} \sin ^{3} \alpha+A_{h} A_{e}+\sqrt{2} A_{e} A_{d} \cos ^{3} \alpha}
$$

where, $A_{e}=4\left(4 \sin ^{3} \theta A_{h} A_{c}\right) /\left(A_{c} \cos ^{3} \theta+2 A_{h}\right)+4 A_{z}$, and the meanings of various notations are the same as before. 


\subsubsection{Stability of the latticed built-up compression members}

As to the latticed built-up members with triangular or quadrangular sections, their cross section should be treated as Class $B$ (Based on the code for design of steel structures of China (GB 50017-2003 [13]) in stability calculation of compression member. The modified slenderness ratios of the single-diagonal-type $\left(\lambda_{s}\right)$ and the double-diagonal-type $\left(\lambda_{d}\right)$ members are respectively given by

$$
\begin{aligned}
& \lambda_{s}=\sqrt{\lambda^{2}+28 A_{z} / A_{c}} \\
& \lambda_{d}=\sqrt{\lambda^{2}+56 A_{z} / A_{c}}
\end{aligned}
$$

in which $\lambda=l / i, \quad i$ is the gyration radius of the latticed built-up member.

The greatest advantage of the latticed built-up member is that its gyration radius can be easily controlled by adjusting the spacing of the parallel chords.

\subsection{Analytical Method for Optimization of Members’ Cross Sections}

Once every latticed built-up member is treated as a two-force member, the nodal displacements and members' internal forces of the whole structure under the action of loads can be calculated by matrix-displacement method.

\subsubsection{Cross section optimization of the latticed built-up members}

Conventional full-stress method is generally suitable for cross-sectional optimization (also known as "size optimization") (Gil and Andren [14], Apostol and Santos [15], and Vanderplaats [16]) of space member structure consisting of conventional circular steel tube aiming for the minimum steel consumption. But the latticed built-up members are not continuous member and have no determinate cross section as well as slenderness ratio in advance, so the conventional full-stress method can't be directly adopted to do optimization analysis. Therefore, a so-called fictitious full-stress method for cross-sectional optimization of the latticed built-up members is presented, and the train of thoughts is as follows.

(1) A series of fictitious members, which have determinate cross-sectional areas and rational slenderness ratios, are first given. The optimization calculation for a latticed-built-up-member-system reticulated mega-structure with given large grid size can then be carried out by full-stress criterion, in which the minimum steel consumption is aimed and the assumed members are inputted for optimization selection. And thus the internal force of each fictitious member in the structure can be obtained.

(2) According to the assumed slenderness ratio, the stability coefficient and geometrical parameters of each latticed built-up member can be obtained. And then the cross sections of various sub-members can be determined in light of the calculated internal forces as well as stability coefficients of the fictitious members. 
(3) From the determined cross sections of various sub-members and geometrical parameters of the latticed built-up members, various equivalent variables of the members can be obtained. By calculation of the whole structure again, the actual internal forces of various latticed built-up members can be obtained, and then the cross sections of various sub-members can be checked.

In this method, a series of fictitious cross sections of members are assumed in advance and the optimization is carried out by full-stress criterion, so it is called fictitious full-stress method in this paper. Numerical examples indicate that, it is valid and effective for cross-sectional optimization of the latticed built-up members in the reticulated mega-structure. The concrete example is not given in the paper for the limited length.

\subsubsection{Overall optimization analysis of the structure}

As mentioned above, the substructures are installed in the large grids of the double-layer cylindrical reticulated mega-structure, so the whole structure is composed of the conventional members of the substructures and latticed built-up members of the main structure. If the main structure and substructures bearing loads cooperatively is not considered in optimization calculation, the two levels of the structure can be analyzed independently. Conventional full-stress method is suitable for selection of cross sections of the members in the substructures, and the fictitious full-stress method should be used to obtain the optimal distribution of internal forces of the main structure. And then each latticed built-up member can be designed according to its obtained fictitious internal force. If the main structure and substructures bearing loads cooperatively need to be considered, the cross sections of members can be determined by the combined conventional and fictitious full-stress method. Cross sections of members in the substructures can be selected from the given actual steel tube list by conventional full-stress method; and those of the latticed built-up members of the main structure should be selected from the fictitious cross section series by fictitious full-stress method. By calculation, the obtained cross sections of members in the substructures are the final results, but various sub-members in latticed built-up members of the main structure should be determined by further design according to the obtained fictitious internal forces.

\section{STRUCTURAL OPTIMIZATION AND COMPARISON ANALYSES}

Based on the above-proposed method, a program for analysis of the latticed-built-up-member-system reticulated mega-structure is developed in this paper. The members' cross-section optimization of the whole structure accounting for the substructures' participation in bearing loads cooperatively with the main structure can be done, and the main structure as well as various substructures can also be optimized independently.

\subsection{Comparison Analyses on Whether or Not Accounting for the Substructures’ Participation in Bearing Load Cooperatively the Main Structure}

After being connected to the main structure by large welded hollow spherical nodes, the substructures may participate in bearing load cooperatively with the main structure in a certain degree according to displacement compatibility of the main nodes. Given a structure with span of 80m, comparison analysis on whether or not accounting for the substructures' participation in bearing loads cooperatively with the main structure is carried out in this section. The optimal cross sections of the members are obtained by structural optimization, in which the minimum steel consumption is taken as the objective. And the steel consumption as well as the structural deflection by optimization analysis are listed in Table 2 . 
Table 2. Result Comparison on Whether or Not Accounting for the Substructures' Participation in Bearing Load Cooperatively with the Main Structure

\begin{tabular}{|c|c|c|}
\hline Load-bearing state & Steel consumption $/ \mathrm{kg} / \mathrm{m}^{2}$ & Deflection /cm \\
\hline $\begin{array}{l}\text { Independent layout of substructures, and the } \\
\text { substructures participate in bearing load } \\
\text { cooperatively with the main structure }\end{array}$ & $\begin{array}{c}32.4 \\
\text { (Main structure: 8.1; } \quad \text { Substructures: } 24.1 \text { ) }\end{array}$ & 7.42 \\
\hline $\begin{array}{l}\text { Hinge-connection layout of substructures, and } \\
\text { the substructures participate in bearing load } \\
\text { cooperatively with the main structure }\end{array}$ & $\begin{array}{c}30.0 \\
\text { (Main structure: } 7.5 ; \quad \text { Substructures: } 22.5 \text { ) }\end{array}$ & 6.44 \\
\hline The main structure bearing load by itself & $\begin{array}{c}31.1 \\
\text { (Main structure: } 10.5 ; \quad \text { Substructures: } 20.6 \text { ) }\end{array}$ & 7.05 \\
\hline
\end{tabular}

From the results it can be seen that, in the case of the main structure bearing load by itself, the cross sections of the upper chord latticed built-up members of the main structure along the transverse direction (i.e. X-direction, as shown in Figure 1) are comparatively large, and the members of the substructures are all conventional steel tubes with relatively small cross sections. However, in the case of the main structure bearing loads cooperatively with the substructures, the cross sections of the transverse upper chord latticed built-up members of the main structure decrease, while those of the members of the substructures at the corresponding positions increase rapidly, especially in the case of hinge-connection layout of substructures. But in this case, the longitudinal (Y-directional) edge chord members of the substructures basically keep the smaller level and have no change, so do the upper chord latticed built-up members of the main structure in the corresponding positions. Additionally, the substructures' participation in bearing loads cooperatively with the main structure leads to increase of the steel consumption of the substructures but decrease of that of the main structure.

Further studies show that, in the case of independent layout of the substructures and their participation in bearing loads being considered, only the cross sections of transverse edge chord members of the substructures change somewhat and those of the interior members almost have no change. This indicates that the substructures' participation in bearing loads is just simple cooperation of the edge chord members of the substructures with the corresponding upper chord latticed built-up members of the main structure. So in this case, there is no need to consider the substructures' participation in bearing loads cooperatively with the main structure. Because it will not only cause the complexity of the connection details, but also lead to the increase of both the total steel consumption and structural deflection as shown in Table 2. However, in the case of hinge-connection layout of substructures, the cross sections of many transverse upper chord members of the substructures increase 2 3 grades for the substructures' participation in bearing load. This indicates that a majority of transverse upper chord members of the substructures participate in bearing load cooperatively with the main structure. And the total steel consumption as well as the structural deflection decrease in a certain degree as shown in Table 2, so the cooperative load-bearing effect is remarkable. Therefore in this case, some measures should be taken to ensure the integrity of the main structure with substructures and thus to consider the cooperative load-bearing effect. Actually, the upper surfaces of all the substructures form a folded plate shell, and the transverse upper chord members of the substructures within a transverse section of the whole structure form a polygonal arch in the case of hinge-connection layout of substructures. 
According to the member distribution of the substructures, which reflects the distribution of internal forces, it can be seen that the internal force flow spreads gradually from the mid area to the two transverse edges of each substructure in the process of being transferred downwards as shown in Figure 6, and it is finally transferred to the supports on the two longitudinal sides of the main

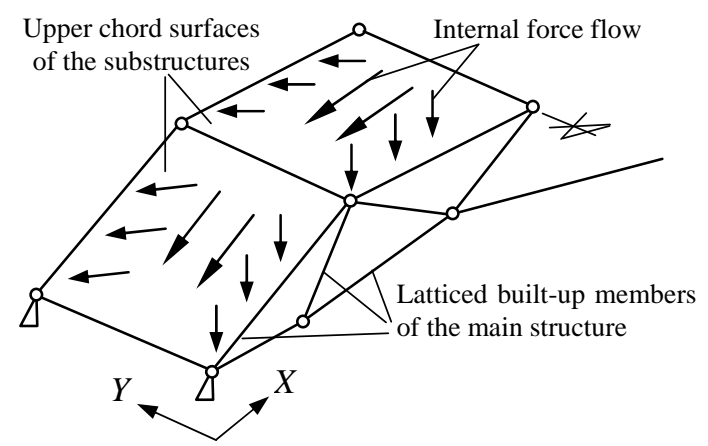

Figure 6. Schematic Diagram of the Force Flow within the Upper Chord Surfaces of the Substructures

structure. The transfer of the internal force flow within the substructures is realized by the web members of the substructures.

\subsection{Comparison Analyses on Whether or Not the Upper Chord Latticed Built-up Members of the Main Structure Are Cancelled}

The substructures are a part of the whole structure. In the case of the substructures participating in bearing loads cooperatively with the main structure, an important character is that the edge upper chord members of the substructures bear load cooperatively with the corresponding parallel upper chord latticed built-up members of the main structure. The substructures' participation in bearing load greatly decreases the cross-sectional sizes of the upper chord latticed built-up members of the main structure. Here a hypothesis is made that the upper chord latticed built-up members of the main structure are canceled and the corresponding load are resisted by the edge upper chord members of the substructures. The previous structure with span of $80 \mathrm{~m}$ is still taken as an example to do comparison analyses on whether or not the upper chord latticed built-up members of the main structure are cancelled. The two layout types of substructures are considered in the case of the substructures participating in bearing load cooperatively with the main structure. From the results it can be seen that, the cross-sectional areas of the edge upper chord members of substructures increase when the upper chord latticed built-up members of the main structure are canceled, but the increase degree is not very remarkable.

Table 3. Result Comparison on Whether or Not the Main Structure' Upper Chord Built-up Members Are Cancelled

\begin{tabular}{cccccc}
\hline Arrangement method of substructure & \multicolumn{2}{c}{ Independent } & & \multicolumn{2}{c}{ Hinge-connection } \\
\cline { 2 - 3 } \cline { 5 - 6 } $\begin{array}{c}\text { The upper chord built-up members of } \\
\text { the main structure are cancelled or not }\end{array}$ & Cancelled & Not cancelled & & Cancelled & Not cancelled \\
\hline Steel consumption / $\mathrm{kg} / \mathrm{m}^{2}$ & 30.56 & 32.52 & & 28.92 & 30.05 \\
Deflection $/ \mathrm{cm}$ & 8.16 & 7.42 & & 7.61 & 6.44 \\
\hline
\end{tabular}


And as shown in Table 3, the steel consumption decreases while the deflection increases a little. Therefore, canceling upper chord latticed built-up members of the main structure and making its web and lower chord latticed built-up members bear load cooperatively with the substructures is a feasible structural formation method. And in the case of independent layout of substructures, the cross sections of interior members of the substructures when the upper chord latticed built-up members of the main structure are cancelled and the cooperative load-bearing is considered are identical with those when these members are not cancelled and the cooperative load-bearing is not considered. This indicates that the interior members of substructures don't participate in bearing load cooperatively with the main structure in this case. However, in the case of hinge-connection layout of substructures as shown in Figure 3(b), the cross sections of the transverse (X-directional) upper chord members within the substructures increase obviously when the upper chord latticed built-up members of the main structure are cancelled, and large number of transverse lower chord members also increase a grade, but the web as well as the longitudinal (Y-directional) upper and lower members of the substructures have not any change. Additionally, in this case, the transfer of internal force flow in the upper chord surface of the substructures is still the same as that shown in Figure 6. So the hinge-connection layout style is superior to the independent one for the substructures in the case of the upper chord latticed built-up members of the main structure being cancelled. This kind of structure, in which the substructures are laid out by hinge-connection style and participate in bearing load cooperatively with the web and lower chord latticed built-up members of the main structure, is similar to the composite grid structure (Chen [17]). The substructures of the former correspond to the reinforced concrete upper chord boards of the latter.

\subsection{Steel Consumption Comparison of Different Kinds of Structures}

From the preceding analyses, two structural layout types are suit for the double-layer cylindrical latticed-built-up-member-system reticulated mega-structure. The first one, which is called type-1 reticulated mega-structure, is that the substructures are supported on the upper chord nodes of the main structure independently and do not participate in bearing load cooperatively with the main structure. The second one is that the substructures are hinged together and supported on the upper chord nodes of the main structure. It is named type-2 reticulated mega-structure, in which the upper chord latticed built-up members of the main structure are cancelled, and the substructures have to participate in bearing load cooperatively with the main structure. In this section, optimization analyses for the cylindrical shell structures with different spans are carried out adopting these two types of reticulated mega-structures as well as the conventional reticulated structure, respectively. And comparison analyses on steel consumptions of these three kinds of structures are conducted. In calculation, the uniform vertical load of $1 \mathrm{kN} / \mathrm{m}^{2}$ on the upper surfaces of the structures is considered, and the fixed-hinged supports are set on the upper chord main nodes along the two longitudinal sides of the main structures. The steel consumptions of different kinds of structures obtained by optimization calculation are listed in Table 4.

Table 4. Comparison on Steel Consumption of Different Types of Structures / kg/m²

\begin{tabular}{cccccccc}
\hline Structural type & \multicolumn{7}{c}{ Structural span $/ \mathrm{m}$} \\
\cline { 2 - 8 } & 80 & 120 & 160 & 200 & 240 & 280 & 320 \\
\hline Conventional reticulated shell & 20.52 & 23.48 & 29.76 & 39.31 & 44.76 & 49.44 & 56.88 \\
Type 1 reticulated mega-structure & 31.36 & 32.64 & 34.92 & 38.04 & 40.51 & 41.71 & 43.42 \\
Type 2 reticulated mega-structure & 30.00 & 32.90 & 33.81 & 36.68 & 39.06 & 46.21 & 47.40 \\
\hline
\end{tabular}


From the results in the table it can be seen that, the steel consumption increases with increase of the structural span, and the increase rate of the conventional reticulated structure is comparatively fast but that of the reticulated mega-structures is relatively slow. For convenience of comparison, the relationship curves of the steel consumptions of these three types of structures with their structural spans are displayed in Figure 7. Obviously, when the structural span is within $200 \mathrm{~m}$, the steel

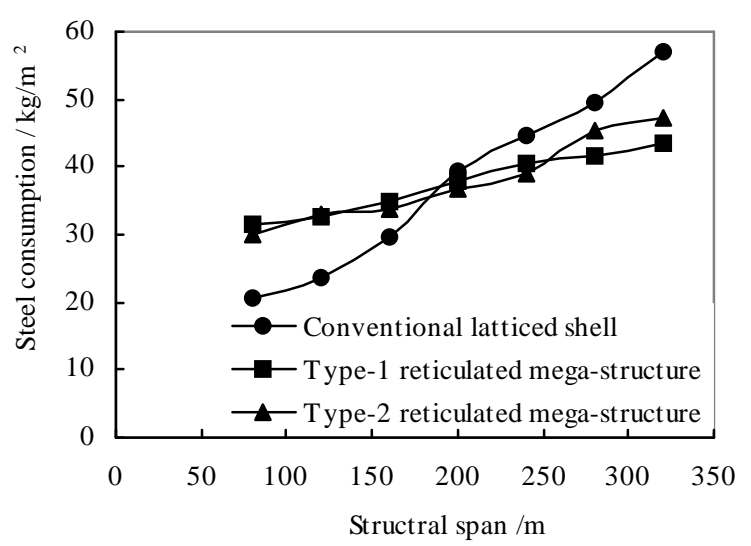

Figure 7. Steel Consumption Comparison of Different

Types of Structures with Change of the Spans

consumption of the conventional reticulated shell is less than those of the mega-structures. But when the span exceeds 200m, it shows a quick increase and thus becomes higher than those of the latter. So a conclusion can be drawn that, it is better to adopt conventional reticulated structure when the span is within $200 \mathrm{~m}$, on the contrary, it's economical to select the reticulated mega-structure when the structural span exceeds $200 \mathrm{~m}$. In addition, the curve of the type- 1 reticulated mega-structure is comparatively flat, and its steel consumption is less than that of the type-2 reticulated mega-structure when the span exceeds $280 \mathrm{~m}$. This indicates that the independent layout of substructures is more suitable for further extension of the structural span than the hinge-connection style. In the section, just comparison on steel consumption between these types of structures is presented. Actually, when the structural span exceeds $200 \mathrm{~m}$, the peak value of internal forces of the conventional reticulated shell becomes larger and larger and difficult to be handled with further increase of the span. But this problem can be easily solved for the reticulated mega-structure.

\section{CONCLUSIONS}

For the cylindrical latticed-built-up-member-system reticulated mega-structure with double-layer grid substructures, the structural configuration including the formation of members of the main structure and layout of the substructures is first analyzed. Then the calculation methods are studied, including the equivalent cross-sectional areas of the latticed built-up members as well as the internal forces of various sub-members in them, and the optimization of the whole structure. In addition, the structural optimization and comparison analyses with the conventional reticulated shell structure are carried out in detail. Synthesizing the calculations and analyses presented above, some conclusions are drawn as follows. 
(1) The calculation formulas of internal forces of various sub-members of the latticed built-up members and those of equivalent cross-sectional areas of them presented in this paper are very accurate. So the results of overall analysis on the structure based on these equivalent formulas are also comparatively accurate and can satisfy the requirement of practical engineering design.

(2) Fictitious full-stress method presented in this paper is suitable and high efficient for cross-sectional optimization of the latticed built-up members in the reticulated mega-structure, and it can be adopted to do optimization analysis of the whole structure combined with the conventional full-stress method.

(3) By comparison analyses on whether or not the substructures' participation in bearing load cooperatively with the main structure is considered, and whether or not the upper chord latticed built-up members of the main structure are cancelled, two optimal structural layout styles are obtained synthesizing details. The first one is that, the substructures are laid out independently and their participation in bearing loads cooperatively with the main structure is not considered. And the second one is that, the substructures are connected with each other along their edges by hinge connections and participate in bearing load cooperatively with the main structure, besides, the upper chord latticed built-up members of the main structure are cancelled.

(4) By comparison analyses with conventional reticulated shell on steel consumption, it is indicated that the reticulated mega-structure is more economical and suitable for super-long-span cylindrical shell structure, and it is recommended to adopt the reticulated mega-structure when the structural span exceeds $200 \mathrm{~m}$, especially the type- 1 reticulated mega-structure when the structural span exceeds $280 \mathrm{~m}$.

\section{ACKNOWLEDGEMENT}

This work was financially supported by the National Natural Science Foundation of China (Grant No. 50508013), Program for New Century Excellent Talents in University (Grant No. NCET-07-0266), Natural Science Foundation of Hunan Province for Distinguished Young Scholars (Grant No. 08JJ1006), and National Key Technology R\&D Program (Grant No. 2006BAJ18B06-01), which are gratefully acknowledged.

\section{REFERENCES}

[1] Dong, S.L. and Yao, J., “The Future and Prospect of Latticed Shell Structures”, Spatial Structures, 1994, Vol. 1, No. 1, pp. 3-10 [in Chinese].

[2] Makowski, Z.S., "Space Structures of Today and Tomorrow”, Space Structures, Guildford, Elsevier, 1984.

[3] Wang, B.B. and Li, Y.Y., “A Theoretical Study of Super-span Latticed Shells”, Journal of Constructional Steel Research, 1999, Vol. 51, pp. 287-96.

[4] He, Y.J., Zhou, X.H., Liu, Y.J., Dong, S.L. and Li, J., "Super-span Reticulated Mega-structure”, Journal of Architecture and Civil Engineering, 2005, Vol. 22, No. 3, pp. 25-9 [in Chinese].

[5] He, Y.J. and Zhou, X.H., "Static Properties and Stability of Cylindrical ILTDBS Reticulated Mega-structure with Double-layer Grid Substructures”, Journal of Constructional Steel Research, 2007, Vol. 63, No. 12, pp. 1580-1589. 
[6] He, Y.J., Zhou, X.H., Dong, S.L. and Li, J., "Seismic Performance of Cylindrical Latticed-intersected-three-dimension-beam-system Reticulated Mega-structure with Double-layer Grid Substructures”, International Journal of Advanced Steel Construction, 2006, Vol. 2, No. 1, pp. 22-36.

[7] Zhou, X.H., He, Y.J. and Xu, L., "Stability of a Cylindrical ILTDBS Reticulated Mega-structure with Single-layer Grid LICS Substructures”, Journal of Constructional Steel Research, 2009, Vol. 65, No. 1, pp. 159-168.

[8] Chiew, S.P. and Soh, C.K., "Strain Concentrations at Intersection Regions of a Multi-planar Tubular DX-joint”, Journal of Constructional Steel Research, 2000, Vol. 53, No. 2, pp. 225-244.

[9] Dexter, E.M. and Lee, M.M.K., "Static Strength of Axially Loaded Tubular K-joints I: Behavior”, Journal of Structure Engineering, ASCE, 1999, Vol. 125, No. 2, pp. 194-201.

[10] Dexter, E.M. and Lee, M.M.K., "Static Strength of Axially Loaded Tubular K-joints II: Ultimate capacity”, Journal of Structure Engineering, ASCE, 1999, Vol. 125, No. 2, pp. 202-10.

[11] Adrin, G. and Virgil, D., “Geometry of Structure Forms”, London, Applied Science Publishers Ltd., 1978.

[12] Zienkiewicz, O.C., Taylor, R.L., and Zhu, J.Z., "The Finite Element Method: Its Basis and Fundamentals (Sixth Edition)”, Oxford, Elsevier Butterworth-Heinemann, 2005.

[13] Ministry of Construction of the People's Republic of China, "GB 50017-2003, Code for Design of Steel Structures of China”, China Planning Press, 2003.

[14] Gil, L. and Andreu, A., "Shape and Cross-section Optimization of a Truss Structure", Computers \& Structures, 2001, Vol. 79, No. 7, pp. 681-689.

[15] Apostol, V. and Santos, J.L.T., "Sensitivity Analysis and Optimization of Truss/Beam Components of Arbitrary Cross-section I-Axial Stresses”, Computers \& Structures, 1996, Vol. 58, No. 4, pp. 727-37.

[16] Vanderplaats, G.N., “Numerical Optimization Techniques for Engineering Design”, New York, McGraw-Hill, 1984.

[17] Chen, H.J., “Analysis and Optimum Design of Composite Grid Structures (5th Edition)”, Stanford, Stanford University, 1994. 


\title{
CABLE SUPPORTED BARREL VAULT STRUCTURE SYSTEM AND RESEARCH ON MECHANICS FEATURE
}

\author{
Zhihua Chen ${ }^{1, *}$, Wentao Qiao ${ }^{2}$ and Xiangyu Yan $^{3}$ \\ ${ }^{1}$ Professor, School of Civil Engineering, TianJin University, China \\ ${ }^{2} \mathrm{PhD}$. Student, School of Civil Engineering, TianJin University, China \\ ${ }^{3} \mathrm{PhD}$. Student, School of Civil Engineering, TianJin University, China \\ *(Corresponding author: E-mail: zhchen@tju.edu.cn)
}

Received: 27 April 2009; Revised: 10 December 2009; Accepted: 22 December 2009

\begin{abstract}
A new prestressed spatial steel structure system--cable supported barrel vault structure system is proposed in this paper. Firstly, the prestress design method for the structure is proposed. Then, we present in-depth analysis on the proposed structure. Research results suggest that the cable supported barrel vault is an efficient spatial steel structure system with improved rigidity, reduced horizontal arch thrust and well controlled horizontal displacement. The influence of several key parameters on the mechanics characteristics of the cable supported barrel vault is evaluated as well. The following conclusions are drawn from our study: (i) the impact of the rise-span ratio on the mechanics characteristics is significant, so the rise-span ratio should be designed properly. Values from 0.08 to 0.12 are suggest; (ii) the influence of the sag-span ratio is also great. The sag-span ratio with range from 0.02 to 0.06 is suggested; (iii) the impact of the strut number on the mechanics characteristics is small. The strut number is usually determined by the span of the structure. Generally speaking, the longer the span is the larger the strut number should be. Struts should be used as few as possible while meeting the safe standards, but the strut number should be more than one.
\end{abstract}

Keywords: Cable supported barrel vault; beam string structure; cylindrical latticed shell; rise-span ratio; sag-span ratio; strut number

\section{INTRODUCTION}

Cylindrical latticed shell (Dong and Yao [1], Wang and Li [2], He et al. [3]) has been widely used in spatial structure projects due to its desirable merits such as beautiful fabrication, reasonable mechanics characteristics, mathematical tractability design method, and automatic machining, etc. However, considering that the out-plane stability of the structure itself is poor, it is very difficult for the single-layer or thin double-layer cylindrical latticed shell to span a long distance, As for the thick double-layer or multi-layer cylindrical latticed shell, it is flawed by the following demerits:

(1) Too much steel is required when a latticed shell is very thick, which makes it cost-ineffective.

(2) The lower supporting structures of the latticed shell such as columns and frames may be overloaded because of the big horizontal arch thrust (i.e., the transverse constraint reactions).

(3) The fabrication and construction of joints is complicated since too many rods converge on a joint.

(4) Long rods in a thick latticed shell complicates the site assembly. 
In order to overcome these mentioned drawbacks above, a new-style prestressed spatial steel structure--cable supported barrel vault structure system (abbr. CSBVSS) is proposed in this paper inspired by cable supported structure system such as beam string structure (Masao and Kurasiro [4], Masao [5], Masao and Ohtake [6], Saitoh and Okasa [7], Wu [8], Xue and Liu [9]) and suspendome (Kawaguchi et al. [10], Tatemichi et al. [11], Chen and Li [12], Kang et al. [13], Kitipornchai et al. [14]), the proposed CSBVSS is composed of a single-layer or thin double-layer cylindrical latticed shell, struts and cables. On the one hand, the rigidity and the out-plane stability of the proposed structure are improved because of the action of struts and cables, consequently, the problem of the span is solved; on the other hand, less steel is used for the single-layer or the thin double-layer cylindrical latticed shell, which makes it cost-efficient and reduces the construction difficulty considerably as well. Moreover, the horizontal arch thrust is reduced effectively by the prestressed cables, so the heavy burden on the lower supporting structures is released significantly.

\section{FABRICATION OF CABLE SUPPORTED BARREL VAULT STRUCTURE SYSTEM}

As shown in Figure 1, the proposed cable supported barrel vault structure is composed of a upper cylindrical latticed shell, lower cables and middle struts. The struts are placed vertically along the span direction. The lower end of the struts is linked by a cable via dead joints and the upper end is attached to the upper latticed shell by a pin roll joint. The two ends of the cable are linked with the latticed shell by anchor joints, which are set up in the place of supports.

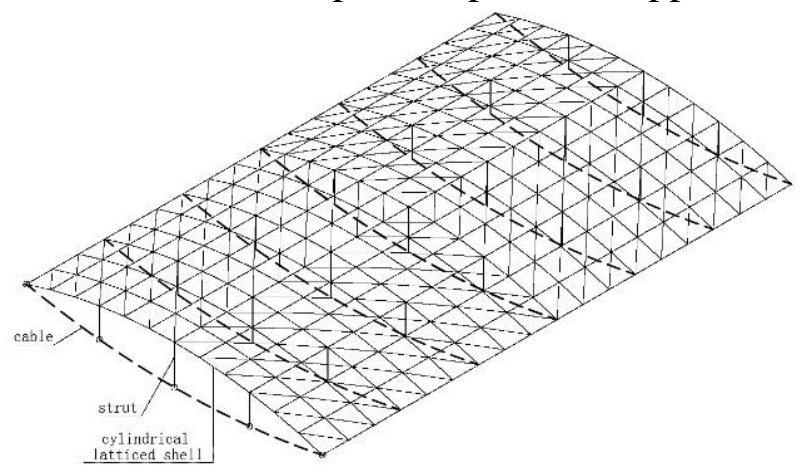

Figure 1. Cable supported Barrel Vault Structure

For the upper latticed shell of the cable supported barrel vault structure, the single-layer or the thin double-layer cylindrical latticed shell is usually used. The span, grid pattern and grid size are determined by demands of the architecture. As for the pattern of the single-layer latticed shell, single-rib orthogonal latticed grids, cross-rib orthogonal latticed grids, lamella latticed grids, or three-way latticed grids can be used; while the thin double-layer latticed shell can adopt two-way orthogonal latticed grids, two-way diagonal latticed grids, orthogonal square pyramid spatial grids, diagonal square pyramid spatial grids, orthogonal square pyramid spatial grids with openings, or square pyramid spatial grids of checkerboard pattern. The number of vertically placed struts along the span direction is determined by the span and optimized by calculation. The cables are set up along the longitudinal direction with the space between two or multiple grids, which is decided by practical conditions. Moreover, the cables should have certain sag. It can be seen in Figure 1 that single-rib orthogonal latticed grids are adopted in the demonstration model and three struts are placed. 


\section{PRESTRESS DESIGN}

The peripheral restriction, in the cable supported barrel vault structure, is usually the spatial pin, i.e., transverse restriction of one side of the structure is released, so the structure can slide freely along this direction, therefore, the huge horizontal arch thrust induced by the cylindrical latticed shell is released, which, of course, causes huge transverse displacement, however, this displacement can be controlled due to the action of cables. From the analysis above, it is easy to find the prestress design principle of the cable supported barrel vault structure. The transverse displacement of each support of the structure (considering the symmetry of this structure system, the transverse displacement of each pin support is similar, so the maximum displacement can be used as the representative value, if it is zero or close to zero, all the transverse displacement can be considered zero or close to zero) is reduced to zero or close to zero by the action of prestressed cables, the detail process is introduced as follows.

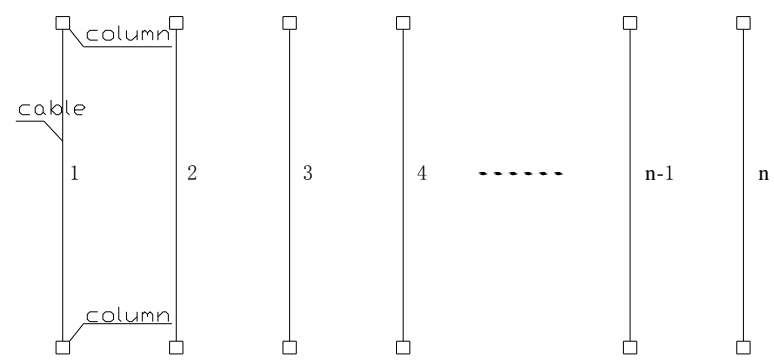

Figure 2. Cable Disposition

The cable disposition of the cable supported barrel vault is shown in Figure 2. Firstly, the prestress is not imposed, i.e., the prestress value of each cable is set to zero, subject to the roof live load and dead weight of the structure, the forces of the cables are calculated as: $\boldsymbol{N}=\left\{\boldsymbol{N}_{1}, \boldsymbol{N}_{2}, \boldsymbol{N}_{3}, \boldsymbol{N}_{4}, \cdots \cdots, \boldsymbol{N}_{n-1}, \boldsymbol{N}_{\boldsymbol{n}}\right\}$. Then, $\boldsymbol{N}$ is updated by the calculated prestress of each cable, the structure is re-analyzed, and the transverse displacement of each support of the structure is figured out. Updating the value of $\boldsymbol{N}$ and recalculating again, this process is repeated and terminated until the displacement reaches zero or a certain predefined threshold, the calculated prestress $\boldsymbol{N}$ put on the cables is the target value. When the cable supported barrel vault is constructed, the steel latticed shell, struts and cables are fixed and supported by the temporary braces. Then the cables are tensioned, according to the mechanical balance principle, the genuine initial prestress of cable is the calculated stress of the cable with the target value put into the cable and the dead weight imposed on the structure. It is worth noting that the geometry nonlinearity of the structure should be taken into account during the calculation process above. The whole process can be carried out by general finite element analysis software such as ANSYS, ABAQUS, Sap, Midas/gen etc.. In the following section, a practical project employing the proposed cable supported barrel vault structure is presented as an example, the prestress design of which is carried out by Midas/gen according to the prestress design method proposed above.

\subsection{Example Analysis}

The project analyzed in this paper is a textile workshop roof, which is the first cable supported barrel vault structure in China. It is $410 \mathrm{~m}$ long and divided into four parts with span of $50 \mathrm{~m}$. One part of them, $116.2 \mathrm{~m}$ long, is analyzed. According to the demand of the architecture, the rise of this cable supported barrel vault structure is $4.3 \mathrm{~m}$, and the sag is $0.7 \mathrm{~m}$. Three-way latticed grids are used for the upper single-layer latticed shell, and the grid size is $4.5 \mathrm{~m}$. For the rod section, five types of sections are selected, including $\Phi$ 180x6, Ф 203x8, Ф 245x8, Ф 299x8 and Ф 325x10. While 
the sections of the struts are all $\Phi 273 \times 10$. The cables are all semi-parallel steel strand $\Phi 7 \times 73$, $1860 \mathrm{Mpa}$. Roof dead and live load are respectively $0.80 \mathrm{kN} / \mathrm{m} 2$ and $0.50 \mathrm{kN} / \mathrm{m} 2$. The building perspective is shown in Figure 3, and Figure 4 depicts the elevational drawing and the plane graph. This example is analyzed in Midas/gen, in which rods of the upper single-layer latticed shell, struts and cables are respectively simulated by beam, truss and tension-only elements.

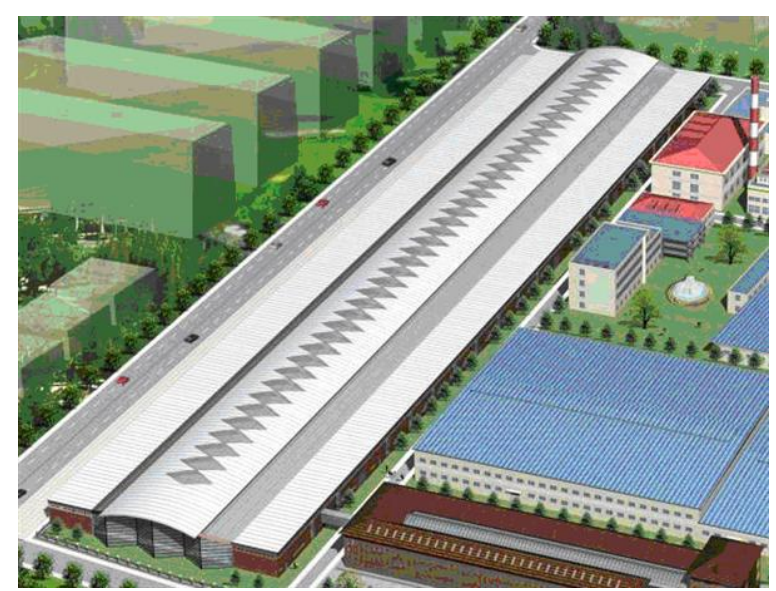

Figure 3. Building Perspective

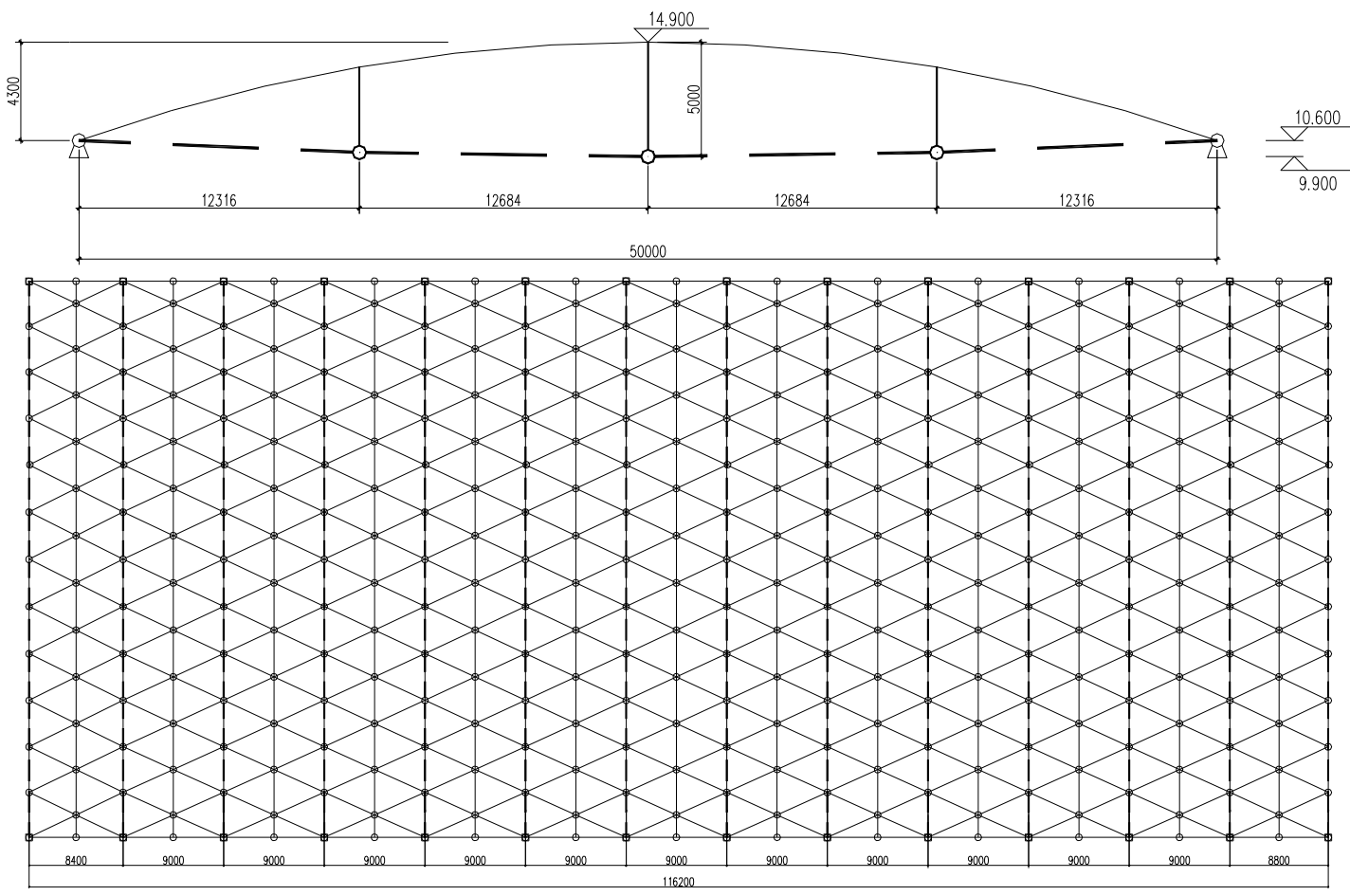

Figure 4. Elevational Drawing and Plane Graph

With the space between two consecutive longitudinal grids, 14 cables are set up in all, therefoce, $N=\left\{N_{1}, N_{2}, N_{3}, N_{4}, \cdots \cdots, N_{13}, N_{14}\right\}$,changing $N$ into $1.4 N, 1.8 N$, and $2 N$, repeating calculation four times, in the end, the calculated prestress versus transverse displacement of supports curve is plotted in Figure 5. 


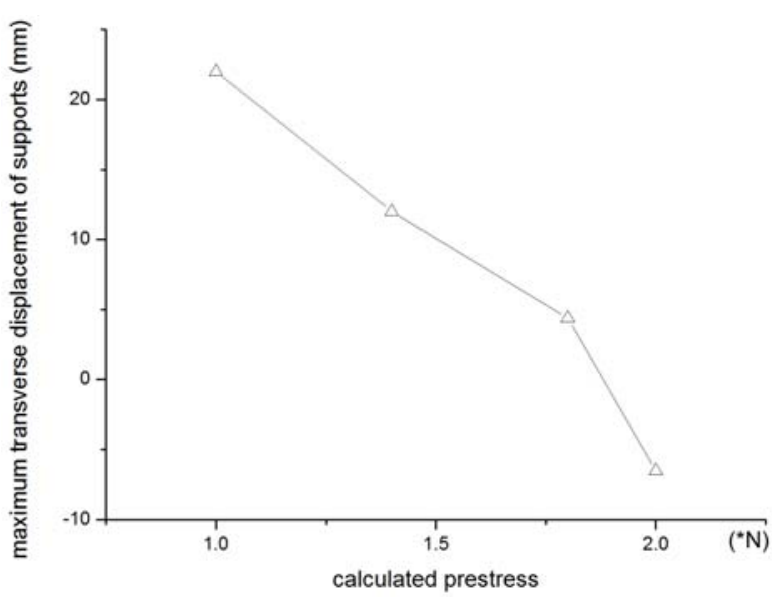

Figure 5. Calculated Prestress-Transverse Displacement of Supports Curve

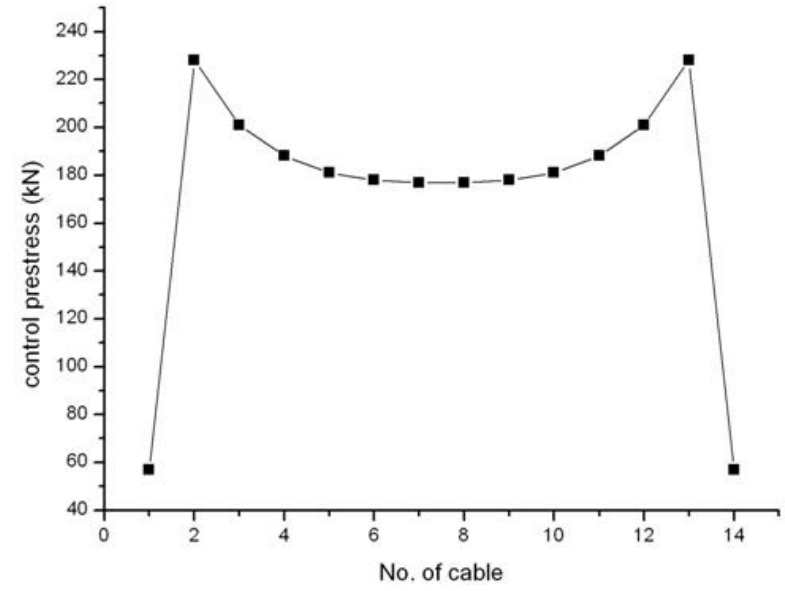

Figure 6. Control Prestress of Cables

Figure 5 denotes that the transverse displacement is approximately linear with calculated prestress, therefore, the target value can be obtained approximately by linear interpolation. In this case, the target value is $1.87 \mathrm{~N}$. The initial prestress of cables are set as $1.87 \mathrm{~N}$, under the dead weight of the structure, the genuine initial prestress which is termed control prestress in Figure 6 can be figured out, the control prestress of all cables are shown in Figure 6.

It can be easily seen from Figure 6 that the prestress of cables are almost symmetrical, which is due to the symmetrical disposition of cables in the structure. Another fact can be unveiled from Figure 6 that the prestress of cables locating around the center of the longitudinal direction is similar. It is evident in Figure 6 that the prestress of six cables around the center of the longitudinal direction are almost the same.

\subsection{Mechanics Feature Comparison between Cable Supported Barrel Vault and Cylindrical Latticed Shell}

The textile workshop roof as an example of CSBV has been analysed in the previous subsection. In what follows, a single-layer cylindrical latticed shell evolving from the CSBV by removing cables and struts will be studied and compared with the CSBV. Subject to the roof live load and dead weight, some key parameters for these two structure systems are evaluated and listed in Table1.

Table1. Results Comparison

\begin{tabular}{|c|c|c|c|c|}
\hline structures results & $\begin{array}{c}\text { Maximum push power of } \\
\text { supports } \\
\text { (ton) }\end{array}$ & $\begin{array}{c}\text { Maximum transverse } \\
\text { displacement of supports } \\
(\mathrm{m})\end{array}$ & $\begin{array}{c}\text { Maximum vertical } \\
\text { displacement of structure } \\
\text { (m) }\end{array}$ & $\begin{array}{c}\text { Maximum stress of } \\
\text { upper rods } \\
\text { (Mpa) }\end{array}$ \\
\hline Cable supported barrel vault & 0.18 & 0.049 & 0.167 & 143.8 \\
\hline $\begin{array}{c}\text { Cylindrical latticed shell (spatial } \\
\text { pin restriction) }\end{array}$ & 0 & 13 & 29.7 & 3875.1 \\
\hline $\begin{array}{c}\text { Cylindrical latticed shell (fixed } \\
\text { pin restriction) }\end{array}$ & 150 & 0 & 0.053 & 125 \\
\hline
\end{tabular}


Through the data comparison in Table1, it is very clear that for the cable supported barrel vault structure system the horizontal arch thrust of supports are almost eliminated completely, and the transverse displacement of supports and vertical displacement of the structure are fairly small. Moreover, the maximum stress of rods are reasonable as well. All of these indicate that the cable supported barrel vault structure system outperforms the general cylindrical latticed shell and the project design standard can be well met.

\section{PARAMETERS RESEARCH}

In cable supported barrel vault structures, rise-span ratio, sag-span ratio and strut number are the key parameters determining the mechanics characteristics of the structures. The research on these parameters will be carried out in the sequel. Its mechanics characteristics are similar to those of the cylindrical latticed shells with the same size proportion (Shen and Chen [15]), for the sake of computational simplicity, in the following parameters analysis, only one fixed span is used, but the rise, sag and the strut number are variable. Thus, the rise-span ratio, sag-span ratio, and the number of struts of the structure are all variable. Moreover, in order to fit the analysis into practical design, the typical range of the rise-span ratio (0.06-0.15), sag-span ratio (0.01-0.08), strut number and the grid pattern-three-way latticed grids are considered. The examples below are all analyzed in Midas/gen, and the choice of elements is the same as that in Section 3.1.

\subsection{Influence of Rise-Span Ratio on Mechanics Feature of Cable Supported Barrel Vault Structure}

The roof of the textile workshop is still taken as an analysis example in this section. Changing the rise and keep all the other parameter settings of the structure, the influence of the rise-span ratio on mechanics characteristics of the structure is analyzed, here four typical rise-span ratios i.e., 0.06, 0.086, 0.12 and 0.15 , are considered, under the load combination of roof dead load, roof live load and dead weight, the main results are obtained and listed as follows in Figure 7-11:

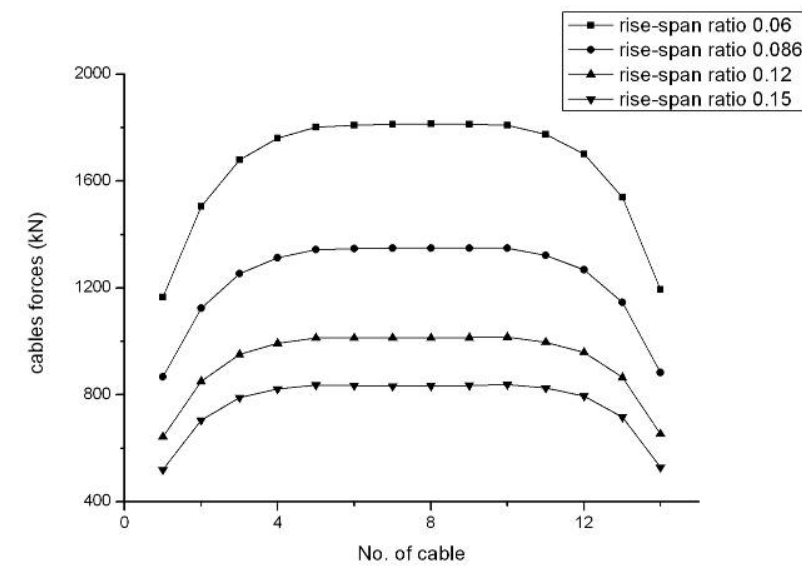

Figure 7. Influence of Rise-Span Ratio on Cables Forces

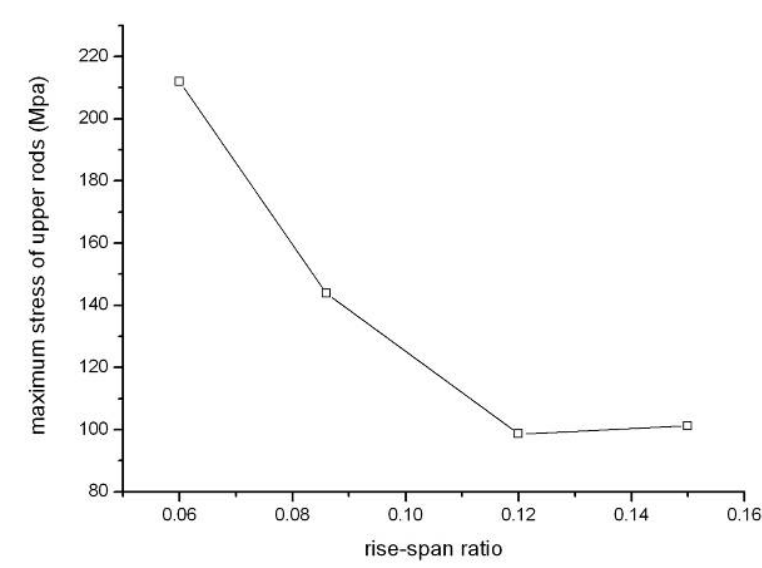

Figure 8. Influence of Rise-Span Ratio on the Upper Rod 


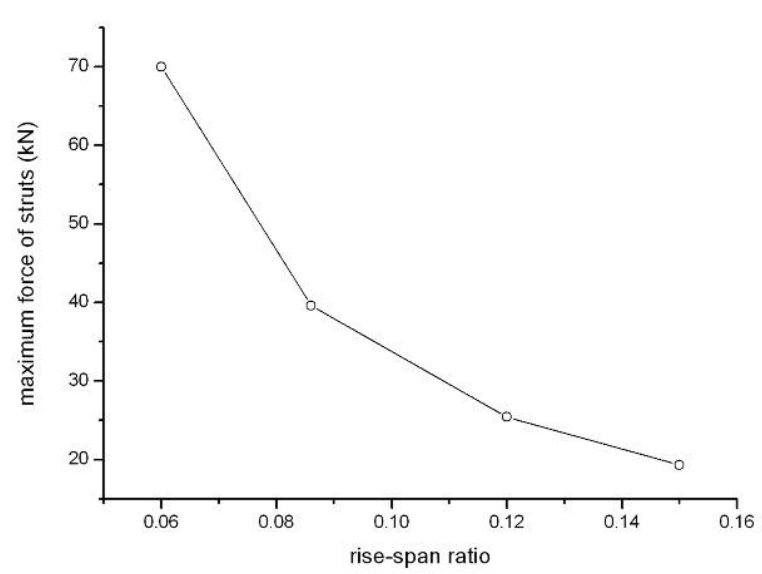

Figure 9. Influence of Rise-Span Ratio on Strut Force

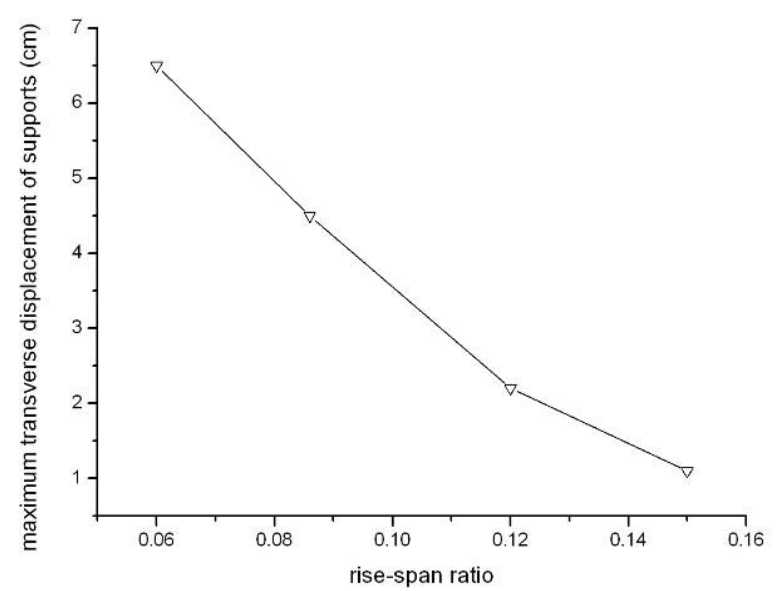

Figure 10. Influence of Rise-Span Ratio on Transverse displacement of Supports

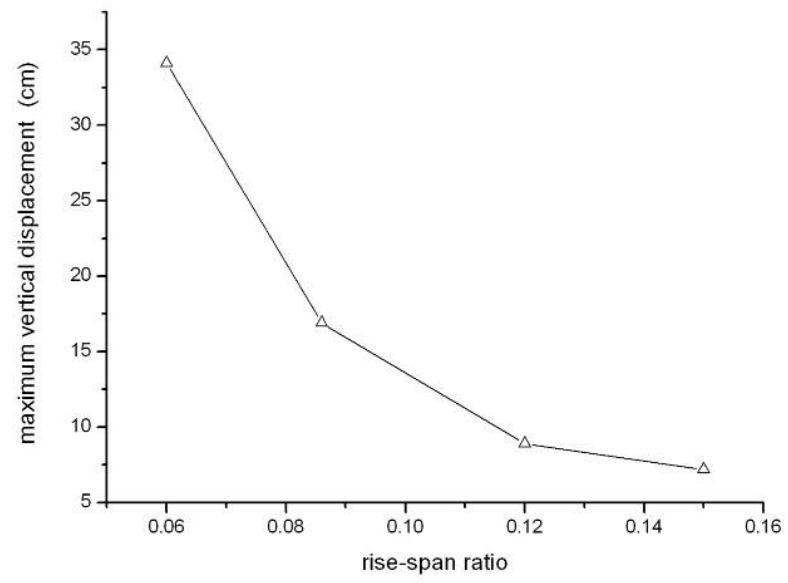

Figure 11. Influence of Rise-Span Ratio on Vertical Displacement of Structure

As shown in Figures 7-11, the forces of cables, the maximum stress of the upper rods, the maximum force of struts, the maximum transverse displacement of supports and the maximum vertical displacement of the structure decrease as the rise-span ratio increases. Another fact can be observed from these figures that the decreasing trend becomes milder as the rise-span ratio increases. More specifically, the decreasing rate for all the parameters shown in the vertical axes of these figures slows down as the rise-span ratio increases. It is worth noting that the shape of the cylindrical latticed shell changes as the rise-span ratio increases, the mechanics characteristics of which changes from "beam" to "arch" accordingly, It is this change that affects the whole structure's mechanics characteristics. Analysing this change further, it is evident that the rise-span ratio should not be too small, otherwise, the structure will be too flat which leads to low rigidity. Meanwhile, the transverse displacement of supports will be large, and the prestress of cables are bound to increase, As a result, much more burden will be induced by prestressed cables, and the sections of elements have to be enlarged to bear this extra burden, Consequently, this structure system becomes no longer economical. Moreover, the rise-span ratio cannot be too large either, otherwise, the forces of cables will be so small that the restriction action on the upper latticed shell induced by the forces of cables will be reduced significantly, in this case, the cables may relax when a gale or earthquake happens, which changes the mechanics characteristics of the cable supported structure system, and may cause catastrophic destroy to the structure. However, it's effective to prevent the cable relaxation by either increasing prestress of cables and the mass of the upper cylindrical latticed shell, or introducing anti-wind cables. To sum up, the rise-span ratio of 
the cable supported barrel vault structure should be selected appropriately. If the architecture permits, values ranging from 0.08 to 0.12 are suggested.

\subsection{Influence of Sag-Span Ratio on Mechanics Feature of Cable Supported Barrel Vault Structure}

Next, the influence of the sag-span ratio on mechanics characteristics of the CSBV is analysed. Four different sag-span ratios, i.e., 0.014, 0.03, 0.05 and 0.08 are considered, under the load combination of roof dead load, roof live load and dead weight, the main results are obtained and listed as follows in Figure 12-16:

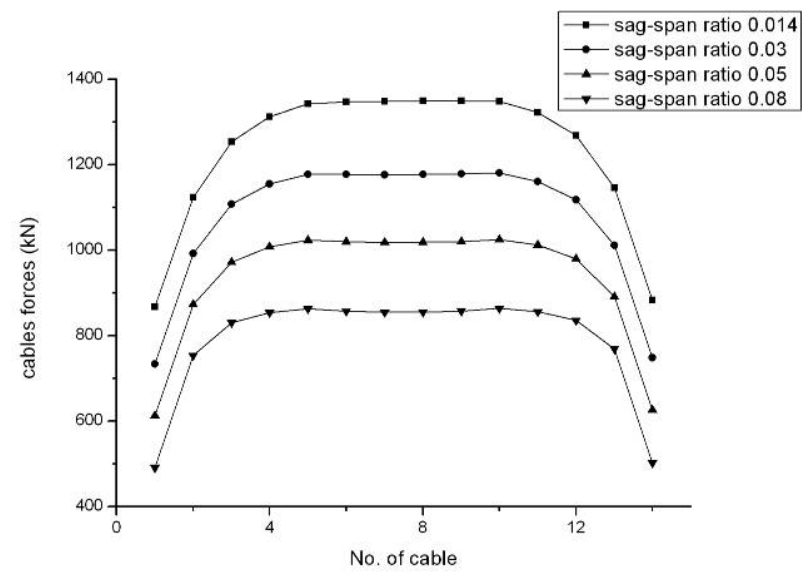

Figure 12. Influence of Sag-Span Ratio on Cables Forces

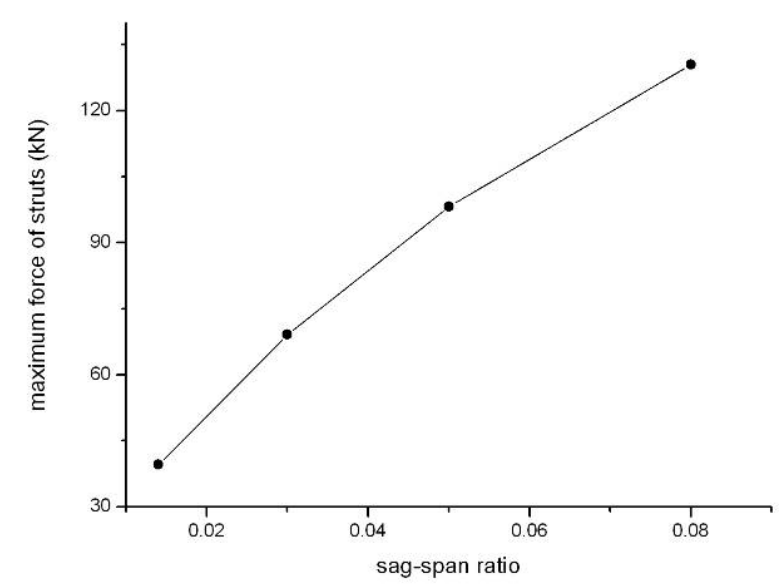

Figure 14. Influence of Sag-Span Ratio on Strut Force

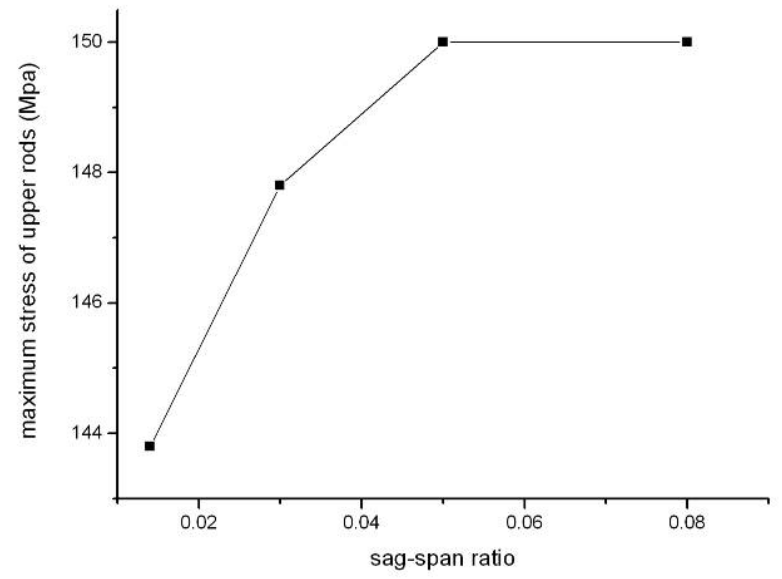

Figure 13. Influence of Sag-Span Ratio on the Upper Rod

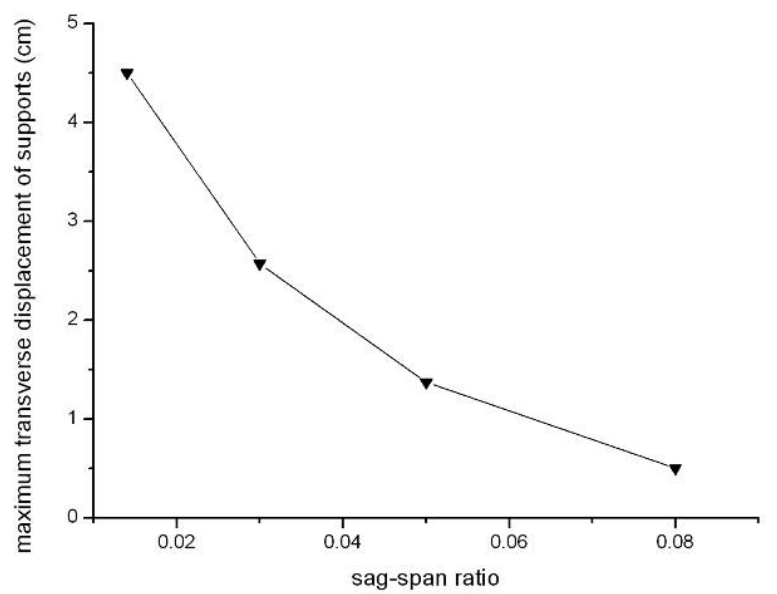

Figure 15. Influence of Sag-Span Ratio on Transverse Displacement of Supports 


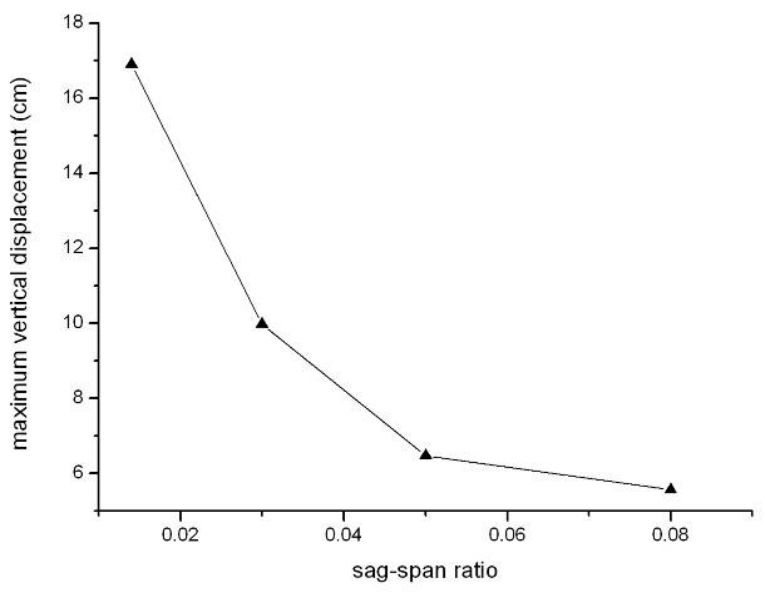

Figure 16. Influence of Sag-Span Ratio on Vertical Displacement of Structure

As shown in Figure 12, the forces of cables decrease as the sag-span ratio increases. It can be seen from Figures 13 and 14 that that both the maximum stress of the upper rods and the maximum force of struts increase as the sag-span ratio increases. Moreover, it is evident that this increasing trend slow down with the increase of sag-span ratio. This trend is more obvious for the maximum stress of the upper rods. It can be seen from Figure 13 that the stress almost keeps unchanged when the the sag-span ratio is larger than 0.05. As shown in Figure 15-16, both the maximum transverse displacement of supports and the maximum vertical displacement of the structure decrease as the rise-span ratio increases, and this decreasing trend slows down with the increase of sag-span ratio. By analyzing this change further, apparently, as the sag-span ratio increases, the restriction action on struts induced by cables increases due to the increased force of struts, therefore, the forces of cables decrease, but the cable supported action on the whole structure system still increases. This is also the main reason why the maximum vertical displacement of the structure decreases as the sag-span ratio increases. Furthermore, Figure 15 also suggests that when the forces of cables decrease, the maximum transverse displacement of supports decreases, which indicates the restriction action on supports induced by cables increases with the increase of the sag-span ratio. Meanwhile, the maximum stress of the upper rods is also bound to increase as the sag-span ratio increases since the upper rod with the maximum stress is close to the anchor joint. To sum up, for the cable supported barrel vault structure, the sag-span ratio should not be too small, otherwise, the action efficiency of cables will be very low, which means that the forces of cables are powerful, but the cable supported action on the whole structure system is weak. Of course, the sag-span ratio should not be too large either, otherwise, the forces of cables will be very small, which is unfavorable to resist wind and earthquake. Moreover, the large sag-span ratio will take up much more interior space, so the sag-span ratio of the cable supported barrel vault structure should be selected appropriately. If the architecture permits, values ranging from 0.02 to 0.06 are suggested.

\subsection{Influence of Strut Number on Mechanics Feature of Cable Supported Barrel Vault Structure}

Finally, the influence of strut number on mechanics characteristics of the structure is analyzed, in this subsection, five cases with strut number being 3, 5, 7, 9 and 11 are considered. Under the load combination of roof dead load, roof live load and dead weight, the main results are obtained and listed as follows in Figure 17-21: 


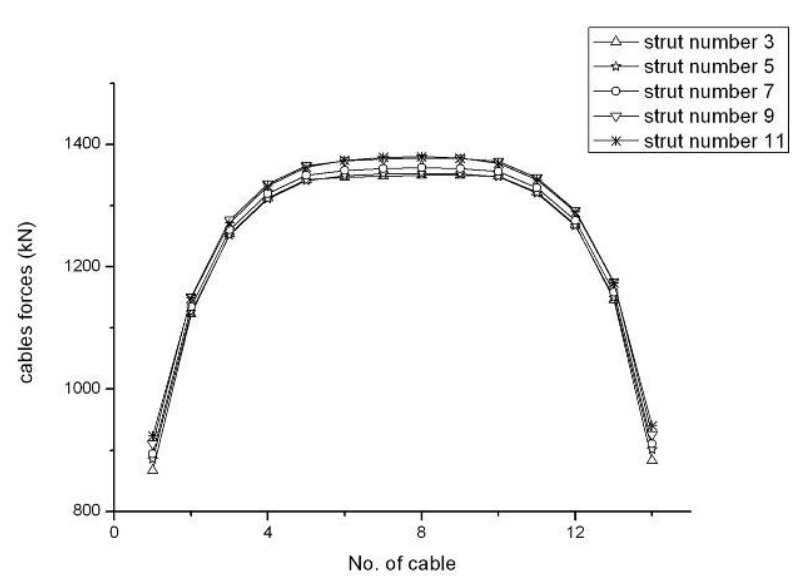

Figure 17. Influence of Strut Number on Cables Forces

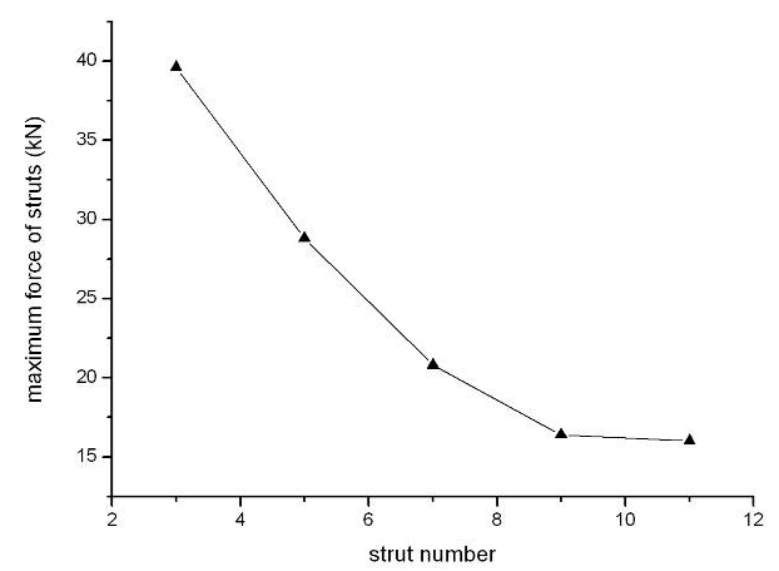

Figure 19. Influence of Strut Number on Strut Force

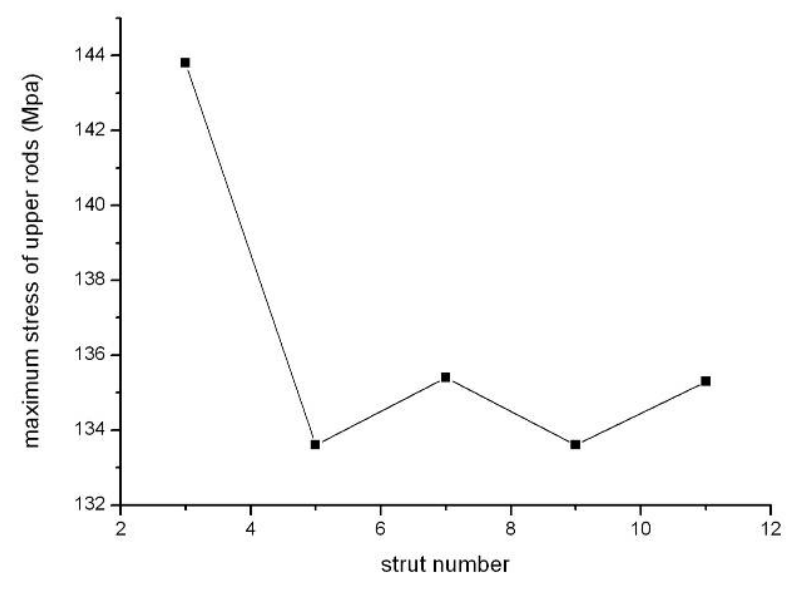

Figure 18. Influence of Strut Number on the Upper Rod

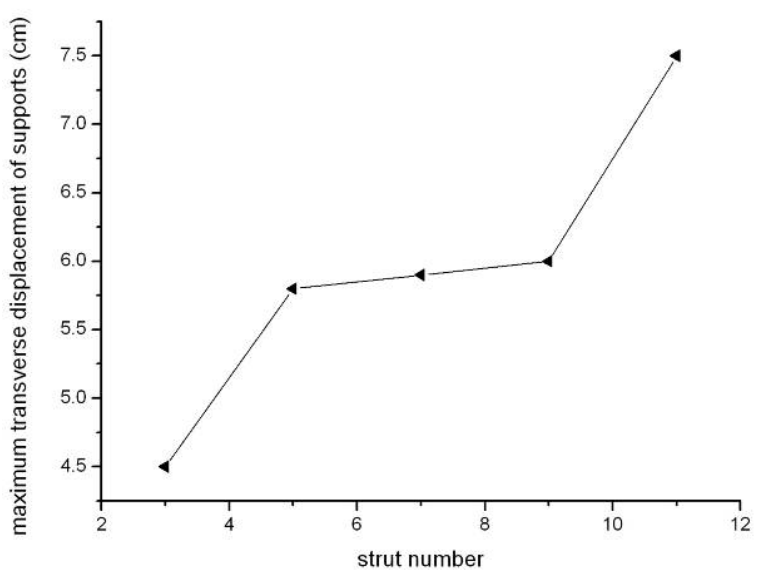

Figure 20. Influence of Strut Number on Transverse Displacement of Supports

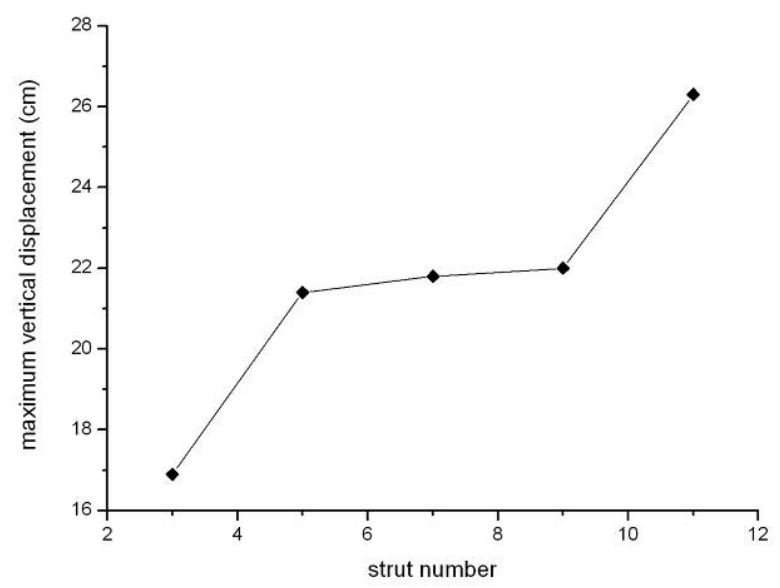

Figure 21. Influence of Strut Number on Vertical Displacement of Structure

As shown in Figure 17, as the strut number increases the forces of cables almost keep the same, and the maximum change is less than 2.5\%. It can be seen from Figure 18 and 19 that both the maximum stress of the upper rods and the maximum force of struts decreases as the strut number increases. Similar as Figure 8 and 9, their decreasing rate slows down with the increase of strut number. This phenomenon is more obvious for the influence on the maximum stress of the upper rods. Moreover, the stress almost does not change as the strut number exceeds 5, and the maximum 
change is less than $1.5 \%$. Also, the maximum force of struts almost remains unchanged when the strut number exceeds 9. As demonstrated in Figure 20 and 21, the maximum transverse displacement of supports and the maximum vertical displacement of the structure both increase with the increase of the strut number, For the strut number ranging from 5 to 9 , both displacements seem unchanged. However, when the strut number is more than 9, both of them begin to increase again. The following facts can be also observed that (i) the impact of strut number on the forces of cables is weak; (ii) only when the strut number is less than 3, the increase of the strut number makes the latticed shell bear load more evenly, in consequence, the maximum stress of the upper rods will be reduced, but this decreasing is very limited, and as the strut number augments this effect becomes weaker. If the strut number increases excessively, as a result, the dead weight of the structure will increase as well, which leads to the increase of the displacement of the structure. Therefore, it is not wise to improve the mechanics behaviors of the upper latticed shell by increasing the strut number excessively. Furthermore, in the cable supported barrel vault, the strut number is usually more than one, when only one strut is used, the structure is usually unstable or the displacement of the strut is too large, so the calculation becomes hard to converge. To sum up, the strut number is usually decided by the span and must be more than one. However, struts should be used as less as possible if the structure permits.

\section{CONCLUSIONS}

A cable supported barrel vault structure has been proposed and analysed in this paper. The research results indicate that it is an efficient spatial structure system and the rigidity of the whole structure system is advanced due to the action of struts and cables. The horizontal arch thrust of supports can almost be eliminated completely, and the horizontal displacement is still under control. By investigating the influence of rise-span ratio, sag-span ratio and strut number on the mechanics characteristics of the structure, the following conclusions have been drawn:

(1) The influence of the rise-span ratio on the proposed CSBV is significant. Reducing the rise-span ratio will decrease the rigidity of the structure and increase the transverse displacements of supports. It has been shown that increasing the cables prestress is not a good solution to solve these problems above, since it makes structure system uneconomical. Moreover, the increase of the rise-span ratio weakens the cable supported action. Meanwhile, it is also unfavorable to resist wind and earthquake, due to the reduced cable forces. Therefore, the choice of the rise-span ratio should be appropriate, the proper value from 0.08 to 0.12 has been suggested.

(2) The impact of the sag-span ratio is also great. Reducing the sag-span ratio will lower the action efficiency of cables, which means that the forces of cables are powerful, but the cable supported action is weak, furthermore, increasing the sag-span ratio strengthens cable supported action but weakens cables forces, which is unfavorable as well to resist wind and earthquake. Large sag-span ratio takes up much much space, so the sag-span ratio should be designed appropriate. The proper value from 0.02 to 0.06 has been suggested. 
(3) The influence of the strut number is small. The strut number is usually decided by the span of the structure, and struts should be used as few as possible under the condition of meeting standards. But the strut number must be more than one, otherwise, the structure is usually unstable or the displacement of the strut is too large, which eventually makes the calculation hard to converge.

\section{REFERENCES}

[1] Dong, S.L. and Yao, J., “The Future and Prospect of Latticed Shell Structures”, Spatial Structures, 1994, Vol. 1, No. 1, pp. 3-10. [in Chinese]

[2] Wang, B.B. and Li, Y.Y., “A Theoretical Study of Super-Span Latticed Shells”, Journal of Constructional Steel Research, 1999, Vol. 51, pp. 287-96.

[3] He, Y.J., Zhou, X.H. and Dong, S.L., "Research on Static and Stability Properties of Single Layer Latticed Intersected Cylindrical Shell”, Journal of Hunan University (Nature Sciences), 2004, Vol. 31, No. 4, pp. 45-50. [in Chinese]

[4] Masao, Saitoh and Kurasiro Tosiya, "A Study on Structural Behaviors of Beam String Structure”, Summaries of Technical Papers of Annual Meeting Architectural Institute of Japan [C], Tokyo, Japan, B 1.1985, pp. 280-284.

[5] Masao, Saitoh, “A Study on Structural Planning of Radial Type Beam String Structures”, Summaries of Technical Papers of Annual Meeting Architectural Institute of Japan [C], Tokyo, Japan, B 1.1988, pp. 1365-1366.

[6] Masao, Saitoh and Ohtake, Tohru, "A Study on Beam String Structure with Flat Circular Arch", Summaries of Technical Papers of Annual Meeting Architectural Institute of Japan [C], Tokyo, Japan, B 1.1988, pp. 1369-1374.

[7] Masao, Saitoh and Okasa, Akira, "The Role of String in Hybrid String Structure”, Engineering Structures, 1999, Vol. 21, No. 8, pp. 756-69.

[8] Wu, M.E., "Analytical Method for the Lateral Buckling of the Struts in Beam String Structures”, Engineering Structures, 2008, Vol. 30, No. 9, pp. 2301-2310.

[9] Xue, W.C. and Liu, S., "Design Optimization and Experimental Study on Beam String Structures”, Journal of Constructional Steel Research, 2008, No. 9, pp. 1-11.

[10] Kawaguchi, Mamoru, Abe, Masaru and Tatemichi, Ikuo, "Design, Tests and Realization of "Suspen-Dome" System”, Journal of the IASS, 1999, Vol. 40, No. 131, pp. 179-192.

[11] Tatemichi, I., Hatato, T. and Anma, Y., et al., "Vibration Tests on a Full-Size Suspen-Dome Structure”, International Journal of Space Structure, 1997, Vol. 12, No. 3 \& 4, pp. 217-224.

[12] Chen, Z.H. and Li, Y., "Parameter Analysis on Stability of a Suspen-Dome”, International Journal of Space Structure, 2005, Vol. 20, No. 2, pp. 115-124.

[13] Kang, W.J., Chen, Z.H. and Lam, Heung-Fai, et al., "Analysis and Design of the General and Outmost-Ring Stiffed Suspen-Dome Structures”, Engineering Structures, Vol. 25, 2003, pp. 1685-1695.

[14] Kitipornchai, S., Kang, W.J. and Lam, Heung-Fai, et al., "Factors Affecting the Design and Construction of Lamella Suspen-Dome Systems”, Journal of Constructional Steel Research, Vol. 61, 2005, pp. 764-785.

[15] Shen, S.Z. and Chen, X., "Stability of the Shell Structures", Beijing: Science Press, 1999. [in Chinese] 


\title{
FURTHER RESEARCH ON CHORD LENGTH AND BOUNDARY CONDITIONS OF CHS T- AND X-JOINTS
}

\author{
G.J. van der Vegte ${ }^{1, *}$ and Y. Makino ${ }^{2}$ \\ ${ }^{1}$ Delft University of Technology, Faculty of Civil Engineering and Geosciences, \\ Section GCC - Stevin II Lab., Stevinweg 1, 2628 CN Delft, The Netherlands \\ ${ }^{2}$ Department of Architecture and Civil Engineering, Kumamoto University, \\ Kurokami 2-39-1, Kumamoto 860-8555, Japan \\ *(Corresponding author: E-mail: g.j.vandervegte@tudelft.nl)
}

Received: 1 October 2009; Revised: 29 January 2010; Accepted: 5 February 2010

\begin{abstract}
In the past many questions existed regarding the effect of the chord length and boundary conditions on the static strength of tubular joints. In addition to previous research by van der Vegte (1995), the current study focuses on the numerical analyses of axially loaded $\mathrm{X}$-joints with the chord length parameter $\alpha$, the brace-to-chord diameter ratio $\beta$, the chord thickness ratio $2 \gamma$ and the chord end conditions (i.e. free versus fully restrained chord ends) being the major variables.

Based on finite element (FE) results, the effect of the chord length and the boundary conditions on the static strength of the X-joints considered is presented. The results are briefly compared with (i) van der Vegte's previous data (1995) on X-joints and (ii) the chord length effect found for CHS T-joints by van der Vegte and Makino (2006).

It is concluded that the influence of boundary conditions can be much more pronounced than originally anticipated. Hence, in designing test specimens or re-evaluating experiments conducted in the past, special attention should be given to these issues in order to prevent the chord length and boundary conditions having a significant influence on the results.
\end{abstract}

Keywords: Tubular joint; circular hollow section; T-joint; X-joint; finite element analysis; chord length; boundary conditions

\section{INTRODUCTION}

At present, design equations for tubular joints are primarily based on isolated joint data either obtained from experiments or numerical analyses. As joints are part of an overall structure, the load transfer through the joint may be different from that in isolated joints, depending on the boundary conditions employed. In the past, many questions existed regarding the effect of the chord length and boundary conditions on the strength of tubular joints. However, with the availability of numerical methods to generate reliable data, in the last two decades, multiple numerical studies were conducted to investigate the influence of boundary conditions and chord length on the strength of tubular joints.

Various researchers assessed the effects of boundary conditions on the strength of uniplanar $\mathrm{K}$-joints by comparing isolated joint versus frame behaviour. In general, the conclusion was that the influence of restraints could be significant (e.g. Connelly and Zettlemoyer [1], Bolt et al. [2], Choo et al. [3]).

For uniplanar T-joints, the evaluation of the chord length and boundary conditions is not as straightforward as for K- or X-joints due to the interaction between brace load and in-plane bending chord moments. In addition, for uniplanar T-joints, chord end plates are necessary to react the brace load, making a simple comparison between the behaviour of unrestrained and restrained chord ends impossible. Van der Vegte and Makino [4] excluded the effect of in-plane bending moments and chord length by applying compensating in-plane bending moments to the chord ends. By adopting 
this approach, the effect of the boundary conditions on the strength of uniplanar T-joints could be made clear.

In 1995, van der Vegte analysed the effect of the chord and can length on the strength of X-joints under axial brace load for a limited range of non-dimensional geometric parameters, using the FE package MARC [5]. Although the brace-to-chord diameter ratio $\beta\left(=\mathrm{d}_{1} / \mathrm{d}_{0}\right)$ covered a wide range of 0.25 - 1.0, the chord length parameter $\alpha\left(=21_{0} / \mathrm{d}_{0}\right)$ was varied between 3 and 18 for a single value of the chord thickness ratio $2 \gamma\left(\mathrm{d}_{0} / \mathrm{t}_{0}=25.4\right)$, whereby the chord ends of the joints were unrestrained. It was concluded that for the geometric parameters investigated, a value of $\alpha>12$ would have minor effect on the strength of the X-joints.

However, because recent research results briefly presented in section 3.2, revealed that the effect of the chord length and boundary conditions could be significantly more pronounced for $2 \gamma$ values greater than 25.4, further research was carried out, presented in this publication.

Numerical analyses are conducted on sixteen $\mathrm{X}$-joint configurations subjected to axial brace compression, considering four $\beta$ and four $2 \gamma$ ratios. Unlike T-joints where end plates are required at the chord ends to support the joint, for X-joints, the chord ends can be either free or restrained. Section 3.2 describes two alternatives for restraining the chord end and the effect each concept has on the ultimate capacity of the joint. The X-joints considered in the parametric study are analysed for both free and restrained (i.e. covered by rigid end plates) chord ends. Section 4 evaluates the effect of chord length and boundary conditions on the static strength of the CHS-to-CHS X-joints investigated.

More recently, Voth and Packer [6] conducted a parametric numerical investigation into the effect of chord length and boundary conditions of branch plate-to-CHS joints, similar to the present study on CHS-to-CHS X-joints. The joints analysed by Voth and Packer [6] covered transverse plates welded to both sides of the chord (i.e. X-type joints). Nine geometric configurations, consisting of three values of $\beta(0.2-1.0)$ and three values of $2 \gamma(19.7-45.8)$ were analysed for five values of the chord length parameter $\alpha(8-24)$. The end conditions of the chord were either free or fully restrained. All joints were subjected to branch plate tension load. In section 4, the findings of Voth and Packer [6] on branch-plate-to-CHS joints are compared with the observations made for CHS-to-CHS X-joints.

Based on the FE results, recommendations are made with respect to the chord length to be used in experimental programmes. Furthermore, selected results of the current study are compared with numerical data obtained from van der Vegte's previous study on X-joints [7]. Finally, a brief comparison is made with the chord length effect found for CHS T-joints by van der Vegte and Makino [4].

\section{RESEARCH PROGRAMME}

The configuration of uniplanar CHS X-joints and the definition of the geometric parameters are illustrated in Figure 1. Table 1 lists the geometric parameters and dimensions of the $\mathrm{X}$-joints investigated. The chord diameter $\mathrm{d}_{0}$ is $406.4 \mathrm{~mm}$ for all joints. Four values of $\beta(0.25-0.98)$ and four $2 \gamma$ ratios $(25.4-63.5)$ are considered. For the joints with $\beta=0.25$ and 0.48 , the brace-to-chord thickness ratio $\tau\left(=\mathrm{t}_{1} / \mathrm{t}_{0}\right)$ is taken as 0.5 , while for the joints with $\beta=0.73$ and $0.98, \tau$ is set to 1.0 . Each of the joints is analysed for the following five values of the chord length parameter $\alpha: 12,16$, 20, 24 and 28, for both free and restrained (i.e. covered by rigid end plates) chord ends. 
The steel type used for all members is $\mathrm{S} 355$ with a yield strength $\mathrm{f}_{\mathrm{y}}=355 \mathrm{~N} / \mathrm{mm}^{2}$ and an ultimate tensile strength $\mathrm{f}_{\mathrm{u}}=510 \mathrm{~N} / \mathrm{mm}^{2}$.

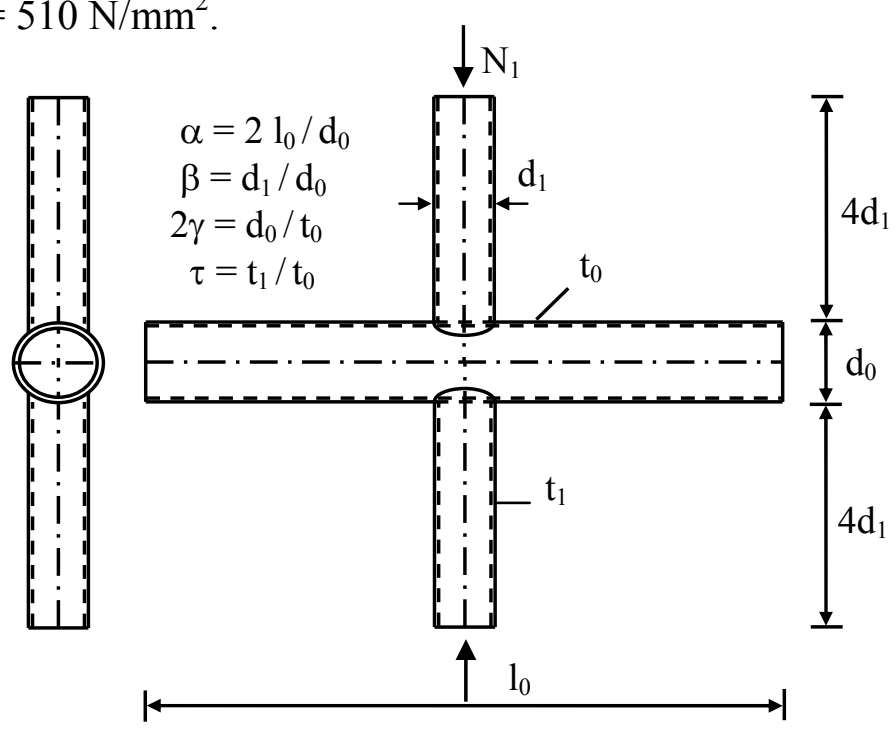

Figure 1. Configuration of a CHS X-Joint

Table 1. Geometric Parameters and Dimensions Investigated

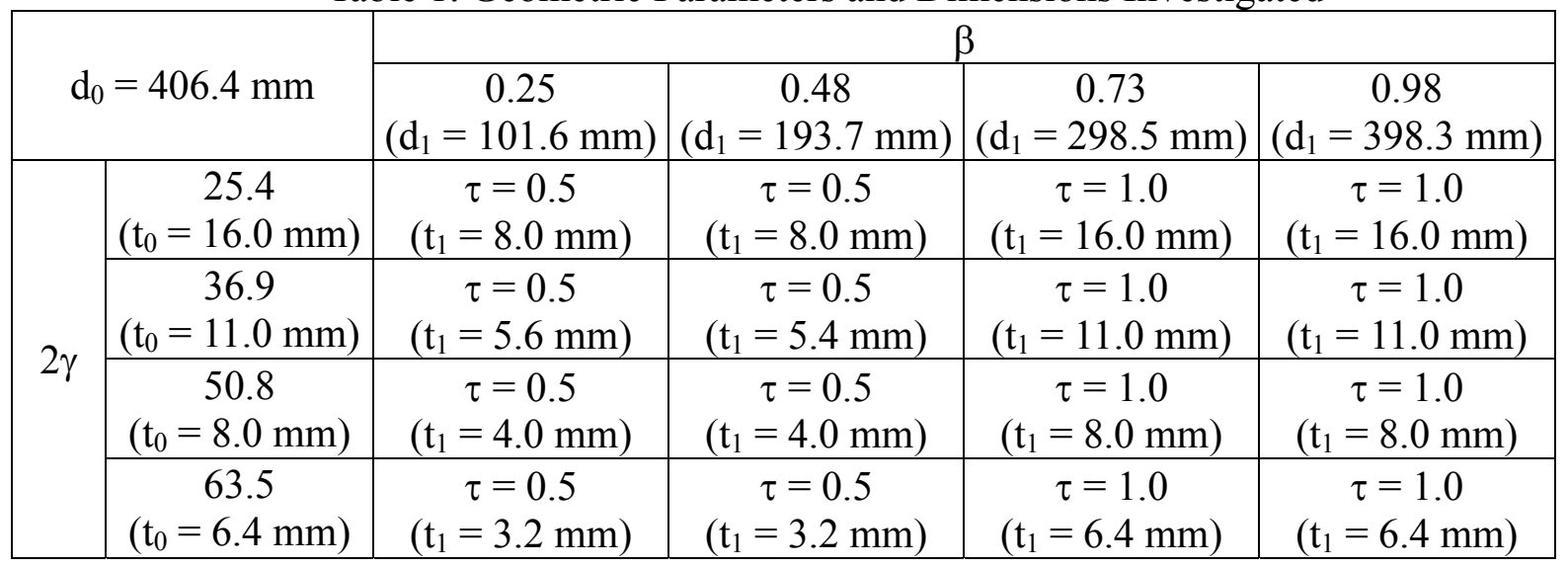

Notes:

- each X-joint is analysed for $\alpha=12\left(1_{0}=2438.4 \mathrm{~mm}\right), \alpha=16\left(1_{0}=3251.2 \mathrm{~mm}\right), \alpha=20\left(1_{0}=\right.$ $4064.0 \mathrm{~mm}), \alpha=24\left(1_{0}=4876.8 \mathrm{~mm}\right)$ and $\alpha=28\left(1_{0}=5689.6 \mathrm{~mm}\right)$

- each X-joint is analysed for both free as well as rigid chord ends

\section{NUMERICAL MODELLING}

\subsection{General}

The current numerical analyses are carried out with the FE package ABAQUS/Standard [9], while the numerical analyses in van der Vegte's research [7] used the FE programme MARC [5]. The FE models generated in both studies are similar and can be summarized as follows.

Due to symmetry in geometry and loading, only one eighth of each X-joint is modelled, whereby the appropriate boundary conditions are applied to the nodes in the various planes of symmetry. The joints are modelled with eight-noded (quadratic) thick shell elements employing reduced integration (ABAQUS element S8R). Seven integration points through the shell thickness are 
applied. Figure 2 illustrates the FE mesh generated for the joints with $\beta=0.48$.

For all joints except $\beta=0.98$, the geometry of the welds at the brace-chord intersection is modelled using shell elements. Experimental and numerical research on axially loaded uniplanar and multiplanar X-joints (van der Vegte et al. [8]) revealed that the use of shell elements to simulate the welds provides accurate predictions of the load-displacement response of the X-joints considered. The dimensions of the welds adopted in the numerical model are in accordance with the specifications recommended by the AWS [10].

Axial brace loads are applied using the displacement control method i.e. prescribing the vertical displacement of the nodes of the brace tip.

Since the incorporation of material- and geometric non-linearity in ABAQUS and MARC requires the use of true stress-true strain relationships, the engineering stress-strain curve is modelled as a multi-linear relationship and subsequently converted into a true stress-true strain relationship. The hardening rule proposed by Ramberg-Osgood is used to describe the true stress-true strain behaviour. Both the engineering stress-strain curve and the true stress-true strain relationship of S355 (the steel grade used in this study) are shown in Figure 3.

Van der Vegte et al. [8] concluded that if plastification of the chord cross section is the major failure mode, the FE models as described above may provide accurate simulations of the static behaviour of T- and X-joints under axial brace loading.

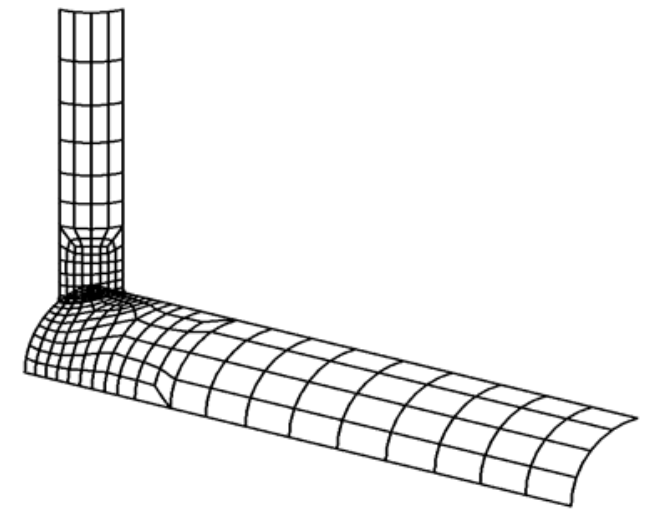

Figure 2. FE Mesh Generated for the X-Joints with $\alpha=16$ and $\beta=0.48$

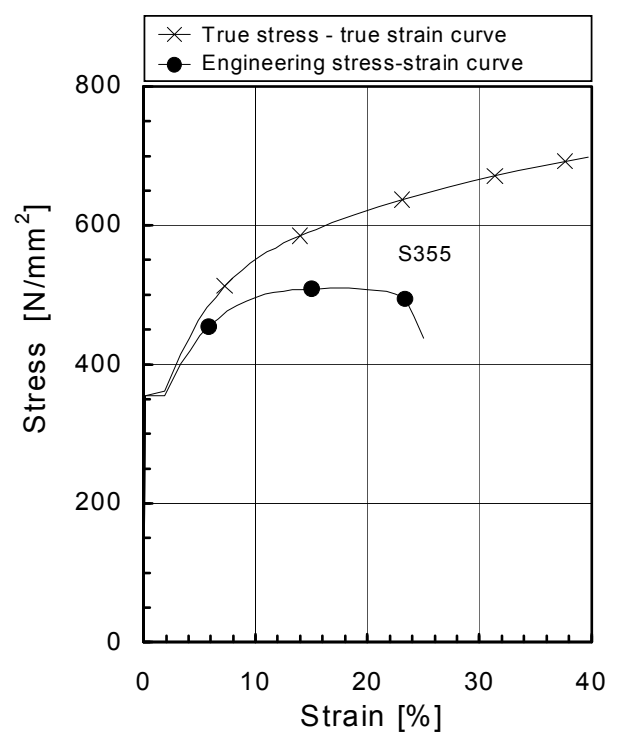

Figure 3. Engineering and True Stress - True Strain Curves for S355 


\subsection{Boundary Conditions}

Unlike uniplanar X-joints for which no chord end plates are required, for uniplanar T-joints, end plates are necessary to support the joint. In preliminary FE analyses conducted on uniplanar T-joints with the chord thickness ratio $2 \gamma$ varying from 14.5 to 50.8, the chord ends were covered by $40 \mathrm{~mm}$ thick steel plates, shown in Figure 4a. The material properties of the end plates were equal to those of the tubular members (S355). Although these end plates are very stiff in-plane, out-of-plane deformations are still possible.

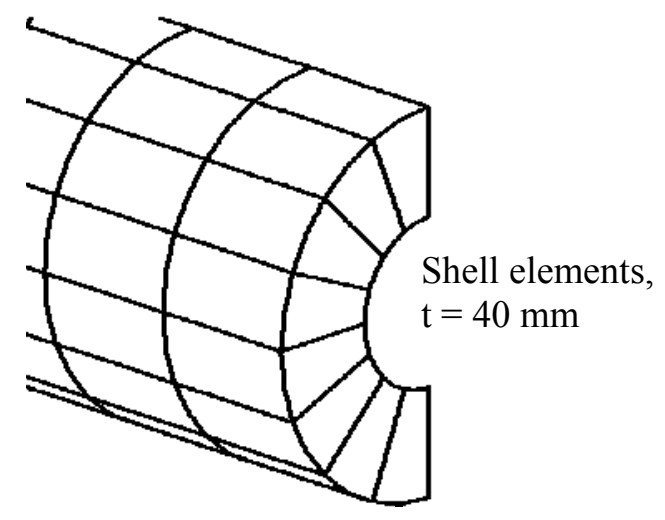

(a) Deformable End Plates

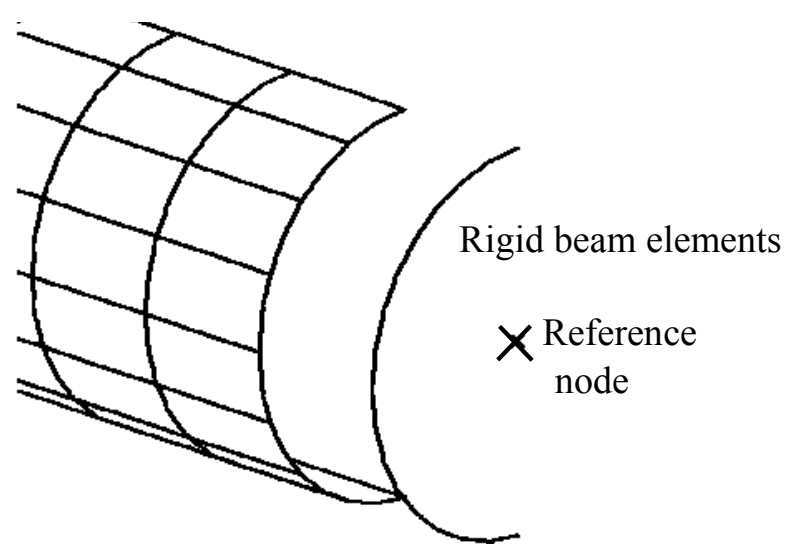

(b) Rigid Beams (Last Row of Chord Elements not Shown)

Figure 4. Chord End Restraints

An alternative method is shown in Figure $4 \mathrm{~b}$. Rigid beams are attached to the chord end, whereby boundary conditions are applied to the reference node, located in the centre of the chord cross section. Because of the rigid behaviour of the beams, the chord end cross section can not deform, but is able to translate and rotate.

From the preliminary analyses, it was found that for the thick walled joints with $2 \gamma=14.5$, the effect of the boundary conditions is almost negligible. However, for the thin walled T-joint with $2 \gamma$ $=50.8$ and $\alpha=12$, the rigid boundary conditions increase the ultimate capacity up to $10 \%$ compared to the strength of the T-joint with deformable end-plates. The lower capacity obtained for the T-joint with the $40 \mathrm{~mm}$ thick end plates is primarily caused by the ability of the end plate to deform out-of-plane. For T-joints with rigid chord ends, the out-of-plane deformations of the chord end plate are prevented, enhancing the ultimate strength. Additional FE analyses on the joint with deformable end plates revealed that a further increase of the thickness of the end plates ultimately gives the same capacity as the values found for the T-joints modelled with the rigid beams.

Because the effect of chord end conditions is more pronounced than anticipated, it was recommended to further evaluate the effect of the chord end conditions of axially loaded X-joins, either modelled with or without rigid beams at the chord end. 


\section{RESULTS AND OBSERVATIONS}

\subsection{Current Research}

For each X-joint under axial brace load listed in Table 1, a load-indentation curve is derived, where indentation is defined as the vertical displacement of the crown point. As an example, Figure 5 illustrates the load-indentation curves obtained for the X-joints with $\beta=0.73$ and $2 \gamma=63.5$ for both free and rigid chord ends. (Note that the symbols shown are only used to differentiate the various curves and do not refer to the failure loads.) The vertical axis displays the non-dimensional compression brace load $\mathrm{N}_{1} /\left(\mathrm{f}_{\mathrm{y} 0} \mathrm{t}_{0}{ }^{2}\right)$, where $\mathrm{f}_{\mathrm{y} 0}$ is the yield strength of the chord material and $\mathrm{t}_{0}$ is the chord wall thickness, while the horizontal axis plots the non-dimensional indentation $\delta / d_{0}$ of the crown point, where $\mathrm{d}_{0}$ is the chord diameter. Ultimate load is defined as the brace load corresponding to the peak in the load-indentation curve.

Examination of both the load-indentation curves and the deformed shapes obtained from the FE analyses made clear that severe deformation of the chord wall i.e. chord plastification of the chord cross section at the intersection between the braces and the chord is the governing failure mode for the X-joints investigated. For the joints with $\beta=0.25$, the deformations are located in the chord wall in the vicinity of the brace, while for the joints with $\beta=0.98$ pronounced deformations are observed in the chord wall between the two braces.

Figure 6 plots, for all X-joints listed in Table 1, the (non-dimensional) ultimate load $\mathrm{N}_{1, \mathrm{u}} /\left(\mathrm{f}_{\mathrm{y} 0} \mathrm{t}_{0}{ }^{2}\right)$ as a function of the chord length parameter $\alpha$ for both sets of boundary conditions. Open symbols in the diagrams refer to the unrestrained chord ends, whereas the filled symbols display the results of the $\mathrm{X}$-joints modelled with rigid beams at the chord end.
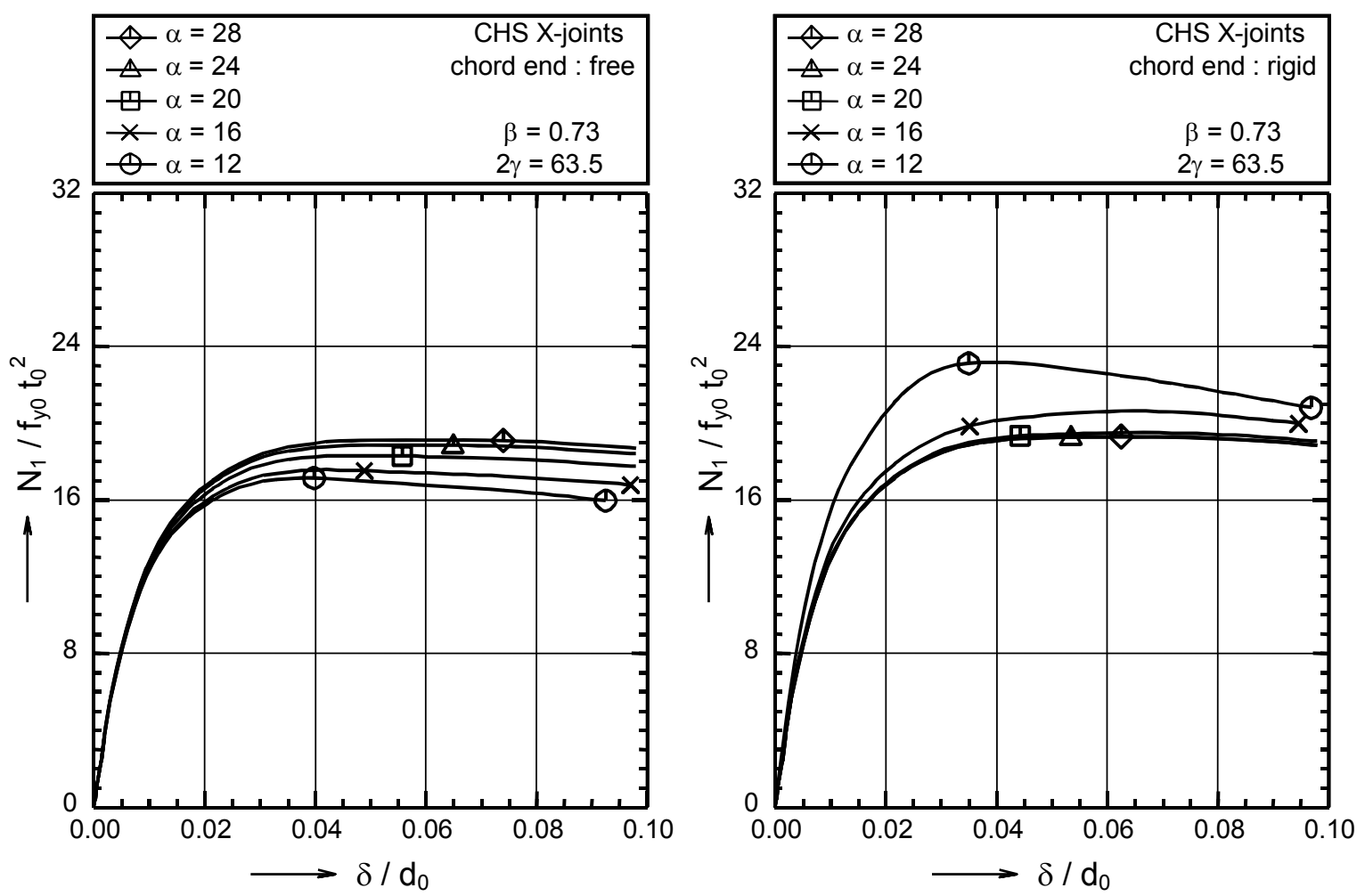

Figure 5. Load-Indentation Curves (in Non-Dimensional Form) for X-Joints with $\beta=0.73$ and $2 \gamma=63.5$ 

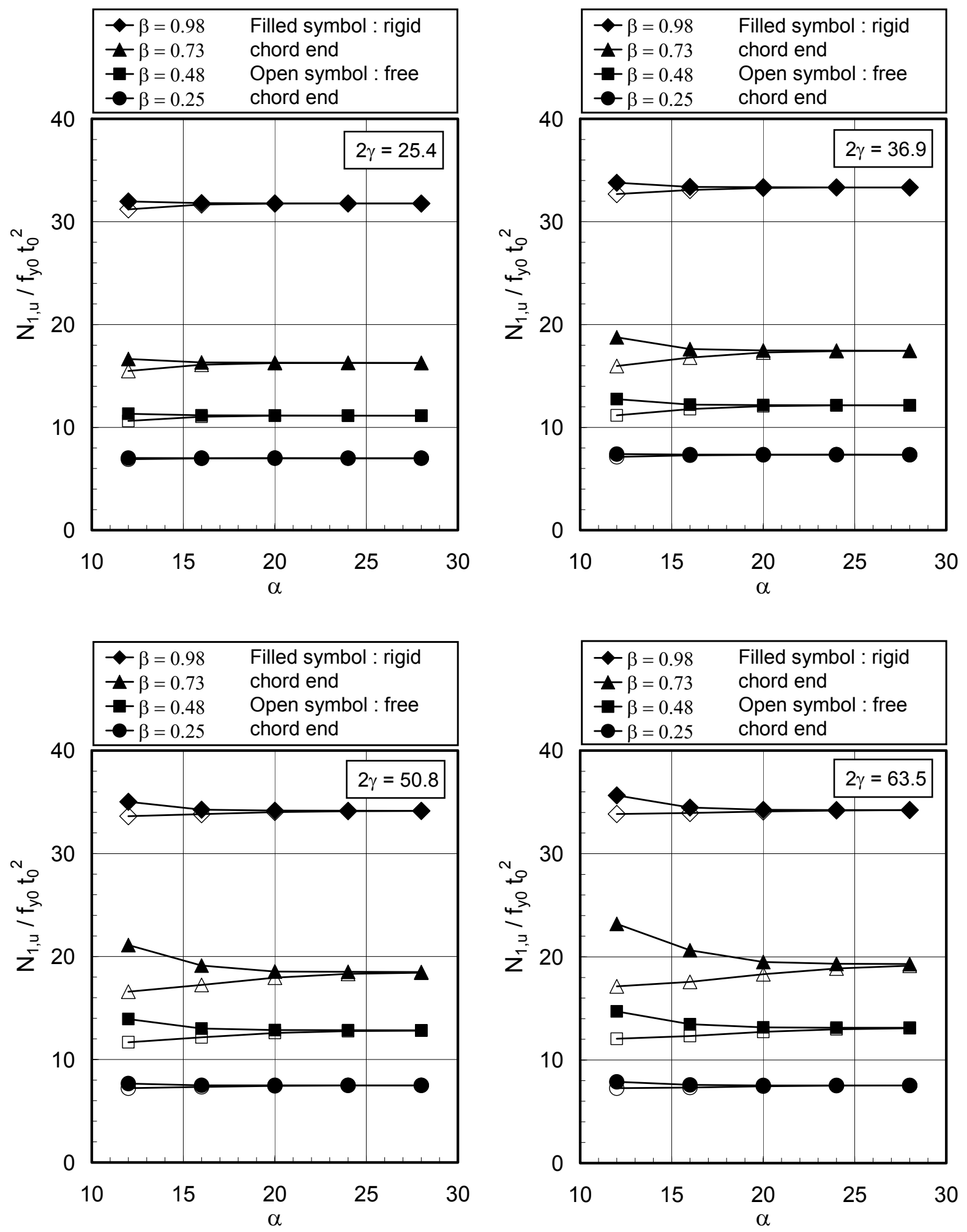

Figure 6. Non-Dimensional Ultimate Load $\mathrm{N}_{1, \mathrm{u}} /\left(\mathrm{f}_{\mathrm{y} 0} \mathrm{t}_{0}{ }^{2}\right)$ as a Function of $\alpha$ 
Figure 6 reveals that the chord length has a marginal or no effect on the ultimate strength for $\alpha$ values equal to or greater than 20 . For these $\alpha$ values, the chord is sufficiently long to exclude possible chord end effects. As a result, the ultimate strength found for X-joints with $\alpha \geq 20$ is independent of the boundary conditions i.e. the presence or absence of chord end plates. This observation corresponds well with the research conducted by Voth and Packer [6] on plate-to-CHS $\mathrm{X}$-joints under tension load.

For $\alpha$ values less than 20, the effect of $\alpha$ and boundary conditions directly depends on the values of $\beta$ and $2 \gamma$. For the four $2 \gamma$ values considered, the value of $\alpha$ hardly affects the strength of the $\mathrm{X}$-joints with $\beta=0.25$, even for the thin walled joints with $2 \gamma=63.5$. For $\beta=0.25$, the deformation of the chord wall is limited to the area of the brace-chord intersection, preventing pronounced chord ovalisation to occur.

For the range of $\alpha$ values investigated, the chord length is also observed to have little effect on the ultimate strength of the joints with $2 \gamma=25.4$, in line with the observations made by van der Vegte [7] and Voth and Packer [6]. Chord ovalisation of thick walled joints dampens out quickly along the chord length, reducing the chord length participating in the joint behaviour.

On the other hand, for X-joints with relatively short chords $(\alpha \leq 16)$ in combination with $\beta$ values exceeding 0.25 or $2 \gamma$ values greater than 25.4 , the influence of the chord length and boundary conditions becomes significant. Using the strength for $\alpha=20$ as reference strength, it is found that for X-joints with rigid chord ends, the strength enhances for chord lengths smaller than $10 \mathrm{~d}_{0}$, whereas for the joints with free chord ends, the ultimate strength reduces if the chord length becomes smaller than $10 \mathrm{~d}_{0}$. From Figure 6 , it becomes clear that this effect is most pronounced for the intermediate $\beta$ values $(0.48-0.73)$ in combination with the largest $2 \gamma$ values (i.e. thin walled joints).

The dependency of $\beta$ can be explained by considering the effective chord length for uniplanar $\mathrm{X}$-joints i.e. the section of the chord that is engaged in the load transfer from one brace to the opposing brace. For small $\beta$ values, the deformation of the chord wall caused by the brace load is very localized, preventing pronounced chord ovalisation to occur. For intermediate $\beta$ values, the chord section participating in the load transfer is considerably larger than for small $\beta$ values, but reduces again for large $\beta$ ratios. The influence of the chord length and boundary conditions on the joint strength follows the same pattern.

To explain the interaction between the chord length effect and the $2 \gamma$ ratio, chord ovalisation should be taken into account. For increasing $2 \gamma$ values, chord ovalisation dampens out slower along the chord length as compared to lower $2 \gamma$ values. In other words, for thin walled joints the disturbance of the indentation at the brace-chord intersection covers a larger section of the chord than that for thick walled joints. Hence, the influence of the chord length and boundary conditions is most pronounced for thin walled joints. Voth and Packer [6] came to a similar observation.

For the X-joints considered, the largest effect of chord length and boundary conditions is obtained for $\beta=0.73$ and $2 \gamma=63.5$. Using the strength of the X-joint with $\alpha=28$ as reference, a strength enhancement of $20.1 \%$ is found for the corresponding X-joint with rigid chord ends and $\alpha=12$, whereas a strength reduction of $10.5 \%$ is obtained for the same joint with free chord ends. 


\subsection{Comparison with Previous Data on X-Joints (van der Vegte [7])}

Figure 7 shows the comparison between selected FE data (with $2 \gamma=25.4$ ) obtained in the current study and the results for $2 \gamma=25.4$ derived from a similar study by van der Vegte [7]. Both sets of data cover analyses on axially loaded X-joints without chord end plates. It is observed that for the joints with $0.25 \leq \beta \leq 0.73$, van der Vegte's FE data [7] for $11.5 \leq \gamma \leq 18$ match well with the current research results for $12 \leq \alpha \leq 20$ i.e. the chord length has little effect on the ultimate strength of these relatively thick walled joints. Van der Vegte's data [7] further show that for $2 \gamma=25.4$, a steep drop of the joint strength is only found for small $\alpha$ values $(\alpha<8)$.

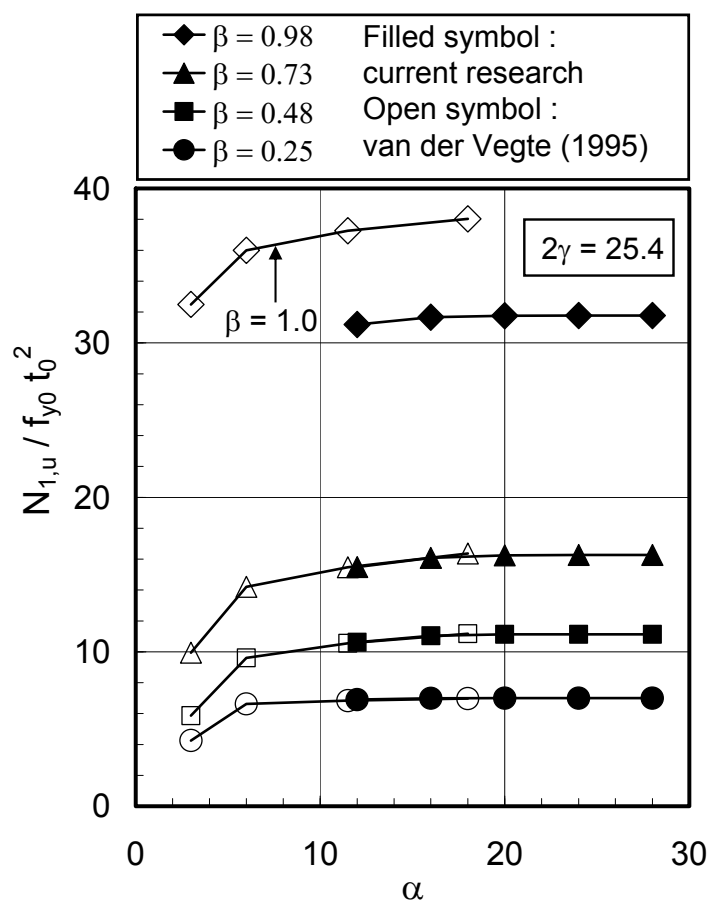

Figure 7. Current Research Results and van der Vegte's Data [7] for X-Joints $(2 \gamma=25.4)$

It should be pointed out that the strength of $X$-joints under axial brace load is rather sensitive with respect to $\beta$ for joints with large $\beta$ ratios $(\beta>0.95)$. As shown in Figure 7 , a slight decrease of $\beta$ (from $\beta=1.0$ to 0.98 ) causes a significant reduction of the ultimate strength. In addition, the deformation capacity of X-joints with $\beta=1.0$ is extremely small. Hence, research on X-joints with $\beta=1.0$ was replaced by numerical analyses in the current study on joints with a slightly lower $\beta$ value $(\beta=0.98)$. Nevertheless, Figure 7 shows that for both $\beta=0.98$ and 1.0 , the influence of the chord length parameter $\alpha$ is well in line with the trend found for the other $\beta$ values.

\subsection{Comparison with Research on T-Joints}

In the numerical research carried out by van der Vegte and Makino [4] on uniplanar T-joints under axial brace, the same matrix of geometric parameters $\alpha, \beta$ and $2 \gamma$ as shown in Table 1 was analysed. Because of the necessity for uniplanar T-joints to model chord end plates to react the brace load, a straightforward comparison between the ultimate strength of T-joints modelled with or without chord end plates is impossible. In addition, for T-joints, axial brace load unavoidably leads to chord in-plane bending moments affecting the joint strength. However, the approach of applying compensating moments to the chord end provides ultimate strength values independent of in-plane bending chord moments. 
Figure 8 plots the strength of selected T-joints with compensating chord end moments $(2 \gamma=25.4$ and 63.5) as a function of $\alpha$. A comparison between the results shown in Figure 8 and data for corresponding $\mathrm{X}$-joints with rigid chord ends reveals that the observations regarding the effect of chord length and boundary conditions are similar for both types of joints: (i) the chord length has little effect on the ultimate strength of the joints with $2 \gamma=25.4$ or $\beta=0.25$ and (ii) for joints with rather short chords $(\alpha \leq 16)$ in combination with $\beta$ values exceeding 0.25 or $2 \gamma$ values greater than 25.4 , a strength enhancement is observed for decreasing values of the chord length.
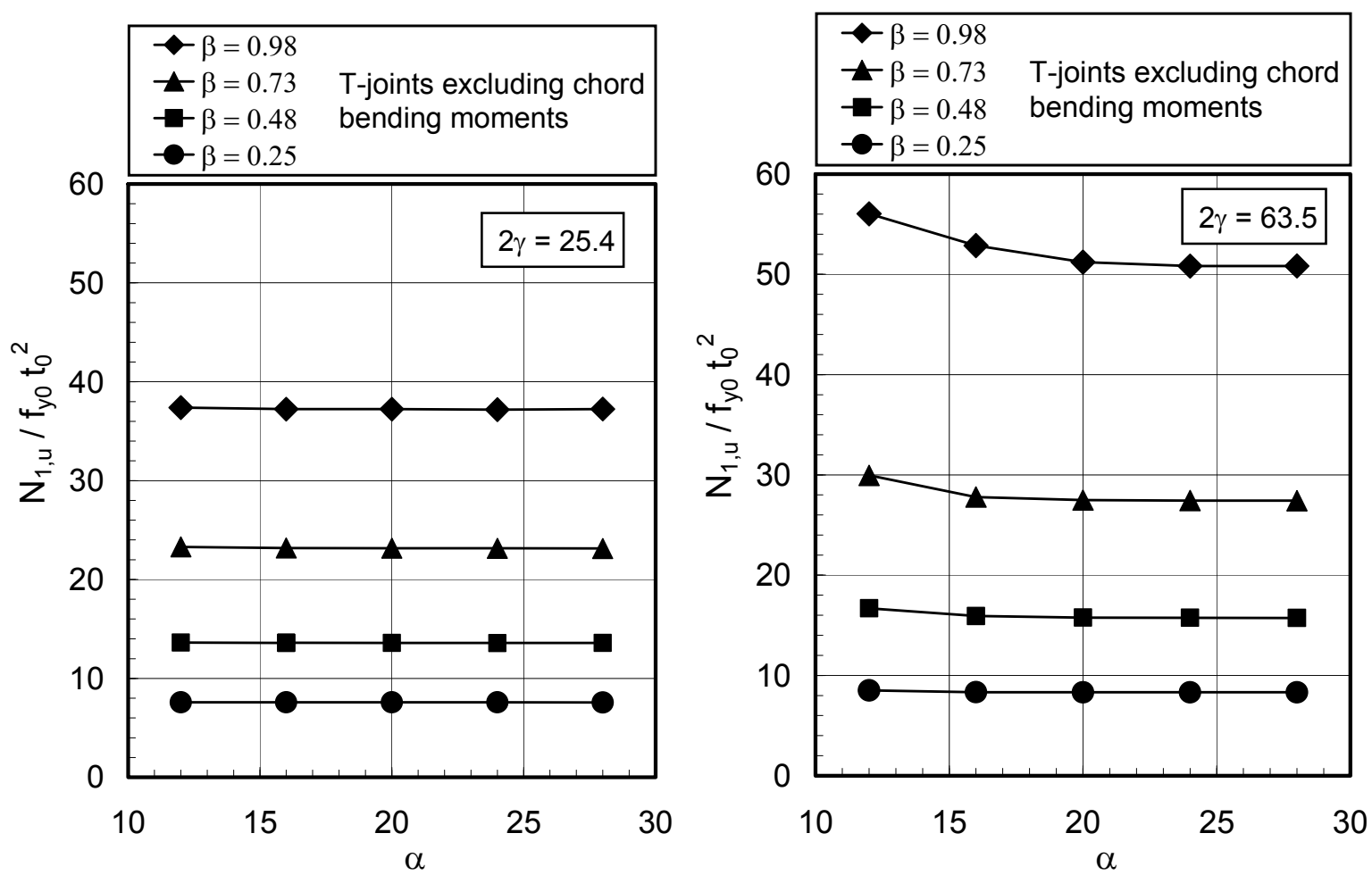

Figure 8. Van der Vegte and Makino's Data [4] for CHS T-Joints

\subsection{Experimental Results}

It should be noted that in various test series carried out in the past, no information is presented regarding the chord length or boundary conditions. However, even for the references that provide these details, $\alpha$ values equal to 12 or even less are not uncommon. As indicated by the presented research, these test results could be significantly affected by the chord length or boundary conditions.

The experiments conducted by Scola et al. [11] on CHS T-joints under axial brace load may serve as an example of (short) chord lengths that were applied in tests. After comparing Scola's results with experimental evidence and numerical data of various researchers, it was observed that Scola's test results are considerably higher for all $\beta$ values considered (van der Vegte et al. [12]). Since the test specimens are reported to have a chord length parameter $\alpha=4.8$, this discrepancy is likely caused by the short chords used in Scola's tests. A chord length parameter of $\alpha=4.8$ in combination with $2 \gamma$ values ranging from 26.8 to 44.5 is too short to exclude the effect of the chord end plates on the strength of axially loaded T-joints. 
A similar conclusion can be drawn from the work of Voth and Packer [6]) on X-type branch plate-to-CHS joints. Very short chord lengths of $2 \mathrm{~d}_{0}$ (for $2 \gamma=45.8$ and $\beta=0.6$ ) were investigated to compare with the results of experiments that closely matched this geometry and length. From the numerical analysis, it became clear that the semi-rigid boundary conditions applied in the experiments likely increased the ultimate connection capacity by a considerable margin.

\section{SUMMARY AND CONCLUSIONS}

Numerical analyses are conducted on uniplanar CHS X-joints subjected to axial brace load for a wide range of the geometric parameters $\alpha, \beta$ and $2 \gamma$. In addition, the effect of the presence or absence of rigid end plates attached to the chord end is evaluated. Based on the presented research, the following conclusions can be drawn :

- Depending on the geometric parameters $\beta$ and $2 \gamma$, both the chord length and the chord end conditions may have a significant influence on the ultimate capacity of X-joints. To exclude possible effects of the chord length and chord end conditions, a chord length of at least $10 \mathrm{~d}_{0}(\alpha \geq$ $20)$ is recommended, while for $X$-joints with $2 \gamma \leq 25$, a chord length of at least $6 \mathrm{~d}_{0}(\alpha \geq 12)$ is sufficient to exclude the influence of the chord length on the ultimate strength.

- Although the effect of boundary conditions on the ultimate strength is more "hidden" for T-joints as compared to X-joints, the influence of the chord end restraints on T-joints is similar as the behaviour found for $\mathrm{X}$-joints with rigid chord ends.

- In case of relatively short, thin walled chords ( $\alpha=12$ and $2 \gamma \geq 50)$ covered by end plates, the end plates should be designed with sufficient thickness in order to prevent the plates from having effect on the ultimate capacity of the joints.

- Before adopting the results of tests carried out in the past, careful screening should be conducted as the results may be affected by the chord length or chord end conditions.

- The above mentioned conclusions match well with the results of FE research on X-type transverse plate-to-CHS joints under tensile loading conducted by Voth and Packer [6].

\section{REFERENCES}

[1] Connelly, L.M. and Zettlemoyer, N., "Frame Behaviour Effects on Tubular Joint Capacity", Proceedings $3^{\text {rd }}$ International Symposium on Tubular Structures, Lappeenranta, Finland, 1989, pp. 81-89.

[2] Bolt, H.M., Seyed-Kebari, H. and Ward, J.K., "The Influence of Chord Length and Boundary Conditions on K-Joint Capacity", Proceedings $2^{\text {nd }}$ International Offshore and Polar Engineering Conference, San Francisco, USA, 1992, Vol. IV, pp. 347-354.

[3] Choo, Y.S., Qian, X.D. and Wardenier, J., "Effects of Boundary Conditions and Chord Stresses on Static Strength of Thick-Walled CHS K-Joints", Journal of Constructional Steel Research, 2006, Vol. 62, No. 4, pp. 316-328.

[4] Vegte, G.J. van der and Makino, Y., "Ultimate Strength Formulation for Axially Loaded CHS Uniplanar T-Joints", International Journal of Offshore and Polar Engineering, ISOPE, 2006, Vol. 16, No. 4, pp. 305-312.

[5] MARC Analysis Research Corporation, Revision K4, Palo Alto, USA, 1990. 
[6] Voth, A.P. and Packer, J.A., "Branch Plate Connections to Round Hollow Sections", CIDECT Report 5BS-5/08, 2008.

[7] Vegte, G.J. van der, "The Static Strength of Uniplanar and Multiplanar Tubular T- and X-Joints", Doctoral Dissertation, Delft University of Technology, the Netherlands, ISBN 90-407-1081-3, Delft University Press, the Netherlands, 1995.

[8] Vegte, G.J. van der, Koning, C.H.M de, Puthli, R.S. and Wardenier, J., "Numerical Simulation of Experiments on Multiplanar Tubular Steel X-Joints", International Journal of Offshore and Polar Engineering, ISOPE, 1991, Vol. 1, No. 3, pp. 200-207.

[9] ABAQUS/Standard, Version 6.3, Hibbitt, Karlsson and Sorensen, Inc, USA, 2003.

[10] American Welding Society, Structural Welding Code, AWS D1.1-92, 1992.

[11] Scola, S., Redwood, R.G. and Mitri, H.S., "Behaviour of Axially Loaded Tubular V-Joints", Journal of Constructional Steel Research, 1990, Vol. 16, No. 2, pp. 89-109.

[12] Vegte, G.J. van der, Wardenier, J., Zhao, X.-L. and Packer, J.A., "Evaluation of New CHS Strength Formulae to Design Strengths", Proceedings of the $12^{\text {th }}$ International Symposium on Tubular Structures, Shanghai, China, 2008, pp. 313-322. 


\title{
EXPERIMENTAL TEST SIMULATING A COLUMN LOSS IN A COMPOSITE FRAME
}

\author{
Jean-François Demonceau ${ }^{*}$ and Jean-Pierre Jaspart \\ University of Liège, Argenco Department, Chemin de Chevreuils, 1 B52/3 4000 Liège, Belgium \\ *(Corresponding author: E-mail: jfdemonceau@ulg.ac.be)
}

Received: 31 January 2010; Revised: 1 February 2010; Accepted: 4 February 2010

\begin{abstract}
Recent events such as natural catastrophes or terrorism attacks have highlighted the necessity to ensure the structural integrity of buildings under exceptional events. According to Eurocodes and some different other national design codes, the structural integrity of civil engineering structures should be ensured through appropriate measures. Design requirements are proposed in some codes but are nowadays seen generally as not satisfactory. In particular, it is not demonstrated that, even if these requirements are respected, the risk of a progressive collapse of the structure subjected to an exceptional event will really be mitigated.

A European RFCS project entitled "Robust structures by joint ductility" has been set up in 2004, for three years, with the aim to provide requirements and practical guidelines allowing to ensure the structural integrity of steel and composite structures under exceptional events through an appropriate robustness. In particular, one substructure test simulating the loss of a column in a composite building was performed at Liège University. The present paper describes in details this substructure test. In particular, the development of membrane forces is illustrated and their effects on the behaviour of the beam-to-column joints are discussed.
\end{abstract}

Keywords: Column loss, experimental test, composite structure, membrane forces, robustness

\section{INTRODUCTION}

Recent events such as natural catastrophes (tsunami, hurricane, ...) or terrorism attacks have highlighted the necessity to ensure the structural integrity of buildings under exceptional events, with the objective to save the life of the occupants and of the safety services (fireman, ambulance man, ...) but also to avoid collateral damages to the adjacent buildings.

The partial collapse of the Ronan Point Tower in 1968 in UK is considered as the starting point of the researches on the structural integrity of buildings; but more recent catastrophes in the last decade such as the terrorist attack of the World Trade Center towers in 2001 or the tsunami associated to the Sumatra earthquake in 2004 have further increased the interest of the engineering community and of the population in this topic.

According to Eurocodes and some different other national design codes, the structural integrity of civil engineering structures should be ensured through appropriate measures. Design requirements are proposed in some codes but are generally not satisfactory. In particular, it is not demonstrated that, even if these requirements are respected, a structure subjected to an exceptional event will really behave properly.

In this context, a European RFCS project called "Robust structures by joint ductility" (Kuhlmann et al [1]) has been set up in 2004, for three years, with the aim to provide requirements and practical guidelines allowing to ensure the structural integrity of steel and composite structures under exceptional events through an appropriate robustness. 
The investigations performed at Liège University, as part of this European project, were mainly dedicated to the exceptional event "loss of a column in a steel or steel-concrete 2D composite building frame"; the main objective was to develop a simplified analytical procedure to predict the frame response further to a column loss.

To achieve this goal, a global strategy has been developed at Liège University; this one is described briefly here below.

When a structure is losing a column, for instance further to an impact, it may be divided in two main parts, as illustrated in Figure 1:

- the directly affected part which is the one directly affected by the loss of the column, i.e. the beams, the columns and the beam-to-column joints which are just above the impacted column and;

- the indirectly affected part which, on one side, is affected by forces transferred from the directly affected part and which, on the other side, influences the response of the directly affected part.

At the top of the column, before it is fully removed (see Figure 1), the following internal forces are identified in the vertical direction:

- $\quad$ the shear forces $\mathrm{V}_{1}$ and $\mathrm{V}_{2}$ at the beam extremities;

- $\quad$ the axial force $\mathrm{N}_{\mathrm{up}}$ in the column just above the impacted one and;

- the axial force $\mathrm{N}_{\mathrm{lo}}$ in the impacted column.

The objective of the studies performed at Liège University was to predict the evolution of $\mathrm{N}_{\mathrm{lo}}$ versus the vertical displacement of point " $\mathrm{A}$ " $\Delta_{\mathrm{A}}$, with due account of the possible membrane forces developing in the structure; from this knowledge, the ductility required from the structural members and joints and the resistance of the indirectly affected part overloaded by forces transferred by the directly affected part may be derived in a second step.

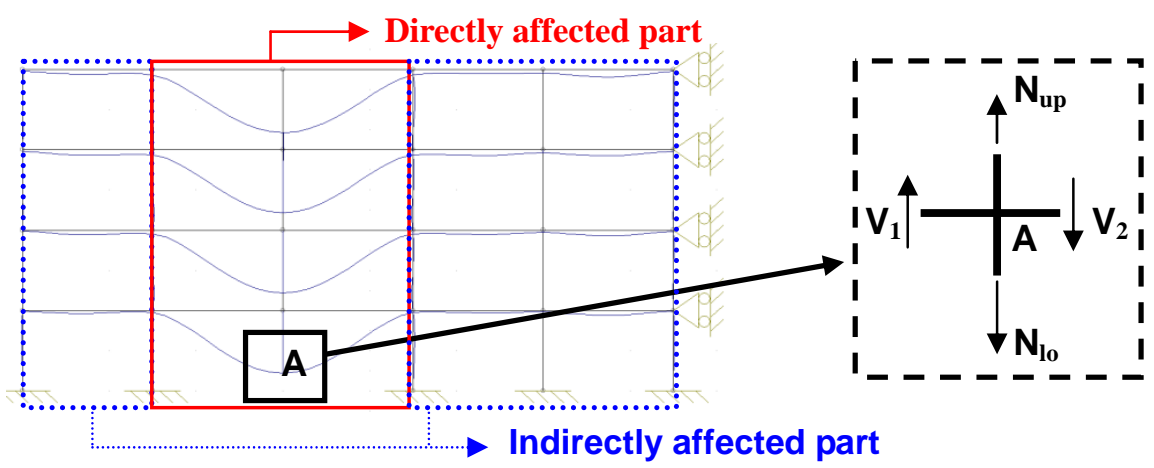

Figure 1. Representation of a Frame Losing a Column and Main Definitions

In Figure 2, the curve illustrating the evolution of the normal load $N_{l o}$ in the loss column (see Figure 1) versus the vertical displacement $\Delta_{a}$ is illustrated:

- From point (1) to (2) (Phase 1), the design loads are progressively applied to the non-damaged structure ("conventional" loading); so, $N_{l o}$ decreases (negative sign for compression) while $\Delta_{A}$ can be assumed to be equal to 0 during this phase (in reality, there is a small vertical displacement at point A associated to the shortening of the columns below point " $\mathrm{A}$ "). It is assumed that no yielding during this phase, i.e. the frame remains fully elastic.

- From point (2) to (5), the column is progressively removed. From point (2), $N_{\text {lo }}$ increases until it reaches a value equal to 0 at point (5) where the column can be considered as fully destroyed. 
So, in this zone, the absolute value of $N_{l o}$ is progressively decreasing while the value of $\Delta_{A}$ is increasing. This part of the graph is divided in two phases as shown in Figure 2:

- From point (2) to (4) (Phase 2): during this phase, a plastic mechanism progressively forms in the directly affected part. Point (3) corresponds to the development of a first plastic hinge.

- Point (4) to (5) (Phase 3): here, large displacements are observed and second order geometrical effects play an important role. In particular, significant membrane forces are developing in the bottom beams of the directly affected part.

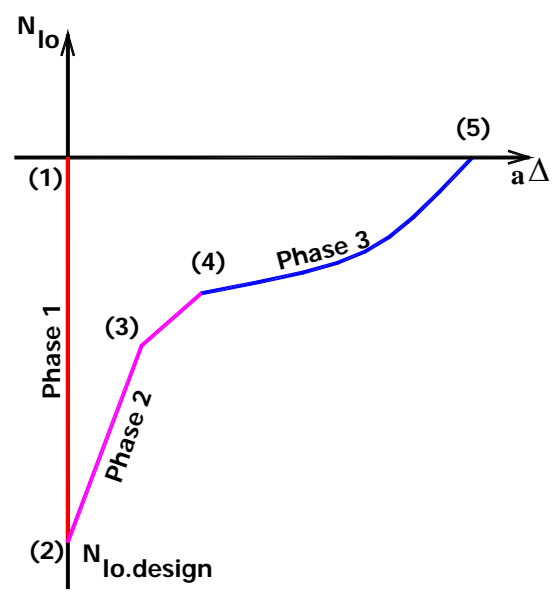

Figure 2. Evolution of $N_{l o}$ Versus the Vertical Displacement at the Top of the Impacted Column

It is only possible to pass from point (1) to (5) if:

- the forces which are transferred from the directly affected part to the indirectly affected part do not induce, in the latter, the failure of structural elements (for instance, buckling of the columns or formation of a plastic mechanism in the indirectly affected part);

- if the different structural members and joints have a sufficient ductility to reach the vertical displacements corresponding to point (5).

Obviously, the complete removal of the column could be reached (i.e. $N_{l o}=0$ ), in some cases, before reaching Phase 3.

To investigate the behaviour of the structure during Phase 3, i.e. when significant membrane forces develop, the following approach has been defined (Demonceau [2]):

- Step 1: an experimental test has been carried out on a substructure with the aim to simulate the loss of a column in a composite building frame.

- Step 2: analytical and numerical FEM tools have been validated through comparisons with the experimental results

- Step 3: parametric studies based on the use of the models validated at step 2 have been carried out; the objective was to identify the parameters influencing the frame response during Phase 3.

- Step 4: a simplified analytical method has been developed with due account of the parameters identified at step 3 and validated through comparisons with the experimental test results of step 1.

For sake of simplicity, all the conducted investigations are based on the assumption that no significant dynamic effects are associated to the exceptional event. So, only the static response of the system is investigated here even if extra developments on dynamic effects have been initiated in the meantime at Liège University. 
The present paper only focused on the experimental test performed at Liège University as part of the "Robustness" project (Kuhlmann et al [1]), i.e. on Step 1. Details about the other steps are available in (Demonceau [2]) which is freely downloadable at http://orbi.ulg.ac.be/handle/2268/2740.

The main objective of the test was to observe the development of membrane forces within a frame and the effect of these actions on the response of semi-rigid and partial-strength composite beam-to-column joints. Indeed these joints are initially designed for bending and shear forces, but have progressively to resist to tensile forces as a result of the development of membrane tying forces in the beams.

To define the substructure to be tested, an "actual" composite building has been first designed according to Eurocode 4 (EN 1994-1-1 [3]), under "conventional” loading conditions (i.e. loads recommended in Eurocode 1 (EN 1991-1-1 [4]) for office buildings); the aim was to obtain realistic structural dimensions and member profiles. The designed building is presented in $\S 2$.

As it was not possible to test a full 2-D actual composite frame within the "Robustness" project, a substructure described in $\S 3$ has been then extracted from the above EC4 designed building; the extracted substructure has been defined so as to respect the dimensions of the testing slab but also to exhibit a similar behaviour as the one which would have been observed in the actual frame.

Finally, the realisation of the test as well as the test results are described in $\S 4$.

\section{DESIGN OF AN “ACTUAL” COMPOSITE BUILDING}

As said in the previous section, an "actual" composite building subjected to "conventional" loading is first designed according to Eurocode 4 (EN 1994-1-1 [3]). The general layout of the building and one of its main frames are presented in Figure 3.
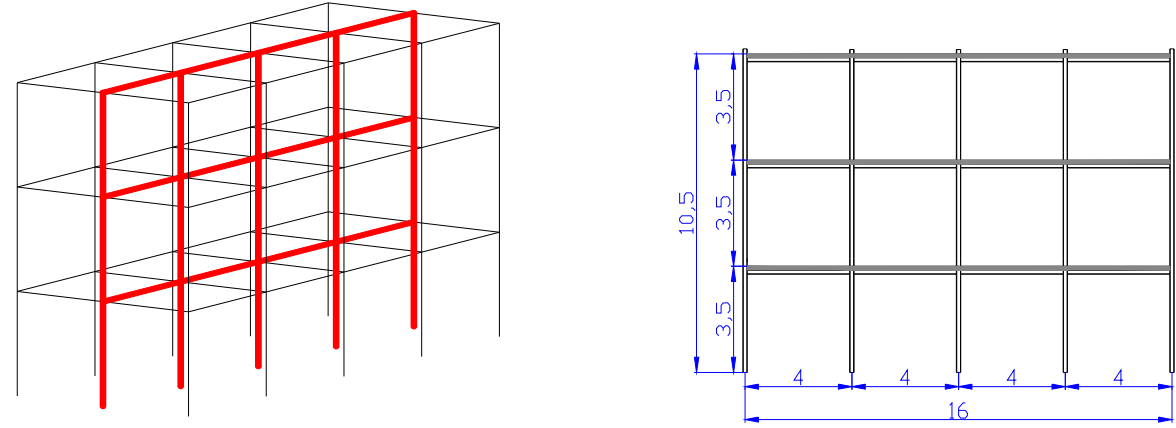

Figure 3. 3D View of the Designed Building and Details of One of the Main Frames

The building is composed of three main frames, $3 \mathrm{~m}$ spaced. The main frames are four bays - three storeys ones with a total width of $16 \mathrm{~m}$ (bay span $=4 \mathrm{~m}$ ) and a total height of 10,5 $\mathrm{m}$ (storey height $=3,5 \mathrm{~m}$ ). The loads which have been considered for the design of the structural elements are the following: the self-weight, a permanent load of $2 \mathrm{kN} / \mathrm{m}^{2}$ and an imposed load of $3 \mathrm{kN} / \mathrm{m}^{2}$ (load recommended for office building in Eurocode 1 (EN 1991-1-1 [4]).

The main frames are assumed to be braced/non-sway and the column bases to be perfect hinges. In a first approach, the external joints are assumed to be fully pinned and the internal ones to be fully rigid; the validity of these assumptions will be checked later on in $\S 2.2$ dealing with the design of joints. The static scheme of the main frame is shown in Figure 4. 


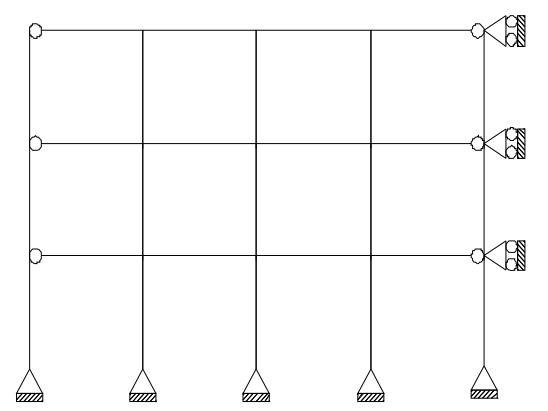

Figure 4. Static Scheme for the Main Frame

\subsection{Design of the Structural Members}

The design of the selected main frame is detailed in (Demonceau [2]); the following structural members result from the design:

- The slab is a reinforced concrete one with a thickness of $120 \mathrm{~mm}$ and made of a C25/30 concrete $\left(f_{c k}=25 \mathrm{~N} / \mathrm{mm}^{2}\right)$. The reinforcement is composed of two meshes: one at the top with $200 \mathrm{~mm}$ spaced $10 \mathrm{~mm}$ rebars and one at the bottom with $150 \mathrm{~mm}$ spaced $10 \mathrm{~mm}$ rebars. The steel grade for these rebars is S500C (high ductility rebars with $f_{s k}=450 \mathrm{~N} / \mathrm{mm}^{2}$ ) and the cover is equal to 25 $\mathrm{mm}$. The cross-section of the slab is presented in Figure 5.

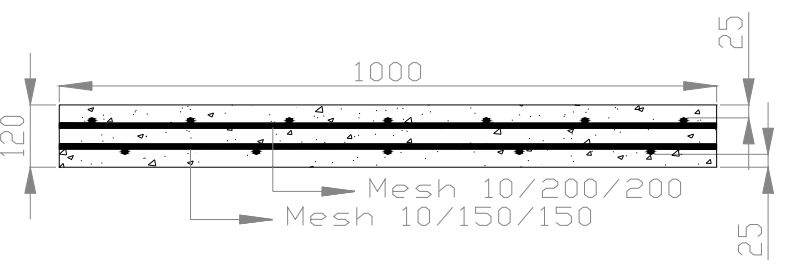

Figure 5. Slab Cross Section

- The beams are composite ones (upper flange of the profile connected to the concrete slab). The steel part of the beam is an IPE140 profile with a S355 steel grade (fyk $=355 \mathrm{~N} / \mathrm{mm}^{2}$ ); the beam composite cross-section is shown in Figure 6. A full shear connection is achieved between the profile and the concrete slab; the number of studs (Nelson studs with a diameter equal to $16 \mathrm{~mm}$ and a height of $75 \mathrm{~mm}-\mathrm{fu}=450 \mathrm{~N} / \mathrm{mm}^{2}$ ) required to ensure this full connection is indicated in Figure 7.

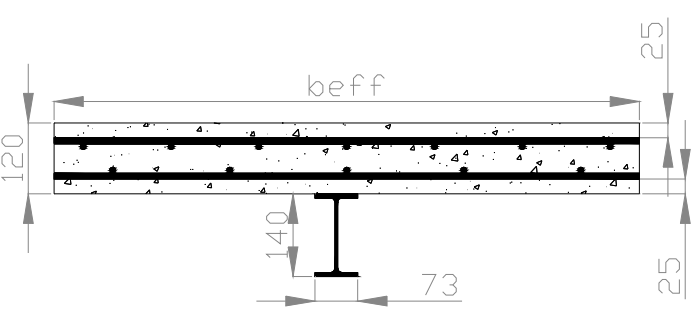

Figure 6. Composite Beam Cross-Section

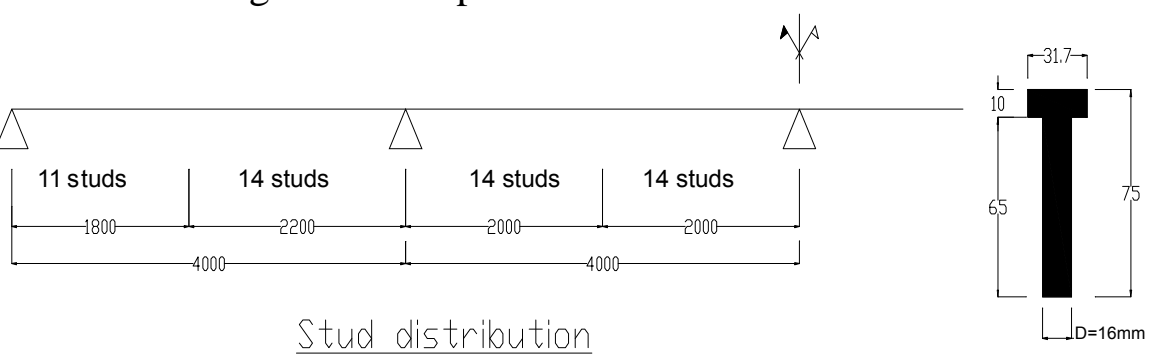

Figure 7. Distribution of the Studs along the Composite Beam Length 
- $\quad$ The columns are steel ones. The profile is an HEA160 with a S355 steel grade.

\subsection{Design of the Structural Joints Subjected to Hogging Bending Moments}

\subsubsection{Design of the external steel joints}

For these joints, it is assumed that the concrete slab is not extended beyond the front face of the external columns (Figure 8); so, they will be considered as steel ones.
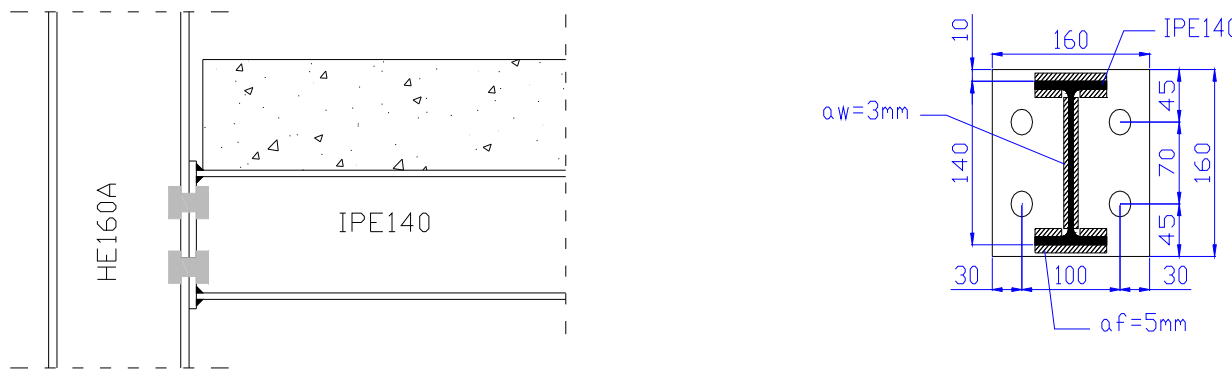

Figure 8. External Steel Joint Configuration and Geometrical Properties of the End-Plate

The joint properties have been chosen so as to ensure a ductile behaviour of the joint at failure and that, with due account of possible overstrength effects. To achieve this goal, only ductile components are activated at failure. The selected connection is a flush-end plate bolted one. Figure 8 gives the geometrical properties of the end-plate.

The bolts are M20 8.8 ones. The end-plate thickness is equal to $8 \mathrm{~mm}$. The steel grade for all the steel components of the joint is S355; a possible overstrength of $35 \%$ (value proposed in Eurocode 8 for seismic design (EN 1998-1-1 [5])) may be expected.

As far as loading is concerned, different situations have been considered in the joint design so as to be sure that, even if overstrength occurs in some components, the joint still fail through a ductile mode. The resulting joint mechanical properties for these different situations are summarised in Table 1; they have been computed by means of the software CoP (www.connectionprogram.com) which is in full agreement with the Eurocode recommendations.

The initial stiffness of the external joints is equal to $970 \mathrm{kNm} / \mathrm{rad}$; the latter is higher than $0,5 E I_{b} / L$ $=890 \mathrm{kNm} / \mathrm{rad}\left(E I_{b}\right.$ is conservatively taken as the uncracked flexural stiffness of the composite cross-section of the beam and $L$ is the span of the beam), which is the upper limit under which a joint can be assumed as pinned. So, strictly speaking, the assumption of pinned external joints in the actual composite building design is not validated. Accordingly, a computation of the internal frame modelled with the predicted properties of the joints has been performed and the internal forces have been compared to the resistance of the joint; the obtained results are presented later on in $\S 2.3$. 
Table 1. Properties of the External Steel Joints with Account of Possible Overstrength Effects

\begin{tabular}{|c|c|c|c|c|c|c|}
\hline & Overstrength & $\begin{array}{c}M_{R d} \\
{[\mathrm{kNm}]}\end{array}$ & $\begin{array}{c}M_{e} \\
{[\mathrm{kNm}]}\end{array}$ & Failure mode & $\begin{array}{c}V_{R d} \\
{[\mathrm{kN}]}\end{array}$ & $\begin{array}{c}S_{j, \text { ini }} \\
{[\mathrm{kNm} / \mathrm{rad}]}\end{array}$ \\
\hline $\begin{array}{l}\text { Initial } \\
\text { situation }\end{array}$ & $\begin{array}{c}\text { No } \\
\text { overstrength }\end{array}$ & 15,1 & 10,1 & $\begin{array}{l}\text { End-plate in } \\
\text { bending }\end{array}$ & 134,4 & 970 \\
\hline $2^{\circ}$ situation & End-plate & 16,6 & 11,1 & $\begin{array}{l}\text { Column flange in } \\
\text { bending }\end{array}$ & 134,4 & 970 \\
\hline $3^{\circ}$ situation & $\begin{array}{l}\text { End-plate + } \\
\text { column }\end{array}$ & 19,9 & 13,3 & $\begin{array}{l}\text { Beam flange in } \\
\text { compression }\end{array}$ & 134,4 & 970 \\
\hline $4^{\circ}$ situation & $\begin{array}{c}\text { End-plate }+ \\
\text { column }+ \\
\text { beam }\end{array}$ & 20,5 & 13,7 & $\begin{array}{l}\text { End-plate in } \\
\text { bending }\end{array}$ & 134,4 & 970 \\
\hline
\end{tabular}

with $M_{R d}$, the resistant moment of design, $M_{e}$, the elastic resistant moment of design (= 2/3 $M_{R d}$ ), $V_{R d}$, the shear resistance and $S_{j, \text { ini }}$, the initial stiffness of the joint.

\subsubsection{Design of the internal composite joints}

The steel components are the same than those characterising the external steel joints presented in the previous section. A sketch of the internal composite joints may be seen in Figure 9.

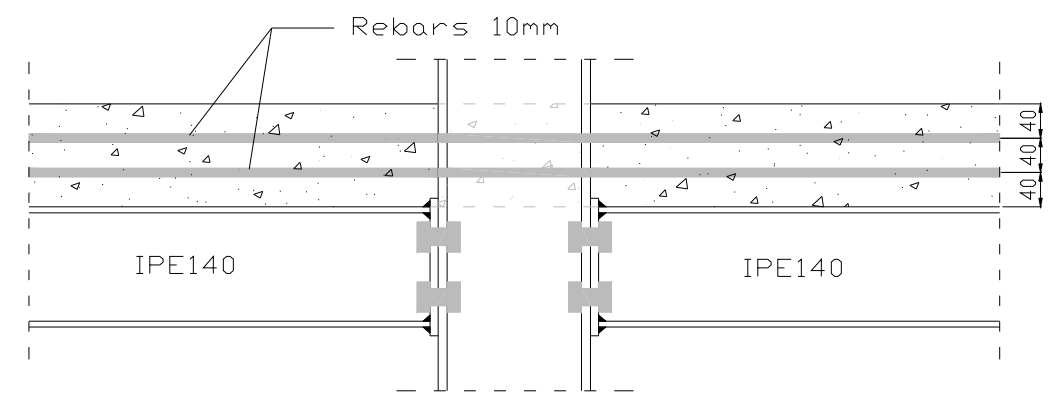

Figure 9. Internal Composite Joint Configuration

The mechanical properties of this joint configuration have been computed according to Eurocode recommendations. The mechanical properties of the internal composite joints for different overstrength situations are summarised in Table 2 (assuming that the internal joint is symmetrically loaded).

The initial stiffness of the internal joints is equal to $7541 \mathrm{kNm} / \mathrm{rad}$; the latter is lower than $8 E I_{b} / L=$ $14240 \mathrm{kNm} / \mathrm{rad}$, which is the lower limit above which a joint may be assumed as rigid. So, the assumption of fully-rigid internal joints when analysing this reference building is not satisfied. As previously, a computation of the internal frame based on the actual properties of the joints has been performed and the internal forces have been compared to the resistance of the joint (see $\S 2.3$ ). 
Table 2. Properties of the Internal Composite Joints with Account of Possible Overstrength Effects

\begin{tabular}{|c|c|c|c|c|c|c|}
\hline & Overstrength & $\begin{array}{c}M_{R d} \\
{[\mathrm{kNm}]}\end{array}$ & $\begin{array}{c}M_{e} \\
{[\mathrm{kNm}]}\end{array}$ & Failure mode & $\begin{array}{c}V_{R d} \\
{[\mathrm{kN}]}\end{array}$ & $\begin{array}{c}S_{j, \text { ini }} \\
{[\mathrm{kNm} / \mathrm{rad}]}\end{array}$ \\
\hline $\begin{array}{l}\text { Initial } \\
\text { situation }\end{array}$ & No overstrength & 39,8 & 26,5 & $\begin{array}{l}\text { Beam flange in } \\
\text { compression }\end{array}$ & 134,4 & 7541 \\
\hline $2^{\circ}$ situation & Beam & 46,8 & 31,2 & $\begin{array}{l}\text { Column web in } \\
\text { compression }\end{array}$ & 134,4 & 7541 \\
\hline $3^{\circ}$ situation & Beam + column & 47 & 31,3 & $\begin{array}{l}\text { Reinforcement in } \\
\text { tension + end-plate } \\
\text { in bending }\end{array}$ & 134,4 & 7541 \\
\hline $4^{\circ}$ situation & $\begin{array}{c}\text { Beam + column } \\
+ \text { end-plate }\end{array}$ & 49,8 & 33,2 & $\begin{array}{c}\text { Beam flange in } \\
\text { compression }\end{array}$ & 134,4 & 7541 \\
\hline
\end{tabular}

\subsubsection{Conclusions}

From the previous results, it can be concluded that all the structural joints within the reference frame are semi-rigid and partially resistant. The failure of the external steel joints is associated to components in tension while that of the internal composite joints is linked to components in compression. It is due to the fact that, in the composite joint configuration, an additional component, the reinforcement in tension, is activated; so, the total resistance of the tension zone is increased.

The failure modes, for the two joint configurations, are ductile, even if overstrength has been seen to be present in some components. Nevertheless, there is a difference in the post-limit behaviour of the two joints as the failure modes are not the same. This difference, illustrated in Figure 10, is explained here below:

- For the composite internal joints with a failure associated to a component in compression: when $M_{R d}$ is reached, the joint cannot sustain this bending moment (no plateau in the behavioural curve) and the bending moment at the joint level decreases rapidly.

- For the steel external joints with a failure associated to a component in tension: when $M_{R d}$ is reached, the joint can sustain this bending moment (sort of plateau in the behavioural curve) while the internal joint rotation increase.

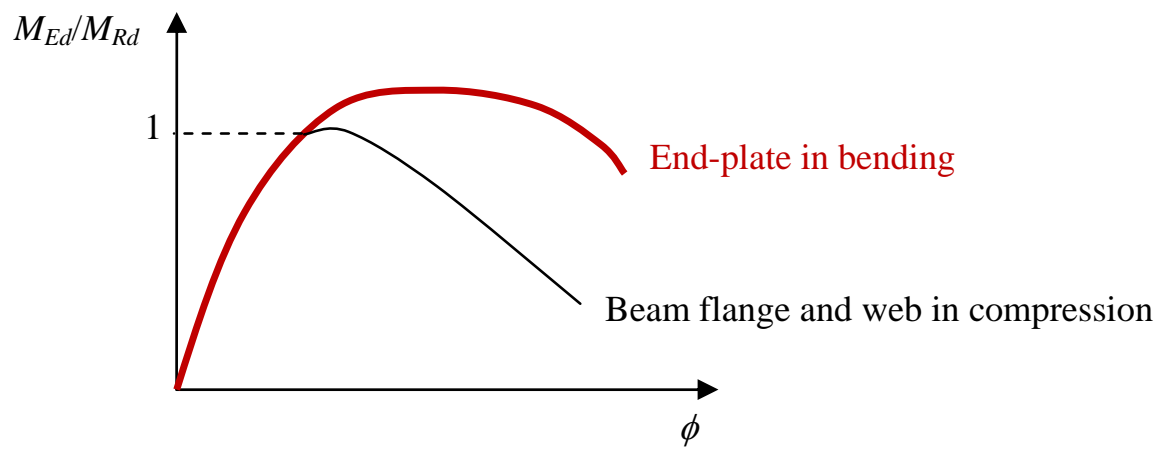

Figure 10. Comparison of Joint Behavioural Curves for Different Types of Failure Modes

In conclusion, both joints are seen to exhibit a significant "rotation capacity" and therefore a significant level of ductility.

When a classical plastic structural analysis is performed, two properties are of importance where plastic hinges form (in members or joints):

- Ductility in rotation and;

- Ability to sustain $M_{R d}$ in the post-limit range. 
In the present case, to ensure a good behaviour of the joint under exceptional loading, the ability to sustain $M_{R d}$ in the post-limit range is not required. Indeed, to have robustness, only ductility is requested. The rotation capacity of the joint must be sufficient so as to allow the hinge to rotate, whatever is the moment transferred through the joint.

\subsection{Ultimate State Verification of the Internal Main Frame with due Account of the Actual Joint Properties}

As the actual joints are semi-rigid, the internal main frame has to be re-analysed taking into account of the predicted properties of the joints. Different load cases are considered; some examples are presented in Figure 11.
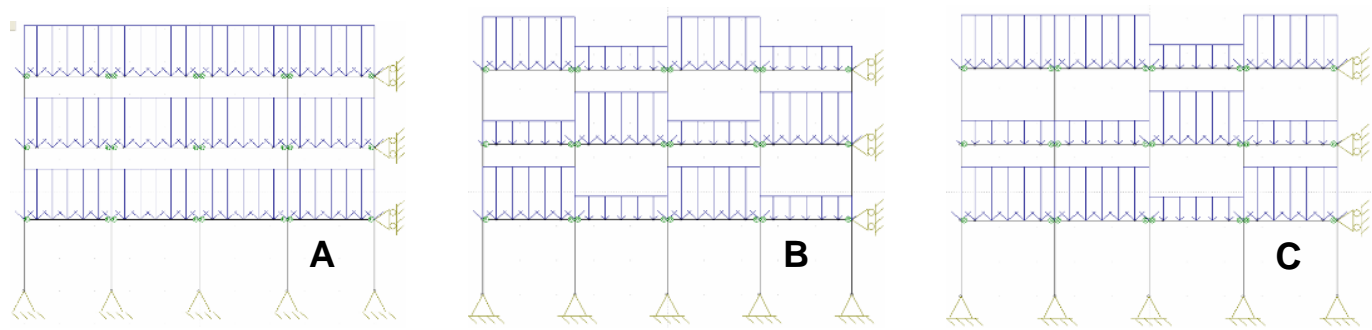

Figure 11. Examples of Considered Load Cases

Through these analyses, it is shown that the designed building respects the ultimate and the serviceability limit states (Demonceau [2]).

\subsection{Conclusions}

In this section, a three storeys - four bays composite frame has been defined; all the structural members (i.e. the composite beams, the steel columns and the composite joints) have been checked in accordance with the Eurocodes. The joints have been designed as partial-strength, with ductile modes of collapse (taking into account possible material overstrength).

In the next section, the substructure tested at Liège University is isolated from the previously defined "actual” building.

\section{SUBSTRUCTURE EXTRACTED FOR TESTING}

As mentioned in $\S 1$, the objective of the substructure test is to investigate the behaviour of a composite structure further to a column loss. According to the project budget and the laboratory facilities, it was not possible to test the full composite frame previously described. So, a substructure has been extracted from the latter; this substructure has been designed so as to conform to the laboratory facilities and to exhibit a behaviour as close as possible to the one of the actual frame. In the present paragraph, the extracted substructure is described.

\subsection{Substructure Layout}

To perform the test, the bottom storey is isolated from the internal frame of the actual building. To accommodate the dimensions of the testing slab, the $16 \mathrm{~m}$ width is reduced to $11 \mathrm{~m}$, as illustrated in Figure 12, through the limitation of the external spans. 
The width of the concrete slab is taken equal to $500 \mathrm{~mm}$ (see Figure 13). It has been fixed so as to be sure that, during the loading, the distribution of the stresses within the concrete is as close as possible to a uniform one; $500 \mathrm{~mm}$ corresponds to the value of the effective width of the concrete slab in the actual building for the hogging moment zone (according to the recommendations of Eurocode 4 (EN 1994-1-1 [3])).

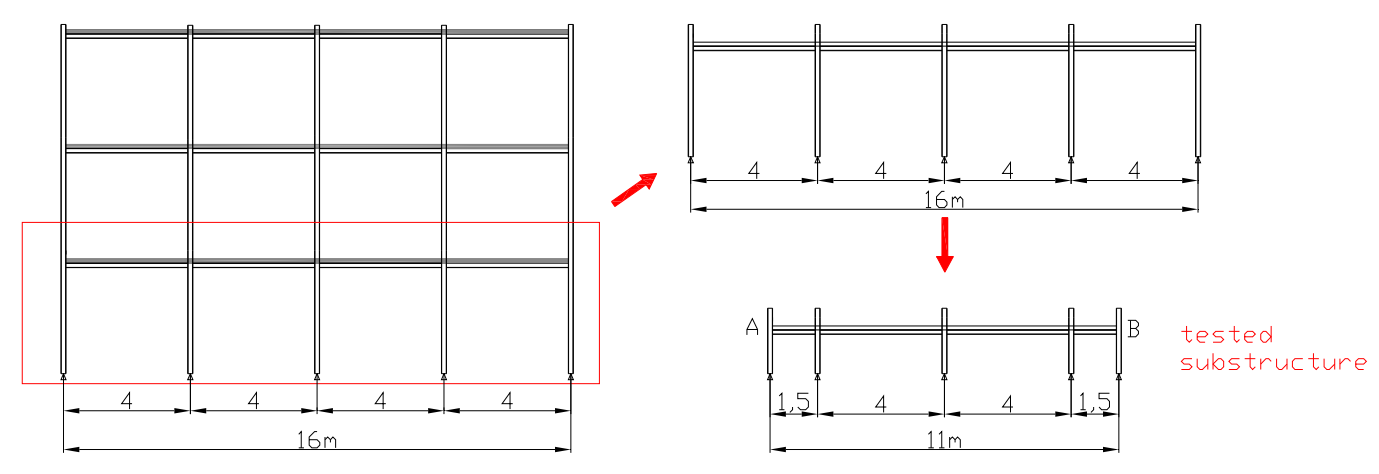

Figure 12. From the Actual Frame to the Tested Substructure

\subsection{Reinforcement and Stud Layouts}

The reinforcement and the studs in the concrete slab have been fixed in collaboration with Stuttgart University. First, it has been agreed to use six $8 \mathrm{~mm}$ rebars for the longitudinal reinforcement (151 $\mathrm{mm}^{2}$ ) instead of four $10 \mathrm{~mm}$ ones $\left(157 \mathrm{~mm}^{2}\right)$, which are the rebars included within the $500 \mathrm{~mm}$ width in the actual frame (see $\S 2$ ). The objective of this modification is to increase the probability to have a distributed small cracks along the slab during the loading instead of big cracks which have to be avoided from the ductility point of view. For the transversal rebars, $10 \mathrm{~mm}$ rebars are used as illustrated in Figure 13.
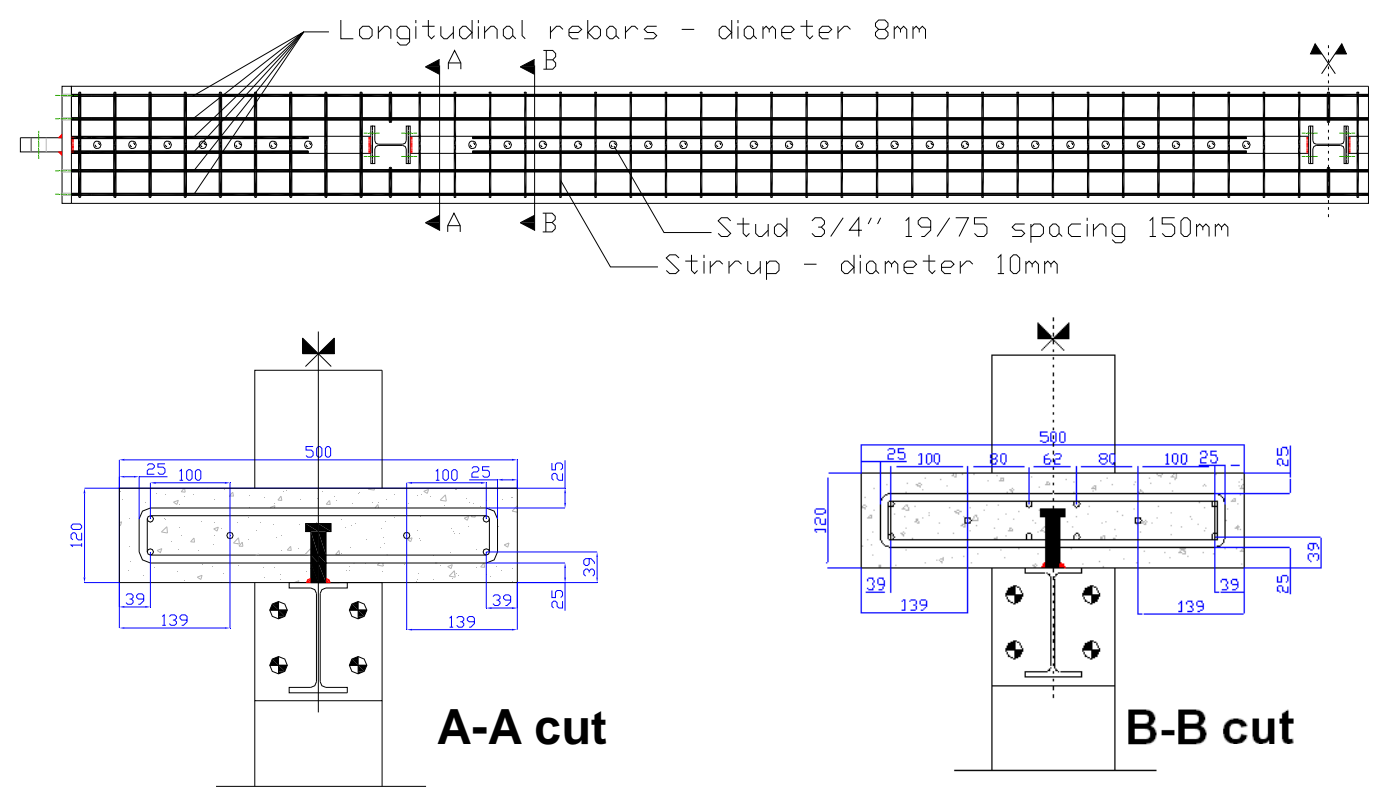

Figure 13. Reinforcement and Stud Layouts

Secondly, the layout of the headed studs and the reinforcement has been chosen in a way that a tension band can develop in the concrete slab, with an especially high ductile behaviour. Therefore 
the distance between the first stud and the face of the column flange is increased compared to standard layout while the amount of reinforcement within this area is kept constant (see Figure 13); this type of layout has already been investigated in a previous project conducted by Kuhlmann/Schäfer (Kuhlmann [6]) and showed good results. Also, it has been decided to use studs with a diameter of $19 \mathrm{~mm}$ instead of $16 \mathrm{~mm}$, what permits to limit the number of studs required to ensure a full connection (23 studs in the internal composite beam instead of 28 - see Figure 7).

\subsection{Joint and Column Base Configurations within the Substructure}

At the column bases, actual hinges are realised (Figure 14); Teflon elements are put between the pin and the column support so as to limit the friction between these two elements during the test.

The composite joint configuration in the substructure is the same than the one in the actual building. However, for the joints between the external beams and the external columns (Beam A and Column A respectively in Figure 16), it has been decided to substitute perfect hinges (as shown in Figure 14) to the actual external joints so as to limit the number of parameters which could influence the response of the internal beams being specifically investigated (Beam B in Figure 16).
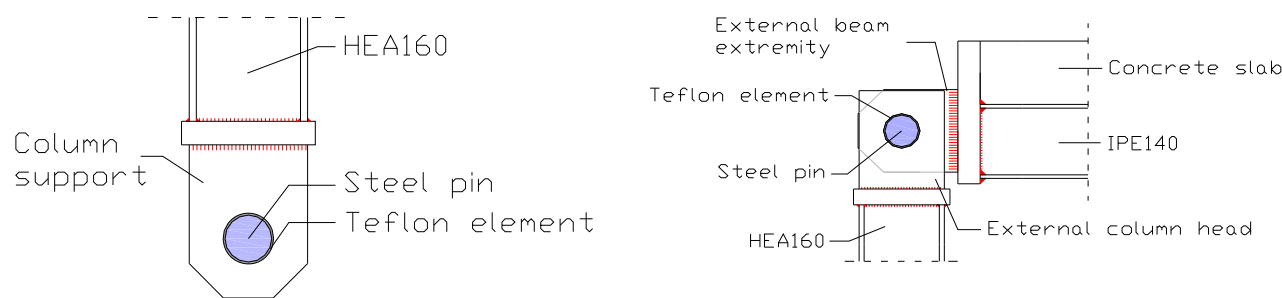

Figure 14. Column Support and Hinge between the External Beam and the External Column

\subsection{Simulation of the Lateral Restraint during the Test}

As previously mentioned, the tested substructure is defined so as to exhibit a behaviour as close as possible to the one of the actual frame. By isolating the substructure from the actual frame, reducing the length of the external spans and realizing actual hinges at the external joints, a key element has been modified: the lateral restraint called " $K$ " brought by the directly affected part (see Figure 1) which influences the development of the membrane forces in the internal beams.

To overcome this problem, "artificial" lateral restraints are activated; they are located each side of the substructure (see point A and B in Figure 12) to induce a "symmetrical" response of the substructure during the test (see Figure 15), what facilitates the application of the loads and the measurements.

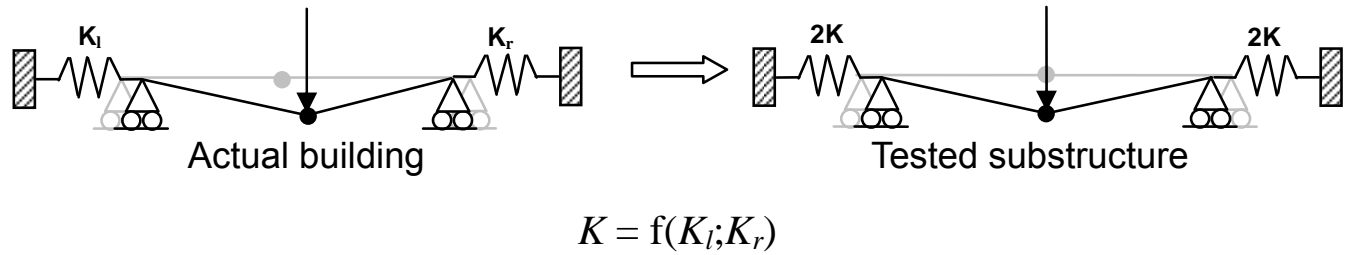

Figure 15. Symmetric Response of the Tested Substructure

These restraints are brought by two horizontal jacks (see Figure 16) which are calibrated so as to exhibit a response close to the actual one, determined numerically through the study of the full "actual" building frame (for the loss of a column at the middle of the bottom storey $-K=1650$ $\mathrm{kN} / \mathrm{m}$ ); the restraint is assumed to be elastic from the beginning to the end of the test (see Figure 17). 


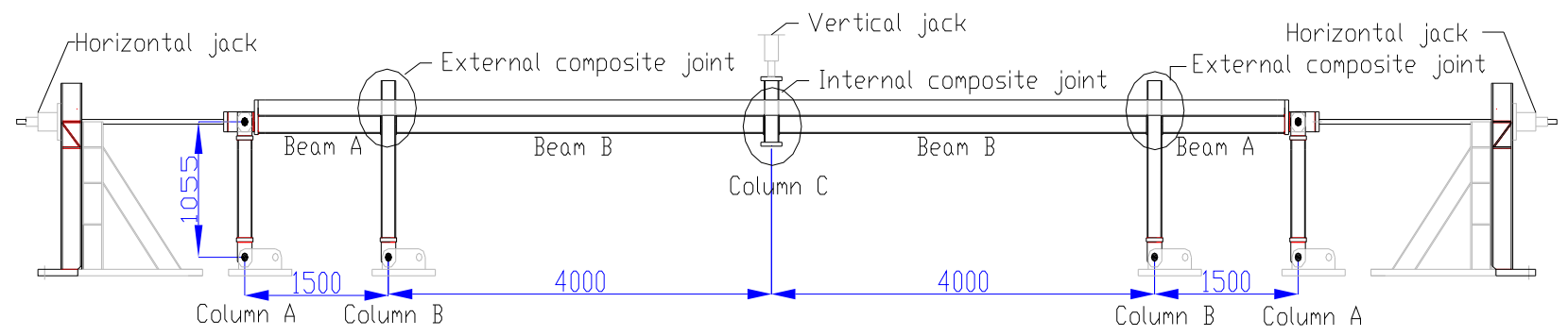

Figure 16. Detailed Illustration of the Substructure Test

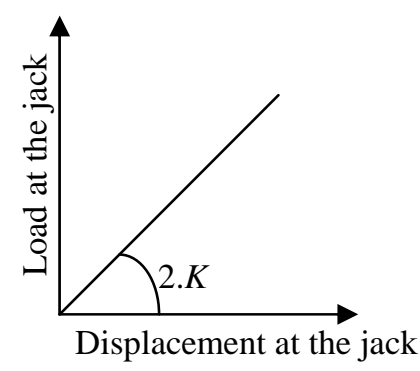

Figure 17. Calibration of the Horizontal External Jacks

\subsection{Conclusions}

This section describes the substructure extracted from the actual building frame to be tested in laboratory.

Some modifications have been realised to pass from the actual frame to the tested substructure with the aim to respect the laboratory facilities and to facilitate the interpretation of the results; all these modifications have been described and justified.

In the next section, the substructure test is described and the obtained results are presented.

\section{SUBSTRUCTURE TEST}

The test in itself and the obtained results are described in the present section which is divided as follows:

- $\quad$ tests aiming at characterising the properties of the constitutive materials are first presented in $\S$ 4.1 ;

- $\quad$ the actual geometrical properties of the tested specimen are given in $\S 4.2$;

- $\quad \S 4.3$ describes the loading sequence applied during the test;

- $\quad$ the test setup and measurements are presented in $\S 4.4$;

- $\quad$ finally, the test results are discussed in $§ 4.5$.

\subsection{Characterization of the Constitutive Materials}

\subsubsection{Steels}

The mechanical properties of the steel materials have been determined through coupon tests; they are presented from Table 3 to Table 5 (Demonceau [2]). In the "Robustness" project mentioned before (Kuhlmann [1]), different tests were also performed at Stuttgart University and Trento University on joints in isolation and on joint components respectively, using steel elements coming from the same production and the same rolling than the ones used for the substructure; accordingly, 
the values reported hereafter are average values of coupon test results obtained in the different laboratories.

Table 3. Mechanical Properties of the Steels for Profiles

\begin{tabular}{|c|ccc|cccc|}
\hline \multirow{2}{*}{ IPE140 } & $f_{y, \text { web }}$ & $f_{\text {y,flange }}$ & $f_{y, \text { average }}$ & $f_{u \text { web }}$ & $f_{u, f l a n g e}$ & $f_{u, \text { average }}$ & $\varepsilon_{u}$ \\
& {$\left[\mathrm{~N} / \mathrm{mm}^{2}\right]$} & {$\left[\mathrm{N} / \mathrm{mm}^{2}\right]$} & {$\left[\mathrm{N} / \mathrm{mm}^{2}\right]$} & {$\left[\mathrm{N} / \mathrm{mm}^{2}\right]$} & {$\left[\mathrm{N} / \mathrm{mm}^{2}\right]$} & {$\left[\mathrm{N} / \mathrm{mm}^{2}\right]$} & {$[\%]$} \\
& 462 & 412 & 437 & 559 & 552 & 556 & 31 \\
\hline \multirow{2}{*}{ HEA160 } & $f_{y, \text { web }}$ & $f_{y, f l a n g e}$ & $f_{y, \text { average }}$ & $f_{u, \text { web }}$ & $f_{u, \text { flange }}$ & $f_{u, \text { average }}$ & $\varepsilon_{u}$ \\
& {$\left[\mathrm{~N} / \mathrm{mm}^{2}\right]$} & {$\left[\mathrm{N} / \mathrm{mm}^{2}\right]$} & {$\left[\mathrm{N} / \mathrm{mm}^{2}\right]$} & {$\left[\mathrm{N} / \mathrm{mm}^{2}\right]$} & {$\left[\mathrm{N} / \mathrm{mm}^{2}\right]$} & {$\left[\mathrm{N} / \mathrm{mm}^{2}\right]$} & {$[\%]$} \\
& 432 & 392 & 412 & 538 & 523 & 531 & 32 \\
\hline
\end{tabular}

Table 4. Mechanical Properties of the $8 \mathrm{~mm}$ Rebar Steel

\begin{tabular}{|c|ccc|}
\hline $8 \mathrm{~mm}$ rebars & $f_{y}\left[\mathrm{~N} / \mathrm{mm}^{2}\right]$ & $f_{u}\left[\mathrm{~N} / \mathrm{mm}^{2}\right]$ & $\varepsilon_{u}[\%]$ \\
& 523 & 646 & 14 \\
\hline
\end{tabular}

Table 5. Mechanical Properties of the $8 \mathrm{~mm}$ End-Plate Steel

\begin{tabular}{|c|ccc|cccc|}
\hline $\mathbf{8 m m}$ & $f_{y, \text { long. }}$ & $f_{y, \text { trans. }}$ & $f_{y, \text { average }}$ & $f_{u, \text { long. }}$ & $f_{u, \text { trans. }}$ & $f_{\text {u,average }}$ & $\varepsilon_{u}$ \\
end-plate & {$\left[\mathrm{N} / \mathrm{mm}^{2}\right]$} & {$\left[\mathrm{N} / \mathrm{mm}^{2}\right]$} & {$\left[\mathrm{N} / \mathrm{mm}^{2}\right]$} & {$\left[\mathrm{N} / \mathrm{mm}^{2}\right]$} & {$\left[\mathrm{N} / \mathrm{mm}^{2}\right]$} & {$\left[\mathrm{N} / \mathrm{mm}^{2}\right]$} & {$[\%]$} \\
& 669 & 565 & 600 & 709 & 663 & 678 & 17 \\
\hline
\end{tabular}

One important thing to be highlighted is the high elastic strength of the $8 \mathrm{~mm}$ end-plate; indeed, the average value of this elastic limit is equal to $600 \mathrm{Mpa}$ while the normal steel grade which was ordered for these plates was S355. This phenomenon induced very high overstrength effects which were not expected and which were therefore not considered in the joint design presented in $\S 2.2$.

\subsubsection{Concrete (C25/30 concrete)}

To characterise the compression resistance of the concrete, twelve tests on cube and two on cylinder were performed. For the cubes, tests were achieved at different times ( 3 cube tests at day 7 , 14, 28 and the day of the test (day 72)) to observe the evolution of the concrete resistance; also, the equivalent resistances which would have been obtained on cylinder, which represents the characteristic value $f_{c k}$ as defined in the Eurocodes, have been computed according to the Eurocode 2 rules (EN 1992-1-1 [7]).

The average value which has been obtained through these tests for $f_{c k}$ is equal to $36 \mathrm{~N} / \mathrm{mm}^{2}$.

\subsection{Geometrical Measurements}

The geometrical measurement aim is to obtain the actual geometrical properties of the constitutive elements of the substructure and to check if they correspond to the elements which were ordered. In fact, insignificant divergences were observed (Demonceau [2]).

\subsection{Description of the Loading Sequence followed during the Test}

As previously mentioned, all the forces have been applied "statically" (i.e. progressive removal of the column), what means that the dynamic effects resulting from the impact action and the column loss itself have not been taken into account. It is justified hereafter:

- The objective is to understand the "physical" phenomena linked to the loss of a column in a frame. So, that is why it was decided to remove progressively the column so as to be able to observe all these phenomena and to measure them. 
- Another reason is that the final aim of the test is to validate later on numerical tools and analytical developments. To reach this goal, it was needed to measure all the displacements, rotations, loads and strains during the column loss, what was only possible with a progressive removal of the column.

The loading sequence during the test was the following one:

- A uniformly distributed load is first applied to the internal beams; during this phase, two locked jacks are placed at the middle of the substructure to simulate the presence of the column, as illustrated in Figure 18. In practice, the uniformly distributed load is applied with steel plates and concrete blocks, as shown in Figure 19; it represents a total load of $6 \mathrm{kN} / \mathrm{m}$; also, L-shaped profiles are placed so as to maintain the steel plates and the concrete blocks at their place when large deflections will take place (see Figure 19). The $6 \mathrm{kN} / \mathrm{m}$ load is smaller than the one to be considered for the ULS verifications under the accidental combination of actions $(\cong 10 \mathrm{kN} / \mathrm{m})$; however, it is the maximum load that could be "safely" applied in the laboratory during the test.

- In a second step, the support brought by the jacks is progressively removed by unlocking the jack; when it is achieved, the "free deflection" of the system is observed. The next step consists in imposing a further vertical displacement to the beams through the use of two jacks located at the top of the column thus (see Figure 20). The displacement is increased until failure of the substructure.

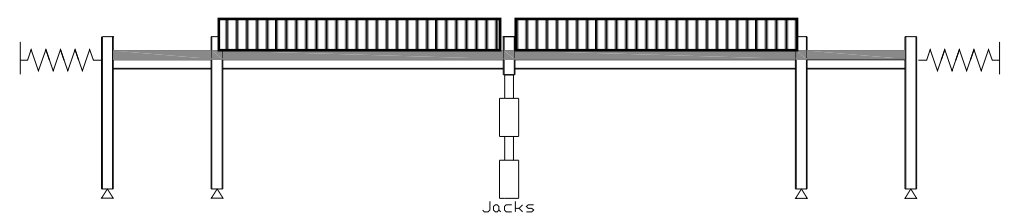

Figure 18. Column at the Middle Simulated by Two Locked Jacks

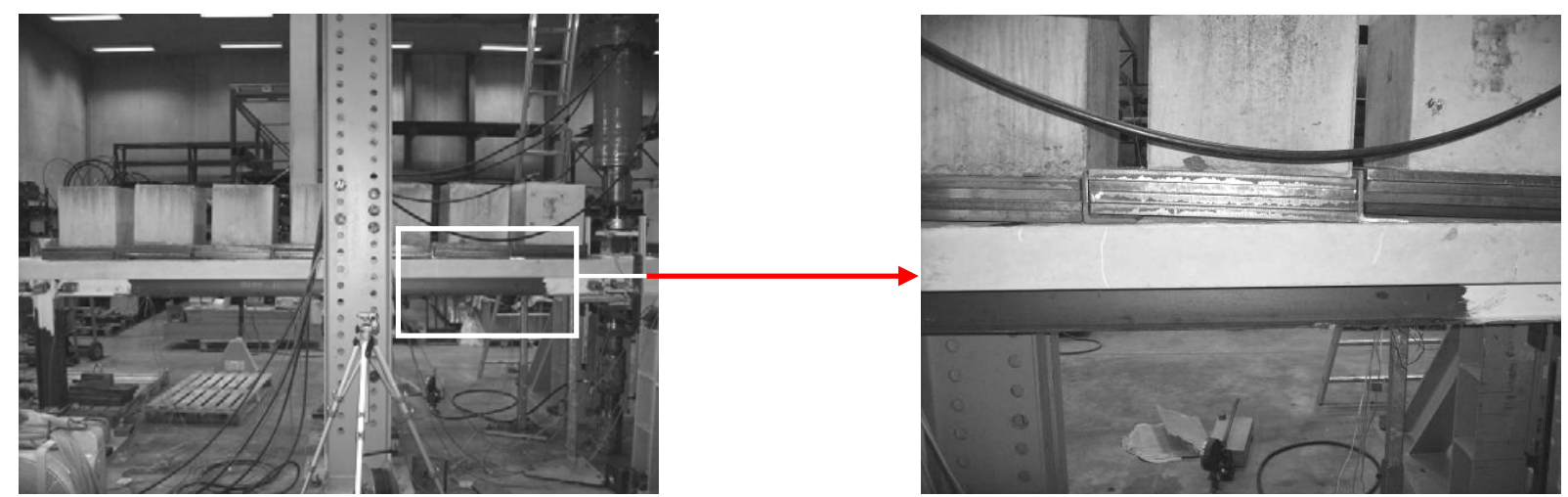

Figure 19. Steel Plates and Concrete Blocks Simulating the Uniformly Distributed Load

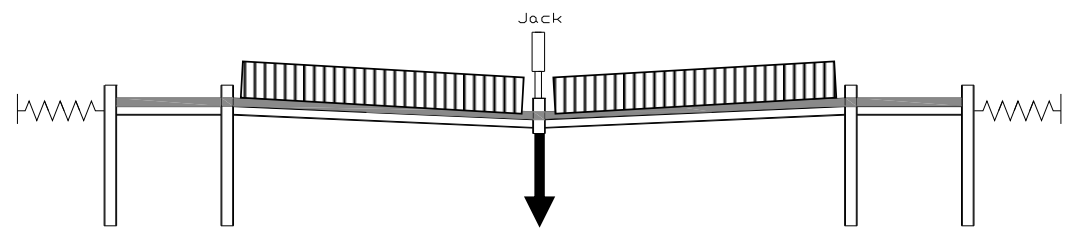

Figure 20. Application of a Further Vertical Displacement with Two Vertical Jacks

\subsection{Test Equipment}

\subsubsection{Hydraulic jacks (controlled displacement)}

In total, six hydraulic jacks are used during the test: 
- to simulate the presence of the column at the middle of the tested specimen, two screw jacks are initially placed under the beams (see Figure 18);

- then, to increase further the vertical displacement until collapse, two hydraulic jacks are placed in series at the top of the column so as to reach a maximum displacement capacity of $800 \mathrm{~mm}$;

- as previously mentioned, the lateral restraints are simulated at each side of the substructure by "hollow" jacks (see Figure 21) with a displacement capacity of $200 \mathrm{~mm}$.

The applied loads at all these jacks are measured through load cells.

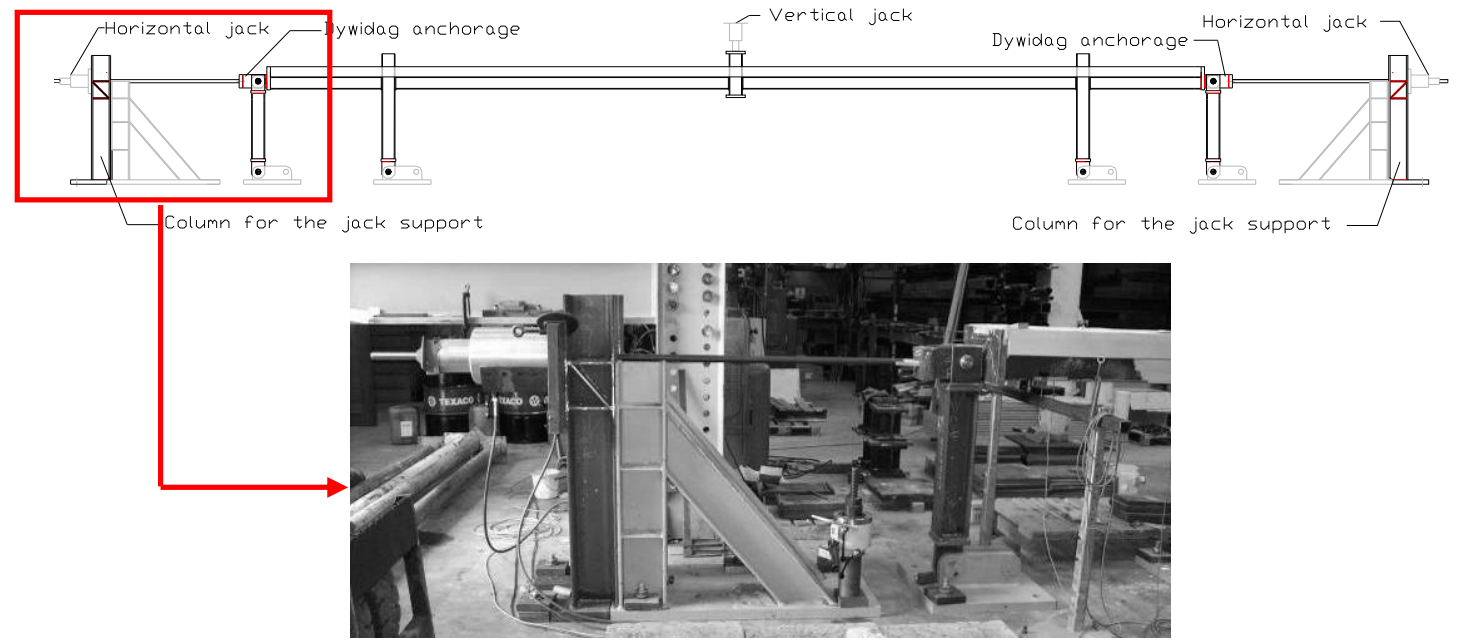

Figure 21. Horizontal Restraint Simulated by Horizontal “Hollow” Jacks

\subsubsection{Displacement and Rotational Transducers}

Five rotational transducers are placed in the vicinity of the joints as shown in figure 22 and four displacement transducers are placed as follows (see Figure 23):

- $\quad$ two at the middle of the substructure to measure the vertical displacement;

- $\quad$ one each side of the substructure to measure the horizontal displacement.

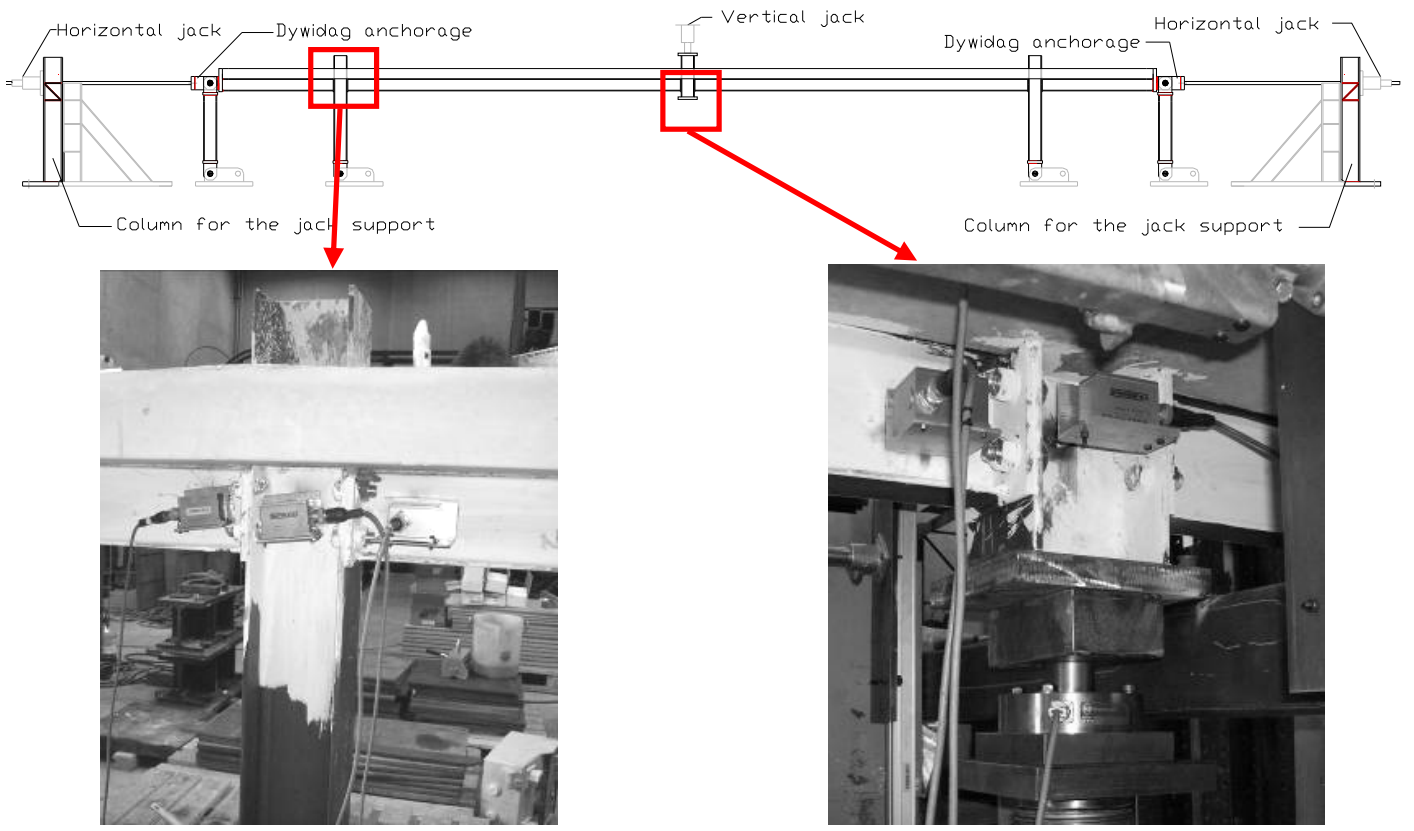

Figure 22. Rotational Transducers 


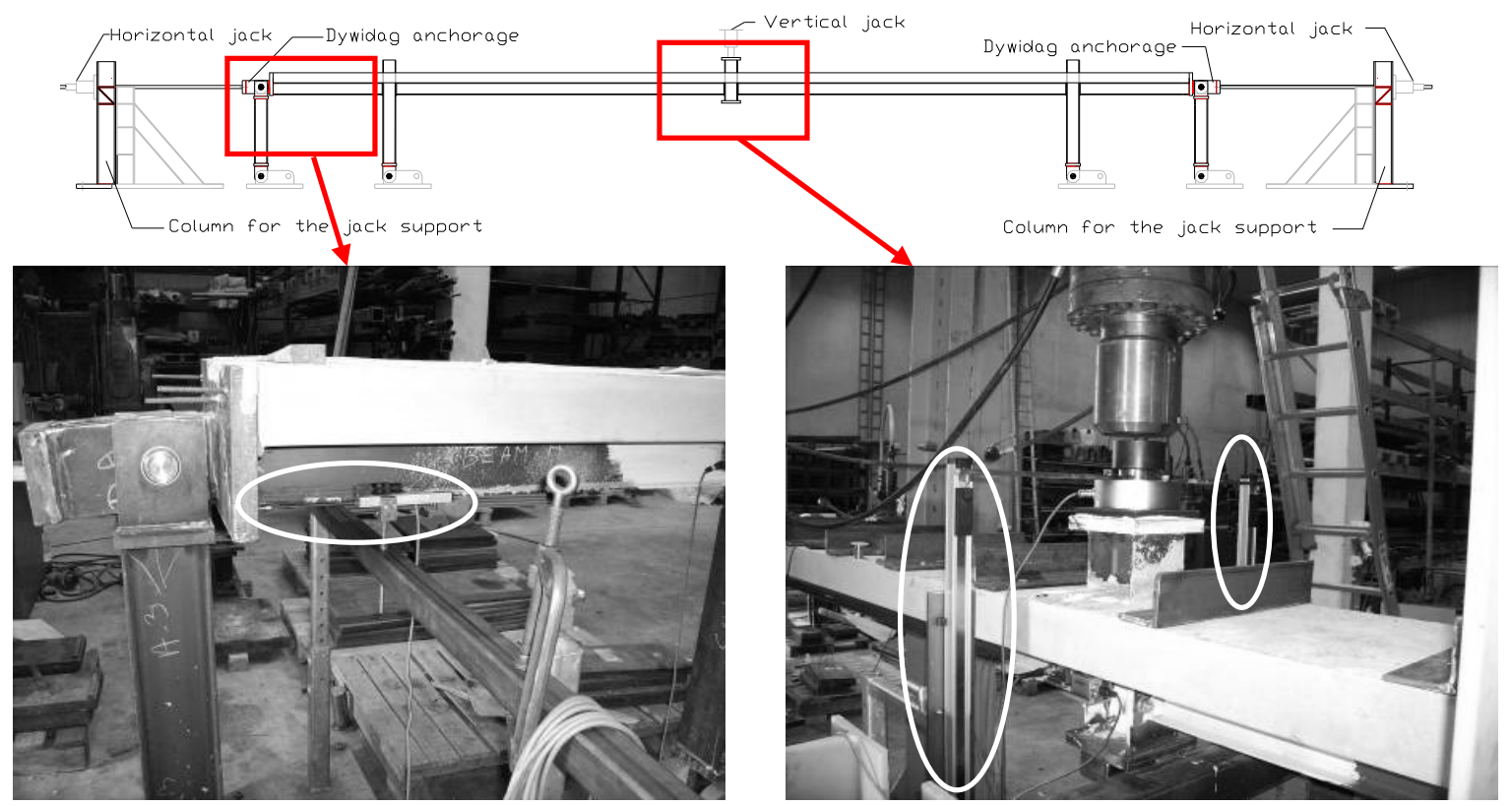

Figure 23. Displacement Transducers

\subsection{Substructure Test Results}

As explained in $\S 4.3$, a uniformly distributed load is first applied on the substructure with steel plates and concrete blocks. After the application of the latter, first small cracks are already observed in the concrete slab in the vicinity of the external composite joints.

The jacks at the middle are then unlocked and progressively removed. The system is completely released; a deflection of $29 \mathrm{~mm}$ is registered at that moment. At this stage, the width of the cracks at the vicinity of the external joints is bigger and first steel yielding is observed in the column web panel of the internal composite joints.

This first step of the test is illustrated by the part "OA" of the curve presented in Figure 24 and which represents the evolution of the vertical load acting on the beams at the middle of the substructure according to the vertical displacement under the "impacted" column. The vertical reaction in the lower column stub, before its removal, is equal to $33,5 \mathrm{kN}$ (value of the load at point "O"). From Figure 24, it can be seen that the structure remains globally elastic when " $A$ " is reached.

Then, as previously explained, a vertical displacement is progressively imposed until failure. During this stage, two “unloading-reloading” sequences are followed as illustrated in Figure 24.

From point "A" to "B" in Figure 24, the substructure yields progressively to finally form a beam plastic mechanism at point " $B$ " with formation of the plastic hinges in the joints. At that moment, the cracks in the vicinity of the external composite joints are more pronounced and yielding of some steel components of the joints is clearly observed (column web and beam flange in compression - see Figure 25 and Figure 26). Also, for the internal composite joint, a detachment of the end-plate and of the column flange is observed (see Figure 26).

From point "B" to "C" in Figure 24, a plateau develops, what means that the vertical displacements increase with a constant vertical load (equal to $30 \mathrm{kN}$ ). All along the plateau, the concrete cracks in the vicinity of the external composite joints continue to extend and yielding spreads further in the 
steel joint components. One important observation is that the concrete in the vicinity of the internal composite joint crushes in compression (Figure 27).

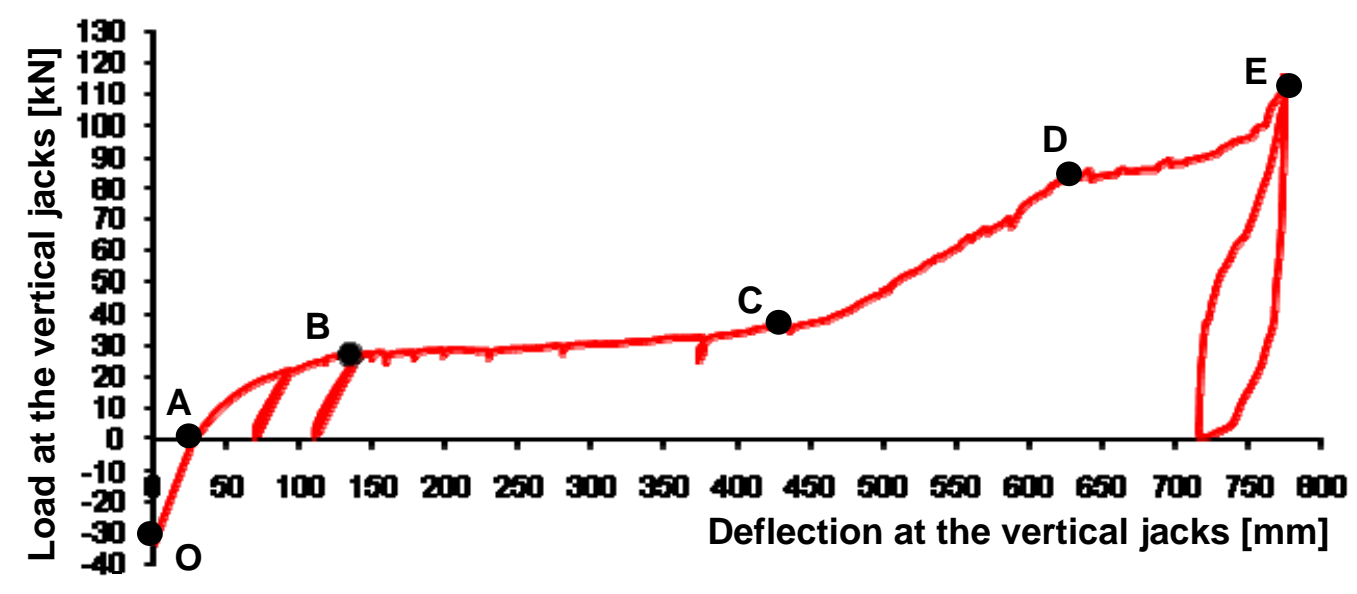

Figure 24. Vertical load vs. Vertical Displacement Curve
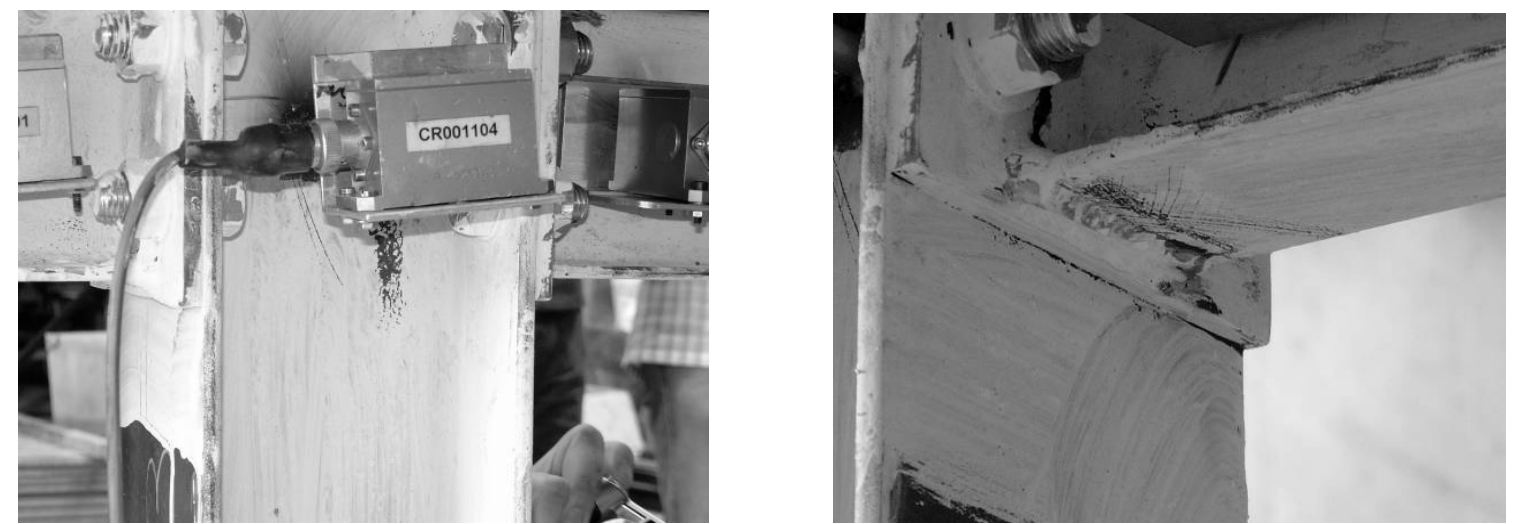

Figure 25. Yielding of Steel Components at the External Composite Joints

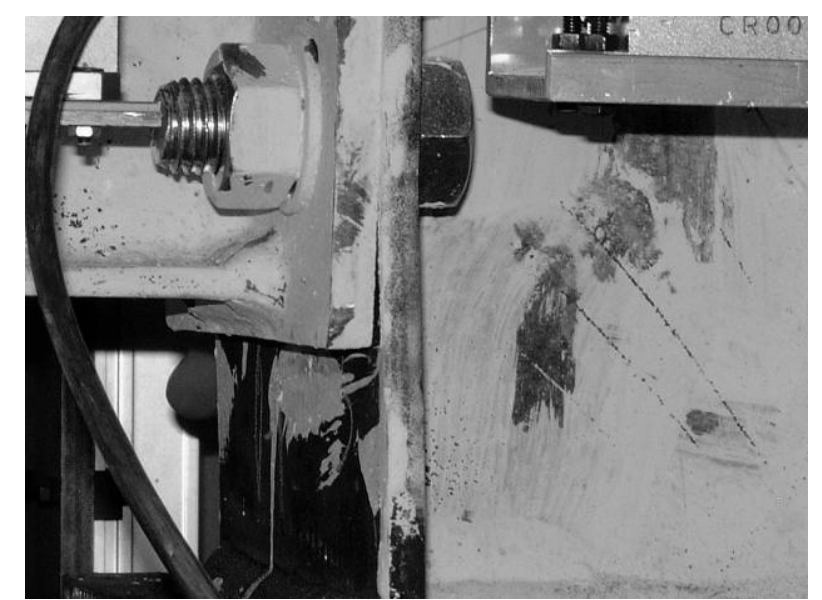

Figure 26. Yielding of Steel Components at the Internal Composite Joints 

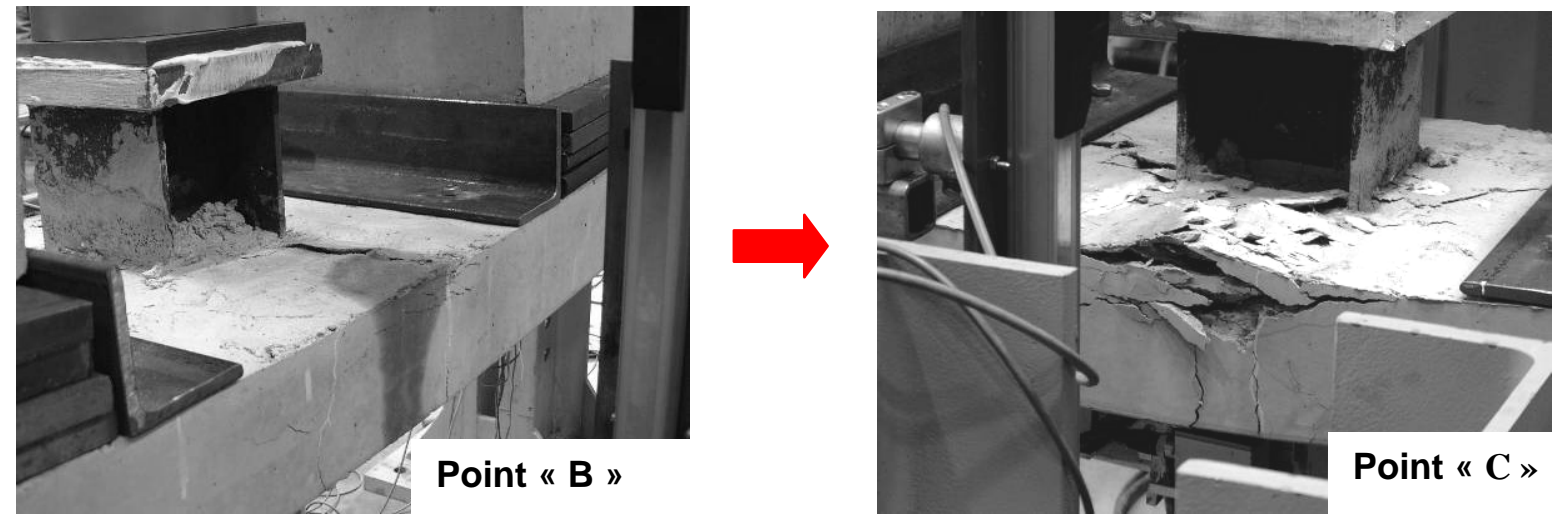

Figure 27. Concrete Splitting at the Internal Composite Joint

The horizontal jacks begin to be significantly activated at point "C" in Figure 24; at this point, membrane forces start to develop as confirmed by the shape of the global displacement curve (part "CD" in Figure 24). At point " $D$ ", the longitudinal rebars in the external composite joints suddenly fail (see Figure 28) and the external joints work later on as steel ones. Yielding affects the different components in the internal and external composite joints as illustrated in Figure 29 and Figure 30. At point "D", a loss of stiffness related to the failure of the rebars is observed in Figure 24; indeed, when these rebars fail, both flexural and tensile stiffness of the external joints decrease, what directly induces the development of further membrane effects.

However, it can be observed that the failure of the rebars does not lead to the failure of the substructure; indeed, after point "D", the vertical load at the vertical jacks still increases with the imposed displacement (part "DE" of the curve in Figure 24).

This is possible as long as the steel connection is able to support, alone, the membrane forces developed in the system. In addition, associated to the loss of the rebars, the vertical displacements are increasing with a low variation of the vertical loads. These additional vertical displacements induce an increase of the membrane forces as confirmed by Figure 31 showing the evolution of the load in the horizontal jacks at the specimen extremities versus the vertical load in the vertical jacks. So, the steel connection working alone has at the end to be sufficiently resistant to support these additional membrane forces and sufficiently ductile to support the additional rotations associated to the vertical displacement. The capacity of the steel connections, working alone, to support significant membrane forces has been confirmed by tests on joint in isolation performed at Stuttgart University (Kuhlmann [1]).
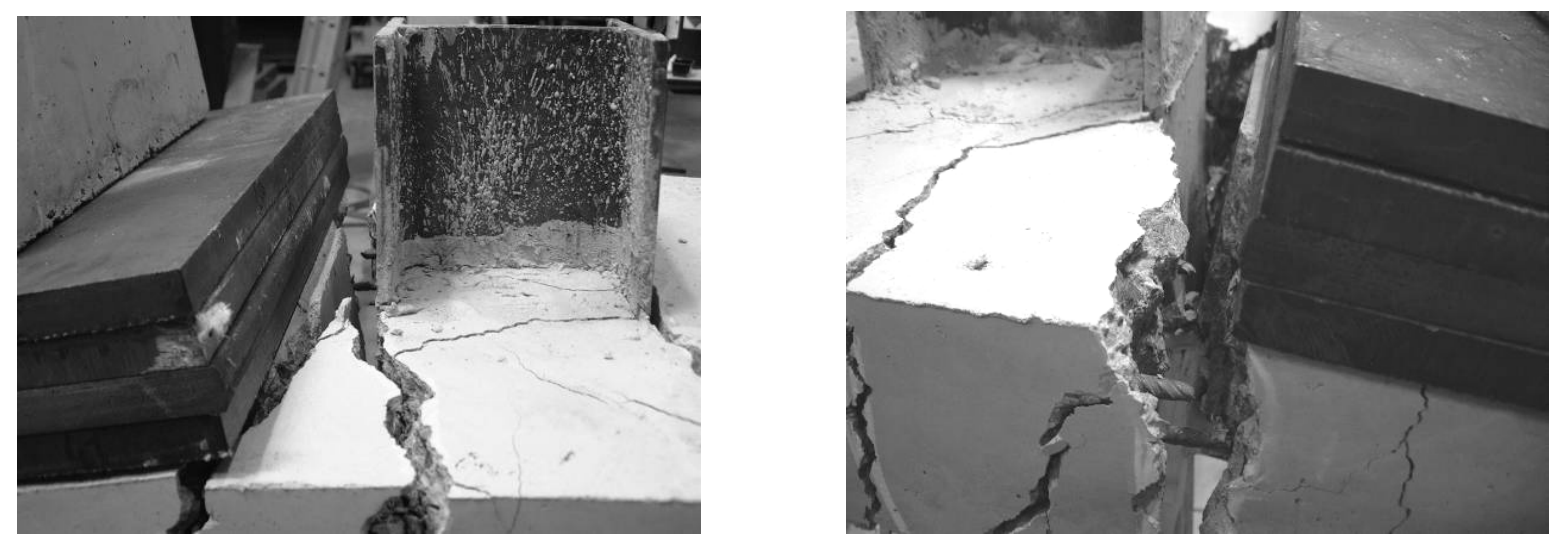

Figure 28. Collapse of the Longitudinal Rebars in the Vicinity of the External Composite Joints 

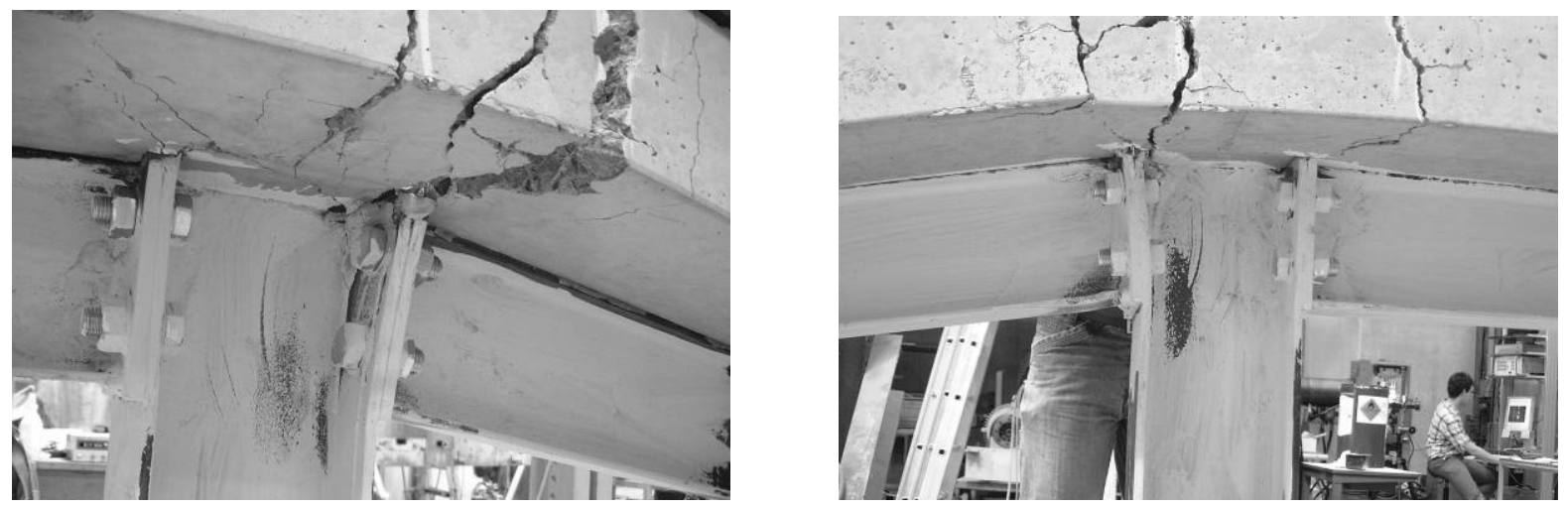

Figure 29. Spread of Yielding in the Steel Components of the External Composite Joints

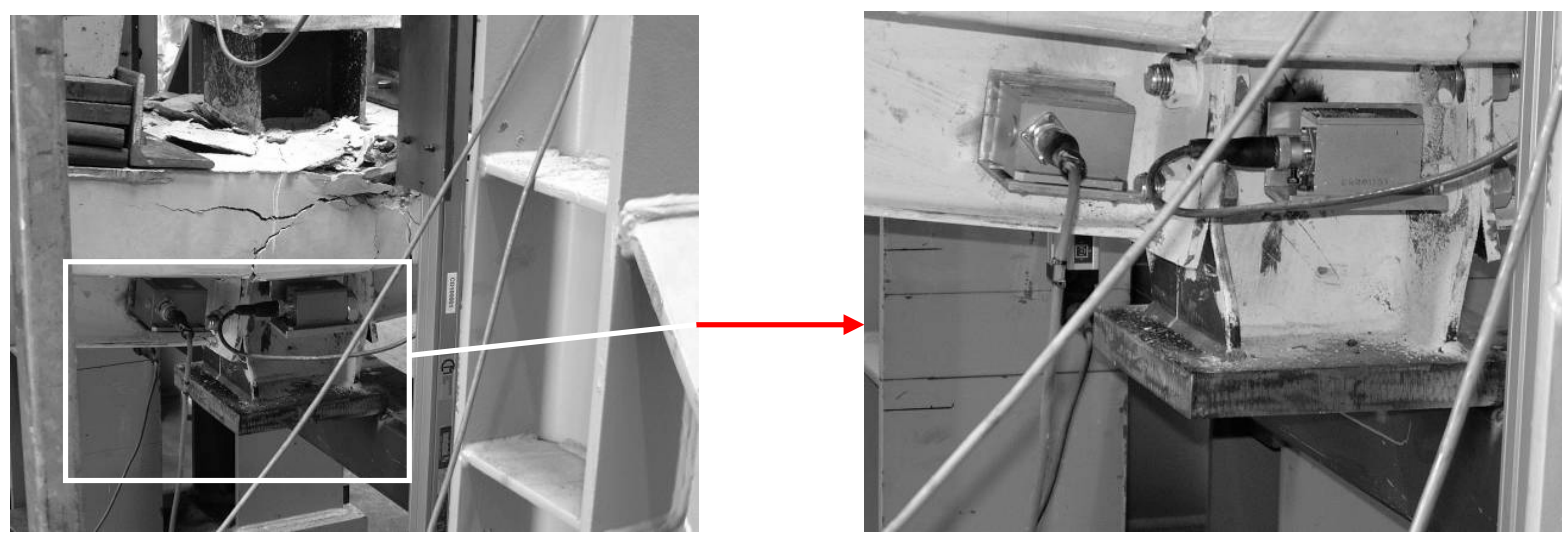

Figure 30. Deformation of the Internal Composite Joint at Point “D” of Figure 24

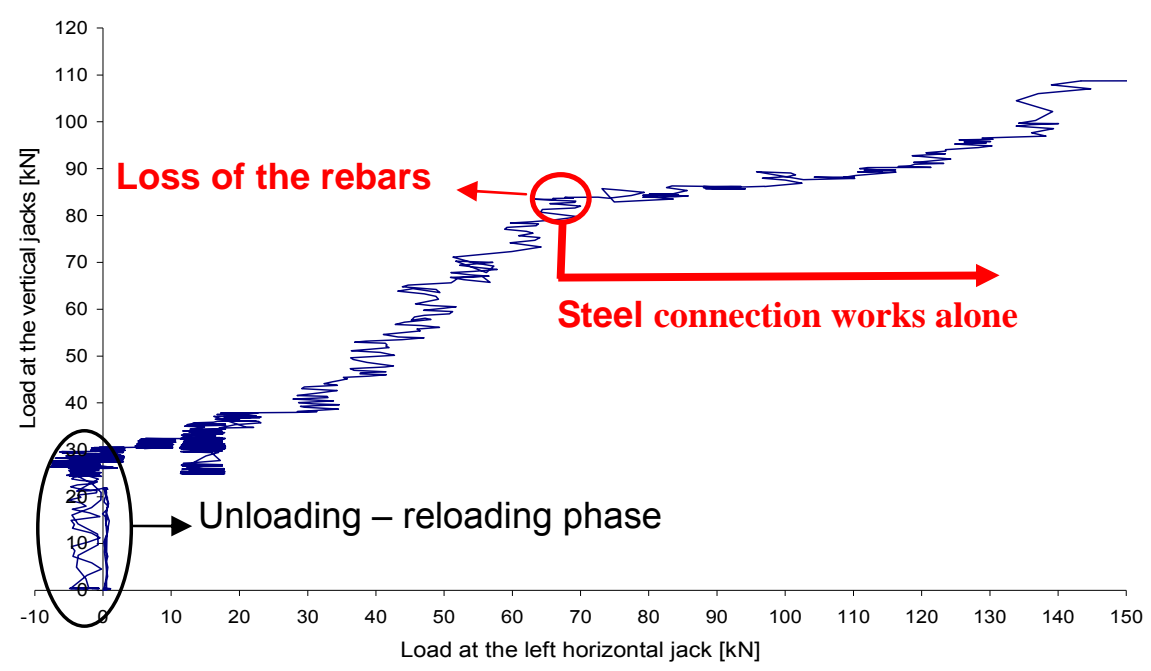

Figure 31. Evolution of the Load in the Left Horizontal Jack according to the Applied Vertical Load at the Middle of the Specimen

The test was stopped with the occurrence of cracks in the weld between the bottom flange of the IPE140 beam and the end-plate in one of the internal composite joints.

At the end of the test, a maximum vertical displacement of $775 \mathrm{~mm}$ is reached for a vertical load at the vertical jacks of $114 \mathrm{kN}$; the deformation of the specimen at this stage may be seen in Figure 32 . The maximum horizontal displacement at each side of the structure is equal to $45 \mathrm{~mm}$ for a horizontal load of $147 \mathrm{kN}$; the observed horizontal displacement appears clearly in Figure 33.

Also, at point E of Figure 24, all the joint components of the internal and external composite joints suffer large deformations and yielding as seen in Figure 34 and Figure 35 (after the damage 
concrete has been removed). In particular:

- for the external composite joints: yielding of the column web in compression, the beam flange and web in compression, the column flange in bending.

- for the internal composite joints: yielding of the column web in tension (Luders bands) associated to the membrane forces, column flange in bending, beam flange and web in tension.

The evolution of the joint rotations versus the load acting in the vertical jacks is given in Figure 36. The maximum joint rotations reached at the end of the test are equal to $11^{\circ}$ (192 mrad) and to $9,5^{\circ}$ (166 mrad), for the internal and external composite joints respectively. It can be observed in Figure 36 that:

- the behaviour of the internal and external composite joints is quite similar;

- the joint rotations are mainly associated to the yielding of the connection elements;

- a beam plastic mechanism develops with formation of plastic hinges in the joints.

From the maximum rotation values observed at the end of the test, it can be concluded that the joints exhibited a very ductile behaviour with a very high rotation capacity, as expected. Also, through these observations, it is confirmed that, even if the collapse mode under hogging bending moment is associated to the component "beam flange in compression", the ductility of the joint is sufficient to develop the catenary action, as predicted in § 2.2.
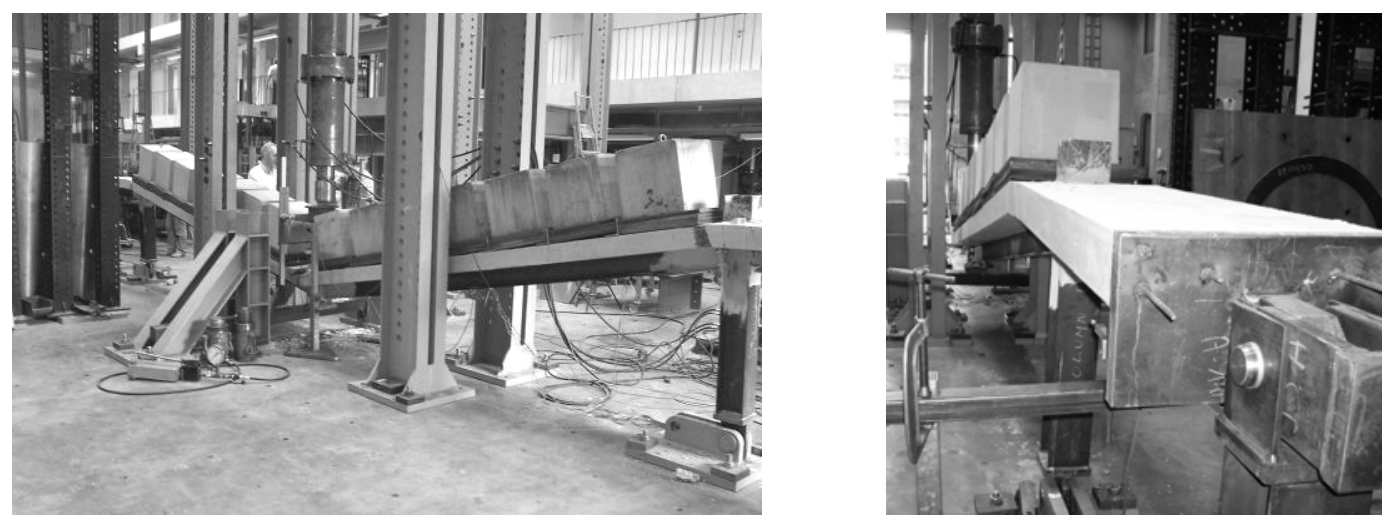

Figure 32. Deformation of the Specimen at Point “E” of Figure 24

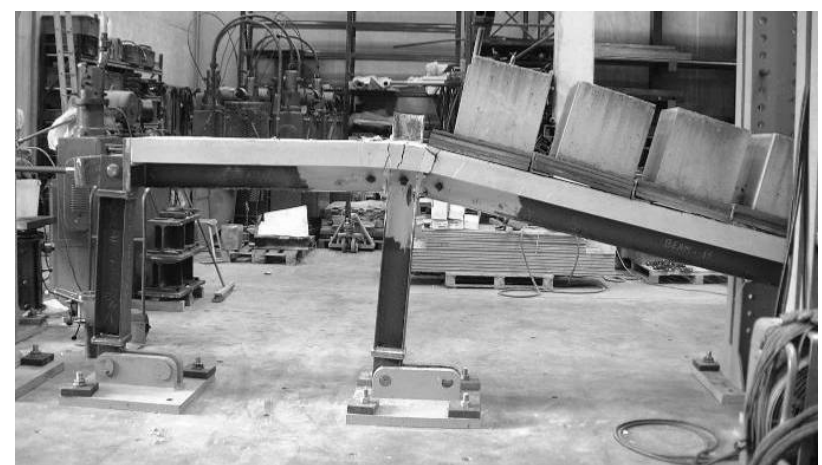

Figure 33. Horizontal Displacement of the Specimen at Point "E” of Figure 24 

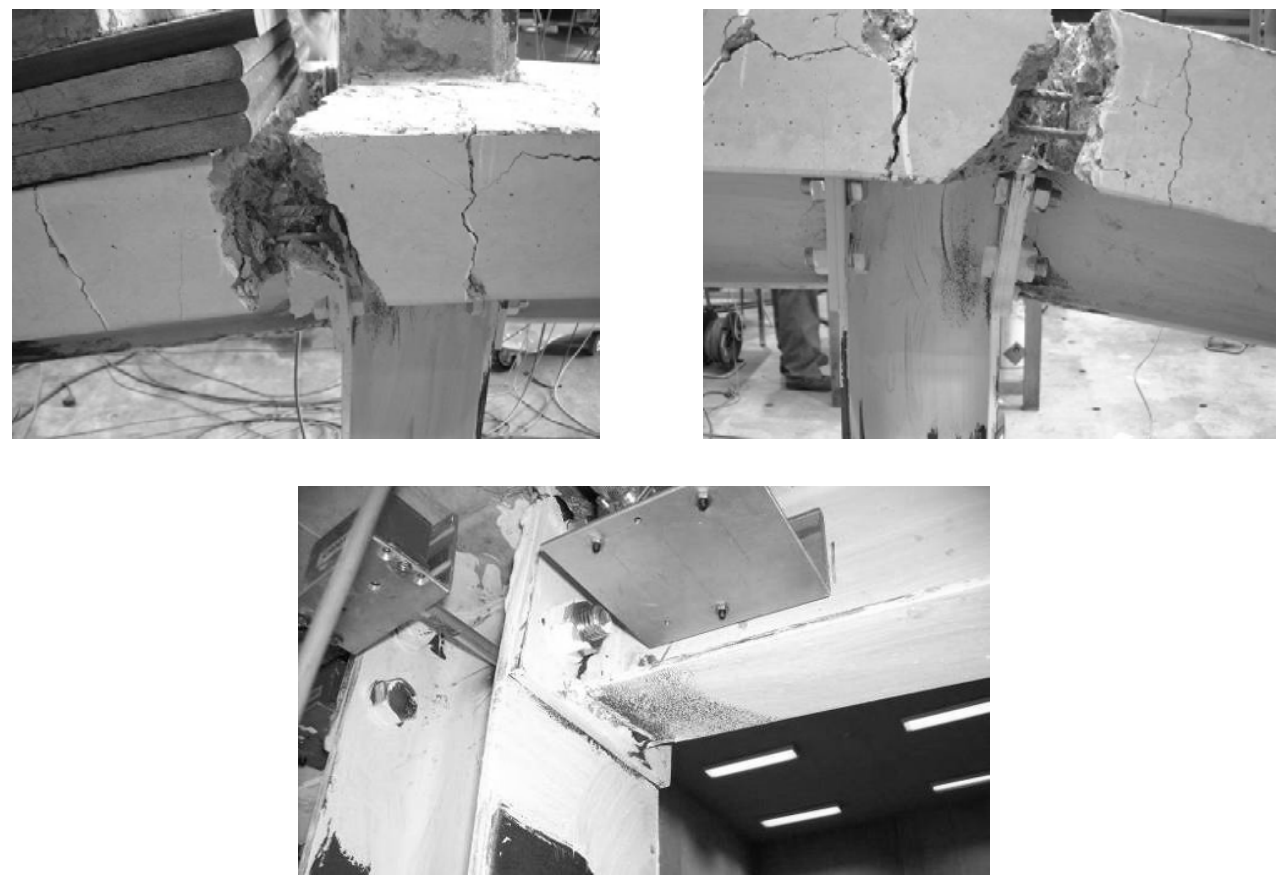

Figure 34. External Composite Joints at the End of the Test
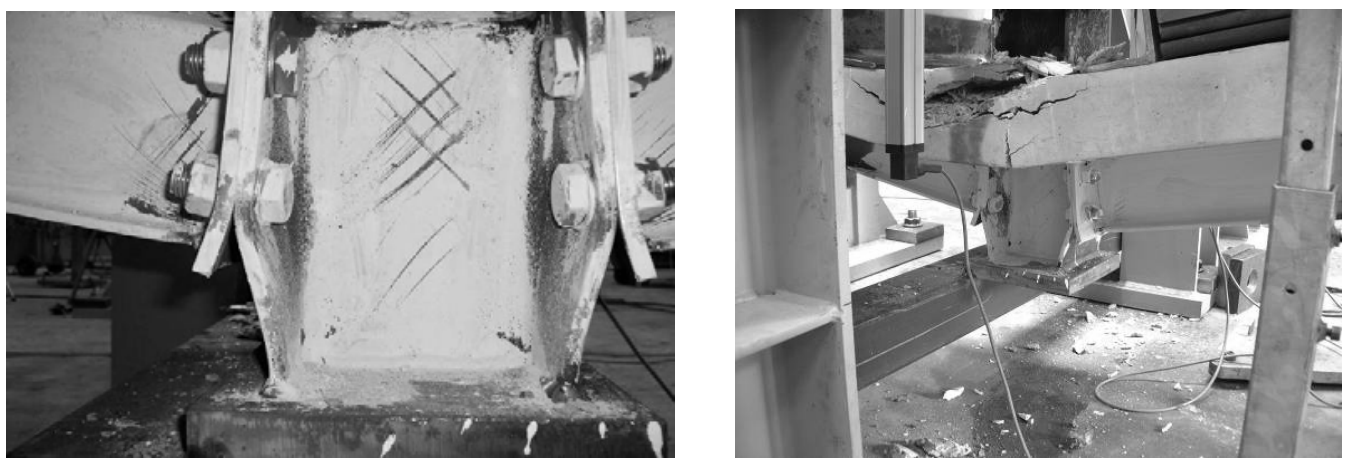

Figure 35. Internal Composite Joints at the End of the Test

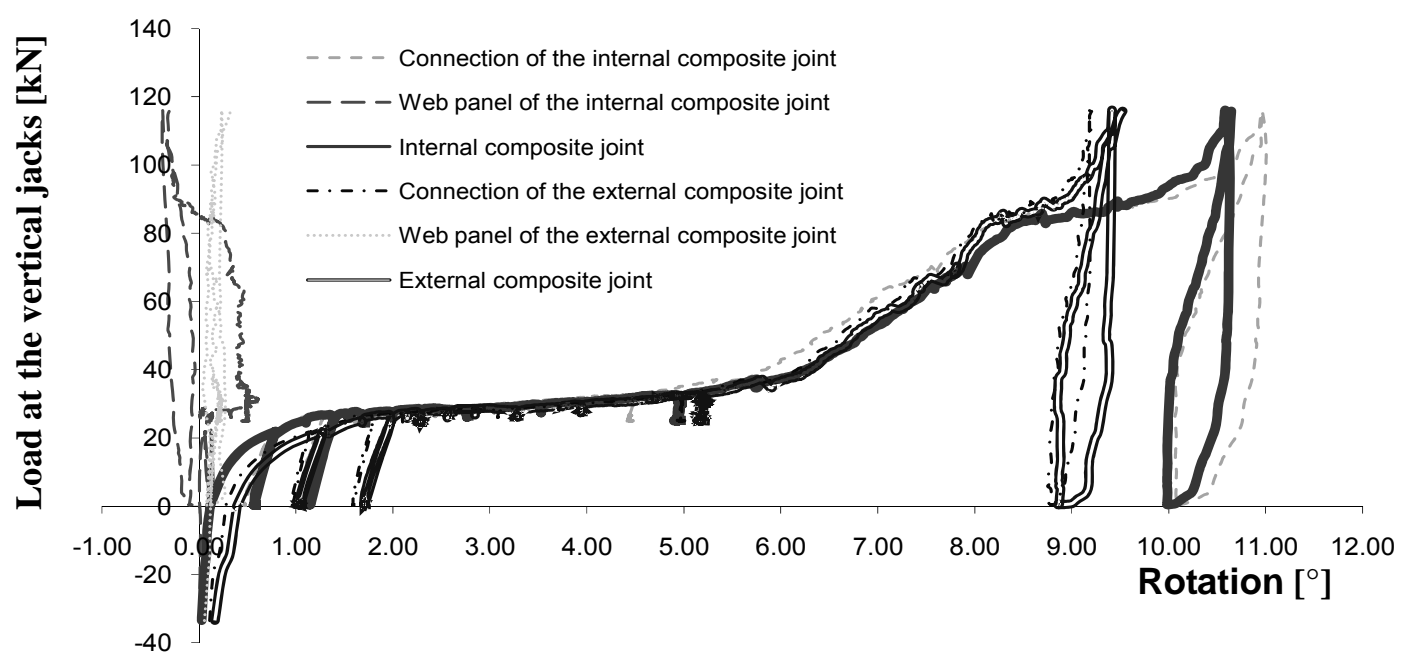

Figure 36. Rotation of the Internal and External Composite Joints 
After the test, the steel plates and the concrete blocks were removed so as to see the location of the cracks along the concrete slab. As shown in Figure 37, two big cracks appeared during the test in the vicinity of the external composite joints. This observation can be explain by the fact that, in the tested substructure, the composite joint configuration are composed of flush end-plates with the upper part embedded in the concrete slab; so, when the end-plates deform, the embedded part deformation can easily initiate a crack in the reinforced concrete slab as illustrated in Figure 38. However, the joints exhibited a very ductile behaviour during the test although to have one big crack is not the best situation from the ductility point of view.
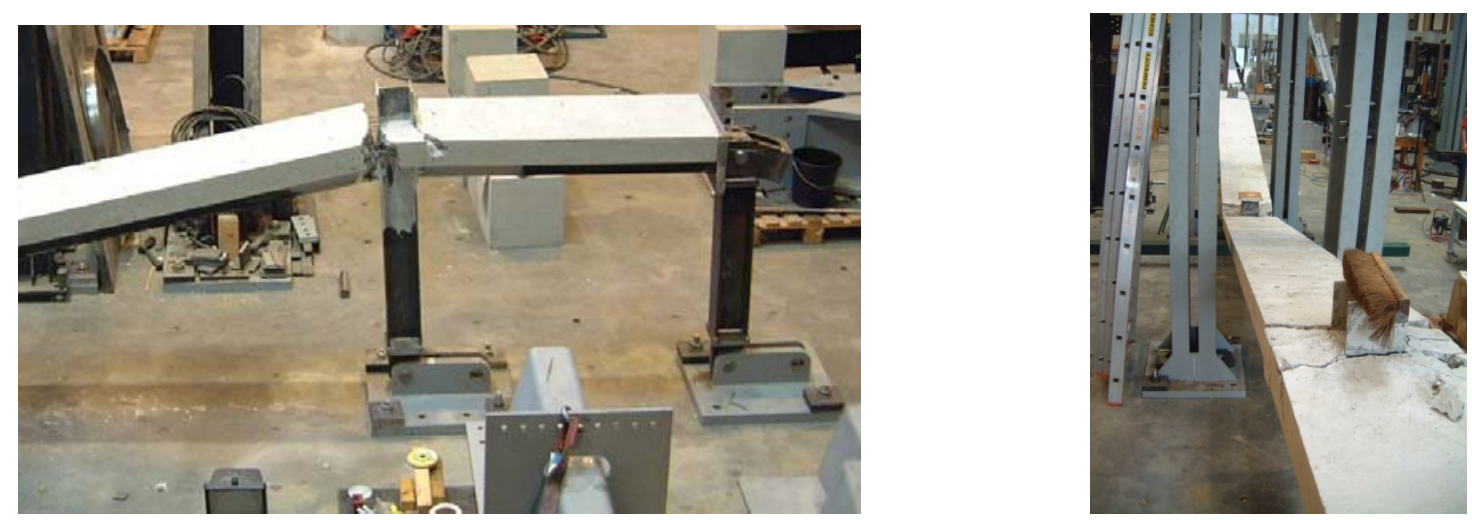

Figure 37. Distribution of the Cracks in the Concrete Slab

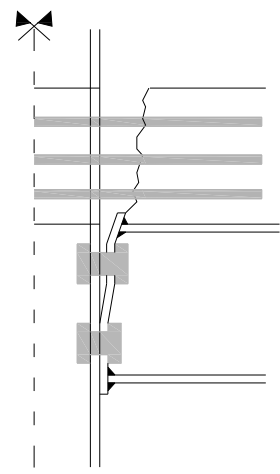

Figure 38. Crack associated to the Deformation of the End-Plate Embedded in the Concrete Slab

\section{CONCLUSIONS}

As part of a global research and development strategy, a laboratory test aiming at the simulation of the loss of a column in a composite frame has been carried at Liège University. The objective was to observe the development of membrane forces in the beams further to the loss of the column as well as the effects of these forces on the joint response.

The tested specimen was extracted from an actual frame designed according to Eurocode 4 recommendations and that, for conventional loading, i.e. design loads recommended in Eurocode 1, without specific account of exceptional events as the "loss of a column". The specimen and the test configuration were defined so as to get a behavioural response as close as possible to the one that the actual frame would have exhibited.

The main measurements which were registered are the vertical displacement at the level of the lost column, the rotations within the structural joints and the horizontal displacements and forces appearing at the specimen extremities. 
The test, which constitutes a European "premiere", was successful and all the phenomena under investigations were registered. Indeed, the development of membrane forces in the system was observed, what was confirmed by the measurement of membrane forces in the beams. Also, the composite joints loaded by combined tensile forces and bending moments exhibited a ductile behaviour as expected.

The results obtained through this test have been used to investigate the validity of a numerical FEM tool and to develop analytical models in (Demonceau [2]) which is freely downloadable at http://orbi.ulg.ac.be/handle/2268/2740.

\section{References}

[1] Kuhlmann U., Rolle L., Jaspart J.-P., Demonceau J.-F., Vassart O., Weynand K., Ziller C., Busse E., Lendering M., Zandonini R. and Baldassino N., "Robust structures by joint ductility”, Final report of the RFCS project N RFS-CR-04046, 2008 (report accepted - to be published).

[2] Demonceau J.-F., "Steel and composite building frames: sway response under conventional loading and development of membrane effects in beams further to an exceptional action”, $\mathrm{PhD}$ thesis presented at Liège University, 2008 (downloadable at http://orbi.ulg.ac.be/handle/2268/2740).

[3] EN 1994-1-1, "Eurocode 4: Design of steel and concrete structures- Part 1-1: general rules and rules for buildings”, CEN - European Committee for Standardization, December 2004.

[4] EN 1991-1-1, "Eurocode 1: Actions on structures - Part 1-1: General actions - Densities, self-weight, imposed loads for buildings”, CEN - European Committee for Standardization, April 2002.

[5] EN 1998-1. "Eurocode 8: Design of structures for earthquake resistance - Part 1: General rules, seismic actions and rules for buildings”. European CEN - European Committee for Standardization, December 2004.

[6] Kuhlmann U. and Schäfer M., "Innovative verschieblichte Verbund-Rahmen mit teiltragfähigen Verbund-Knoten“, Forschung für die Praxis P 505, Forschungsvereinigung Stahlanwendung e.V. im Stahl-Zentrum, 2004.

[7] EN 1992-1-1, "Eurocode 2: Design of concrete structures - Part 1-1: General rules and rules for buildings”, European CEN - European Committee for Standardization, December 2004. 


\title{
EXPERIMENT AND FE ANALYSIS ON SHEAR RESISTANCE OF COLD-FORMED STEEL STUD ASSEMBLED WALL IN RESIDENTIAL STRUCTURE
}

\author{
Xuhong Zhou ${ }^{1,2}$, Yongjun $\mathrm{He}^{1, *}$, Yu Shi ${ }^{3}$, Tianhua Zhou ${ }^{4}$ and Yongjian Liu ${ }^{4}$ \\ ${ }^{I}$ Professor, College of Civil Engineering, Hunan University, Changsha, 410082, China \\ ${ }^{2}$ Professor, Lanzhou University, Lanzhou, 730000, China \\ ${ }^{3}$ Lecturer, ${ }^{4}$ Professor, Chang'an University, Xi'an, 710064, PR China \\ *(Corresponding author: E-mail: hyj0087@163.com)
}

Received: 1 December 2009; Revised: 22 January 2010; Accepted: 18 February 2010

\begin{abstract}
In this paper, experiment and finite element (FE) method are adopted to study the shear resistance of cold-formed steel stud walls in low-rise residential structures. Firstly, the shear resistance of the cold-formed steel stud assembled walls under monotonic loading is tested. The test models, including walls with single-sided gypsum sheathing, walls with single-sided oriented strand board sheathing, and walls with gypsum sheathing on the back and oriented strand board on the front, are made in full scale of engineering project. The test apparatus, test method, and the failure process of the specimens are introduced in detail. Then, based on the ANSYS program, the FE model of the cold-formed steel stud walls considering geometric large deformation and materials nonlinearity is presented. The walls are simulated as shell elements. The studs as well as the tracks are simply connected, and the screws connecting the sheathings to the frame are modeled by coupling methods. The validity of the FE method is verified, and then a series of parametric analyses are carried out. All this work will provide guidance in theory for practical application of this kind of wall.
\end{abstract}

Keywords: Cold-formed steel; Assembled wall; Shear resistance; Experimental research; Finite element analysis

\section{INTRODUCTION}

Assembled walls are the main load-bearing members of the cold-formed steel residential buildings, and the cold-formed steel stud walls are assembled by C-shaped steel studs (channel with lip flanges), U-shaped tracks(channel without lip flanges), gypsum board, and oriented strand board (OSB), which are connected by self-piercing or self-drilling screws(NASFA [1]).

The shear resistance of the cold-formed steel stud walls is associated with many factors, such as materials of studs and sheathing, screw spacing, height-width ration of wall, stud spacing and so on. So it is difficult to be determined only by theoretical calculation, and the available researches have been carried out mainly by test method (AISI [2], Serrette and Ogunfunmi [3], and Serrette et al. [4]). However, tests can not totally reflect the influence of all the factors on the shear resistance of walls. Finite element (FE) method validated by test is an effective method to study it (Xia and Dong [5], Emad et al. [6]). Many scholars have only studied the shear resistance for a certain kind of cold-formed steel stud walls because of the complex factors mentioned above. In order to provide design guidelines, tests and FE analyses are carried out to study the shear resistance of the cold-formed steel stud walls in residential structures, and many influencing factors are also analyzed in this paper.

\section{TEST PROGRAM}

\subsection{Details of Specimens}

The configurations of specimens are described in Table 1 , and the walls with size of $3 \mathrm{~m} \times 2.4 \mathrm{~m}$ (height by wide) and $1.0 \mathrm{~mm}$ thick steel framing are sheathed with gypsum or OSB sheathing. But 
there is a vertical connecting seam on the wall because every board is only half the width of the wall, and there is a horizontal connecting seam on the wall sheathed with OSB because the length of the OSB sheathing is shorter than that of the wall, so a steel strap with $50 \mathrm{~mm}$ wide and $1.0 \mathrm{~mm}$ thick is fixed along the horizontal connecting seam to strengthen the wall. The studs in the middle of the wall are single $\mathrm{C}$-shaped cold-formed steel members, and the studs at both ends of the wall are two back-to-back C-shaped members connected by two lines of self-drilling screws. The $16 \mathrm{~mm}$ diameter uplift anchors are used to connect the walls to the test beam at the corner of the wall, and the top and bottom tracks of the wall are fixed to the test beam by $12 \mathrm{~mm}$ diameter shear anchors. The yield strength of steel $f_{y}$ is $320 \mathrm{~N} / \mathrm{mm}^{2}$, the ultimate tensile strength $f_{u}$ is $379 \mathrm{~N} / \mathrm{mm}^{2}$, and the extension percentage of steel is $34 \%$. The configuration of the DSGO wall (wall with gypsum sheathing on the back and oriented strand board on the front) is displayed in Figure 1.

Table 1. Specimens of Shear Wall Tests

\begin{tabular}{|c|c|c|c|c|}
\hline $\begin{array}{l}\text { Denotation } \\
\text { of wall } \\
\text { specimens }\end{array}$ & Sheathing & $\begin{array}{l}\text { Self-drilling } \\
\text { fastener }\end{array}$ & $\begin{array}{l}\text { Fastener } \\
\text { spacing }\end{array}$ & Cold-formed steel member \\
\hline SSG & $\begin{array}{l}\text { gypsum board on one side, } \\
\text { with dimensions of } 1.2 \mathrm{~m} \times 3 \mathrm{~m} \\
\text { and thickness of } 12 \mathrm{~mm}\end{array}$ & ST4.2 & & $\begin{array}{l}\text { C } 89 \times 44.5 \times 12 \times 1.0 \text { studs (lipped } \\
\text { channel section with web height }\end{array}$ \\
\hline $\mathrm{SSO}$ & $\begin{array}{l}\text { OSB on one side, with } \\
\text { dimensions of } 1.2 \mathrm{~m} \times 2.44 \mathrm{~m} \\
\text { and thickness of } 9 \mathrm{~mm}\end{array}$ & ST4.8 & $\begin{array}{l}\text { the } \\
\text { perimeter } \\
\text { and } 300 \mathrm{~mm} \\
\text { in the }\end{array}$ & $\begin{array}{l}89 \mathrm{~mm} \text {, flange width } 44.5 \mathrm{~mm} \text {, } \\
\text { lip width } 12 \mathrm{~mm} \text { and thickness } \\
1 \mathrm{~mm} \text { ), Spaced } 600 \mathrm{~mm} \text { on center } \\
\text { U92 } \times 40 \times 1.0 \text { tracks (channel } \\
\text { section with web height } 91 \mathrm{~mm}\end{array}$ \\
\hline DSGO & $\begin{array}{l}\text { gypsum board with thickness } \\
\text { of } 12 \mathrm{~mm} \text { on one side and } \\
\text { OSB with thickness of } 9 \mathrm{~mm} \\
\text { on the other side }\end{array}$ & $\begin{array}{l}\text { ST4.2 and } \\
\text { ST4.8 }\end{array}$ & $\begin{array}{c}\text { middle field } \\
\text { of board }\end{array}$ & $\begin{array}{c}\text { flange width } 40 \mathrm{~mm} \text { and } \\
\text { thickness } 1 \mathrm{~mm} \text { ) } \\
50 \mathrm{~mm} \times 1.0 \mathrm{~mm} \text { strap }\end{array}$ \\
\hline
\end{tabular}

\section{$2.2 \quad$ Test Apparatus}

The test apparatus are shown in Figure 2. The horizontal load is applied to the wall through electro-hydraulic servo actuator, and the lateral braces are also provided to limit out-of-plane movement of the test wall. The test process is operated by M2801 servo-control mechanism and computer. All the test data are collected by $7 \mathrm{~V} 08$ date collector.

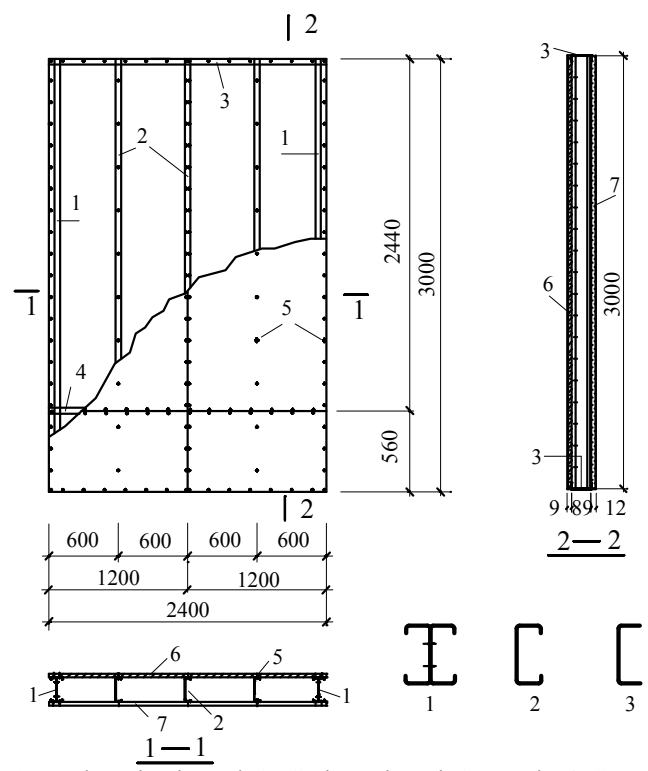

1. Back-to-back stud; 2. C-shaped stud; 3. Track; 4. Strap; 5. Self-drilling fastener; 6. Gypsum sheathing; 7. OSB sheathing Figure 1. Configuration of the DSGO Wall

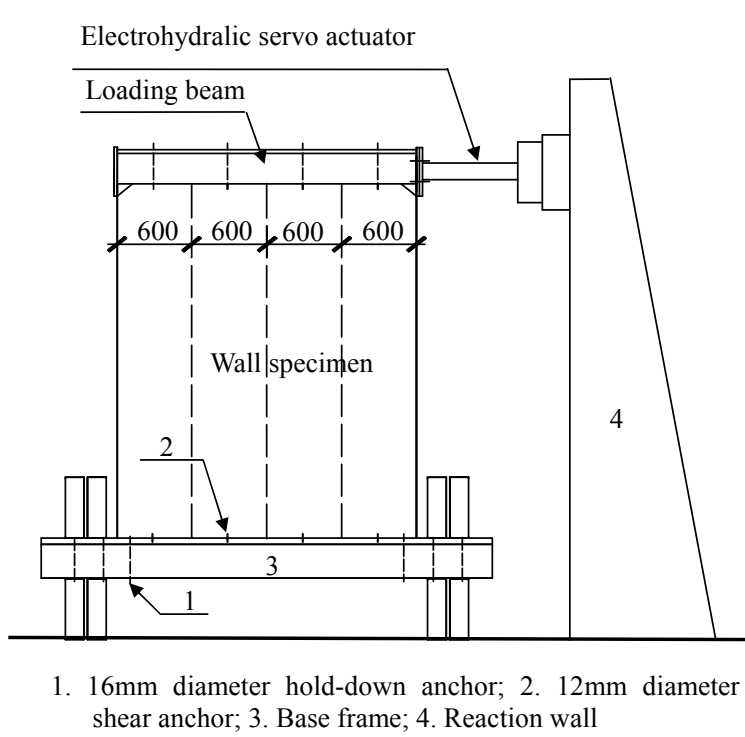

Figure 2. Test Apparatus 


\subsection{Loading Process and Failure Characteristics of the Specimens}

The specimens are loaded to yield period by controlling 5 7 loading steps. After yielding, the specimens are loaded to failure by controlling displacement steps. And the duration of each loading stage is about 3 minutes. It is found that the shear resistance and stiffness of the SSG (single-sided gypsum sheathing) specimen are lower. As a result, the relative rotation occurs between the two panels of gypsum sheathings, and their vertical connecting seams offset. The gypsum sheathing is torn at the corner of the wall (as shown in Figure 3(a)). The shear resistance strength and ductility of the SSO wall (wall with single-sided oriented strand board sheathing) are better than those of the SSG wall, but the horizontal connecting seam in the SSO wall has influence on its bearing capacity and stiffness. With increase of the load, the buckling of the steel strap occurs apparently (as shown in Figure 3(b)), and the slip of the four panels of OSB sheathing is relatively great (as shown in Figure 3(c)), which makes the shear stiffness of the wall reduced. The integrity, strength, and stiffness of the DSGO wall remarkably excel those of the SSG wall and SSO wall. But the failure modes of three kinds of walls are similar. In general, when the failure of all the wall specimens occur under the shear load, most of the screw connecting sheathing and steel members around the wall fail, and local buckling of the stud on the end of the wall takes place (as shown in Figure 3(d)). But the gypsum sheathing or OSB sheathing does not drop off integrally due to the less damage of the screw connections in the middle field of the wall, so we can conclude that the screws at the perimeter bear higher shear load than those in the middle field.

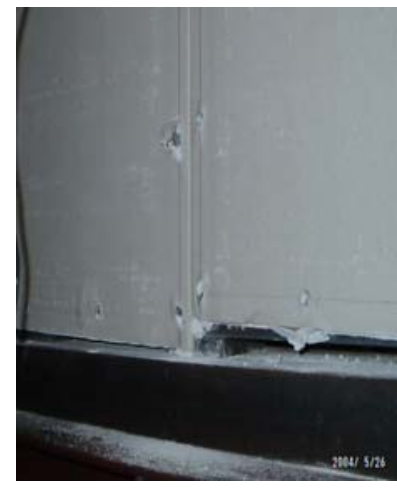

(a)

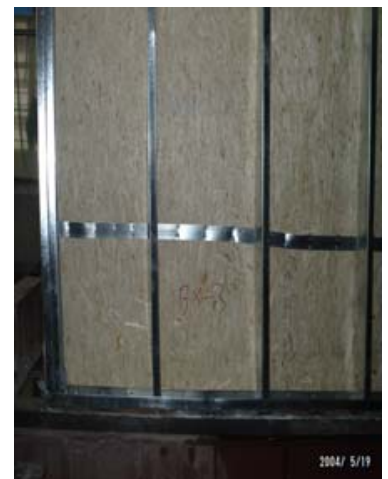

(b)

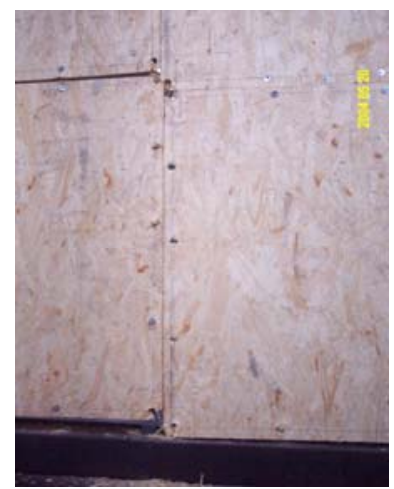

(c)

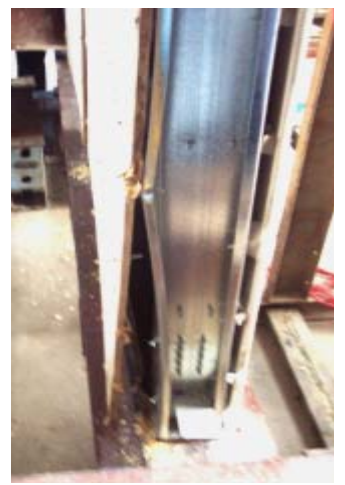

(d)

Figure 3. Failure Modes of Specimens:

(a) Gypsum Sheathing Tearing at Corner of Wall; (b) Buckling of Strap;

(c) Slip of Four Panels of OSB Sheathing; (d) Local Buckling of Studs

\section{$2.4 \quad$ Analysis of the Test Results}

The shear load-displacement $(P-\Delta)$ curves of all the wall specimens are showed in Figure 4 . The yield load of all the walls can not been easily found from these curves, so all the characteristic loads including yield load are determined by the method prescribed in Chinese Specification of Testing Methods for Earthquake Resistant Building (JGJ 101-96 [7]). The method for determining the characteristic loads of the wall is illustrated in Figure 5. Horizontal Line AB is drawn form the point A defining maximum load $P_{\max }$, then secant $\mathrm{OD}$ is drawn intersecting line $\mathrm{AB}$ and curve $\mathrm{OA}$ at point $\mathrm{D}$ and $\mathrm{C}$ respectively on condition that the area $\mathrm{ADCA}$ is equal to the area CFOC. $\mathrm{A}$ vertical line is drawn form point $\mathrm{D}$ intersecting curve $\mathrm{OA}$ at point $\mathrm{E}$. The shear load and the corresponding displacement of point E are the yield load $P_{y}$ and the yield displacement $\Delta_{y}$ of the wall, respectively. After the maximum value, the load will descend with the increase of the displacement, and when it descends to $0.85 P_{\max }$, the corresponding load and displacement are 
defined as the failure load $P_{u}$ and displacement $\Delta_{u}$, respectively. The test results determined by the method described above are listed in Table 2.

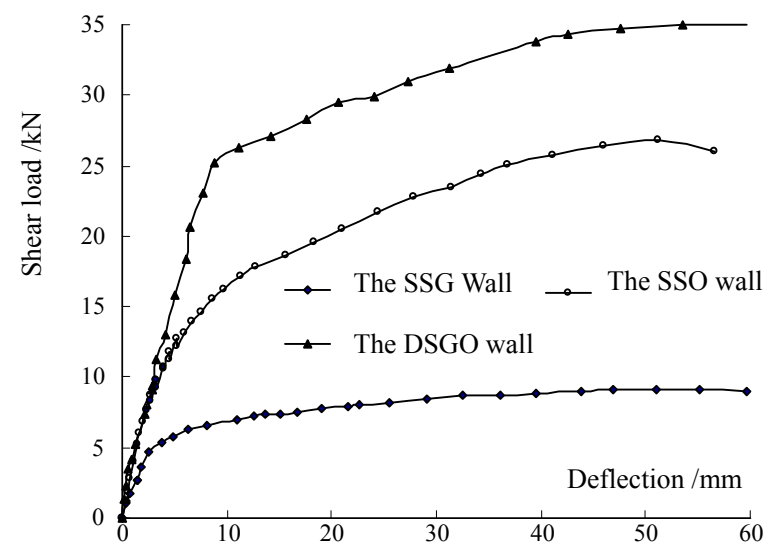

Figure 4. Load Displacement Curves of the Specimens

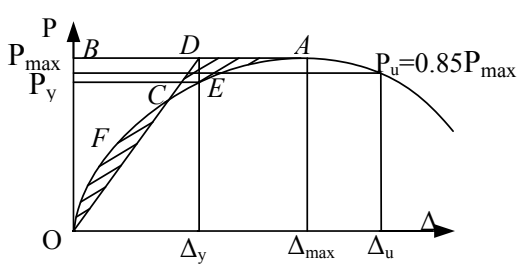

Figure 5. Determination for Special Load Points of the Specimens

Table 2. Experimental Results

\begin{tabular}{cccccccc}
\hline $\begin{array}{c}\text { Wall } \\
\text { type }\end{array}$ & $\mathrm{P}_{\mathrm{y}}(\mathrm{kN})$ & $\begin{array}{c}\Delta_{\mathrm{y}} \\
(\mathrm{mm})\end{array}$ & $\begin{array}{c}\mathrm{P}_{\max } \\
(\mathrm{kN})\end{array}$ & $\begin{array}{c}\Delta_{\max } \\
(\mathrm{mm})\end{array}$ & $\mathrm{P}_{\mathrm{u}}(\mathrm{kN})$ & $\begin{array}{c}\Delta_{\mathrm{u}} \\
(\mathrm{mm})\end{array}$ & $\begin{array}{c}\text { Shear } \\
\text { resistance } \\
(\mathrm{kN} / \mathrm{m})\end{array}$ \\
\hline SSG & 7.48 & 13.5 & 9.12 & 48 & 7.75 & 74.8 & 3.8 \\
$\mathrm{SSO}$ & 21.5 & 23.9 & 26.84 & 51.21 & 22.81 & 68 & 11.18 \\
$\mathrm{DSGO}$ & 29.12 & 19.6 & 34.99 & 59.62 & 29.72 & 74 & 14.58 \\
\hline
\end{tabular}

It is found from the table that, the yield load $P_{y}$, maximum load $P_{\max }$, and failure load $P_{u}$ of the SSO wall are approximately 2.87, 2.94, and 2.94 times those of the SSG wall under the monotonic loading. That is, the load bearing capacity of the wall with single-sided gypsum sheathing is $34 \sim 34.8 \%$ that of the wall with single-sided OSB sheathing.

The sum of the yield loads of the SSG and SSO walls is $28.98 \mathrm{kN}$, sum of the maximum loads of those two kinds of walls is $35.96 \mathrm{kN}$, and that of the failure loads of them is $30.56 \mathrm{kN}$, which are close to the corresponding yield load $29.12 \mathrm{kN}$, maximum load $34.99 \mathrm{kN}$, and failure load $29.72 \mathrm{kN}$ of the DSGO wall, respectively. This indicates that the total load bearing capacity of the two kinds of single-sided walls is close to that of the double-faced wall with the two corresponding kinds of sheathings.

\section{FE ANALYSIS}

\subsection{FE Analysis Model}

FE model is a mathematic representation of the practical structure, and it should reflect the main performance of every member. The equilibrium equation of the wall is given by

$[K]\{\delta\}=[P]$ 
where $[P]$ and $\{\delta\}$ are the nodal displacement and load vectors, respectively; $[K]=\int_{V}[B]^{\mathrm{T}}[D][B] d V$ is the structural stiffness matrix, $[B]$ and $[D]$ denote the geometric and material constitutive matrices, respectively, and $V$ represents the structural volume. In addition,

$$
\begin{aligned}
& \{\sigma\}=[D]\{\varepsilon\} \\
& \{\varepsilon\}=[B]\{\delta\}
\end{aligned}
$$

in which $\{\sigma\}$ and $\{\varepsilon\}$ are the stress and stain matrices, respectively.

Since the geometrical and materials nonlinearities are considered in the equilibrium equation, the both matrices $[B]$ and $[D]$ are related to the stress or strain, the structural stiffness matrix $[K]$ is therefore not constant in the process of gradually loading.

The FE analysis software ANSYS (ANSYS version 10.0 [8]) is adopted to analyze the wall specimens under the monotonic load. The plastic shell element 'Shell181' is used to simulate the cold-formed steel members and sheathing panels, and the material properties referring to the References (Kasal and Leichti [9], Thomas [10], Zhou and He [11]) are listed in Table 3. The screw

Table 3. Material Properties of Specimen

\begin{tabular}{cccc}
\hline Material & $\begin{array}{c}\text { Young's modulus } \\
\left(\mathrm{N} / \mathrm{mm}^{2}\right)\end{array}$ & $\begin{array}{c}\text { Tensile strength } \\
\left(\mathrm{N} / \mathrm{mm}^{2}\right)\end{array}$ & Poisson's ratio \\
\hline Gypsum board & 1124.7 & 0.66 & 0.23 \\
OSB & 3500 & 7.86 & 0.3 \\
Steel & $2.06 \mathrm{e} 5$ & 320 & 0.3 \\
\hline
\end{tabular}

connections are handled by coupling method, and the screws are assumed to have free rotations but no displacements along $X_{-}, Y_{-}$, and $Z$-directions without considering the slip between the sheathing and the steel members. The studs and tracks are simply connected. The displacements of the bottom track along $X$-, $Y$-, as well as $Z$-directions and rotations along $Y$ - and $Z$-directions are restrained, that

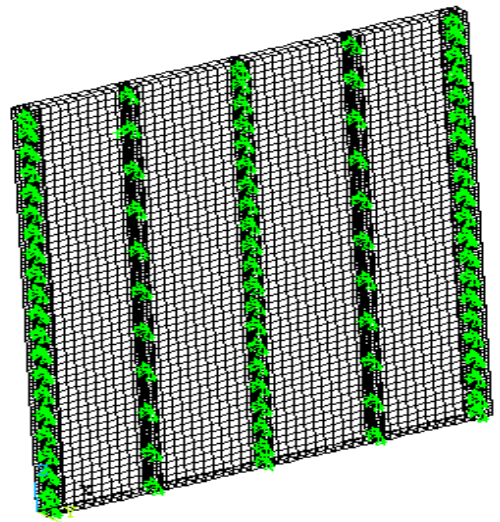

Figure 6. FE Model of Wall 
is, $U_{X}=0, U_{Y}=0, U_{Z}=0, \theta_{Y}=0$, and $\theta_{Z}=0$. Additionally, the top track is assumed to have no displacement and rotation along $Y$ - and $Z$-directions, i.e., $U_{Y}=0, U_{Z}=0, \theta_{Y}=0$, and $\theta_{Z}=0$. The FE model is shown in Figure 6, in which the nodes of top track are coupled in $X$-direction and the displacement corresponding to the maximum load is applied on the coupled nodes. The loading process is also controlled by displacement.

\subsection{Analyses of the Specimens}

To verify the validity of the above-mentioned FE method, the test specimens of the SSG, SSO and SSGO walls described in Section 2 are analyzed first, and the analytical results are displayed in Figures 7-9. It is found that, when the horizontal monotonic load is applied to the top point $c$, the side $a c$ of the walls is in tension while the side $b d$ is in compression, and the walls slope. In addition, the sheathing is mainly damaged in the screw connections at both the top and the bottom of the walls, and local buckling occurs at the top and bottom ends of the compressed back-to-back studs, even the overall buckling of the stud No. 4 in the single-sided wall. But the studs in the double-faced wall have lighter distortion than those in the single-sided wall, since the double-faced sheathing can constrain the steel frame more effectively than the single-sided sheathing.

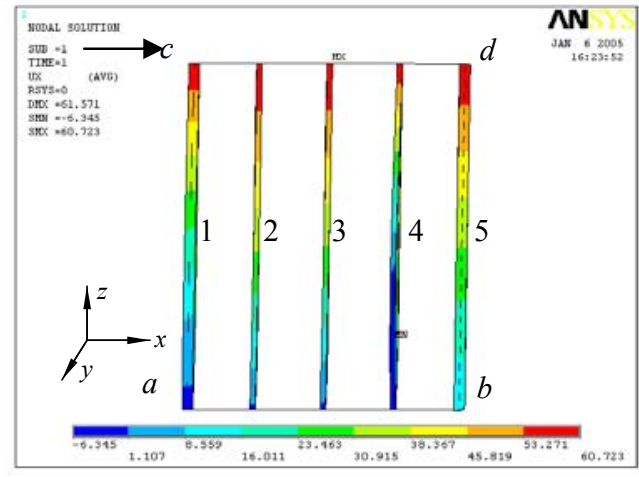

(a)

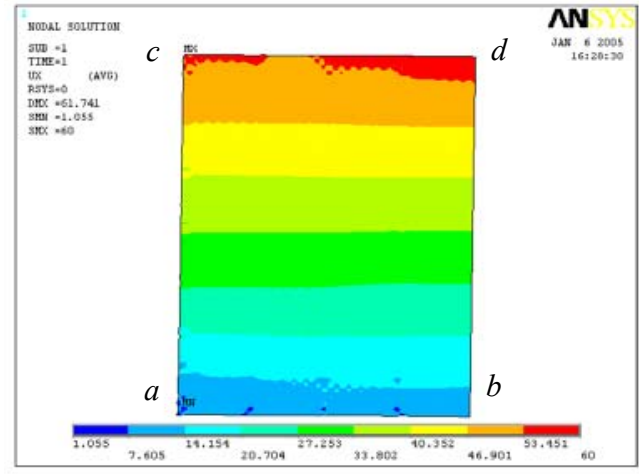

(b)

Figure 7. Displacement of the SSG Wall: (a) Displacement along X-direction of Steel Framing Gypsum; (b) Displacement along X-direction of Sheathing

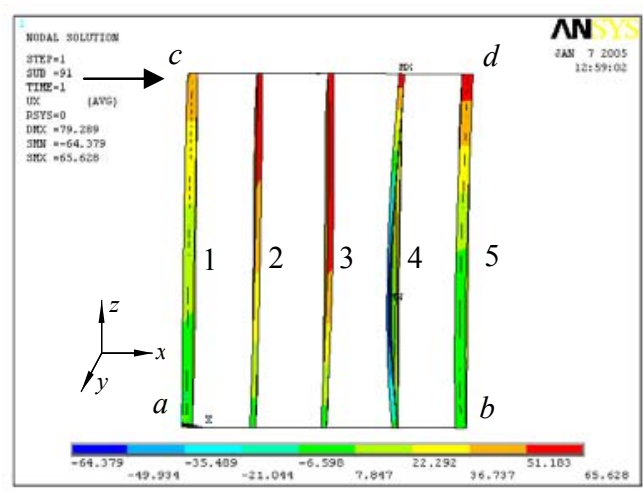

(a)

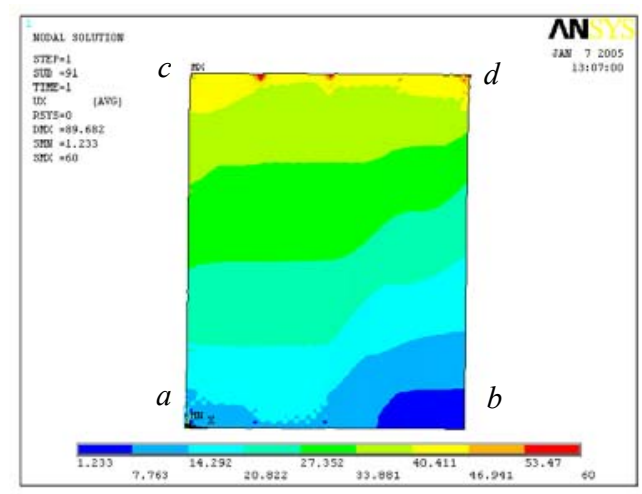

(b)

Figure 8. Displacement of the SSO Wall: (a) Displacement along X-Direction of Steel Framing; (b) Displacement along X-Direction of OSB 


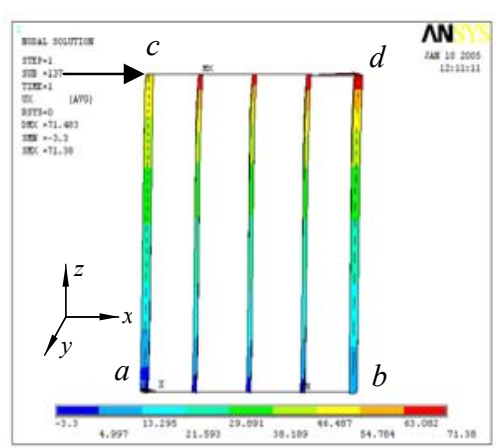

(a)

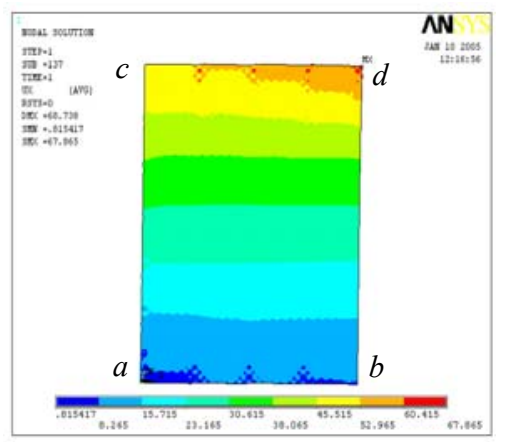

(b)

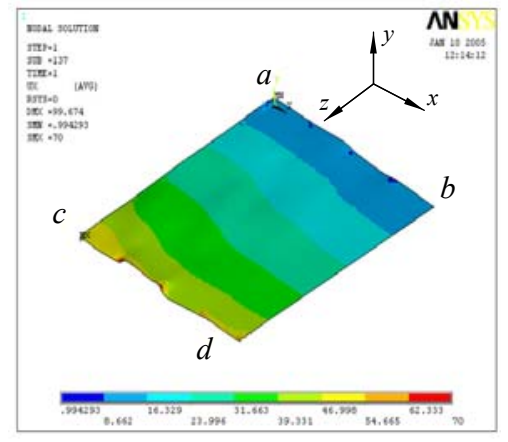

(c)

Figure 9. Displacement of the DSGO Wall: (a) Displacement along X-Direction of Steel Framing; (b) Displacement along X-Direction of Gypsum Sheathing; (c) Displacement along X-Direction of OSB

From the comparison of the load-displacement curves as shown in Figure 10, it can be seen that the results by FE analysis are very close to those by test. Since there are not obvious characteristic points in the load-displacement curves, they are determined according to the methods suggested in Chinese Specification of Testing Methods for Earthquake Resistant Building (JGJ 101-96 [7]). And the result comparisons between the test and FE analysis are shown in Table 4.

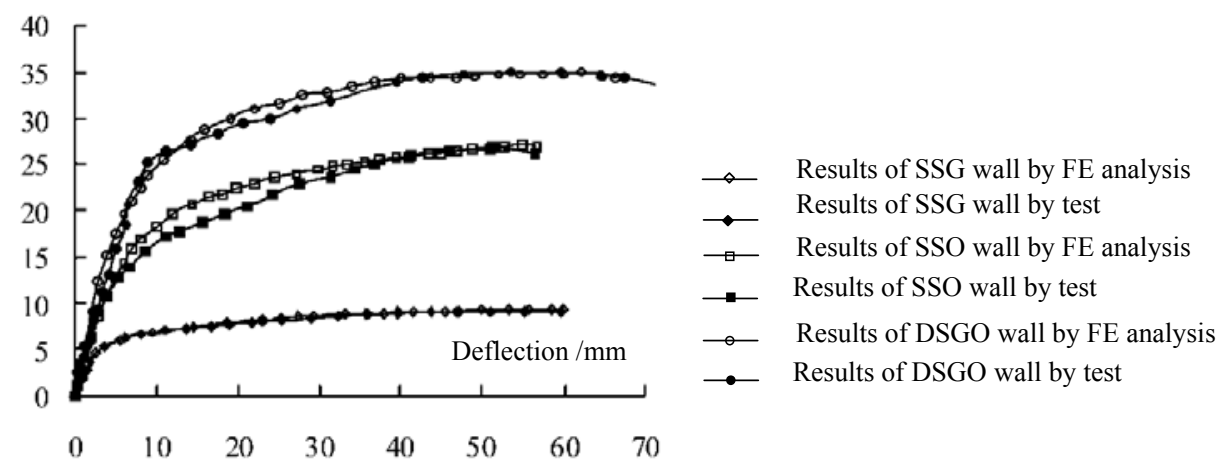

Figure 10. Comparison of the Results between Test and FE Analysis

Table 4. The Results of Test and FE Analyses

\begin{tabular}{ccccccc}
\hline Wall type & Items & $\begin{array}{c}\mathrm{P}_{\mathrm{y}} \\
(\mathrm{kN})\end{array}$ & $\begin{array}{c}\Delta_{\mathrm{y}} \\
(\mathrm{mm})\end{array}$ & $\begin{array}{c}\mathrm{P}_{\max } \\
(\mathrm{kN})\end{array}$ & $\begin{array}{c}\Delta_{\max } \\
(\mathrm{mm})\end{array}$ & $\begin{array}{c}\text { Shear } \\
\text { resistance } \\
(\mathrm{kN} / \mathrm{m})\end{array}$ \\
\hline \multirow{2}{*}{ SSG } & Test & 7.48 & 13.5 & 9.12 & 48 & 3.8 \\
& FE analysis & 7.71 & 16.59 & 9.29 & 59.79 & 3.87 \\
\multirow{2}{*}{ SSO } & Test & 21.5 & 23.9 & 26.84 & 51.21 & 11.18 \\
& FE analysis & 22.46 & 20.33 & 26.98 & 55.15 & 11.24 \\
& Test & 29.12 & 19.6 & 34.99 & 59.62 & 14.58 \\
& FE analysis & 29.73 & 17.92 & 34.86 & 60.11 & 14.52 \\
\hline
\end{tabular}

The displacements of the walls related to the yield point and maximum load point measured by test differ somewhat from those obtained by FE analysis, and the maximum error reaches to $24.56 \%$. But the errors of shear load bearing capacities of the SSG, SSO, and DSGO walls are only $0.34 \%$ to $1.84 \%$, and those of yield loads of these three kinds of walls are only $2.1 \%$ to $6.03 \%$. So the results 
by FE analysis are very consistent with those by test. Especially, the shear resistance of the SSO wall obtained by FE analysis is $11.24 \mathrm{kN} / \mathrm{m}$, which is only $3.1 \%$ lower than that of the wall with the same configuration presented in Reference (The Japan Iron and Steel Federation [12]). This indicates that the method of FE analysis adopted in this paper is correct and valid.

\subsection{Parametric Analyses}

Based on the FE method, a series of parametric analyses on the SSG, SSO, and DSGO walls are carried out in this section to study the influence of the steel strength, stud spacing, stud height, and screw spacing on the shear load bearing capacity of the walls.

\subsubsection{Influence of the steel strength on the shear resistance of wall}

The yield strength of steel in the wall with single-sided gypsum sheathing is $320 \mathrm{~N} / \mathrm{mm}^{2}$, and the maximum resistance of the wall is $9.29 \mathrm{kN}$. But when the steel yield strength of this wall is changed to $205 \mathrm{~N} / \mathrm{mm}^{2}$, the maximum resistance calculated by FE method is $8.95 \mathrm{kN}$, which is only $3.65 \%$ lower than that of the former. For more clarity, the load-displacement curves of those two kinds of walls are showed in Figure 11. Obviously, the change of steel strength has little influence on the shear resistance of the wall.

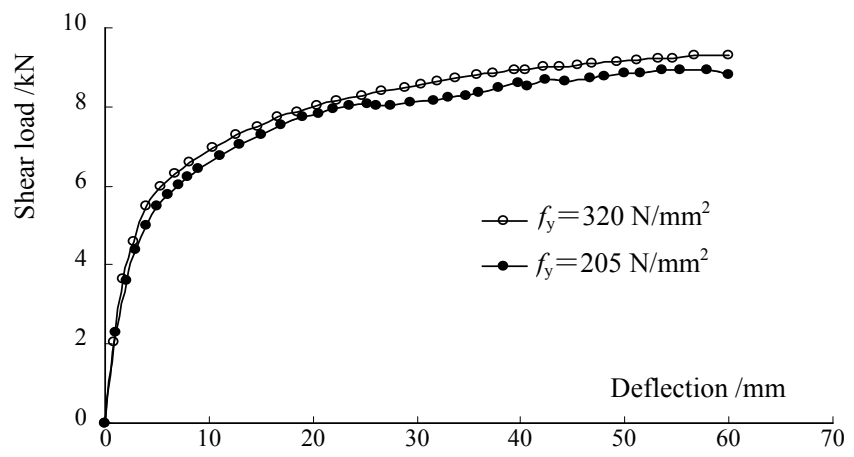

Figure 11. Load-Displacement Curves of the SSG Walls with Different

\subsubsection{Influence of the studs spacing on the shear resistance}

The studs of cold-formed steel stud walls usually space $400 \mathrm{~mm}$ and $600 \mathrm{~mm}$. However, stud spacing of the test specimens and the FE models described above is $600 \mathrm{~mm}$. Now the stud spacing of the SSG, SSO, and the DSGO walls is adjusted as $400 \mathrm{~mm}$, and the FE analytical results of these walls are listed in Table 5, and the load-displacement curves are showed in Figure 12. It can be seen that, when the stud spacing reduce from $600 \mathrm{~mm}$ to $400 \mathrm{~mm}$, the shear resistances of the SSG, SSO, and the DSGO walls increase by $14.47 \%, 24.11 \%$, and $29.96 \%$, respectively. Therefore, the stud spacing has remarkable influence on the shear load bearing capacity of the cold-formed steel stud walls, and this influence is strengthened with increase of the sheathing restriction.

Table 5. FE Analysis Results of the Walls

\begin{tabular}{cccc}
\hline Wall type & Stud spacing $(\mathrm{mm})$ & $\mathrm{P}_{\max }(\mathrm{kN})$ & $\begin{array}{c}\text { Shear resistance } \\
(\mathrm{kN} / \mathrm{m})\end{array}$ \\
\hline \multirow{2}{*}{ SSG } & 400 & 10.62 & 4.43 \\
& 600 & 9.29 & 3.87 \\
\multirow{2}{*}{ SSO } & 400 & 33.47 & 13.95 \\
& 600 & 26.98 & 11.24 \\
\multirow{2}{*}{ DSGO } & 400 & 45.29 & 18.87 \\
& 600 & 34.84 & 14.52 \\
\hline
\end{tabular}




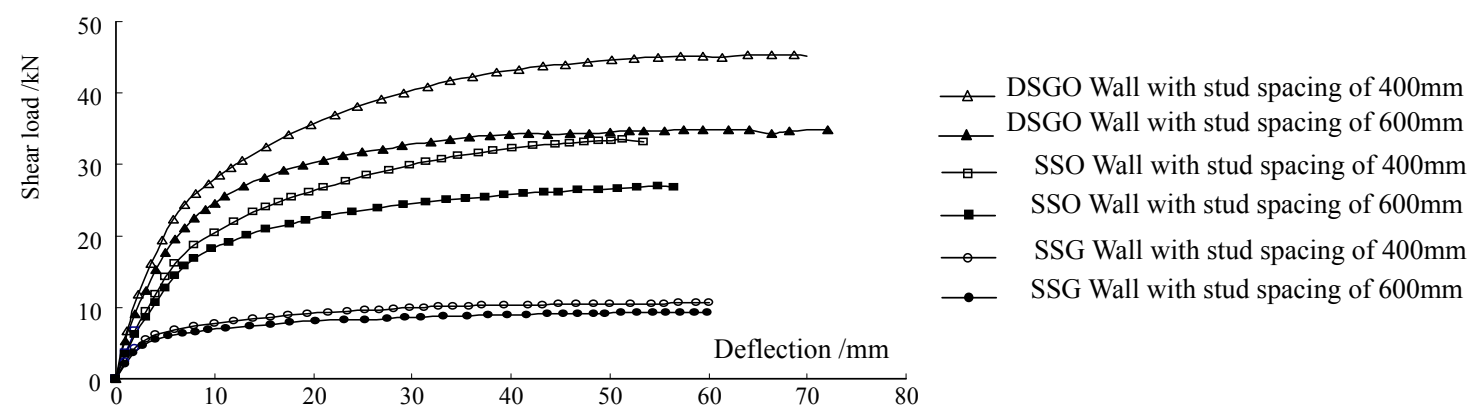

Figure 12. Load-displacement Curves of Cold-formed Steel Stud Walls with Different Stud Spacing

\subsubsection{Influence of the height-width ratio of wall on the shear resistance}

To investigate the influence of the height-width ratio of wall on the shear resistance, three walls with single-sided gypsum sheathing are analyzed by FE method, in which the widths of the walls are all $2.4 \mathrm{~m}$ and the heights are $2.4 \mathrm{~m}, 2.7 \mathrm{~m}$, and $3 \mathrm{~m}$, respectively. The analytical results are listed in Table 6, and the load-displacement curves are showed in Figure 13.

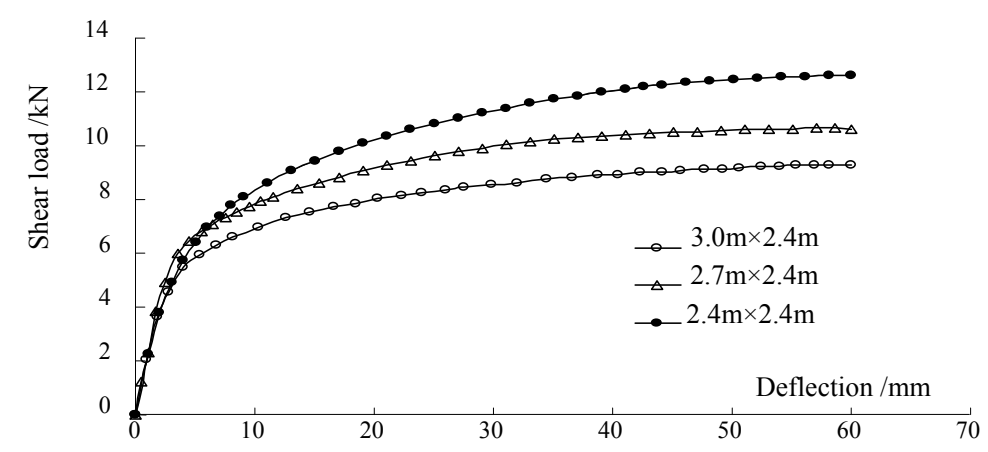

Figure 13. Load-displacement Curves of SSG Walls with Different Dimensions

Table 6. FE Analysis Results of the SSG Wall with Different Height-width Ratios

\begin{tabular}{cccc}
\hline $\begin{array}{c}\text { Dimension of walls } \\
(\text { height } \times \text { width })\end{array}$ & Height-width ratio & $\mathrm{P}_{\max }(\mathrm{kN})$ & $\begin{array}{c}\text { Shear resistance } \\
(\mathrm{kN} / \mathrm{m})\end{array}$ \\
\hline $2.4 \mathrm{~m} \times 2.4 \mathrm{~m}$ & $1: 1$ & 12.63 & 5.26 \\
$2.7 \mathrm{~m} \times 2.4 \mathrm{~m}$ & $1.125: 1$ & 10.63 & 4.44 \\
$3.0 \mathrm{~m} \times 2.4 \mathrm{~m}$ & $1.250: 1$ & 9.29 & 3.87 \\
\hline
\end{tabular}

It is found that, the shear resistance of the wall with dimensions of $3 \mathrm{~m} \times 2.4 \mathrm{~m}$ is $12.84 \%$ lower than that of wall with dimensions of $2.7 \mathrm{~m} \times 2.4 \mathrm{~m}$, whose shear resistance is then $15.59 \%$ lower than that of wall with dimensions of $2.4 \mathrm{~m} \times 2.4 \mathrm{~m}$. So the shear resistance of the wall will decrease with increase of the height-width ratio, the height-width ratio of the wall has large influence on the shear load bearing capacity.

\subsubsection{Influence of the screw spacing on the shear resistance}

Similarly, to investigate the influence of the screw spacing on the shear resistance of wall, the SSG, SSO, and the DSGO walls with different screw spacing are analyzed by FE method, and analytical results are listed in Table 7. 
Table 7. FE Analysis Results of the Walls with Different Screw Spacing

\begin{tabular}{cccc}
\hline Wall type & Screw spacing $(\mathrm{mm})$ & $\mathrm{P}_{\max }(\mathrm{kN})$ & Shear resistance $(\mathrm{kN} / \mathrm{m})$ \\
\hline \multirow{3}{*}{$\mathrm{SSG}$} & $100 / 300$ & 9.93 & 4.14 \\
& $150 / 300$ & 9.29 & 3.87 \\
& $150 / 150$ & 9.60 & 4 \\
\hline \multirow{3}{*}{$\mathrm{SSO}$} & $100 / 300$ & 27.34 & 11.39 \\
& $150 / 300$ & 26.98 & 11.24 \\
& $150 / 150$ & 27.74 & 11.56 \\
\hline \multirow{2}{*}{ DSGO } & $100 / 300$ & 38.52 & 16.05 \\
& $150 / 300$ & 34.84 & 14.52 \\
& $150 / 150$ & 35.53 & 14.80 \\
\hline
\end{tabular}

It is found that, the shear resistances of the walls increase with decrease of the screw spacing. When the screw spacing of these three kinds of walls, is adjusted from 150/150 (the screw spacing at the perimeter / that in the middle field of the wallboard) to 150/300, their shear resistance will increase by $3.36 \%, 2.85 \%$, and $1.93 \%$, respectively. And if the screw spacing is changed as $100 / 300$, the corresponding shear resistances of these three kinds of walls will respectively increase by $6.98 \%, 1.33 \%$, and $10.54 \%$, comparing with the walls with screw spacing of $150 / 300$. So we can conclude that, when the screw spacing is less than $300 \mathrm{~mm}$, the decrease of the screw spacing in the middle field has not remarkable influence on the shear resistance of the wall, but the shear resistance will be effectively strengthened with decrease of the screw spacing at the perimeter. This is consistent with the phenomenon observed in the test.

\subsection{Design Suggestions}

To guide actual engineering design, a great number of cold-formed steel stud walls with different values of parameters are further analyzed by FE method combined with test introduced in this paper. And the recommended shear resistances of the walls are presented in Table 8 , in which, the steel yield strength is $300 \mathrm{~N} / \mathrm{mm}^{2}$, sections of the studs and tracks are $\mathrm{C} 89 \times 44.5 \times 12 \times 1$ and $\mathrm{U} 92 \times 40 \times 1$, respectively.

Table 8. The Shear Resistances of Cold-formed Steel Stud Walls with Different Parameters

\begin{tabular}{|c|c|c|c|c|}
\hline $\begin{array}{c}\text { Dimension of wall } \\
\text { (height } \times \text { width) } \\
(\mathrm{m})\end{array}$ & $\begin{array}{c}\text { Stud } \\
\text { spacing } \\
(\mathrm{mm})\end{array}$ & $\begin{array}{l}\text { Screw } \\
\text { spacing } \\
(\mathrm{mm})\end{array}$ & Sheathing & $\begin{array}{c}\text { Shear } \\
\text { resistance } \\
(\mathrm{kN} / \mathrm{m})\end{array}$ \\
\hline \multirow[t]{14}{*}{$3 \times 2.4$} & \multirow{14}{*}{600} & \multirow{7}{*}{$150 / 300$} & $12 \mathrm{~mm}$ thick gypsum board on one side & 3.87 \\
\hline & & & 9mm thick OSB on one side & 11.24 \\
\hline & & & $12 \mathrm{~mm}$ thick OSB on one side & 13.48 \\
\hline & & & $\begin{array}{l}12 \mathrm{~mm} \text { thick gypsum board on one side and } 9 \mathrm{~mm} \\
\text { thick OSB on the other side }\end{array}$ & 14.52 \\
\hline & & & $12 \mathrm{~mm}$ thick gypsum board on both sides & 7.31 \\
\hline & & & $12 \mathrm{~mm}$ thick OSB on both sides & 25.1 \\
\hline & & & $\begin{array}{l}12 \mathrm{~mm} \text { thick gypsum board on one side and } 12 \mathrm{~mm} \\
\text { thick OSB on the other side }\end{array}$ & 17.11 \\
\hline & & \multirow{7}{*}{$100 / 300$} & $12 \mathrm{~mm}$ thick gypsum board on one side & 4.14 \\
\hline & & & $9 \mathrm{~mm}$ thick OSB on one side & 12.54 \\
\hline & & & $12 \mathrm{~mm}$ thick OSB on one side & 15.01 \\
\hline & & & $\begin{array}{l}12 \mathrm{~mm} \text { thick gypsum board on one side and } 9 \mathrm{~mm} \\
\text { thick OSB on the other side }\end{array}$ & 15.89 \\
\hline & & & $12 \mathrm{~mm}$ thick gypsum board on both sides & 7.94 \\
\hline & & & $12 \mathrm{~mm}$ thick OSB on both sides & 25.12 \\
\hline & & & $\begin{array}{l}12 \mathrm{~mm} \text { thick gypsum board on one side and } 12 \mathrm{~mm} \\
\text { thick OSB on the other side }\end{array}$ & 18.45 \\
\hline
\end{tabular}




\begin{tabular}{|c|c|c|c|c|}
\hline & \multirow{14}{*}{400} & \multirow{7}{*}{$150 / 300$} & $12 \mathrm{~mm}$ thick gypsum board on one side & 4.43 \\
\hline & & & 9mm thick OSB on one side & 13.95 \\
\hline & & & $12 \mathrm{~mm}$ thick OSB on one side & 21.26 \\
\hline & & & $\begin{array}{l}12 \mathrm{~mm} \text { thick gypsum board on one side and } 9 \mathrm{~mm} \\
\text { thick OSB on the other side }\end{array}$ & 18.87 \\
\hline & & & $12 \mathrm{~mm}$ thick gypsum board on both sides & 8.26 \\
\hline & & & $12 \mathrm{~mm}$ thick OSB on both sides & 42.72 \\
\hline & & & $\begin{array}{l}12 \mathrm{~mm} \text { thick gypsum board on one side and } 12 \mathrm{~mm} \\
\text { thick OSB on the other side }\end{array}$ & 27.85 \\
\hline & & \multirow{7}{*}{$100 / 300$} & $12 \mathrm{~mm}$ thick gypsum board on one side & 4.82 \\
\hline & & & 9mm thick OSB on one side & 15.75 \\
\hline & & & $12 \mathrm{~mm}$ thick OSB on one side & 21.98 \\
\hline & & & $\begin{array}{l}12 \mathrm{~mm} \text { thick gypsum board on one side and } 9 \mathrm{~mm} \\
\text { thick OSB on the other side }\end{array}$ & 20.57 \\
\hline & & & $12 \mathrm{~mm}$ thick gypsum board on both sides & 8.32 \\
\hline & & & $12 \mathrm{~mm}$ thick OSB on both sides & 38.84 \\
\hline & & & $\begin{array}{l}12 \mathrm{~mm} \text { thick gypsum board on one side and } 12 \mathrm{~mm} \\
\text { thick OSB on the other side }\end{array}$ & 27.87 \\
\hline \multirow{6}{*}{$2.7 \times 2.4$} & \multirow{6}{*}{600} & \multirow{3}{*}{$150 / 300$} & $12 \mathrm{~mm}$ thick gypsum board on one side & 3.91 \\
\hline & & & 9mm thick OSB on one side & 12.08 \\
\hline & & & $12 \mathrm{~mm}$ thick OSB on one side & 14.30 \\
\hline & & \multirow{3}{*}{$100 / 300$} & $12 \mathrm{~mm}$ thick gypsum board on one side & 4.24 \\
\hline & & & 9mm thick OSB on one side & 12.92 \\
\hline & & & $12 \mathrm{~mm}$ thick OSB on one side & 14.67 \\
\hline \multirow{6}{*}{$2.4 \times 2.4$} & \multirow{6}{*}{600} & \multirow{3}{*}{$150 / 300$} & $12 \mathrm{~mm}$ thick gypsum board on one side & 4.97 \\
\hline & & & 9mm thick OSB on one side & 13.70 \\
\hline & & & $12 \mathrm{~mm}$ thick OSB on one side & 16.51 \\
\hline & & \multirow{3}{*}{$100 / 300$} & $12 \mathrm{~mm}$ thick gypsum board on one side & 5.29 \\
\hline & & & 9mm thick OSB on one side & 14.33 \\
\hline & & & $12 \mathrm{~mm}$ thick OSB on one side & 18.23 \\
\hline
\end{tabular}

\section{CONCLUSIONS}

The shear resistances of cold-formed steel stud assembled walls in residential structures are investigated in this paper. By experiment and FE analyses, some conclusions are drawn as follows.

(1) The FE analytical results are close to the experimental results, which indicates that the method of FE analysis adopted in this paper is correct and valid.

(2) The material properties of the panel sheathing influence the shear load bearing capacity of the cold-formed steel stud wall greatly. The shear resistance of the wall with single-sided gypsum sheathing is 34.8 percent of that of the wall with single-sided OSB sheathing, and the total shear resistance of these two kinds of single-sided walls is close to that of the double-faced wall with gypsum board on one side and OSB on the other side.

(3) The shear resistance of the walls increases obviously with decrease of the stud spacing and the screw spacing at the perimeter of the walls, and it also increases with decrease of the height-width ratio of the walls. However, the influence of the steel strength on the shear resistance is not remarkable, though it will be enhanced with increase of the steel strength. 


\section{ACKNOWLEDGEMENT}

This work was financially supported by the National Natural Science Foundation of China (Grant No. 50578013), Program for New Century Excellent Talents in University (Grant No. NCET-07-0266), Natural Science Foundation of Hunan Province for Distinguished Young Scholars (Grant No. 08JJ1006), and National Key Technology R\&D Program (Grant No. 2006BAJ18B06-01), which are gratefully acknowledged.

\section{REFERENCES}

[1] NASFA, "Prescriptive Method for Residential Cold-Formed Steel Framing", North American Steel Framing Alliance, 2000.

[2] AISI, "Shear Wall Design Guide", American Iron and Steel Institute, 1998.

[3] Serrette, R. and Ogunfunmi K., "Shear Resistance of Gypsum-sheathed Light-gauge Steel Stud Walls", Journal of Structural Engineering, 1996, Vol. 122, No. 4, pp. 383-389.

[4] Serrette, R., Encalada, J., Juadines, M., and Nguyen, H., "Static Racking Behavior of Plywood, OSB sheathing, Gypsum, and Fiberboard Walls with Metal Framing", Journal of Structural Engineering, 1997, Vol. 123, No. 8, pp. 1079-1086.

[5] Xia, B.Q. and Dong, J., "Finite Element Analysis of the Lateral Force Resistance of Light Gauge Steel Framed Compound Bearing Walls", Building Structure, 2004, Supplement (8), pp. 334-337 (in Chinese).

[6] Emad, F.G.., Adrian, M.C., and Colin, F.D., "Lateral behavior of Plasterboard-clad Residential Steel Frames", Journal of Structural Engineering, 1999, Vol. 125, No. 1, pp. 32-39.

[7] JGJ 101-96, "Chinese Specification of Testing Methods for Earthquake Resistant Building”, 2006 (in Chinese).

[8] ANSYS version 10.0, "Finite Element Analysis Software", ANSYS Inc., 2006.

[9] Kasal, B. and Leichti, R.J., "Nonlinear Finite Element Model for Light-Frame Stud Walls", Journal of Structural Engineering, 1992, Vol. 118, No. 11, pp. 3122-3135.

[10] Thomas, W.H., "Concentrated Load Capacity and Stiffness of OSB: Calculation versus Test", Journal of Structural Engineering, 2002; Vol. 128, No. ST7, pp. 908-912.

[11] Zhou, T.H. and He, B.K., "Test Report of the Shear Resistance of Cold-formed Steel Stud Wall”, Report of Xi'an University of architecture \& technology, 2004 (in Chinese).

[12] The Japan Iron and Steel Federation, "Design Guide for Thin Light-gauge Steel Construction", Japan: Gihodo Shuppan Co. Ltd, 2002. 